Florida International University FIU Digital Commons

$11-18-2016$

\title{
Understanding the Value of Travel Time Reliability for Freight Transportation to Support Freight Planning
}

Kollol Shams 3085942

ksham004@fiu.edu

DOI: 10.25148 /etd.FIDC001255

Follow this and additional works at: https://digitalcommons.fiu.edu/etd

Part of the Transportation Engineering Commons

\section{Recommended Citation}

Shams, Kollol 3085942, "Understanding the Value of Travel Time Reliability for Freight Transportation to Support Freight Planning" (2016). FIU Electronic Theses and Dissertations. 2828.

https://digitalcommons.fiu.edu/etd/2828

This work is brought to you for free and open access by the University Graduate School at FIU Digital Commons. It has been accepted for inclusion in FIU Electronic Theses and Dissertations by an authorized administrator of FIU Digital Commons. For more information, please contact dcc@fiu.edu. 


\section{FLORIDA INTERNATIONAL UNIVERSITY}

Miami, Florida

\section{UNDERSTANDING THE VALUE OF TRAVEL TIME RELIABILITY FOR FREIGHT TRANSPORTATION TO SUPPORT FREIGHT PLANNING AND DECISION- MAKING}

A dissertation submitted in partial fulfillment of the requirements for the degree of DOCTOR OF PHILOSOPHY in CIVIL ENGINEERING

by

Kollol Shams 


\section{To: Interim Dean Ranu Jung}

College of Engineering and Computing

This dissertation, written by Kollol Shams, and entitled Understanding the Value of Travel Time Reliability for Freight Transportation to Support Freight Planning and Decision-Making, having been approved in respect to style and intellectual content, is referred to you for judgment.

We have read this dissertation and recommend that it be approv ed.

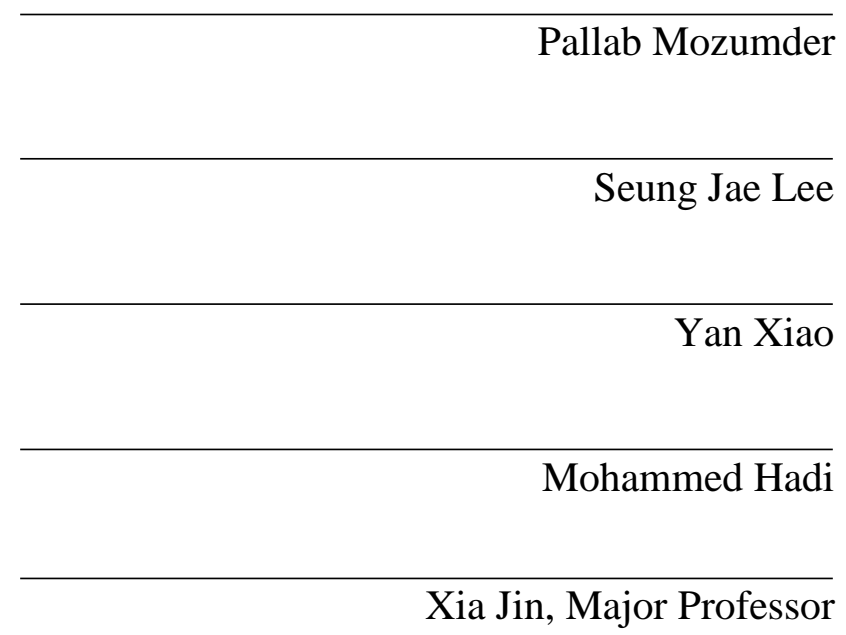

Date of Defense: October 18, 2016

The dissertation of Kollol Shams is approved.

Interim Dean Ranu Jung College of Engineering and Computing

Andrés G. Gil

Vice President for Research and Economic Development and Dean of the University Graduate School

Florida International University, 2016 
(C) Copyright 2016 by Kollol Shams

All rights reserved. 


\section{DEDICATION}

I dedicate this dissertation to beloved my parents Shamsul Alam and Romana Shams, and my two lovely sisters. Without their patience, understanding, support, and most of all love, the completion of this work would not have been possible. 


\section{ACKNOWLEDGMENTS}

First and foremost, I would like to express my deepest gratitude toward my major advisor, Dr. Xia Jin, for her guidance, patience, support, and understanding at every stage of this dissertation. This dissertation would not have been possible without her inspiration and mentoring.

My deepest appreciation is extended to the committee members Dr. Mohammed Hadi, Dr. Yan Xiao, Dr. Pallab Mozumder, and Dr. Seung Jae Lee for serving on my committee and for their invaluable input to my research work. I am thankful for their time and help in reviewing my work.

I experienced a great teamwork environment in the Geographic Information System (GIS) lab. A special credit belongs to my late mates: Hamid and Mamun for being part of my journey. I would also like to thank Dibakar and Shahadat for their support. 
ABSTRACT OF THE DISSERTATION

UNDERSTANDING THE VALUE OF TRAVEL TIME RELIABILITY FOR FREIGHT TRANSPORTATION TO SUPPORT FREIGHT PLANNING AND DECISION-

MAKING

by

Kollol Shams

Florida International University, 2016

Miami, Florida

Professor Xia Jin, Major Professor

Today's logistics practices are moving from inventory-based push supply chains to replenishment-based pull supply chains, leading to a lower and less centralized inventory, smaller shipment sizes, and more just-in-time deliveries. As a result, industries are now demanding greater reliability in freight transportation. Delays and uncertainty in freight transportation translate directly into additional inventory, higher manufacturing costs, less economic competitiveness for businesses, and higher costs of goods that are being passed on to the consumers. Given the growing demand in freight transportation, the emerging needs to better understand freight behavior for better policy and investment decisions, and the increasing role of reliability in freight transportation, this research aims at providing a) better understanding of how the freight system users value travel time reliability in their transportation decisions, and b) advanced methods in quantifying the user's willingness to pay for the improvement of transportation related attributes, particularly travel time reliability. 
To understand how the freight industry values travel time reliability in their transportation decisions, and particularly the presence of user heterogeneity, this research designed and conducted a stated preference (SP) survey for freight users in road transportation. Based on the feedback received during the pilot stage, reliability was measured as the standard deviation of travel time and presented as a frequency of on-time and late delivery in the choice scenarios. The survey collected 1,226 responses from 159 firms in Florida between January and May 2016 via online and paper methods.

Various modeling approaches were explored to estimate the willingness to pay (WTP) measures among freight users, including multinomial logit (MNL) and mixed logit model. Market segmentation and interaction modeling techniques were employed to investigate preference variations among user groups, commodity groups, product type, and various other shipment characteristics, including shipping distance and weight.

In general, across all groups in the sample, values of $\$ 37.00$ per shipment-hour (\$1.53 per ton-hour) for travel time savings and $\$ 55.00$ per shipment-hour ( $\$ 3.81$ per tonhour) for improvements of reliability were found in this research. Furthermore, while investigating the effects of shipping characteristics on the user's preference in WTP, the results suggested that shipping distance and weight were the two most important variables.

The results of the study help advance the understanding of the impact of the performance of transportation systems on freight transportation, which will lead to policy and investment decisions that better serve the needs of the freight community. 


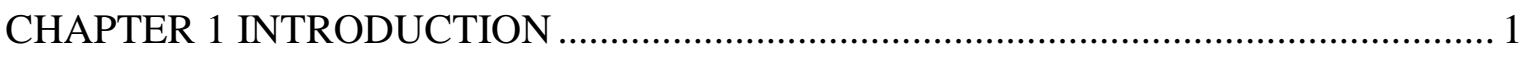

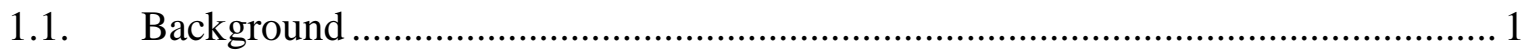

1.2. Research Needs and Problem Statements …………........................................ 2

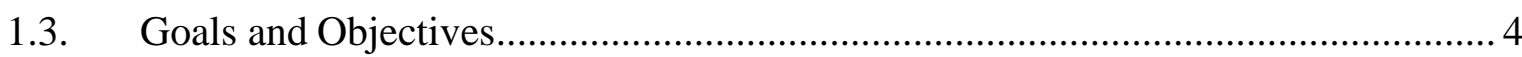

1.4. Dissertation Organization ……………………....................................... 5

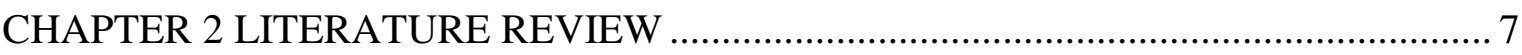

2.1. Overview of Logistics ..............................................................................

2.2. Consequences of Unreliability in Freight Industry ……....................................... 11

2.3. Travel Time Reliability - Freight Perspective ..................................................... 13

2.4. Value of Reliability -Mathematical Formulation .............................................. 15

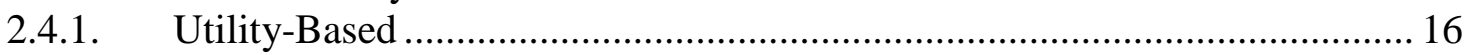

2.4.1.1 Mean-Variance Based ............................................................................ 17

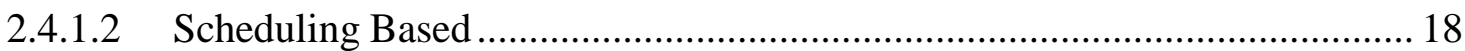

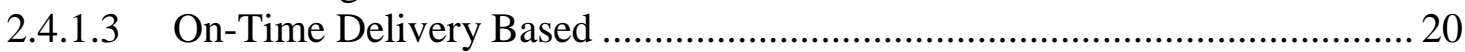

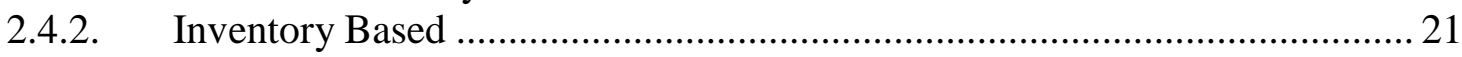

2.5. Value of Reliability -Modelling Techniques ......................................................... 23

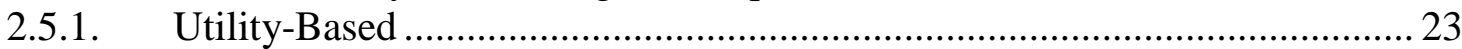

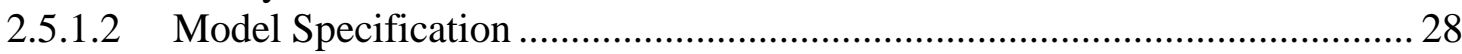

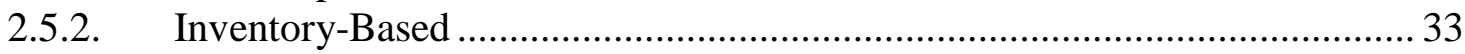

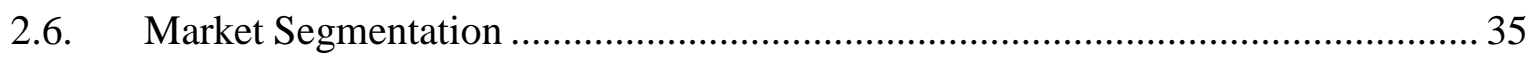

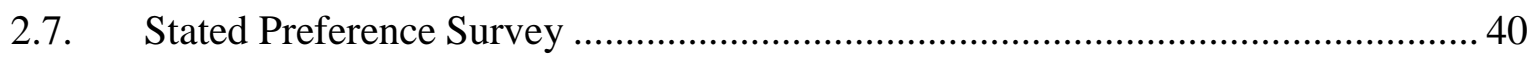

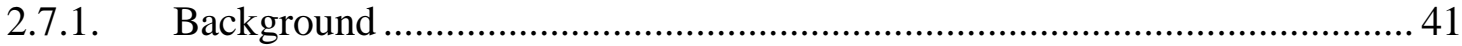

2.7.2. Different Types of Experimental Design ....................................................... 41

2.7.3. Design Steps for Choice Based Stated Preference Survey............................ 43

2.7.3.1 Stage 1 - Defining the Problem Statement .................................................. 43

2.7.3.2 Stage 2 - Identifying Alternatives, Attributes, and Attribute Levels ............. 43

2.7.3.3 Stage 3 - Experimental Design ................................................................. 45

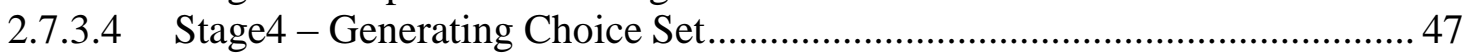

2.7.3.5 Stage 5 - Survey Administration ................................................................... 48

2.7.3.6 Stage5 - Model Estimation ............................................................................. 49

2.7.4. Revealed Preference versus Stated Preference............................................ 49

2.7.5. Adaptive Stated Preference ..................................................................... 50

2.7.6. Review of Survey Design used in Freight Transportation ............................ 52 


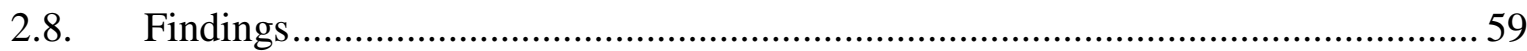

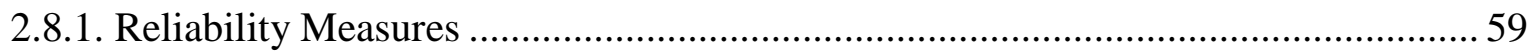

2.8.2 Value of Reliability from a Logistics Point of View .............................................. 59

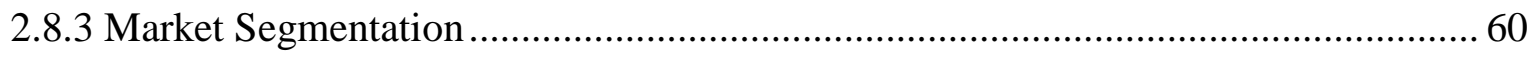

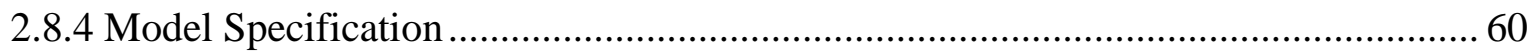

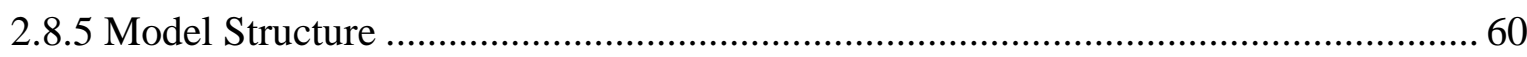

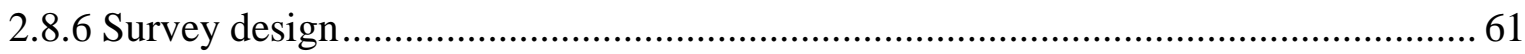

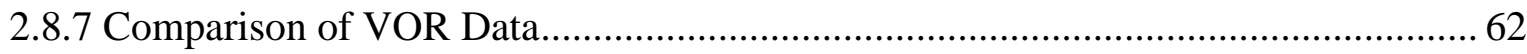

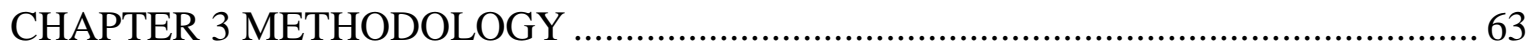

3.1. Development of a Stated Preference Survey Framework ......................................... 64

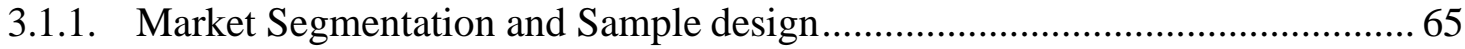

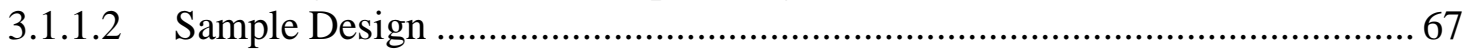

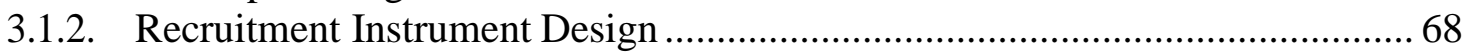

3.1.3. Stated Preference Choice Experiment ………...................................................... 69

3.1.3.1 Determining Attributes and Attribute Levels................................................ 72

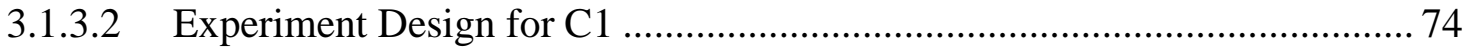

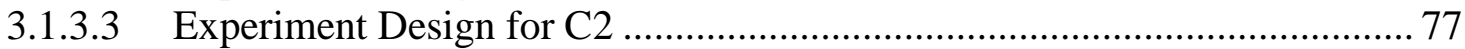

3.1.3.4 Experiment Design for $\mathrm{C} 3$....................................................................... 78

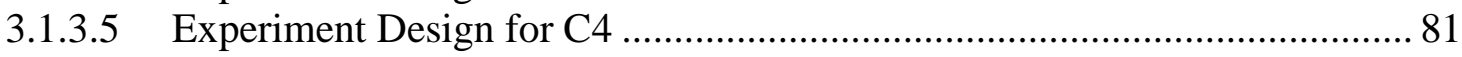

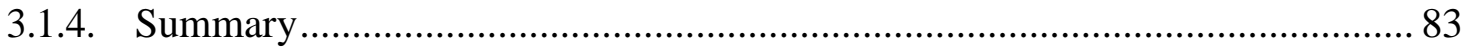

3.2. Development of Econometric Models for VOR Estimation .................................. 84

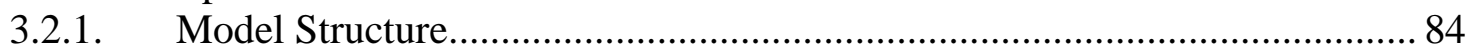

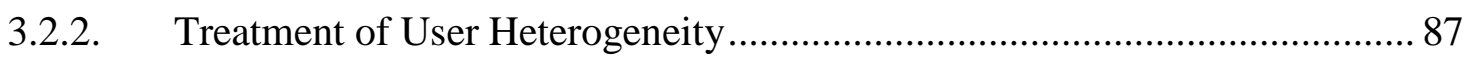

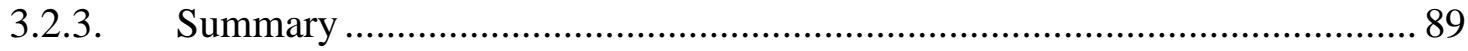

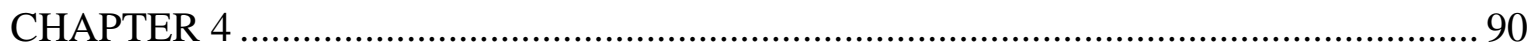

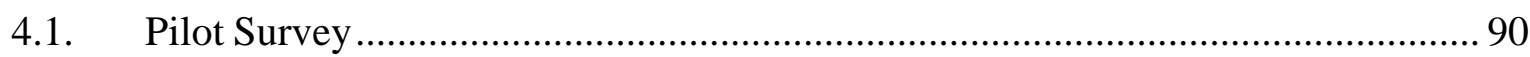

4.1.1. Florida Customs Brokers \& Forwarders Association, Inc. (FCBF) .............. 91

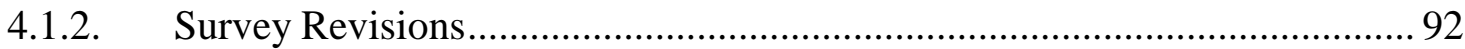

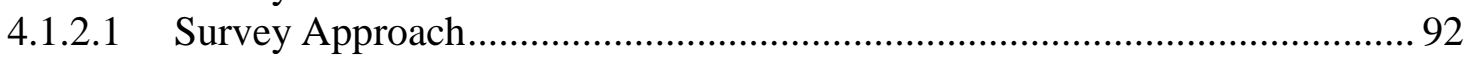

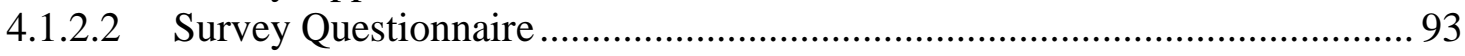

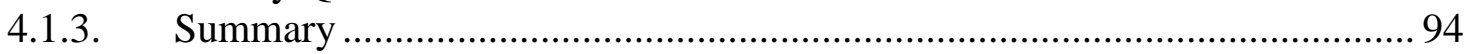

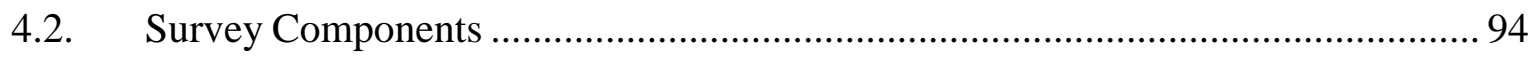

4.2.1. Part 1: Introduction and Qualification Questions........................................ 95

4.2.2. Part 2: Base Shipment Characteristics ...................................................... 96

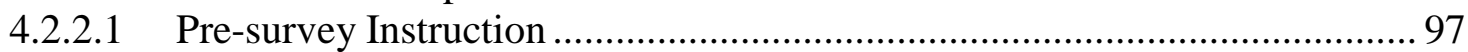

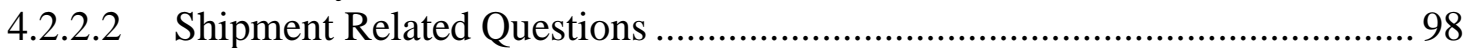

4.2.3. Part 3: Stated Preference Questions ..................................................... 104

4.2.3.1 Introductory Note and Qualification questions for SP experiment types.... 105 


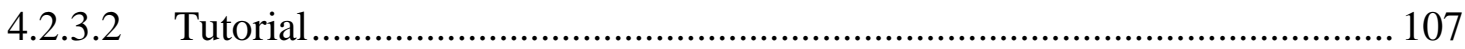

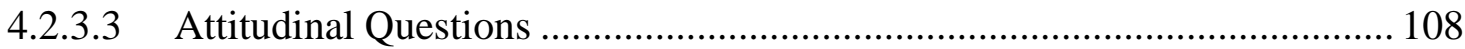

4.2.3.4 Main SP Choice Questions ................................................................... 110

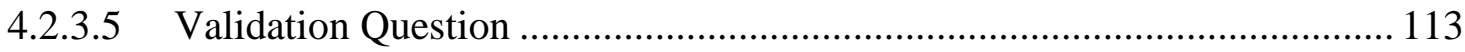

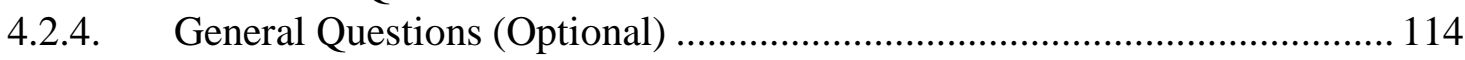

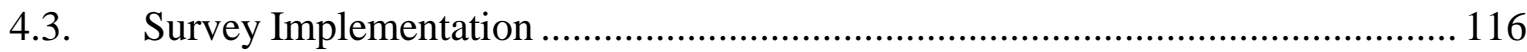

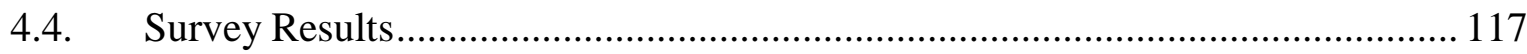

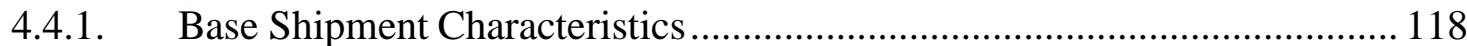

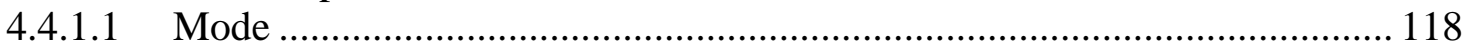

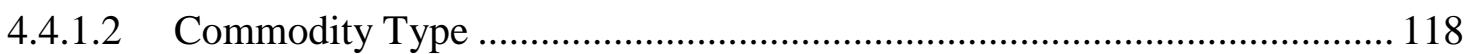

4.4.1.3 Shipping Distance and Duration ............................................................. 120

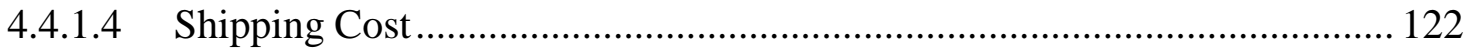

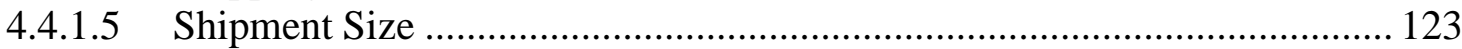

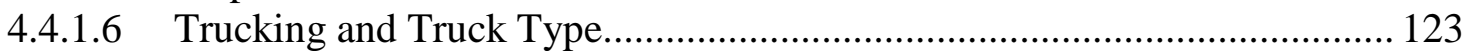

4.4.1.7 Delivery Time Specification and Monetary Penalty for Delay................... 125

4.4.2. Stated Preference Choice Question.............................................................. 127

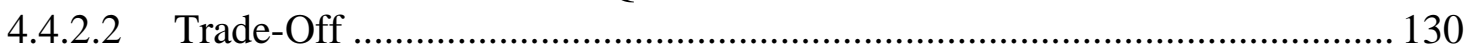

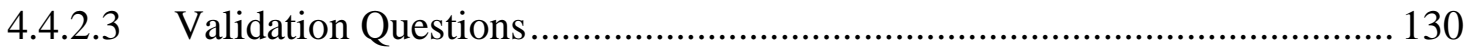

4.4.3. General Information (Optional part) ....................................................... 131

4.4.3.1 Frequency of outb bn ound shipment delay ............................................. 131

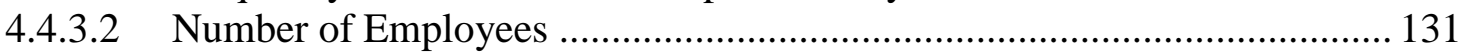

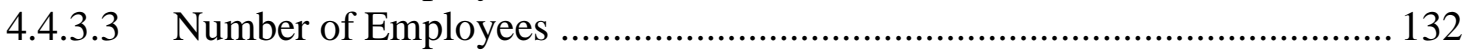

4.4.3.4 Routing Decisions and Reimbursement of Tolls........................................ 133

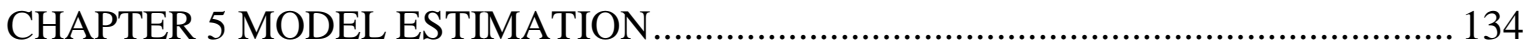

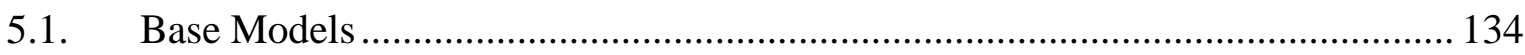

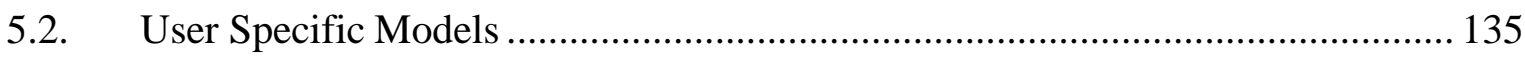

5.3. User Specific Models with Interaction Effects ……………………………...... 136

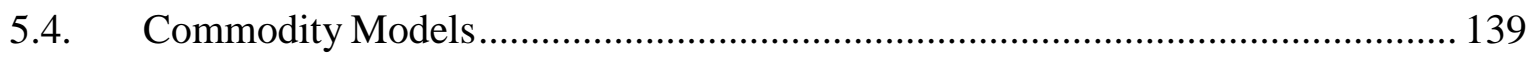

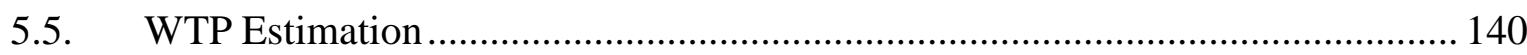

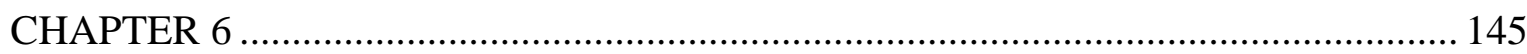

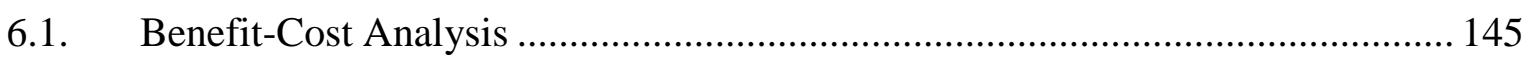

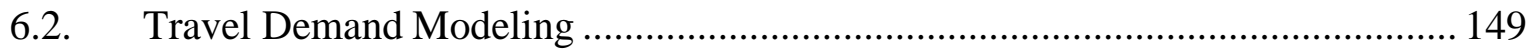

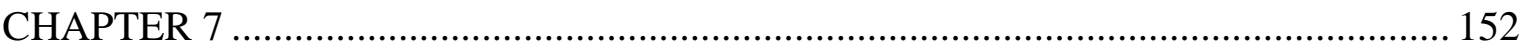

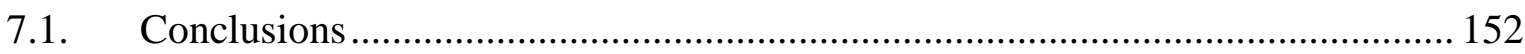

7.2. Study Limitations and Recommendations of Future Research ............................. 155 


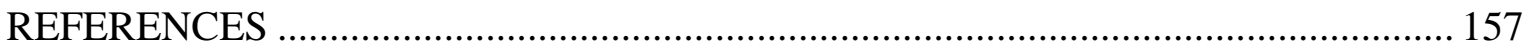

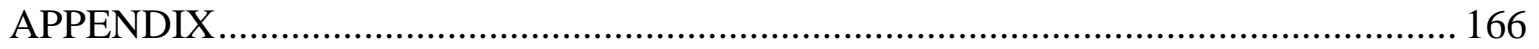

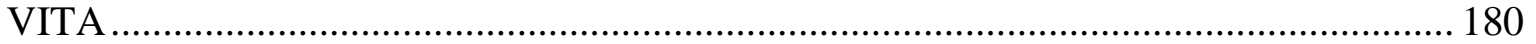




\section{LIST OF TABLES}

TABLE

PAGE

Table 2-1 Utility based Modeling Techniques Used in Freight VOR Studies...................32

Table 2-2 Marketing Segments Used in Freight Studies ............................................37

Table 2-3 Overview of Different Types of Experimental Design ...................................46

Table 2-4 Range of Attribute Levels Used by Halse (2011).........................................53

Table 2-5 Range of Simulation Coefficients Used by Small (1999) ................................55

Table 2-6 Summary of Survey Design among Existing Freight VOR Studies .................57

Table 2-7 Summary of VOR Estimates from Selected Freight Studies .........................62

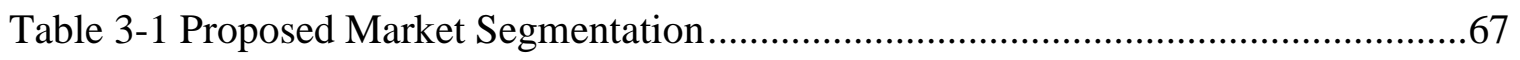

Table 3-2 Truck Type Definition from the FISHFM ..................................................67

Table 3-3 Attribute Level and the Values Considered in the Experiments......................73

Table 3-4 Table 3-4: Attribute Values of Transit time reliability considered for Set 1 .....74

Table 3-5 Table 3-5: Attribute Values of Transit time reliability considered for Set 2.....74

Table 3-6 Orthogonal Factorial Design for Experiment C1 .......................................75

Table 3-7 Choice Sets Using the Sequential Orthogonal Design for Experiment C1 ......76

Table 3-8 Orthogonal Factorial Design for Experiment C2 …...................................77

Table 3-9 Choice Sets Using the Sequential Orthogonal Design for Experiment C2 .......78

Table 3-10 Choice Sets Using the Bradley Design for Experiment C3 ...........................80

Table 3-11 Orthogonal Factorial Design for Experiment C4 .....................................81

Table 3-12 Choice sets using the sequential orthogonal design for Experiment C4 „.......82

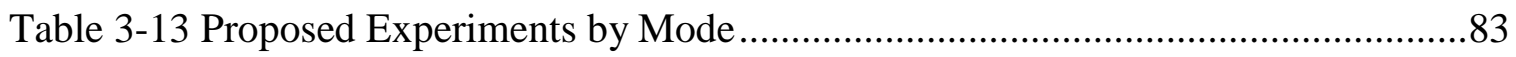

Table 4-1 Completed responses by survey method ................................................116

Table 4-2 Number of Survey Participants by Segment (Road Only).............................116 
Table 4-3 Number of Survey Participants by User Group and Mode 118

Table 4-4 Commodity types transported by users from Waterways and Air...................120

Table 4-5 Shipping size by groups (lbs. only) ....................................................123

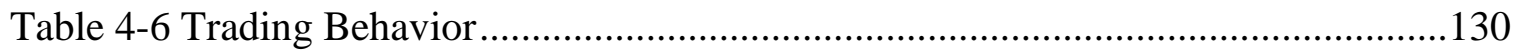

Table 5-1 MNL and ML Models Based on the Whole Dataset .....................................135

Table 5-2 User Specific MNL Model Results ............................................................136

Table 5-3 User Specific MNL Model Results (With Interaction Effects) ......................138

Table 5-4 ML Model Results by Commodity Group and Product Type ........................140

Table 5-5 Summary of WTP Estimation by User Group and Commodity Type .............142

Table 5-6 Summary of WTP Estimation by Shipping Characteristics ..........................143

Table 6-1 Estimated VOT and VOR Values by Groups based on Florida Survey ..........148 


\section{LIST OF FIGURES}

FIGURE

PAGE

Figure 2-1 Overview of Logistics Management Process (source: Jessica et al., 2012) ......9

Figure 2-2 EOQ Model and Stochastic Distribution of Demand during Lead Time.........22

Figure 2-3 Proposed Market Segmentation for Shipper (source: Bone et al., 2013) .........39

Figure 2-4 Proposed Market Segmentation for Transport (source: Bone et al., 2013)...40

Figure 2-5 Marginal Utility (source: Hensher et al., 2005) .......................................... 45

Figure 3-1 Proposed approach for the SP survey ..................................................64

Figure 3-2 Classification of experiment design .................................................... 71

Figure 4-1 A set of hypothetical example of choice sets ............................................92

Figure 4-2 Sample screen capture: qualification question ........................................96

Figure 4-3 Sample screen capture: pre-survey instructions .......................................98

Figure 4-4 Sample screen capture: mode and commodity type .................................99

Figure 4-5 Sample screen capture: shipping distance for road mode ...........................100

Figure 4-6 Sample screen capture: shipping distance for rail mode ............................100

Figure 4-7 Shipping distance for air and waterway modes........................................101

Figure 4-8 Sample screen capture: shipping cost (carriers \& shippers with transport)...102

Figure 4-9 Sample screen capture: shipping cost (3PL\& shippers without transport)...102

Figure 4-10 Sample screen capture: shipping duration and shipment size ....................103

Figure 4-11 Sample screen capture: delivery time and delay penalty ..........................103

Figure 4-12 Sample screen capture: trucking type and truck size ...............................104

Figure 4-13 Sample screen capture: introduction and qualification for experiments ......106 
Figure 4-14 Sample screen capture: willingness to shift departure time and mode 107

Figure 4-15 Sample screen capture: tutorial question 108

Figure 4-16 Sample screen capture: attitudinal questions $\quad$......109

Figure 4-17 Sample screen capture: an example of SP choice question for C1 exp....... 111

Figure 4-18 Sample screen capture: an example of SP choice question for C2 exp.......111

Figure 4-19 Sample screen capture: an example of SP choice question for C3 exp......112

Figure 4-20 Sample screen capture: an example of SP choice question of C4 exp. .....112

Figure 4-21 Sample screen capture: validation question $\quad 113$

Figure 4-22 Sample screen capture: firm background information .............................114

Figure 4-23 Routing and Toll related questions (Carriers \& 3PLs) ...............................115

Figure 4-24 Spatial distribution of completed responses by user type ..........................117

Figure 4-25 Shipment by commodity type (Road only) .........................................119

Figure 4-26 Shipment by shipping distance (Road Only)........................................120

Figure 4-27 Shipment by shipping duration (Road Only) .........................................121

Figure 4-28 Shipment by Shipping Cost (Road Only)...........................................122

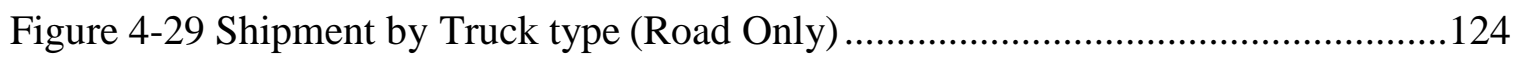

Figure 4-30 Shipment by trucking type (Road only) .............................................125

Figure 4-31 Shipment by delivery time specified in contract ....................................126

Figure 4-32 Percentage of shipment having monetary penalty..................................126

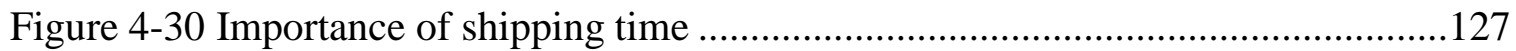

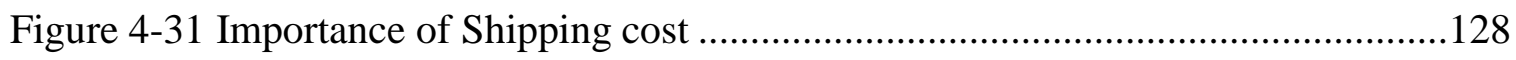

Figure 4-32 Importance of shipping time reliability .............................................. 128

Figure 4-33 Importance of security and damage ...................................................129 
Figure 4-34 Importance of service flexibility

Figure 4-35 Frequency of out-bound shipment delay (out of 10 times)

Figure 4-36 Firm size

Figure 4-37 Shipment under delivery pressure

Figure 4-38 Reimbursement for tolls

Figure 4-39 Routing decisions 133

Figure 5-1 Summary of VOR value changes by shipping characteristics .142

Figure 6-1 Stylized representation of the user cost linkages (source: AASHTO, 2010) 147

Figure 6-2 Incorporation of reliability into the travel demand modeling process 150 


\section{ABBREVIATIONS AND ACRONYMS}

\begin{tabular}{|c|c|}
\hline Shippers & $\begin{array}{l}\text { A person or company typically that sends goods to customers } \\
\text { using own transport, hiring carriers or forwarding. }\end{array}$ \\
\hline Carriers & $\begin{array}{l}\text { A person or company that transports goods from Customer A } \\
\text { to B and is not involved in any kinds of manufacturing or } \\
\text { warehousing }\end{array}$ \\
\hline Forwarding & $\begin{array}{l}\text { A person or company that arranges to pick up or deliver goods } \\
\text { on behalf of a shipper or a consignee from or to point by } \\
\text { various necessary conveyance and common carriers }\end{array}$ \\
\hline Alternatives & Options containing specified levels of attributes \\
\hline Attribute Levels & $\begin{array}{l}\text { A specific value taken by an attribute; experimental designs } \\
\text { require that each attribute takes on two or more levels, which } \\
\text { may be quantitative or qualitative }\end{array}$ \\
\hline Attributes & Characteristics of an alternative \\
\hline Blocking & $\begin{array}{l}\text { The process of sub-setting the treatment combinations to } \\
\text { decision makers }\end{array}$ \\
\hline Base table & $\begin{array}{l}\text { Containing range of attribute values, within which shipment } \\
\text { characteristics are more or less same }\end{array}$ \\
\hline Choice set & The set of alternatives over which a respondent makes a choice \\
\hline D-efficiency & $\begin{array}{l}\text { It is a measure related to D-optimal design to calculate the } \\
\text { efficiency of design, which is performed by minimizing the } \\
\text { determinant of inverse of variance-covariance matrix }\end{array}$ \\
\hline Experimental design & $\begin{array}{l}\text { The specification of attributes and attribute levels for use in an } \\
\text { experiment }\end{array}$ \\
\hline Main effect & $\begin{array}{l}\text { The direct independent effect of each factor on a response } \\
\text { variable }\end{array}$ \\
\hline Interaction effect & $\begin{array}{l}\text { An effect on the response variable obtained by combining two } \\
\text { or more attributes which would not have been observed had } \\
\text { each of attributes been estimated separately }\end{array}$ \\
\hline Orthogonal design & $\begin{array}{l}\text { An orthogonal design in which only the main effects are } \\
\text { estimated; all other interactions are assumed to be insignificant }\end{array}$ \\
\hline Treatment combination & Combinations of attributes, each with unique levels \\
\hline Unlabeled Experiment & $\begin{array}{l}\text { Alternatives are described generically conveying no } \\
\text { information to particular item (e.g. listed as "Alternative A") }\end{array}$ \\
\hline MNL & Multinomial Logit \\
\hline ML & Mixed Logit \\
\hline VOR & Value of Reliability \\
\hline VOT & Value of Time \\
\hline
\end{tabular}




\section{CHAPTER 1}

\section{INTRODUCTION}

\subsection{Background}

Freight transport is the backbone of the nation's economy. The efficient flow of freight is essential for the competitiveness of American industries in the global economy. The performance of the freight transportation system also has direct implications on the standard of living as well as the social and environmental goals of communities. In 2012, the US transport network carried more than 32 million tons of goods which equates to nearly $\$ 37.30$ billion (Margreta et al., 2014). The numbers of freight tons is also expected to increase $62 \%$ by 2040 (Strocko et al., 2014)

Increasing congestion in the transportation system is expected to accompany this growth, as there are obvious limitations in the capacity of the nation's freight transportation system to carry the goods and services. Schrank et al. (2012) reported that congestion alone cost the nation $\$ 121$ billion in 2011, an increase of 30\% from 2000 . Similarly, A study sponsored by the Federal Highway Administration confirmed that highway bottlenecks cost the trucking industry more than $\$ 7.80$ billion annually (Cambridge Systematics,2005).

Today's logistics practices are moving from inventory-based push supply chains to replenishment-based pull supply chains, leading to lower and less centralized inventory, smaller shipment sizes, and more just-in-time deliveries. As a result, industries are now demanding greater reliability in freight transportation than ever. Delays and uncertainty in freight transportation translate directly into additional inventory, higher 
costs of manufacturing, less economic competitiveness for businesses, and higher costs of goods, all of which are passed on to the consumers.

There is an imminent need to plan freight effectively, identify the necessities of the various sectors of the freight community, and assess their responses to planning and management strategies. As freight users constantly adapt to changes in the transportation system (e.g., mode shifts, temporal and route shifts, moving points of manufacturing, and shifting points of entry), understanding the pattern and sensitivity of the demand is critical to freight investment and policy decisions.

The growing demand for freight transportation, the emerging needs to understand better freight behavior for better policy and investment decisions, and the increasing role of reliability in freight transportation. this study aims at providing a) better understanding on how the freight system users value travel time reliability in their transportation choices and b) advanced methods in quantifying the user's willingness to pay for the improvement of transportation-related attributes, particularly travel time reliability. The findings of this study will greatly benefit local, state, and national agencies in evaluating and prioritizing alternative investments and policy strategies that promote the best use of the freight transportation system and support the needs of the freight stakeholders.

\subsection{Research Needs and Problem Statements}

Unreliability in travel time has been one of the primary sources of concern in freight industry for years. In supply chain and logistics terms, shippers make agreements with the customers to deliver the shipment within an agreed timeframe, which often includes sanctions for lateness. Failure to provide on-time delivery could put shippers at risk (e.g., financial loss or effect on reputation). Consequently, customers are forced to 
rush production, assign extra labor, and more importantly, face the possibility of missing an outbound delivery. If these events happen frequently, a business will struggle to remain viable. Therefore, freight transport users are very likely to pay extra in return for more reliable transport. In this regard, value of reliability (VOR) refers to the monetary cost that a freight user is willing to pay to reduce the variability of travel time to move goods from origin to destination. In other words, VOR is associated with freight users' gain on marginal utility for a unit reduction in variability of shipment time.

Despite the importance of reliability in freight transportation, most research on value of reliability in the U.S. has focused on passenger travel. There have been a few studies conducted in different countries (e.g., Norway, UK, Australia, and the Netherlands) that specifically investigated how the freight community values travel time reliability in their transportation decisions. Among these, there was little consensus on what the value of reliability should be (Zamparini et al., 2007). Several empirical studies show a wide range of VOR values ranging from $\$ 1.30$ to $\$ 497.00$; however, such variability in VOR values is hard to compare to one another as the studies used different definitions, units, and market segments to estimate VOR. As a result, VOR values are yet to be utilized in any cost-benefit analysis or freight planning projects. 


\subsection{Goals and Objectives}

The goal of this research is to investigate the role of reliability in freight users' transportation decisions and to quantify their preference towards the improvement of the travel time reliability.

The specific objectives of this dissertation can be summarized as:

1. To design a stated preference survey to collect freight users' responses to the changes of transportation-related attributes, such as travel time, cost, and travel time reliability. The lack of this type of information has been the main hurdle preventing an understanding of freight user behavior. The task involves extensive investigation of relevant literature to answer research questions, such as:

- How has VOR been defined and measured in past freight studies?

- What are the current practices of survey design for the valuation studies in freight transportation?

- What is the best mode of administering the survey?

The findings facilitate the development of a comprehensive framework for the aforementioned preference survey.

2. To explore efficient methods of modeling freight users' willingness to pay for travel time savings and travel time reliability. This research investigates the advanced specifications and estimation techniques, capturing of users' heterogeneity, and addressing the model limitations that arise due to multiple data collection from the same respondents in the SP survey.

3. To identify possible ways of integrating the major findings of this study (i.e. Value of time (VOT) and Value of reliability) into the freight planning and 
project prioritization. This task requires reviewing the current freight planning practices and project evaluation techniques, and also identifying areas and procedures to integrate the VOT and VOR values into the current planning framework and evaluation procedures.

This research is particularly challenging due to the complex interaction among freight users (carriers, shippers, and forwarding companies) involved in taking any transportation-related decisions. The findings of this research will be useful for developing a common framework of valuation of travel time reliability in freight transportation and more importantly, incorporating VOR values into the freight planning and project appraisal.

\subsection{Dissertation Organization}

This dissertation is organized as follows: Chapter 2 provides an overview of logistics industry and the importance of reliability to the industry, followed by a review task which summarizes major VOR freight studies in terms of definition of reliability, the methods to measure value of reliability, and the market segment and the modeling techniques. This chapter also discusses major elements of stated preference survey (SP) and provides a summary of the SP designs used by past studies.

Chapter 3 presents the research methodology, which is comprised of two major tasks: the design of stated preference survey framework and development of econometric models for VOR estimation. A detailed discussion of the proposed SP survey framework, including market segment, sample design, recruitment instrument design and 
administration mode, is included. Various model structures are explored for VOT and VOR estimation.

Chapter 4 summarizes the key lessons learned from the pilot survey and presents the finalized survey questionnaires. Descriptive statistics of the responses collected in the survey are also presented in this chapter.

Chapter 5 presents the model estimation results. Multinomial and Mixed logit models are developed to quantify a user's willingness to pay (WTP) for the improvement of travel time and reliability. Preference heterogeneity is also explored by commodity group, product type and various other shipment characteristics, including shipping distance and weight.

Chapter 6 provides a brief discussion on the conceptual framework of incorporating VOR in the benefit-cost analysis (BCA) for freight project evaluation and accommodating the effect of unreliability into demand models.

Finally, Chapter 7 summarizes general conclusions and points out further research opportunities. 


\section{CHAPTER 2}

\section{LITERATURE REVIEW}

This chapter provides a comprehensive literature review on all the relevant topics, which are grouped into three sections. The first section provides the overview of logistics and the importance of travel time reliability in the freight industry and its role in the supply chain and logistics. Following this, the next section summarizes the modeling framework, including theories, mathematical formulations and analytical techniques for the valuation of travel time reliability. Finally, the chapter concludes with the discussion of stated preference survey, along with a detailed review of past evaluation studies used in freight transportation.

\subsection{Overview of Logistics}

In general, there are three parties involved in the logistics decision-making process: the shipper, the receiver, and the carrier (Small, 1999). Typically, shippers, which mainly include the distribution managers of a manufacturing firm, are those who send their goods to the receivers. Receivers are customers, retailers, or the purchasing, inventory managers of manufacturing firms. Carriers are the transportation firms that provide services to the shippers. Usually, receivers give orders to shippers with the number of products required and the desired delivery schedule. By choosing shippers, receivers create demand for shippers' goods, and pay for the products. On the other hand, shippers (those who do not own any form of transportation) select carriers for the transportation of the goods. Carriers are responsible for transporting the goods from shippers to receivers within a scheduled timeframe. Carriers make the decisions 
independently on the transportation mode, route and travel time. However, these decisions often are influenced by different factors, such as logistics cost, commodity value, level of inventory stock, reliability, and loss and damage.

Guo and Gong (2012) proposed a multi-layer theoretical framework to present the complex underlying interactions among different stakeholders in the freight industry. In the study, seven stakeholders from different industries were interviewed and an extensive literature review on the firms' logistics systems was conducted. The framework put customer demand and services in the first layer at the core of the system, as shown in Figure 2-1. The activities and interactions among the components of the framework are influenced by the recent moving trend from "Push" strategies (Firms first assess the demand based on past data/experiences, then supply those products to the local distributors.) to "Pull" strategies (Customers' demands are assessed at the local level, then orders are placed in the factories accordingly.).

The most challenging part of this paradigm shift is to assess the demand accurately and to select what percentage of the customer demand should be satisfied with on-hand inventories, which dictates three important components of the process: the policy on inventory and ordering, the firm's structure and facility location, and the purchasing procedure, which are shown in the second layer in Figure 2-1. Although purchasing goods and selecting suppliers do not have any direct impact on freight transportation, other activities such as inventory and ordering goods dictate the shipment size and schedule, whereas planning a firm's structure and facilities influence the long-term commodity flow of the firms. 


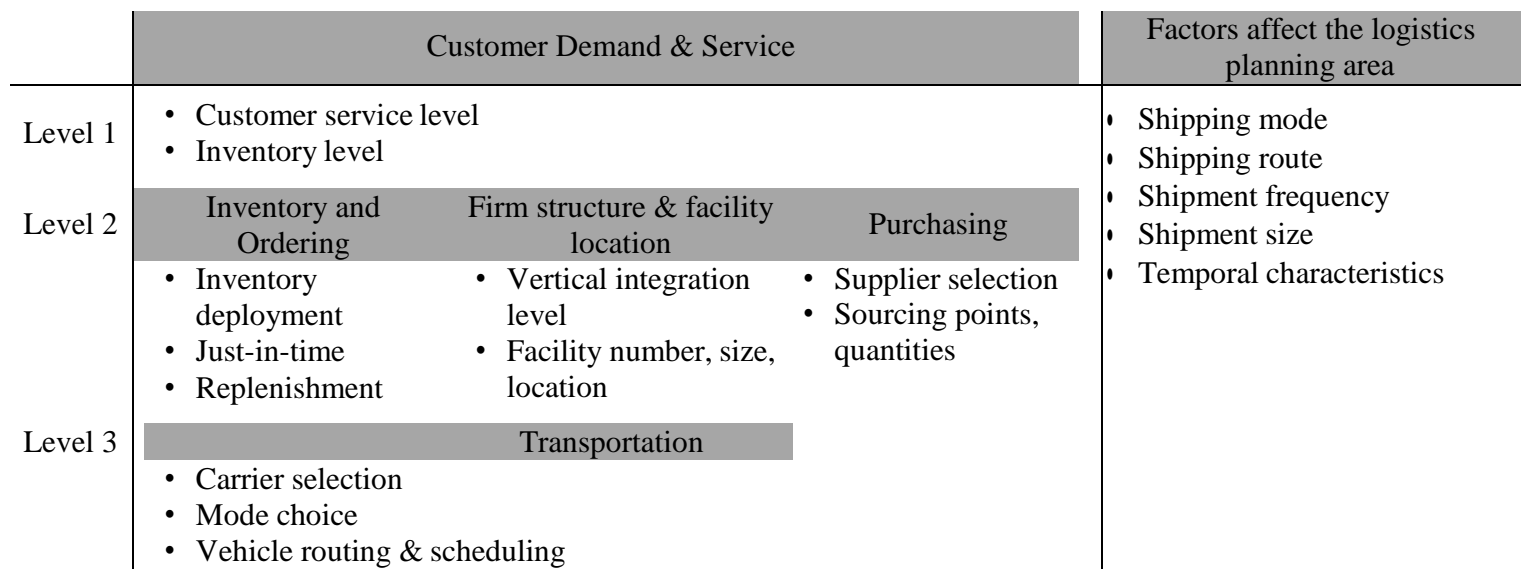

Figure 2-1 Overview of Logistics Management Process (source: Guo and Gong, 2012)

The inventory and ordering process, from freight transport's point of view, involves the transportation and storage of commodities and relates to all other components of the logistics management process. Inventory and ordering strategies can be discussed from two perspectives, one focus on the supply of finished products and the other on the supply of raw materials for production use. For the supply of finished products, there are two types of inventory management, as indicated previously, "Push approach" and "Pull approach." In the Push approach, local demand is assessed and inventory management at all levels is designed in such a way that the demand is met at a satisfactory level. Raw materials are first passed on to the manufacturers, then manufacturers push the finished products to distribution centers, which again, in turn, serve the customer's demand. On the contrary, the Pull approach involves all decisions from manufacturing to delivering products based on the customer's need or orders. Since this approach does not depend on on-hand inventory, it demands a highly reliable and timely delivery of products; otherwise, it runs a high risk of loss. For the supply of raw materials, firms use either the advanced buying or just-in-time (JIT) strategy. While 
advanced buying may not have an impact, the impact of the JIT strategy on freight transport planning is significant. For example, JIT is favorable as long as supplies come in at scheduled times because this prevents the need to manage inventory, which in turn reduces overhead product costs. However, the consequence of a missed shipment may be more severe. The activities at the second level set up the basic operations for firms, such as establishing the commodity flow, and production strategies, etc.

The final layer of the process is the transportation services that focus on how goods are moved from one location to another. Typically, this involves making decisions about transportation modes, routes, and service providers. However, the decision-making process of this stage depends on the firm's policy on the transportation of goods. A firm's policy will determine whether to use the firm's vehicles, contract a carrier or use a third party (3PL) service provider. The amount of responsibility that a firm is willing to relegate influences the hiring of a carrier firm or third party service provider (3PL). The simplest definition of a 3PL is a company that works with shippers to manage their logistics operations. Logistics can include elements of warehousing, transportation management software, freight rate negotiation, in-depth reporting, forecasting, freight bill auditing, etc. There are thousands of 3PLs in the market that have different models and perform different tasks. Some 3PLs specialize in certain industries, e.g., frozen foods. Others might specialize in one specific area of logistics such as auditing freight bills, warehousing, or providing logistics related software. One advantage of using a third party service is that the service provider arranges everything for the shippers, from transport to the warehouse facility. This results in reduced cost, expedited delivery, and reliability. 


\subsection{Consequences of Unreliability in Freight Industry}

Unreliability in travel time has been a major source of concern in freight industry for a long time. Previous studies (SHRP L02, 2012; FHWA, 2012) found that factors, such as traffic incidents, weather, work zones, fluctuations in demand, special events, traffic control devices, and inadequate base capacity are the main sources of travel time unreliability on road networks. Not only does congestion affect business logistics, but it also shrinks business market areas and reduces the agglomeration economies of business operations (Weisbrod et al., 2001).

The cost incurred by freight delays could be categorized into four types: excess holding cost, additional labor cost, losses due to stock-out, and the risk of losing customers/business (Mckinnon, 1998). Situations may become complicated when multiple deliveries come late, and shipments are to wait for clearance in the unloading areas. Moreover, in the case of cross-docking operations, where products from a supplier or manufacturing plant are distributed directly to a customer or retail chain with marginal to no handling capabilities, the issues will escalate quickly. Typically, firms keep a safety stock to avoid running out of stock which depends on factors such as lead time, uncertainty about the lead time, customer demands, and uncertainty about demand during the lead time. Again, this excess stock comes with a higher inventory-carrying cost. While a single late delivery may not affect operations significantly, regular and frequent delays may drive away business or deter future customers. 
From a manager's perspective, freight delays can be classified into five levels (McKinnon et al., 2008), including:

Level 1: delays are accommodated within normal operating procedure

Level 2: temporary redeployment of staff and equipment at minimal cost

Level 3: temporary deployment of additional resources such as overtime work

Level 4: delay to the next link in the supply chain - such as an outbound departure

Level 5: missed connection - more serious consequences involving the possibility of an out-of-stock situation, loss of sales and underutilization of outbound transport

The lower levels of delay (Levels 1-3) can be accommodated by normal operating procedures, by doing nothing, or by assigning labor and equipment to the issue. However, when delays are longer (Levels 4-5), there exists a great probability of delaying outbound departures, an out-of-stock situation, loss of sales, and under-utilization of outbound transport.

Fowkes and Whiteing (2006) investigated the delay in terms of disutility from a production point of view. In this paper, the author stated that disutility is minimized at the optimal departure time, but it increases slowly for a slack/buffer time and continues to rise for some time due to the redeployment of resources. Finally, the delay reaches a stage where disutility no longer matters as shipments are likely to be missed by then. Fowkes et al. (2004) also highlighted some possible opportunity costs to freight shippers while analyzing them from the supply side. In the case of reliable transport, shippers can consolidate multiple deliveries and even plan for a two-way operation, thus saving operating costs and reducing shipping times. 
Facing increasing traffic congestion, a report from the Netherlands (Kuipers and Rozemeijer, 2006) summarized the responses taken by freight shippers and carriers. Shippers generally allow more time for transport, making use of information communication and technology (ICT) for short mitigation, and planning for more distribution centers in the future. On the other hand, carriers are focusing more on the early departure of trucks, operating at night more frequently, using more vehicles, and consolidating the transport networks. In either case, taking into account reliability plays an important role in operation decisions.

\subsection{Travel Time Reliability - Freight Perspective}

Travel time unreliability can be defined as the unexpected deviation from the expected duration of travel. Travelers develop a mental basis for expected journey time through their travel experiences or from external sources (i.e. online sources) and make their travel plans accordingly. However, journey times are likely to vary in real life; congestion being the main source of the variation. This causes travelers to allocate additional time, or adjust the departure time for their next destination. Given that, travel time reliability can be regarded as the degree to which randomness in journey time is realized. Although this randomness is hard to measure, travel time reliability can be quantified statistically based on the variance of travel times. Lower variation in travel times means higher reliability (Zamparini and Reggiani, 2007).

Although travel time reliability has been defined by agencies and researchers in a variety of ways, it can be broadly categorized into two categories. The first is based on the variation in travel time, and the other involves the probability of success or failure 
against a pre-established threshold travel time (List et al., 2012). The following are a few definitions that have been adopted by different agencies:

- National Cooperative Highway Research Program (NCHRP) defined travel time reliability as a measure of variability that can be measured using the standard deviation of travel time (Cambridge Systematics et al., 1998).

- Federal Highway Administration (FHWA) defined travel time reliability as the consistency or dependability in travel times, as measured from dayto-day and/or at different times of the day (TTI, 2006).

- Florida Department of Transportation (FDOT) defined reliability as the percentage of travel that takes no longer than the expected travel time, plus certain acceptable additional time (FDOT, 2000).

- The Texas Transportation Institute Urban Mobility Report made a distinction between variability and reliability of travel time. The Report stated that variability refers to the amount of inconsistency of operating conditions, while reliability refers to the level of consistency in transportation service (Schrank and Lomax, 2003).

From the freight perspective, users are more concerned about the scheduled arrival time of the shipment. Hence, researchers in freight studies have employed slightly different definitions for reliability. Some definitions are given as follows: 
- The absolute or relative variations in transit/travel times (Winston, 1981; Halse et al., 2010; Significance et al..,2012).

- Delay from the preferred/scheduled arrival time (Small, 1999; Fowkes et al., 2004; Halse et al., 2010)

- The percentage of deliveries/shipments that arrive within a scheduled time (Bolis and Maggi, 2003; De Jong et al., 2004; Beuthe and Bouffioux,2008)

In supply chain and logistics terms, shippers make agreements with the customers to deliver the shipment within an agreed timeframe. The formality of the time of the delivery agreement between the customers and shippers can vary, while sanctions for lateness are usually included. When a delivery fails, the shippers run the risk of incurring losses which can be financial or in terms of reputation. At the same time, customers have to rush for production, assign extra labor, and more importantly, face the possibility of missing an outbound delivery. If these events happen regularly, a business may not survive. Therefore, freight transport users are very likely to pay extra in return of more predictable transport.

\subsection{Value of Reliability -Mathematical Formulation}

Value of reliability (VOR) refers to the monetary value that users are willing to pay to reduce travel time variability when moving shipping goods from one place to another. In the past, two approaches have most commonly been used to estimate VOR in freight transportation: random utility maximization (RUM) and inventory-based (Bone et al., 2013). The first one attempts to identify the key decision makers (i.e. shippers, carriers, customers) and to maximize their utility using discrete choice models. The second one attempts to quantify VOR from the integrated logistics approach using inventory-based models. 


\subsubsection{Utility-Based}

A utility-based behavioral model has been widely used to estimate the VOR for freight transportation. By definition, utility is a measure of the relative attractiveness which a decision-maker tries to maximize through his or her choice(s). The critical assumption of this model is that decision makers (i.e. shippers, carriers, customers) perceive some monetary value in avoiding uncertainty in shipment times; thus an equivalency between the reliability of travel time and cost can be derived that gives an estimate of VOR. In this attempt to maximize utility, the user is forced to trade off reliability and shipment costs (Winston, 1981; Small, 1999, Bone et al., 2013, etc.). When this is considered, equilibrium between travel time reliability and cost can be derived to estimate of VOR. If $\mathrm{n}$ individuals face with $\mathrm{J}$ alternatives in $\mathrm{T}$ choice scenarios, the choice can be modeled as:

$$
\begin{aligned}
& y_{\text {int }}= \begin{cases}1, & \text { if } U_{\text {int }}>U_{\text {int }} \text { for } j=1, \ldots, J \\
0, & \text { otherwise }\end{cases} \\
& \text { Utility, } U_{\text {int }}=V_{\text {int }}+\epsilon_{\text {int }}
\end{aligned}
$$

where Vint is the deterministic part of the utility, which can be expressed as:

$V_{\text {int }}=\sum_{k} \beta_{k} X_{\text {intk }}$ (for linear-in-attribute case), and $\epsilon_{\text {int }}$ is the error term (Ben-Akiva and Lerman, 1985).

The VOR can now be easily estimated by first taking the total derivative of utility with respect to changes in the reliability attribute $\left(\mathrm{X}_{\mathrm{r}}\right)$ and the cost attribute $\left(\mathrm{X}_{\mathrm{c}}\right)$. When this is set to zero it yields:

$$
V O R=\frac{d X_{c}}{d X_{r}}=-\frac{\beta_{r}}{\beta_{c}}
$$


Based on how travel time reliability is defined, the studies which were reviewed were classified into three groups: mean-variance based approach, scheduling based approach, and on-time delivery based approach.

\subsubsection{Mean-Variance Based}

Mean-variance based approach measures the variations in travel times. This method is attributed to Jackson and Jucker (1982), where a model was proposed to study the choice behavior of travelers who sought to trade between travel time and its variability explicitly. The most critical assumption of this model was that the users were aware of the uncertainty involved in their travel times and they tried to reduce this uncertainty as well as the expected travel time.

Following this approach, Winston (1981) developed one of the first freight models which considered reliability. In his model, reliability was measured as the ratio of the standard deviation of travel time to travel time. The model also considered other variables describing model attributes and firms' characteristics such as production plans, desired lots, daily quantities received, and attitudes towards risk. However, recent models solely have used the standard deviation of travel time as reliability measure studies (Halse et al., 2010; De Jong et al., 2014). Thus, the formulation of the utility function is as follows:

$U=\beta_{c} C+\beta_{T} T+\beta_{R} \sigma+\varepsilon$

where

$\beta_{T}=$ travel time coefficient to be estimated

$\beta_{C}=$ travel cost coefficient to be estimated,

$\beta_{R}=$ reliability coefficients to be estimated,

$\sigma=$ standard deviation of the travel time, 
$T=$ travel time,

$C=$ travel cost,

$\varepsilon=$ the random error term.

\subsubsection{Scheduling Based}

Any shipment arriving before or after the preferred arrival time (PAT) would likely to cause disutility. The theoretical basis of this approach comes mainly from the seminal work of previous researchers, Gaver (1968), Knight (1974) while Small (1982) was the first that incorporated schedule delay (both early and late) directly in the utility functions to investigate the travel behavior towards early or late arrival at the work place, as shown below:

$$
U=\beta_{c} * C+\beta_{T} * T+\beta_{\text {Early }} * S D E+\beta_{\text {Late }} * S D L+\Theta * D_{L}
$$

where

$$
\begin{aligned}
& \beta_{\text {Early }}=\text { coefficient of early arrival } \\
& \beta_{\text {Late }}=\text { coefficient of late arrival } \\
& \mathrm{SDE}=\text { schedule delay early (in number of minutes earlier than preferred) } \\
& \mathrm{SDL}=\text { schedule delay late (in number of minutes late than preferred) }
\end{aligned}
$$

The study estimated freight users' willingness to pay in order to avoid early or late arrival shipments from their choices. Their choices reflected their trade-offs among attributes such as delay, cost, and travel time.

Later Small (1999) extended the model for uncertain conditions, by incorporating the stochastic characteristics of travel time reliability in the utility functions. The main hypothesis is that since users will not be able to anticipate their transit times beforehand, 
every departure time (td) corresponds to the transit time they choose as options will now be associated with the probability of occurrence. Hence, the utility function (which is expected now) can be written as a function of travel time distribution and the utility is maximized when they choose the optimal departure $\left(t_{d}\right)$. The expected utility function is as follows:

$$
\begin{aligned}
& E(U)=\int_{0}^{\infty} U\left(t_{d}\right) f(T) d T \\
& =\beta_{c} C+\beta_{T} E(T)+\beta_{E a r l y} E(S D E)+\beta_{\text {Late }} E(S D L)+\theta E\left(D_{L}\right)
\end{aligned}
$$

where

$$
E\left(X_{1 . .} X_{n}\right)=\text { the expected value of attributes }\left(\mathrm{X}_{1} . . \mathrm{X}_{\mathrm{n}}\right)
$$

Nevertheless, the literature indicated that few freight studies (Kurri, 2000; Gong, 2012) used SDE and SDL directly in their utility functions without taking into consideration the probability function. Others argue that values estimated from the latter approach may not truly represent unreliability because individuals in this case make decisions without uncertainty (Carrion and Levinson, 2012). For example, if carriers are aware of congestion, they may adjust their departure time and can be certain that the shipment will arrive on time which essentially ends variability in travel time.

It should be noted that a theoretical equivalence between the scheduling based approach and the mean-variance based approach can be made under certain assumptions (Fosgerau et al., 2010). The main assumptions include that travel time distribution is independent of departure time, there is no discrete lateness penalty, the departure time is continuous, and there is no congestion. Many studies, in the freight context, use the scheduling approach more often. This equivalence shows a promise to bridge the gap between these two approaches. 


\subsubsection{On-Time Delivery Based}

The on-time delivery approach measures reliability according to the percentage of shipments arriving on time. As shown in Table 1, this approach has been used extensively in past studies. It is possible that the frequency of its use is related to its explicit meaning and similarity to inventory management. This is impactful as it may make it easier for respondents to understand and make trade-offs between attributes. The utility function for this approach is as follows:

$$
U=\beta_{c} C+\beta_{\text {ont }} X_{\text {ont }}+\varepsilon
$$

where

$\beta_{\text {ont }}=$ coefficient for on-time delivery based reliability, $X=$ the percentage of delivery arrived on-time.

In summary, three main measurement approaches, including scheduling, meanvariance and on-time delivery have been used in freight studies. The discussion revealed that each of these methods makes different assumptions and has a slightly different formulation which is responsible for variability in estimated values. The primary difference among these three approaches is that on-time delivery reflects the user's willingness to pay for an improved ratio of on-time deliveries, while scheduling relates more to the user's willingness to pay to avoid late arrivals. The mean-variance based approach focuses more on variations in travel time.

From a theoretical perspective, it may be preferable to use the scheduling based approach as it directly measures deviations from a pre-determined schedule. However, the most suitable approach greatly depends on the intended use of estimate. For instance, some studies preferred to use the mean-variance approach over other approaches because the 
VOR values derived from this model can be easily incorporated into the existing travel demand model framework and the project appraisal stages without any major modifications (Halse et al., 2010; De Jong et al., 2014; De Jong et al., 2015).

\subsubsection{Inventory Based}

Inventory based model, on the other hand, considers transportation and inventory decisions jointly while estimating the VOR. The background for this method draws on the traditional economics theorem where optimum order size, also known as economic quantity of order (EOQ), is determined by minimizing the cost function. Typically, the cost function considers all possible incurring costs, such as purchase, order, in transit and holding cost, which are functions of the average annual demand quantity and reorder point. (At this level new order is placed for stock replenishment, as shown in Figure 2-2).

When the demand and lead time are deterministic, the inventory manager can order at the reorder point level to avoid stock-out. This point can be directly determined from the annual average demand quantity and lead time (the time between the ordering and receiving the shipment). In reality, demand and lead time are hardly deterministic. There is a considerable amount of uncertainty involved in estimating the lead time and demand, especially during lead times. These variations, which are also unreliable, can be incorporated into the inventory model through the stochastic consideration of lead time, and demand during lead time (Paknejad et al., 1992; Lee and Schwarz, 2007; Nasri et al., 2008).

These concepts can be better explained, with the assumption that demand during lead time follows normal distribution (Fetter and Dalleck, 1961; Dullart et. al. 2013). Then, the variation of demand during lead time and safety stock can be expressed as 
follows (Eq: 8 \& 9):

Standard deviation of demand during lead time,

$$
\sigma_{D D L T}=\sqrt{\left(L \sigma_{D}^{2}+D^{2} \sigma_{L}^{2}\right)}
$$

Safety stock,

$$
\mathrm{SS}=\mathrm{k} \sigma_{\mathrm{DDLT}}
$$

where

$\mathrm{L}=$ lead time,

$\mathrm{D}=$ annual average demand,

$\sigma_{\mathrm{D}}^{2}$ and $\sigma_{\mathrm{L}}^{2}$ are variation in demand and lead time respectively, and

$\mathrm{k}=$ safety factor multiplier

When these expressions are put into the main cost function, the impact of the reduction in lead time and the variation in lead time on total cost can be quantified, which are VOT and VOR. Thus, VOT and VOR can be derived as the amount of savings in total inventory costs due to reduction in lead time and the variation of lead time.

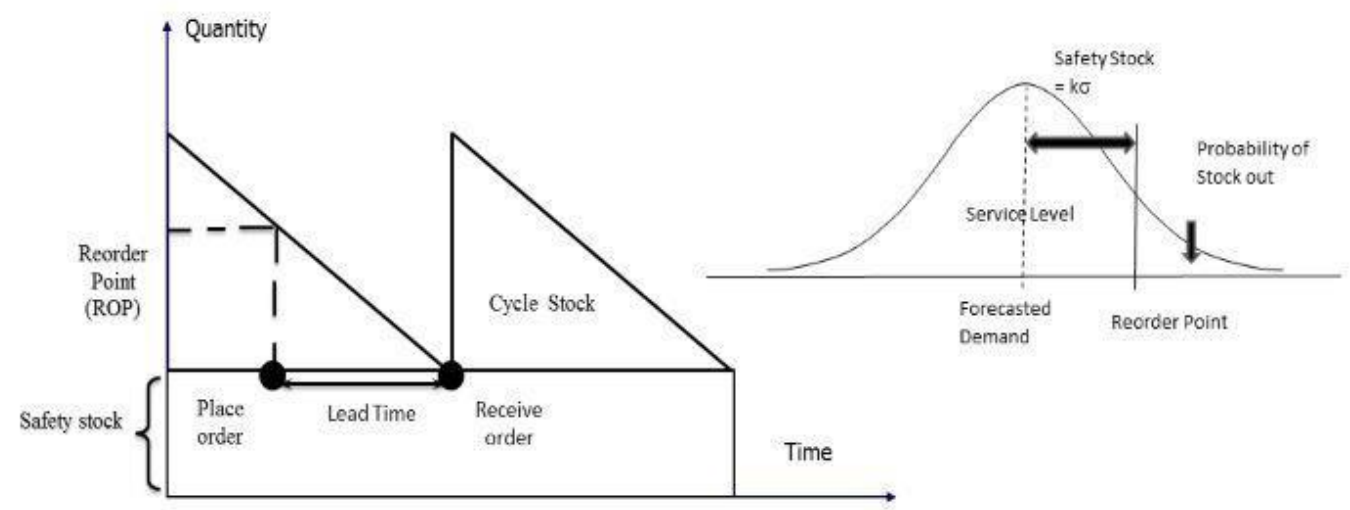

Figure 2-2 EOQ Model and Stochastic Distribution of Demand During Lead Time

Besides utility based and inventory based methods, a small group of studies 
employed the profit maximization or cost minimization approach (Bergkvist, 2001). It uses a cost function where all attributes including shipper's quantity, transport related model attributes, firm characteristics, and shipment characteristics are converted into a generalized cost. From this, it attempts to minimize the cost, or maximize the profit, within given constraints. The underlying assumption of this model is that a user is likely to choose the transport option with the lowest cost.

\subsection{Value of Reliability -Modelling Techniques}

As indicated in the previous section, there are two approaches, the inventory-based model and the utility-based behavioral model, which have provided the foundation to quantify VOR in freight transportation. This section provides a detailed discussion on these two methods to estimate VOR. In the utility-based behavioral model, the focus has been on the identification of economic agents (i.e. shippers, carriers, customers, or something else along the chain) and the maximization of its utility. The inventory-based model, on the

other hand, follows a more holistic approach that considers all kinds of possible costs incurred along the supply chain such as transport cost, labor cost, and varying inventory cost due to varying lead time and degrees of service level.

\subsubsection{Utility-Based}

\subsubsection{Model Structure}

Various model structures have been used in freight studies in order to better fit the data (Ben-Akiva and Lerman, 1985; Garrow, 2012) and often to accommodate heterogeneity (user's preference towards taste) in the model estimation (Marcucci and Gatta, 2012). Logit models, including multinomial logit (MNL) and mixed logit (ML), were the most commonly used to analyze SP data. Earlier studies mainly used MNL 
models which require the user to assume that the error terms are Independent and Identically Distribution (IID) (Ben-Akiva and Lerman, 1985). With these assumptions, the probability of individual q choosing alternative $\mathrm{i}$ can be estimated with the following closed form:

$$
P_{i q}=\frac{\exp \left(V_{i q}\right)}{\sum_{j=1}^{J} \exp \left(V_{j q}\right)}
$$

The estimation is typically based on the statistical principle of "likelihood maximization" (Ben-Akiva and Lerman, 1985). However, both rating and ranking can be analyzed as choice data through appropriate transformations (Chapman and Staelin, 1982). Previous studies, (Fowkes et al., 1996; 2001; Bolis et al., 2003) used the following transformation equations 2-11:

$$
\begin{aligned}
& \text { If Rating }<100, \\
& \text { then } P_{A}=1-\left(\frac{0.5 \cdot \text { Rating }}{100}\right) \\
& \text { If Rating }>100, \\
& \text { then } P_{A}=\left(\frac{0.5 \cdot \text { Rating }}{100}\right)
\end{aligned}
$$

The greatest limitation of using the Logit model for SP design is the violation of the Independent and Identically Distribution (IID) across individuals, alternatives, and choice situations as responses are collected multiple times from the same individuals. Later studies adopted several techniques to overcome this limitation. One such technique was to re-sample (i.e. jackknife) the dataset before model estimation (De Jong et al., 2014). This eliminated systematic bias by taking the average of the estimated model parameters for each sub-sample (De Jong et al., 2014). However, the MNL model can 
provide only the mean effect of model parameter on the utility because of its assumptions. As a result, most freight studies accommodated heterogeneity by developing separate models for different market segments or interacting variables with the main attributes in the model (see Table 2-1).

Mixed Logit (ML) has also been used to relax the restrictions imparted by the IID assumption and to capture individual preferences in the model parameters (Puckett and Hensher, 2008; Halse et al., 2010; De Jong et al., 2014; Masiero and Hensher, 2010). ML models use the same utility function as MNL, but assume continuous or discrete distribution for the coefficients (instead of fixed values such as in MNL). In that sense, ML is an extension of MNL, and becomes MNL when there is no statistically significant deviation. The mixed logit model can be expressed for individual $\mathrm{q}$ in choice situation $\mathrm{t}$ choosing alternative $\mathrm{j}$ as follows:

$$
U_{j t q}=\beta_{q}^{\prime} X_{j t q}+\varepsilon_{j t q}
$$

where,

$\varepsilon_{j t q}=$ error component, which is correlated across individual $q$

$\beta_{q}^{\prime}=$ coefficient distributed randomly across individuals

Since there is no closed form expression for this model, it can be solved using simulation techniques with the following log-likelihood equation 2-13:

$$
\log (L)=\sum \log \int \prod\left(P_{n j t}\right)^{y n}(1-P n j t)^{1-y n} d, G(\alpha \mid \delta)
$$

where

$\mathrm{G}(\alpha \mid \delta)$ is the mixing function given the distribution function of $\alpha$ $\delta$ represents the parameters of the distribution 
A few important remarks on the use of the mixed logit model:

- Since one (or more) of the coefficients are no longer fixed, the researcher must assume an underlying distribution. This can be either a continuous distribution or a discrete distribution. In the case of a continuous distribution, usually a specific statistical distribution is employed such as normal or lognormal. By simply examining whether the standard deviation is zero or not, the performance of mixed logit model over MNL can be tested (Hensher et al., 2005; Significance et al., 2012).

- The number of draws used for simulation needs to be previously specified.

- Sometimes, complicacy arises while specifying the continuous mixed logit model, but can be overcome by latent class or non-parametric techniques (Fosgerau et al., 2007).

However, most of previous studies were unable to estimate statistically significant coefficients due to inadequate sample size (Halse et al., 2010; De Jong et al., 2014). One of the advantages of ML is that the limitation of IID violations can be addressed in model specifications. In addition, the literature showed that other models such as latent class model (LCM) and heteroskedastic multinomial logit (H-MNL) have also been used. These models were mostly used to capture unobserved heterogeneity of freight users (Puckett and Rasciute, 2010; Masiero and Hensher, 2012). Theoretically, LCM is an alternative form of ML. LCM assumes a discrete class of distribution of coefficients rather than continuous, but offers more advantages. For example, it provides a closed-form solution, which reduces the computational burden. The estimation of this model does not depend on the distribution assumption as it uses the probabilistic function which improves the estimation accuracy. 
While the investigating mode choice among freight users in another study in the Friuili Venezia Giulia region of Italy, Zotti and Danielis (2004) found that there was considerable randomness in transport related attributes; the attributes included in the development of ML models were travel time, reliability, damage, and losses.

Additionally, the study found two groups when LCM was developed for the same survey: one group was more interested in the travel time of shipments and the other cared more about safety. In Australia, Puckett et al. (2007) conducted a freight SP survey, with the purpose to capture the freight users' preference towards a (hypothetical) distance-based road pricing system. Using the data from this survey, Puckett and Rasciute (2010) were able to distinguish two sub-groups within the survey group for both shippers and carriers using LCM (Puckett and Rasciute, 2010). Their findings showed that one group was more sensitive towards the cost related attributes, such as freight rate paid by the receivers of the goods and fuel cost and the other placed more emphasis on the on-time reliability and level of service.

Similarly, H-MNL bases the assumption of IID across alternatives which makes it possible to represent the scenarios with varying variance (i.e. the variance associated with travel time or reliability increases with shipment distances). For example, using H-MNL model enabled Masiero and Hensher (2012) to investigate the combined effect of shipment distance and weight on VOR values. The results indicated a positive effect for weight and a negative effect for distance which implied that as distance increased the overall utility decreased, but could be compensated by the increase of shipment weight.

Recent studies have benefited from the improvement of econometric models and the computational abilities of commercial software used in model estimations. However, it 
seems that there is still a need for a systematic approach of probing heterogeneity, as suggested in Marcucci and Gatta (2013). By systematically investigating heterogeneity through the model developments for the observed part (i.e. MNL models with and without interaction variables, ML, LC models), the unobserved part (i.e. error component model (EC), see Hensher et al., 2015 for more detail), or as a whole (using conjoint MLand EC

model), the authors showed that only examining a single or two model structures might not be enough to reveal user's preference wholly.

\subsubsection{Model Specification}

According to the literature, the most recent studies have focused on formulating non-linear utility specifications and non-linear attribute functions. The main motivation for this was to explore non-additive linear specifications or attribute effects that could better explain the random errors in the model and to produce better estimations.

For example, in Netherlands De Jong et al. (2014) found that the model shown below performed well when the error term was assumed to be multiplicative in the utility function.

$$
U=\lambda * \log (C+\operatorname{VOT} * T+V O R * \sigma)+\epsilon
$$

where

$\lambda=$ the scale parameter associated with error term, $\epsilon$.

Halse et al. (2010) also had similar findings in Norway. The authors proposed a multiplicative form of error specification, with the inclusion of one additional variable which captured the systematic bias due to the order in which questions were presented. 
This form is shown below.

$$
U=e^{\alpha L}+(C+V O T * T+V O R * \sigma)^{\mu} e^{\epsilon}
$$

where

$L=$ conditional variable which is equal to one if the alternative is shown on the left side in choice questions and zero otherwise. This treatment of left side is in line with the previous finding that the order in which information is encountered has a strong impact on choice making. As an example, information appearing early in a sequence may have a stronger influence on the choice making than does subsequent information (Kardes and Herr, 1990).

Similar to the specification, there were a few studies which considered the nonliner attribute effects in their model estimations. This has led to explain limited complex user's underlying behaviors, such as risk prone or averse, which was ignored in previous studies. For example, Li and Hensher (2012) investigated the risk-taking attitude among freight users (shippers and carriers) in Australia by adopting a power specification (U= $\left.\mathrm{x}^{\wedge}(1-\alpha) /(1-\alpha)\right)$ of travel time variable $(\mathrm{x})$ for the utility function, as below:

$$
U=\beta_{\text {time }} *\left[T^{1-\alpha} / 1-\alpha\right]+\beta_{\text {Cost }} * C+\epsilon
$$

where

$$
\alpha=\text { coefficient of risk proneness. }
$$


Similarly, Masiero and Hensher (2012) formulated a utility function with the purpose of capturing the combined effect of variables on the overall utility. Assuming that shipment distance and weight play a significant role in freight transportation decisions, the study introduced a multiplier which is a function of all conditional variables, into the specification as shown in equation 2-17:

$$
U=\left(1+\beta_{c e} * C E+\sum \beta_{(c e / z)} * Z\right) \cdot \sum_{k} \beta_{k} X_{k}+\epsilon
$$

where

$\mathrm{CE}=$ conditional effect, its value will be 1 when true, otherwise 0 ; is the coefficient associated with the conditioning effect of variables, such as shipping distance and weight; = coefficients associated with those variables $(\mathrm{Z})$ that are assumed to be related to this effect, $\mathrm{X}_{\mathrm{k}}=$ all other variables.

De Jong et al. (2014) employed a relative model specification, in which the attributes were normalized by their base values, as shown in Equation 2-18:

$$
U=\beta_{c}^{r e l} C / C_{0}+\beta_{T}^{r e l} T / T_{0}+\beta_{R}^{r e l} \sigma / \sigma_{0}+\epsilon
$$

where

$C_{0}=$ Base values for transport cost

$T_{0}=$ Base values for travel time

$\sigma_{0}=$ Base values for the standard deviation of travel time 
Since the typical shipment characteristics vary widely among the users, the use of this relative specification helps cope with the heterogeneity by eliminating abnormal effects of any attribute on the utility in model estimation. In this regard, past studies (i.e. Gatta and Marcucci, 2016) showed that ignoring the non-linearity in the attribute level tended to generate unreliable model estimates, which ultimately led to two different policy implications.

Table 2-1 provides a summary of the utility function and model structures used in past studies. The table also shows that studies before 2000 mostly used simple MNL models, with no consideration for the violation of IIA. Recent studies (De Jong et al., 2004; Hales et al., 2010; Significance et al., 2012) took this into account and estimated the models with different approaches. For example, De Jong et al. (2004) estimated MNL with a bootstrapping (i.e. Jackknife) technique, whereas Hales et al. (2011) estimated ML with a panel data approach. Significance et al. (2012) applied both of these techniques, but with a different error specification for ML. 
Table 2-1 Utility-based Modeling Techniques Used in Freight VOR Studies

\begin{tabular}{|c|c|c|c|}
\hline Author & Utility/cost function & Attributes & Model Structure \\
\hline Winston, 1981 & Utility function & Transit time, reliability & \\
\hline $\begin{array}{l}\text { Bergkvist and } \\
\text { Westin, } 1998\end{array}$ & Utility function & $\begin{array}{l}\text { Time, cost, reliability, damage } \\
\text { per mill }\end{array}$ & $\begin{array}{l}\text { Logit models and } \\
\text { solved with weighed } \\
\text { Maxi LL method }\end{array}$ \\
\hline Jovicic G., 1998 & Utility function & $\begin{array}{c}\text { Travel cost and time (door to } \\
\text { door), risk of damage (per mile), } \\
\text { delay, frequency, information } \\
\text { system and flexibility }\end{array}$ & $\begin{array}{l}\text { Hierarchical } \\
\text { multinomial logit }\end{array}$ \\
\hline Small,1999 & Utility function & $\begin{array}{c}\text { Travel cost, travel time, } \\
\text { reliability }\end{array}$ & $\begin{array}{c}\text { Conditional logit } \\
\text { model }\end{array}$ \\
\hline Wigan et al., 2000 & Liner utility function & Travel time, reliability, damage & Logit Model \\
\hline Kurri et al., 2000 & Utility function & Travel time, cost, reliability & Logit Model \\
\hline $\begin{array}{c}\text { Bolis and Maggi, } \\
2003\end{array}$ & Cost function & $\begin{array}{l}\text { Travel time, reliability, } \\
\text { frequency, flexibility }\end{array}$ & Tobit model \\
\hline Fowkes et al.,2004 & $\begin{array}{l}\text { Weighted utility } \\
\text { function }\end{array}$ & Time, reliability & $\begin{array}{l}\text { Weighted linear } \\
\text { regression of logit } \\
\text { transforms of the } \\
\text { ratios of the ratings }\end{array}$ \\
\hline $\begin{array}{l}\text { De Jong et al., } \\
2004\end{array}$ & Linear utility function & $\begin{array}{l}\text { Travel time, cost, reliability, } \\
\text { damage and loss, frequency }\end{array}$ & $\begin{array}{l}\text { Mixed logit; MNL } \\
\text { with Jack knife } \\
\text { bootstrapping }\end{array}$ \\
\hline $\begin{array}{c}\text { Danielis et al., } \\
2005\end{array}$ & Utility function & $\begin{array}{l}\text { Cost, time, reliability, and } \\
\text { damage }\end{array}$ & $\begin{array}{c}\text { Probit ordered; logit } \\
\text { model }\end{array}$ \\
\hline $\begin{array}{c}\text { Fowkes and } \\
\text { Whiteing, } 2006\end{array}$ & Cost function & $\begin{array}{l}\text { Cost, journey time duration, } \\
\text { spread, early shift, late shift, } \\
\text { lateness, lateness squared, } \\
\text { earliness, earliness squared }\end{array}$ & $\begin{array}{l}\text { Weighted linear } \\
\text { regression of logit } \\
\text { transforms of the } \\
\text { ratios of the ratings }\end{array}$ \\
\hline $\begin{array}{c}\text { Beuthe and } \\
\text { Bouffioux, } 2008\end{array}$ & $\begin{array}{l}\text { Expected utility } \\
\text { function }\end{array}$ & $\begin{array}{l}\text { Travel time, frequency, } \\
\text { reliability, carrier's flexibility } \\
\text { and safety }\end{array}$ & Ordered logit model \\
\hline $\begin{array}{l}\text { Hales et al., } \\
\quad 2010\end{array}$ & Utility function & $\begin{array}{c}\text { Transport cost, travel time, } \\
\text { reliability }\end{array}$ & $\begin{array}{l}\text { Mixed logit with } \\
\text { multiplicative error; } \\
\text { MNL with panel } \\
\text { data approach }\end{array}$ \\
\hline $\begin{array}{r}\text { Significance et al., } \\
2012\end{array}$ & Utility function & $\begin{array}{c}\text { Transport cost, travel time, } \\
\text { reliability }\end{array}$ & $\begin{array}{c}\text { Mixed logit with } \\
\text { additive error; MNL }\end{array}$ \\
\hline
\end{tabular}


The literature shows that a wide number of freight transport quality attributes had been used by researchers in addition to travel time and reliability. These include travel cost, frequency (the number of shipments offered by a transport company, or any freight forwarding agent in a determined period of time), flexibility (the number of unplanned shipments that are executed without excessive delay), and loss and/or damage (the percentage of the shipment that is damaged or lost during transportation).

\subsubsection{Inventory-Based}

Typically, this type of methods considers in-transit inventory cost, stationary inventory cost, freight charges, ordering cost, cost of holding stock safely, and cost for out of stock. Quing et al. (2012) estimated the VOR for freight using data collected from the Texas and Wisconsin regions. This study considered truck costs and in-transit costs, in addition to the warehouse inventory costs, as shown below:

$$
\text { Cost }_{\text {overall }}=C_{\text {Truck }}+C_{\text {in-transit }}+C_{\text {Inventory holding }}
$$

where,

$C_{\text {Truck }}=f($ Order size; Annual demand $;$ weight of goods $)$

$C_{\text {intransit }}=f($ Mean transit time; Annual demand; in - transit inventory cost $)$

$C_{\text {Inventory holding }}=$ Sum of holding cost, ordering cost and stock-out cost, which is a function of Order size; Reorder point; Demand during lead time; holding cost; purchasing cost; ordering cost; and lead time.

This cost function was minimized with respect to order quantity and mean transit time for two possible cases; one with the possibility of out of stock and another with no out of stock; along with other assumptions such as consideration of random lead time 
only, or random demand only, or both random demand and lead time. Finally, the value of eliability were derived from different types of commodities (such as food, chemical, pharmaceuticals, auto, paper, electronics, clothing, other manufactures, merchandise) based on corresponding unit cost price, which was collected from the survey.

Similarly, Dullart et al. (2013) also estimated the VOR for freight using data from Vernimmen et al. (2008), with the assumption that lead time and demand during the lead time are stochastic. Unlike the previous one, this study considered the unreliability in shipment time implicitly into the variation of lead time. The study simulated the safety stock levels for different levels of service, which is related to the company's policy to fulfill the customers' demands at $95 \%$ of the time, given the level of service at $95 \%$. This estimation of safety stock for different uncertainty levels presented an opportunity to assess the amount of inventory that can be saved. Nevertheless, these amounts were quantified into monetary values by multiplying the corresponding value of goods, (600 euro per ton) and the inventory holding costs, (20\% per year), which reflected the monetary value that firms were willing to pay for different service levels. This research also showed that empirical studies may get negative values of VOR when the reduction in variability does not necessarily always lead to savings in inventory quantity for certain range of level of service (0.5 to 0.65$)$. 
Overall, the main drawback of the inventory-based method was the firms' unwillingness to reveal this information as they feared that they may lose their competitive edge in the market. Thus, VOR estimates from most of the studies that employed inventory-based models show great variations in value.

\subsection{Market Segmentation}

The market segmentation for freight is particularly complex as there are no unanimous decision makers as in the case of passenger travel. As described in Section 2.1 (Overview of logistics), the responsibility of freight transport may be placed on many different agents along the supply chain depending on the firm's structure, the firm's policy on inventory management, and policy on hiring transportation services.

Literature indicates that most of the freight studies estimated VOR by transport mode or route. The decision of mode choice among the available alternatives (rail, roadway, sea, air, or a combination) is mainly based on the decision maker's past experiences, perceptions of modes, the commodity values, and time sensitivity of the goods. For instance, managers typically possess negative views towards the use of rail, whereas shipment via air is usually associated with great urgency and a limited time window. Many studies (Hales et al., 2010; Beuthe and Danielis, 2005; Kurri, 2000) have focused on rail and roadway, while others (Beuthe, 2006; Significance et al., 2012) considered other modes such as air, inland waterways, and sea transportation. Kawamura (1999) estimated the VOT values for commercial trucks (by business type, shipment weight, pay scale) in California, with a focus on estimating the effect of 
congestion pricing (SR 91 corridor) asking respondents to choose between general purpose lanes and toll lanes.

Other segmentation strategies have also been implemented to take into account the heterogeneity that exists in freight transportation. Common categories are summarized below (see Table 2-2 for more detail).

- Commodity Type (time sensitivity, amount, values)

- Shipment Characteristics (such as type, weight, distance)

- Firm's Characteristics (size, transport ownership, inventory management)

- Miscellaneous (time of day, congestion versus non-congestion)

It is well established that the importance of on-time delivery is greatly influenced by the type of commodity being shipped. For example, perishable commodities like food, beverages, or fresh produce are time sensitive and need to be delivered within a short time period, while non-perishable commodities such as coal, petroleum oil, and construction materials may be able to tolerant reasonable delays. Many studies categorized VOR estimates based upon commodity types.

Similarly, shipping characteristics such as distance, weight, or type (container or non-container) are critical in the estimation of VOR. Wigan (2000) considered shipment weight, distance, and different types of commodities (finished versus unfinished, low versus high time sensitivity, low versus high value density) for segmentation. The study measured shipment traveling less than $100 \mathrm{~km}$ as metropolitan transport and any other distances as inter-capital shipment, but cautioned that these values were only applicable for Australia. One of the findings was that shippers value reliability for urban/metropolitan areas almost twice as much as the reliability for inter-region/intercity 
shipment. Many studies (Beuthe, 2006; Erik, 1998; Jovicic, 1998) used shipping distance for market segmentation.

Table 2-2 Marketing Segments Used in Freight Studies

\begin{tabular}{|c|c|c|}
\hline Characteristics & Segments & Studies \\
\hline Model Choice & $\begin{array}{l}\text { Rail vs. road and all other mode } \\
\text { choices }\end{array}$ & $\begin{array}{c}\text { Significance (2012), Hales (2011), } \\
\text { Beuthe (2006), Danielis (2005), } \\
\text { Beuthe (2006) }\end{array}$ \\
\hline Shipment Type & Container vs. Non-container & $\begin{array}{c}\text { Significance (2012), Fowkes (2006, } \\
\text { 2004) }\end{array}$ \\
\hline Shipment Weight & Full truck load vs. Partial truck load & Beuthe et.al. (2006), Wagan (1998) \\
\hline Shipment Distance & $\begin{array}{l}\text { Inter-capital/city, Metropolitan, } \\
\text { (Single drop), Metropolitan (Multi } \\
\text { drop) }\end{array}$ & $\begin{array}{c}\text { Beuthe (2006), Wigan(200), } \\
\text { Bergkvist(1998), Jovicic (1998) }\end{array}$ \\
\hline Ownership of Transport & $\begin{array}{c}\text { Shippers with or without transport } \\
\text { Carriers }\end{array}$ & $\begin{array}{l}\text { Hales (2011), Fowkes (2004), } \\
\text { Significance (2012) }\end{array}$ \\
\hline Commodity Type & $\begin{array}{c}\text { Low-value (food, drink, grocery) } \\
\text { High-value (chemicals, minerals, } \\
\text { textiles) } \\
\text { Perishable vs. Non-perishable } \\
\text { Bulk vs. Non-bulk } \\
\text { Time sensitivity (low, moderate, } \\
\text { high) }\end{array}$ & $\begin{array}{c}\text { Beuthe (2006), Fowkes (2007, } \\
\text { 2004), Erik (1998), Jovicic (1998), } \\
\text { Small (1999) }\end{array}$ \\
\hline Inventory Management & $\begin{array}{l}\text { Jitney transport operation vs. Non- } \\
\text { jitney }\end{array}$ & Fowkes (2004), Danielis (2005) \\
\hline Inflow or Outflow & $\begin{array}{c}\text { Supply of raw materials vs. } \\
\text { Finished product }\end{array}$ & Danielis (2005) \\
\hline Transportation Network & Congestion vs. Non-congestion & Small (1999) \\
\hline $\begin{array}{l}\text { Geographical } \\
\text { limitations }\end{array}$ & $\begin{array}{l}\text { Regional differences (i.e. south, } \\
\text { north) }\end{array}$ & $\begin{array}{l}\text { Fowkes (2004), Bergkvist(1998), } \\
\text { Jovicic (1998) }\end{array}$ \\
\hline Miscellaneous & Firm size, time of day & Bolis (1998), Danielis (2005) \\
\hline
\end{tabular}

Significance et al. (2012) argued for separate estimates of VOR for shippers and carriers. The reason was that shippers are in a better position to assess the value of time and reliability related to the goods, whereas carriers better relate to the value of time and reliability to the cost of transport services. These statements are well justified considering that freight managers are more focused on invested capital, value of goods, and on-time supply of raw materials for smooth production, while carrier managers focus more on incurring transportation service related cost such as vehicle cost, staff cost, and fuel cost, etc. 
A few studies (Fowkes, 2007; 2004; Erik, 1998; Jovicic, 1998; Bolis, 1998; Danielis, 2005) considered firm characteristics and miscellaneous factors such as time of day, congestion versus non-congestion and regional differences.

The New Zealand Transport Agency Report (2013) recommended that market segmentation should be conducted to reflect the shippers and carriers point of view separately. Based on this report, in the event of a significant delay the shipper's primarily concern is on additional costs due to holding excess inventory, assigning extra resources, or on losses due to stock-outs. Therefore, the report proposed the following four types of market segments, as shown in Figure 2-3:

- Ordering/Delivery Time Tightness. Segmentation based on the constraints of the time available for delivery and any constraints on the delivery window.

- Degree of Product Customization. Segmentation based on the range of products offered, ranging from undifferentiated products to supply a market on the traditional push-production stockholding approach to highly customized products using the pull-production, or lean or zero stocking approach.

- Loss of Product Value with Time. Segmentation based on the sensitivity of commodity value loss with time.

- Opportunity cost of commodity stock value. Segmentation based on the value tied to holding the commodity, which can be represented by the opportunity cost of investment per ton or other appropriate units. 


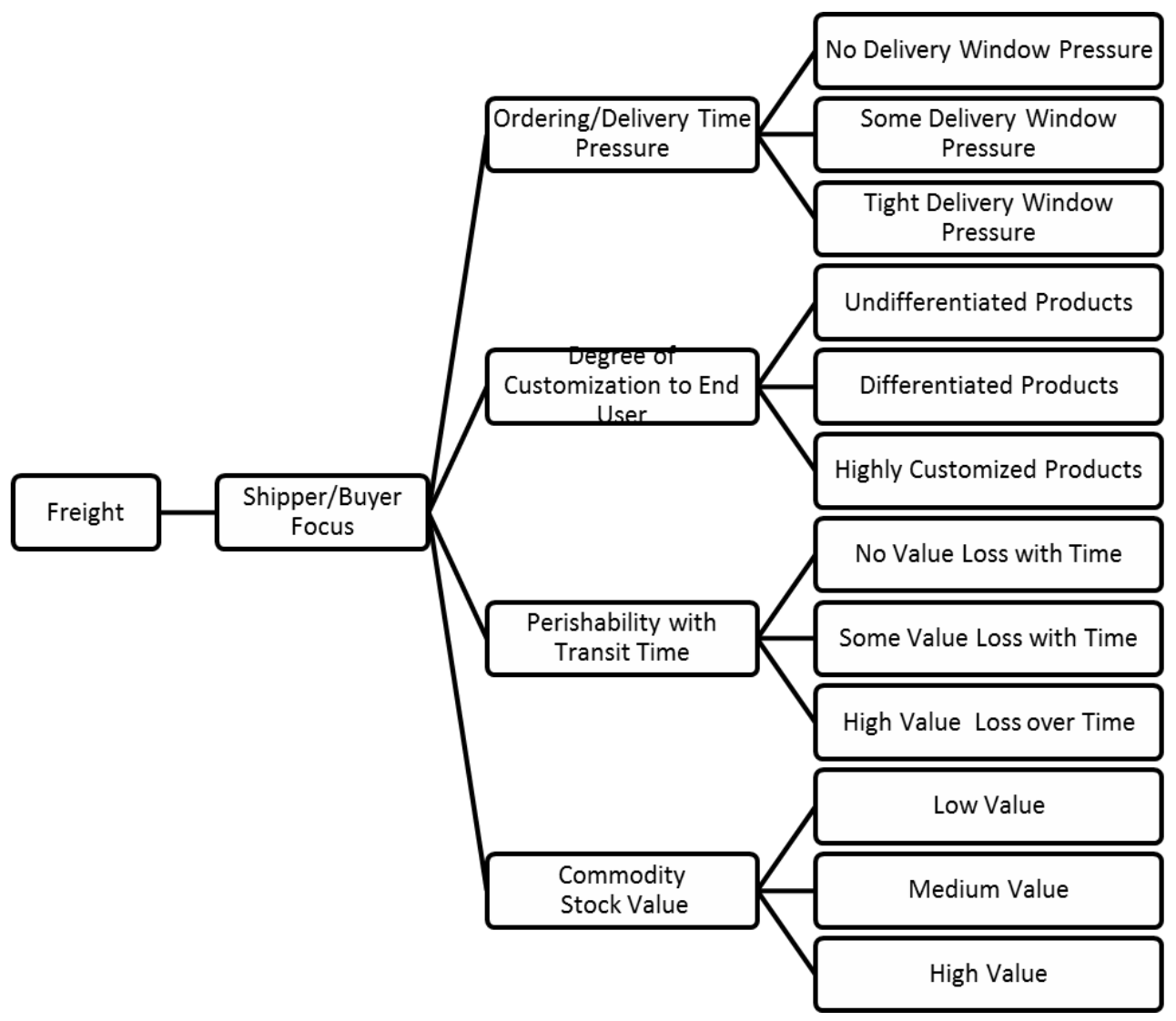

Figure 2-3 Proposed Market Segmentation for Shipper (source: Bone et al. 2013)

On the contrary, carriers put more emphasis on minimizing vehicle/overhead cost and maximizing the utilization of transport and staff. In order to do that, carriers often take certain factors into consideration. One of these factors is the volume of shipment (full truck load or less than full) which dictates whether more shipments have to consolidate or not. Another factor considered is shipment distance and the type of commodity determines which mode (road, air, sea, inter-urban, inter-region, and international). Ultimately, the carriers decide on the route and mode to be used for a shipment. Factors that influence the decisions on the carrier's sides are illustrated in Figure 2.4 below. 


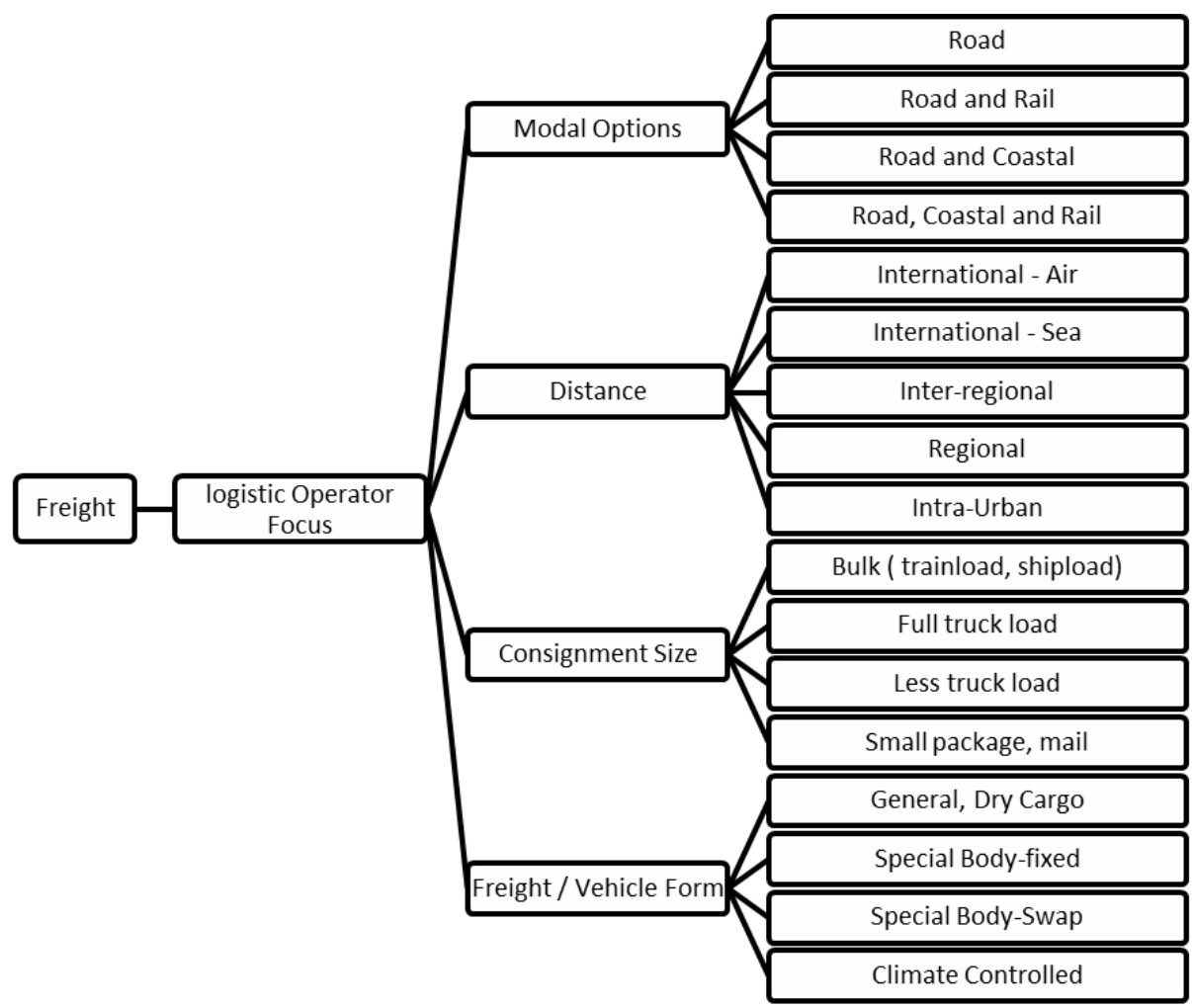

Figure 2-4 Proposed Market Segmentation for Carriers (source: Bone et al. 2013)

\subsection{Stated Preference Survey}

This section focuses on the stated preference survey techniques used in freight VOR studies. It provides an overview of the SP method, the steps involved in the survey design, and a comparative summary of the survey design drawn from previous studies. Literature shows that the SP method is also referred to as "conjoint analysis" in other fields, such as marketing. 


\subsubsection{Background}

Choice experiments have a long history dating back to the early nineteenth century when Thurstone (1927) tried to estimate indifference curves experimentally by asking people to make choices between different combinations of coats, hats, and shoes. Later on, these experiments were studied extensively (Bradley and Terry, 1952; Davidson and Farquhar, 1976; Wardman, 1987) by experts from different professions (i.e. marketing, psychology, economics, etc.). Davidson (1973) and Louviere et al. (1973) were the first to publish papers in the transportation field using this technique. Following this research, many studies were conducted (Louviere and Hensher, 1982; Louviere and Woodworth, 1983; Louviere and Kocur, 1983; Bradley and Bovy, 1984; Green and Srinivasan, 1990), which contributed to the escalation of experiments to its current state.

\subsubsection{Different Types of Experimental Design}

The experimental design of an SP study can be categorized into three classes based on the types of the response variables:

- Rank based experimental design. In this method, proposed by Chapman and Staelin (1982), individuals are asked to rank the alternatives, which are then translated into choice responses. Although this type of design allows for more information about the alternatives, the method was questioned by many researchers (Ben-Akiva et al., 1992, Hensher and Louviere, 1983; , etc.), because of the monotonic translation of ratings into utility scales. 
- Rate based experimental design. In this method, proposed by Krantz and Tversky (1971) all options were presented to individuals who were then required to rate the hypothetical options in order of preference, thus implying a hierarchy of utility values. This type of response requires respondents to express the strength of their preferences on numerical or "semantic" scale (preferably 1 to 10 ). Like the previous method, this survey design has limitations such as the validity of a monotonic translation of rating into utility scale as error components vary among models and a naïve assumption that respondents can consistently rate the options. However, this approach provides the richest type of response data, if one can assume that the scores are cardinal in measurement. The power of the technique improves with the fineness of the scales used.

- Choice based experiment design. In this method, the individual simply selects the most preferred option from a pair or group of options that comes closest to achieving the goal. The development of suitable analytical procedures, such as the logit model, has enabled these particular

types of stated preference approaches to come to the forefront of modeling.

In summary, each method of response has its own merits and limitations. Currently, there is no consensus in the literature to favor one method of response over another. Ranking and rating methods offer the richest form of data but offer less realistic choice applications. In particular, the greatest drawback for rating is that respondents 
tend not to differentiate between perceived "good" attributes and rate them all as attractive. Rank based method captures order preference but fail at capturing relative importance. Choice-based method does not suffer from any of these deficiencies and can be easily computed.

\subsubsection{Design Steps for Choice Based Stated Preference Survey}

Most of the discussion of this section is taken from Hensher et. al., 2005 and Louviere et. al., 2001. The SP methods involve six steps:

- Defining the problem statement

- Identifying the alternatives, attributes and attribute levels

- Experimental design considerations

- Generating choice sets

- Administrating surveys

- Estimating the models

\subsubsection{Stage 1-Defining the Problem Statement}

The first and foremost thing of SP survey design is defining the problem statement. At this stage, researchers explore all possibilities and do not constrain their ideas to the limitations of the available methodological approaches. More importantly, this stage will produce all the research questions that needed to be answered to define the problem statement.

\subsubsection{Stage 2 - Identifying Alternatives, Attributes, and Attribute Levels}

This stage involves defining the universal, but finite list of alternatives available to decision-makers in order to meet the utility maximizing rule. However, this prompts 
the chance of considering too many alternatives. The issue of too many alternatives can be dealt with by investigating the problem from a contextual point of view. This allows the survey designers to omit fewer alternatives, which may not be relevant to the choices in that context. Another way to deal with this problem is to exclude insignificant alternatives from the list based on personal experience. Since the respondent eventually will put more value on one over the other, this may not affect the experiment when insignificant alternatives are carefully selected for removal. However, the most preferred approach is to use experiments that do not name the alternatives (i.e. the analyst defines generic or unlabeled alternatives). In doing so, the possible alternatives are created by differentiating the attributes and attribute levels. One of the benefits of using unlabeled alternatives is that it does not require the identification and use of all alternatives within the universal set of alternatives, although it is not recommended in estimating alternativespecific parameter estimates, or specific attributes.

After finalizing the list of alternatives, the survey designer identifies the attributes and the attribute levels for each alternative. The alternatives may have some common or different attributes. Then, the designer must assign the levels for each corresponding attribute. The advantage of having more attribute levels is that the utility associated with the various levels can be measured more precisely, as shown in Figure 25. However, as the number of levels goes up, so does the number of possible choice sets.

Another important consideration while developing the SP experiment is that the questionnaire should not be so long that respondents get confused in answering the questions. This problem can be illustrated using the possible full enumeration choice set formula: LMA, where $\mathrm{L}=$ number of attribute levels, $\mathrm{M}=$ the number of alternatives, 
and $\mathrm{A}=$ the number of attributes.

As the attribute levels (L) increase, the number of choice sets also increase in an exponential fashion.
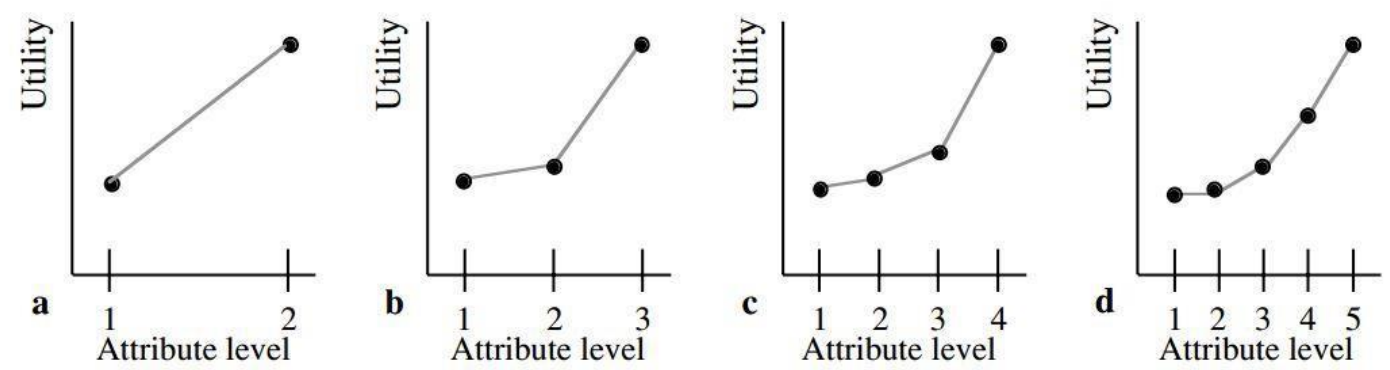

Figure 2-5 Marginal Utility (source: Hensher et al., 2005)

\subsubsection{Stage 3 - Experimental Design}

After identifying the alternatives, attributes, and the number of attribute levels, the next step is to determine the experimental design. Alternatives can be generated with the aid of statistical design theory. Table 2-3 summarizes some common designs in SP surveys.

Full factorial design considers all possible scenarios defined the attributes, while the fractional factorial design allows for the reduction of insignificant factors. Both designs can be used to test the main effects and the interaction effects. The main effects can be defined as the effect on the experimental response of going from one level of the variable to the next given that the remaining variables do not change, whereas interaction effects can be defined as the effect of one variable of the response depends on the value of other variables. Moreover, orthogonal design only considers the main effect assuming that the attributes are statistically independent of each other. 
Table 2-3 Overview of Different Types of Experimental Design

\begin{tabular}{|c|c|c|}
\hline $\begin{array}{c}\text { Type of } \\
\text { Experiment }\end{array}$ & Characteristics & Effects Tested \\
\hline $\begin{array}{l}\text { Full Factorial } \\
\text { Design }\end{array}$ & $\begin{array}{l}\text { Each level of each attribute is combined with every } \\
\text { other level of every other attribute. For example, a } \\
\text { design with two, three-level attributes and two, } \\
\text { two-level attributes would have } 36 \text { scenarios }\left(3^{2} \cdot 2^{2}\right. \\
=36) \text {. This design captures all the main effects and } \\
\text { interaction effects of variables within the dataset. }\end{array}$ & $\begin{array}{l}\text { Main effect and all kinds of } \\
\text { interaction effects }\end{array}$ \\
\hline $\begin{array}{l}\text { Fractional } \\
\text { Factorial Design }\end{array}$ & $\begin{array}{l}\text { When not all interaction effects are statistically } \\
\text { significant, the insignificant effects can be ignored. } \\
\text { Fractional factorial design allows for the reduction } \\
\text { of extensively large volume of scenarios created by } \\
\text { the full factorial design. In this process some } \\
\text { interactions are ignored. }\end{array}$ & $\begin{array}{l}\text { Main effect and } \\
\text { some interaction } \\
\text { effects }\end{array}$ \\
\hline $\begin{array}{l}\text { Orthogonal } \\
\text { Design }\end{array}$ & $\begin{array}{l}\text { Attributes are statistically independent of one } \\
\text { another. Only main effects can be estimated as } \\
\text { there is no interaction among the variables. }\end{array}$ & Only Main effect \\
\hline $\begin{array}{l}\text { Efficient/ } \\
\text { Optimal Design }\end{array}$ & $\begin{array}{l}\text { Optimizes the amount of information obtained from } \\
\text { a design, also achieves statistical efficiency by } \\
\text { maximizing the determinant of the variance-- } \\
\text { covariance matrix. }\end{array}$ & $\begin{array}{l}\text { Main effect and some } \\
\text { interaction effects, but } \\
\text { statistically more } \\
\text { efficient than fractional }\end{array}$ \\
\hline
\end{tabular}

The optimal design, also known as D-optimal, is a design which not only optimizes the amount of information obtained from a design but also constitutes the most statistically efficient design by maximizing the determinant of the variance-covariance matrix (Kuhfeld, Toblas, and Garratt, 1994; Lazari and Anderson, 1994; Huber and Zwerina, 1996; Bunch, Louviere, and Anderson, 1996; Sandor and Wedel, 200; Kanninen, 2002). In determining the D-optimal design, it is common to use the inversely related measure to calculate the level of D-efficiency, i.e., minimizing the determinant of the inverse of the variance-covariance matrix. McFadden (1974) showed the covariance matrix (Eq 2-20):

$$
\begin{aligned}
& \Omega=\left(X^{\prime} P X\right)=\left[\sum_{m=1}^{M} \sum_{j=1}^{J} X_{n j s}^{\prime} P_{n j s} X_{n j s}\right] \\
& \text { and } \Omega^{-1}=\left(X^{\prime} P X\right)^{-1}=\left[\sum_{m=1}^{M} \sum_{j=1}^{J} X_{n j s}^{\prime} P_{n j s} X_{n j s}\right]^{-1}
\end{aligned}
$$


where

$\mathrm{P}$ is a js $\times \mathrm{js}$ diagonal matrix with elements equal to the choice probabilities of the alternatives (j) over choice sets (s) and M equals to total number of respondents (N) multiplies choice sets (s).

For $\Omega$, several established summary measures of error have been shown to be useful for comparing designs. The most often used summary measure is known as Derror which is inversely related to D-efficiency:

$$
D-\operatorname{error}=\left(\operatorname{det} \Omega^{-1}\right)^{1 / k}
$$

where

$\mathrm{k}$ is the total number of generic parameters to be estimated from the design.

Minimizing this will produce the design with the smallest possible errors around the estimated parameters.

\subsubsection{Stage4 - Generating Choice Set}

In this stage, experiment designs are transformed into a set of real questions and are shown to the respondents for execution of the data collection. The form of conducting surveys also influences the generation of choice sets. For instance, the use of pencil/pen and paper does not allow the survey designers to put the choice sets in randomized orders, which is necessary to avoid ordering bias. This is important in case of partial factorial or optimal design as respondents may not trade attributes, and choose alternatives based on previous choice sets. Three common types of choice set generation methods are described below.

- Simultaneous Choice Set: Simultaneous choice set is a method to create alternatives and choice sets at the same time. This method also 
called as $\mathrm{L}^{\mathrm{MN}}$ method (Sanko et. al. 2001). The name $\mathrm{L}^{\mathrm{MN}}$ stems from the fact that this is used when one wants a design whereby choice sets each contain $\mathrm{N}$ alternatives of $\mathrm{M}$ attributes of $\mathrm{L}$ levels.

- Sequential Choice Set: Sequential choice set is a method to create one alternative at first and then create other alternatives based on the first. “Shifting” (Bunch et al., 1994) and "Fold over" (Louviere et al., 2000) are two most popular sequential choice set methods.

- Randomized Choice Set: Randomized choice set is a method to create one alternative first and then randomly pick other alternatives after that. In this design, respondents are randomly selected to receive different versions of choice sets. For within product design (choices among alternatives from same products but varying attributes levels), the alternatives are simultaneously chosen; whereas for between-product design/choices among alternatives from different products, alternatives are chosen from their alternative sets.

Furthermore, there are popular practices to randomize the experiment. One practice involves dividing the full choice sets into different sub-sets (blocking) for two or more times and then sort and prepare questions for different combinations of choice sets (Louviere et al., 2001).

\subsubsection{Stage 5 - Survey Administration}

SP surveys may be administered by interviewers in a face-to-face format or by completion of questionnaires that may be returned by mail or internet. The decision on which method to use depends on the complexity of the SP survey. 
This stage involves the determination of a survey method, desired sample size with segments, recruitment of respondents, collection of respondent background information for screening and other purposes, survey implementation, retrieval of survey responses, initial data processing and monitoring, and revision of the survey questionnaire if necessary.

\subsubsection{Stage5 - Model Estimation}

The final stage of the SP method is data processing and model estimation. Different forms of Logit and Probit models have been used for estimation of the stated preference such as Binary Logit, Multinomial Logit, Mixed Logit, and Probit Model. A more detailed discussion of these analytical techniques is provided in section 2.7.

\subsubsection{Revealed Preference versus Stated Preference}

To evaluate the impact of different policies, Revealed Preference (RP) data are often collected and analyzed. RP data are observations of actual behavior and choices in real-world conditions. However, when it is a completely new policy or alternative, real responses to the policy do not exist because it has not been implemented. There other cases where collecting revealed data is impossible, extremely costly or difficult. Under this situation, SP techniques are developed to gather information on how respondents would react to different policies or choices in hypothetical scenarios. In SP survey, the researchers have full control over the design of the choice questions and have the freedom to modify these in order to evaluate the trade-off between attributes.

Simultaneously, researchers can check for the associated correlation among variables. Another advantage of SP data is that it can be used to evaluate policy for areas where there is little or no RP data. Also, SP data requires a smaller sample size, if the surveys 
are designed efficiently. However, the success of this technique depends on how well and how realistic the choice questions appear to the respondents.

\subsubsection{Adaptive Stated Preference}

This method, developed by Fowkes and Tweddle (1988), is very useful for studies with a smaller sample size. This method takes advantage of computer technology and applies adaptive algorithms to develop choice sets. Trade-offs between the attributes are based on the stated preferences in previous questions. This gives enough information to calibrate a model for each respondent. Adaptive stated preference is particularly useful for freight studies as data are scarce in the freight industry because freight movement data tends to be proprietary in nature making it difficult to collect information from the private sector.

Fowkes et al. (2002) estimated the values for different types of delays using Leeds adaptive stated preference (LASP) methods with a sample size of 40 respondents from different industries in the United Kingdom. While designing the survey, this study used four attributes to describe the alternatives:

- Travel cost

- Delay time (an increase in free flow time for a given departure time) which is calculated by the difference between earliest possible arrival and departure time

- An increase of spread of arrival times (98\% of deliveries arrival time earliest arrival)

- Schedule delays (greater than the departure times)

The study collected the survey data in two stages. First, all the background 
information about the company and a detailed description of a typical shipment was gathered. Then, based on the information, the LASP software asked the respondents to rank four choices, including one option stating the typical shipment. The respondents were presented with more alternatives than the typical flow and ultimately guided through less desirable choice sets.

Bolis et al. (2002) estimated the reliability in freight services for regions in Italy and Switzerland using the adaptive stated preference method. Unlike other studies that focused only on mode or route alternatives, this paper attempted to find out the values from an integrated approach (transport modes, logistics services, and production rates). This was done by designing the survey questions in such a fashion that questions were presented with the intention of discovering whether transportation decisions were separate from logistics decisions. This study used a sample size of 41 and considered seven attributes in the models. These attributes included:

- Cost

- Journey time

- Reliability (percent of shipments per year arriving on time)

- Frequency (number of shipments per months)

- Notice (minimal notice time for transport orders in hours)

- Multiple dummy variables of using road transport or not

Danielis et al. (2005) also used Adaptive Conjoint Analysis (ACA) but used software developed by the Sawtooth Software Inc. to estimate the values for attributes and attribute levels. This study used data from 65 manufacturing firms and followed the same procedure mentioned in the previous study. The results indicated a strong 
preference of shippers for reliability, safety and journey times as opposed to cost. Although there are some concerns regarding the adaptive SP method and its use and many details not shared by the software developers, the results from the studies were found to be plausible (Small et al., 1999).

\subsubsection{Review of Survey Design used in Freight Transportation}

This section summarizes the survey design methods adopted by previous studies. While reviewing the studies, particular attention was given to critical components in survey design, such as sample size, number and level of attributes, ranges of the attribute level, types of choice sets considered, experiment design method, survey administration, or any other unique protocol followed by the researchers. Many reports didn't provide much information about their survey methods; therefore, this section mainly focuses on those papers that gave sufficient details concerning survey design.

Wigan et al. (2000) used a Contextual Stated Preference (CSP) survey method to investigate the values of freight travel time and reliability in Australia. The study considered four attributes (costs, delays, freight damage, and reliability) and was able to collect 129 responses from 43 firms in four industries. A few of the represented industries were automotive parts, food and beverages, building materials, and packaging. This study defined reliability as the percentage of deliveries which reached the destination at the scheduled time. For the purpose of conducting the survey, this study assembled possible respondents by inviting them through a postal survey and also asked them to give detailed descriptions of a typical flow. Later, the main survey was conducted in person. This study followed the fractional factorial design. The variation in the attribute values were $\pm 20 \%$ of the mean values. The paper did not provide much 
information about the generation of choice sets.

Halse et al. (2011) estimated the VOR in freight transport in Norway using SP survey data. Their sample consisted of 640 shippers 117 and carriers. This study evaluated both forms of reliability measures: variation of travel time and probability of delay. The study was designed in such a way that the respondents had to decide between transport time, cost, and reliability. The study also used coefficients for differentiating the alternatives in choice tasks, as shown in Table 2-4.

The questionnaires were divided into three parts. First, the respondents were asked about a typical shipment or transport. Next, they were presented with the main survey questions. Finally, respondents were asked which attributes were more important during the decision-making process.

Table 2-4 Range of Attribute Levels Used by Halse (2011)

\begin{tabular}{|c|c|c|c|}
\hline Attributes & Experiment-1 & Experiment-2 & Experiment-3 \\
\hline Cost & $\begin{array}{c}\text { 8 intervals } \\
5-60 \% \text { for decrease }\end{array}$ & $\begin{array}{c}6 \text { intervals } \\
5-35 \%\end{array}$ & $\begin{array}{c}\text { intervals } \\
3-50 \%\end{array}$ \\
\hline Time & $\begin{array}{c}\text { M-300\% for increase } \\
\text { Maximum -50\% }\end{array}$ & $\begin{array}{c}\text { Minimum -50\% } \\
\text { Maximum +100\% }\end{array}$ \\
\hline Distribution & & $\begin{array}{c}\text { 5 different degrees } \\
\text { of variability }\end{array}$ & \\
\hline Probability of delay & & & $\begin{array}{c}0-40 \% \\
\text { (Increments of 5\%) }\end{array}$ \\
\hline Delay length & & & $\begin{array}{c}\text { Minimum 3\% of reference } \\
\text { transport time, Maximum } \\
100 \%\end{array}$ \\
\hline
\end{tabular}

The purpose of the final part was to verify whether the respondents have made choices or not. Another feature of this study was that they discarded responses that took less than 10 minutes to fill out and were then considered invalid.

Significance et al. (2012) conducted an SP survey to estimate the value of travel time and value of reliability in freight for the Dutch Ministry of Infrastructure and the 
Environment. This study was able to collect 812 total responses, although it fell short from the target sample size for some of the sub-segments. However, it was found that there was not much concern after consultation with the experts and clients. In terms of survey design, this study used three experiments. The first experiment considered two attributes: transport time and cost. The next experiment considered four: reliability, arrival time, transport time, and cost. The last experiment considered three attributes: travel time, cost, and reliability. In terms of conducting three experiments instead of one, the study argued that respondents would not get bored (which may lead to higher chances of stop making decisions) since he/she would face new forms of questions at each experiment. Besides, the sequence of these three experiments will also work as a gradual learning curve. VOT or VOR from these three experiments can be compared and crosschecked. While selecting the attribute levels, the study considered three levels $(-14 \%$, $0 \%,+20 \%)$ for the travel time attributes, and five levels $(85 \%, 95 \%, 100 \%, 110 \%, 125 \%)$ for the cost, reliability, and arrival time attributes. The study adopted the Bradley Design method for two of the experiments, which produced alternatives in such a way that no dominant alternative exists. Orthogonal design, which considers only main effects, was used for the experiment which had four attributes. Finally, respondents were interviewed in person and asked to reply to 19 pairs of choice questions. One dominant question was included to check the rationality of respondents using computer graphics.

Small et al. (1999) also conducted an SP survey in California. According to the report, only 20 respondents were able to participate due to budget constraints. This had a significant impact on the plausibility of the results. For the survey design, this study considered four attributes: travel time, cost, coefficient of variation of travel time, and 
time between departure and desired arrivals. Reliability variables can be derived from these data in the form of standard deviation and scheduled delay (early and late). However, this repot did not give much information concerning the attribute levels for freight studies, but provided information on the attribute ranges used for passenger studies as shown in Table 2-22.

$$
\begin{aligned}
& \text { Low level }=\text { current }- \text { cofficient } \cdot(\text { current }- \text { free flow }) \\
& \text { High level }=\text { current }+ \text { cofficient } \cdot(\text { current }- \text { free flow })
\end{aligned}
$$

Table 2-5 Range of Simulation Coefficients Used by Small (1999)

\begin{tabular}{|c|c|c|c|}
\hline Attribute & Low & Medium & High \\
\hline Cost & -0.5 & -1 & -2 \\
\hline Mean Travel time & -0.05 & -0.1 & -0.25 \\
\hline Standard deviation & -0.06 & -0.13 & -0.27 \\
\hline Departure time & -0.025 & -0.05 & -0.1 \\
\hline Stop-to-go & -0.06 & -0.13 & -0.27 \\
\hline
\end{tabular}

For the passenger study, it first designed a full factorial design with 81 possible combinations $\left(3^{4}=81\right)$. Then dominant choices were removed in such a way that no row possessed a dominant choice among the treatments/choices, but each row was dominated by at least one treatment in the row above and the row below. This reduced the number of pairs to 19 , of which 7 were discarded based on their correlation matrix. Finally, the study assigned 6 pair-wise choice questions randomly for each respondent. For the freight study, the report followed the same procedure but came up with only 10 statistically stable. The survey was conducted over the telephone.

Beuthe et al. (2006) estimated the value for freight shippers of qualitative factors that characterize transport solutions. The qualitative factors estimated by this study were service frequency, transport time, reliability of delivery, carrier's flexibility, and safety using ranked based conjoint analysis. First, a preliminary face-to-face interview was 
conducted to determine the characteristics of the firm and its transport organization. Then respondents were asked to describe a typical shipment which was used as a reference in the survey. For the survey design, this study considered six transport attributes:

- Frequency of service per week

- Travel time (door to door transport time including loading and unloading)

- Reliability (\% of deliveries reaching the destination at the scheduled time)

- Flexibility (\% of unplanned shipments serviced without undue delay)

- Loss (\% of commercial value lost from damages, stealing, and accidents)

- Cost (out of pocket door-to-door cost including loading and unloading)

The study only considered the main effect (orthogonal) with five levels of attributes $(-20 \%,-10 \%, 0 \%,+10 \%,+20 \%)$ and 25 alternatives. Moreover, this study asked respondents to rank the alternatives presented during the survey. One unique feature of this study is that it used cards for each alternative so that respondents could go back to previous cards and change the ranking if desired.

Table 2-6 below presents a brief summary of freight studies in terms of various aspects in the survey design. The summary is developed based on the literature that provided enough details on the survey methods employed. 
Table 2-6 Summary of Survey Design among Existing Freight VOR Studies

\begin{tabular}{|c|c|c|c|c|c|c|c|c|}
\hline Author & Location & $\begin{array}{l}\text { Survey } \\
\text { Method }\end{array}$ & $\begin{array}{l}\text { Sample } \\
\text { Size }\end{array}$ & Market Segment & Alternatives & $\begin{array}{c}\text { Experiment } \\
\text { Design }\end{array}$ & Attribute Level & Choice Set \\
\hline $\begin{array}{l}\text { Bolis and } \\
\text { Maggi, } 1998\end{array}$ & $\begin{array}{l}\text { Italy \& } \\
\text { Switzerland }\end{array}$ & $\begin{array}{l}\text { Adaptive } \\
\text { stated } \\
\text { preference }\end{array}$ & 24 firms & $\begin{array}{l}\text { By weight limit (Swiss } \\
\text { weight limit, } 15 \text { ton ; } \\
\text { Eu weight limit } 27 \text {-ton } \\
\text { net weight) }\end{array}$ & $\begin{array}{l}\text { Integrated } \\
\text { approach }\end{array}$ & Adaptive & $\begin{array}{l}\text { First, attributes related to } \\
\text { transport change followed } \\
\text { by changes in logistics } \\
\text { (flexibility, frequency) } \\
\text { and finally by mode }\end{array}$ & $\begin{array}{l}40 \text { binary } \\
\text { choices per } \\
\text { firm }\end{array}$ \\
\hline Small, 1999 & USA & $\begin{array}{l}\text { Stated } \\
\text { Preference }\end{array}$ & 20 firms & $\begin{array}{l}\text { Commodity value with } \\
\text { respect to time } \\
\text { sensitivity }\end{array}$ & $\begin{array}{l}\text { Within mode } \\
\text { experiments } \\
\text { (road only) }\end{array}$ & $\begin{array}{l}\text { Full factorial } \\
\text { design, then } \\
\text { removing } \\
\text { dominant } \\
\text { choices }\end{array}$ & 3 levels for each attribute & $\begin{array}{l}10 \text { pair } \\
\text { choice set }\end{array}$ \\
\hline $\begin{array}{l}\text { Wigan, et al. } \\
2000\end{array}$ & Australia & $\begin{array}{l}\text { Contextual } \\
\text { Stated } \\
\text { Preference }\end{array}$ & 43 firms & $\begin{array}{l}\text { Mode (Road, All); } \\
\text { Shipper type (with } \\
\text { Transport, w/o } \\
\text { transport, Carriers) }\end{array}$ & $\begin{array}{l}\text { Within mode } \\
\text { experiments } \\
\text { (road only) }\end{array}$ & $\begin{array}{l}\text { fractional } \\
\text { factorial design }\end{array}$ & -0.2 & NA \\
\hline $\begin{array}{l}\text { Kurri, et al. } \\
2000\end{array}$ & Finland & $\begin{array}{l}\text { Choice } \\
\text { based } \\
\text { Stated } \\
\text { Preference }\end{array}$ & $\begin{array}{l}236 \text { Road } \\
\text { shipments, } \\
162 \text { Rail } \\
\text { shipments }\end{array}$ & $\begin{array}{l}\text { Mode (Road \& Rail) } \\
\text { and commodity types }\end{array}$ & $\begin{array}{l}\text { Two separate } \\
\text { within-mode } \\
\text { experiments } \\
\text { (road, rail) }\end{array}$ & $\begin{array}{l}\text { fractional } \\
\text { factorial design }\end{array}$ & $\begin{array}{l}4 \text { levels }(-15 \% \text { to } 20 \%) \text { for } \\
\text { cost, time }(<10 \%) \text { and } \\
\text { reliability (either } 10 \% \text { and } \\
5 \%, \text { or } 5 \% \text { and } 2 \%)\end{array}$ & $\begin{array}{l}120 \text { different } \\
\text { choice sets, } \\
\text { with each } \\
\text { respondent } \\
\text { answer } 12 \text { to } \\
15 \text { pairwise } \\
\text { choice } \\
\text { questions }\end{array}$ \\
\hline $\begin{array}{l}\text { Fowkes et } \\
\text { al. } 2004\end{array}$ & UK & $\begin{array}{l}\text { Adaptive } \\
\text { stated } \\
\text { preference }\end{array}$ & 40 firms & $\begin{array}{l}\text { By Shipment type, } \\
\text { Ownership of transport, } \\
\text { JIT or not, Commodity } \\
\text { type, Intermodal or not, } \\
\text { Daytime or not, } \\
\text { Distribution or not, }\end{array}$ & Unlabeled & Adaptive & $\begin{array}{l}\text { Cost, departure time, } \\
\text { spread (earliest arrival } \\
\text { time), scheduled delay }\end{array}$ & NA \\
\hline
\end{tabular}




\begin{tabular}{|c|c|c|c|c|c|c|c|c|}
\hline Author & Location & $\begin{array}{l}\text { Survey } \\
\text { Method }\end{array}$ & $\begin{array}{l}\text { Sample } \\
\text { Size }\end{array}$ & Market Segment & Alternatives & $\begin{array}{c}\text { Experiment } \\
\text { Design }\end{array}$ & Attribute Level & Choice Set \\
\hline $\begin{array}{l}\text { Beuthe and } \\
\text { Bouffioux, } \\
2008\end{array}$ & Belgium & $\begin{array}{l}\text { Ranked } \\
\text { based } \\
\text { Stated } \\
\text { Preference }\end{array}$ & 113 firms & $\begin{array}{l}\text { Mode (road, rail, } \\
\text { Inland waterways, } \\
\text { others); Shipping } \\
\text { distance; Goods value; } \\
\text { Commodity Type; } \\
\text { Weight }\end{array}$ & $\begin{array}{l}25 \text { unlabeled } \\
\text { alternatives }\end{array}$ & $\begin{array}{l}\text { fractional } \\
\text { factorial design }\end{array}$ & $\begin{array}{l}5 \text { levels }(+-10 \&+-20 \text { with } \\
\text { respect to status quo) }\end{array}$ & NA \\
\hline $\begin{array}{l}\text { Halse et } \\
\text { al. } 2011\end{array}$ & Norwegian & $\begin{array}{l}\text { Stated } \\
\text { Preference }\end{array}$ & $\begin{array}{l}117 \\
\text { transport } \\
\text { firms and } \\
640 \\
\text { shippers }\end{array}$ & $\begin{array}{l}\text { Mode (road, all } \\
\text { modes), and Shipper } \\
\text { Types(shippers or } \\
\text { carriers) }\end{array}$ & $\begin{array}{l}\text { Within mode } \\
\text { experiments }\end{array}$ & $\begin{array}{l}\text { Randomized } \\
\text { block design }\end{array}$ & $\begin{array}{l}\text { For Experiment } 1: 8 \text { levels } \\
\text { for cost, } 5 \text { levels for travel } \\
\text { time; For Experiment } 2: 6 \\
\text { levels for cost, } 5 \text { levels for } \\
\text { travel time, } 5 \text { levels for } \\
\text { reliability; For Experiment } \\
3: 6 \text { levels for cost, } 7 \\
\text { levels for probability of } \\
\text { delay, } 5 \text { levels for } \\
\text { reliability }\end{array}$ & $\begin{array}{l}20(8+6+6) \\
\text { choice } \\
\text { situations }\end{array}$ \\
\hline $\begin{array}{l}\text { Zamparini, } \\
\text { et al. } 2011\end{array}$ & Tanzania & $\begin{array}{l}\text { Ranked } \\
\text { based } \\
\text { Stated } \\
\text { Preference }\end{array}$ & 24 firms & $\begin{array}{l}\text { Transport provider } \\
\text { (internal, external) and } \\
\text { value density of goods }\end{array}$ & Within mode & NA & NA & NA \\
\hline $\begin{array}{l}\text { Significance, } \\
\text { et al., } 2012\end{array}$ & Netherland & $\begin{array}{l}\text { Stated } \\
\text { Preference }\end{array}$ & 812 firms & $\begin{array}{l}\text { Transport mode (road, } \\
\text { rail, air, sea, inland } \\
\text { waterways); Shipment } \\
\text { type (container, non- } \\
\text { container); Transport } \\
\text { ownership }\end{array}$ & Within-mode & $\begin{array}{l}\text { Orthogonal, } \\
\text { fractional } \\
\text { factorial design }\end{array}$ & $\begin{array}{l}\text { Three levels for travel } \\
\text { time, and five levels for } \\
\text { cost, reliability, and arrival } \\
\text { time attributes. }\end{array}$ & $\begin{array}{l}19(6+6+7) \\
\text { choice } \\
\text { situations }\end{array}$ \\
\hline $\begin{array}{l}\text { Gong, et al. } \\
2012\end{array}$ & USA & $\begin{array}{l}\text { Stated } \\
\text { Preference }\end{array}$ & 24 firms & $\begin{array}{l}\text { By route (congested } \\
\text { road, toll road) }\end{array}$ & Routes & NA & 3 levels for delay & $\begin{array}{l}12 \text { choice } \\
\text { situations }\end{array}$ \\
\hline
\end{tabular}




\subsection{Findings}

This section of the report summarizes the major findings from literature review.

\subsubsection{Reliability Measures}

Reliability in freight transport has been defined in a variety of ways. It has been measured as the absolute or relative variations in travel times, the delay from the preferred/scheduled arrival time, or the percentage of deliveries/shipments that arrive within a scheduled time. Similar to passenger transport, recent studies have adopted both the mean variance and scheduled based delay approaches for the estimation. However, the greatest challenge encountered when using variation of travel time in the SP design was to obtain understanding from the respondents of the magnitude of the trade-offs. One solution was to present the variation of travel time as well as the equivalent likely travel times at the same time.

\subsubsection{Value of Reliability from a Logistics Point of View}

The importance of reliability has been realized by all types of freight transport users. While shippers are more concerned with delivering shipments within an agreed scheduled time, carriers tried to minimize the vehicle, staff, and fuel costs. To date, none of the previous studies explored the estimates of reliability in freight transport from the customer's point of view. This is most critical when the customers are the inventory managers of firms that orders goods based on internal inventory policy. 


\subsubsection{Market Segmentation}

Previous studies mainly considered mode choice or route choice while estimating the VOT and VOR in freight transport. These estimated values were then further segmented into different shipment characteristics, commodity types, and firm's characteristics.

However, recent studies suggest the development of separate estimates for shippers and carriers as shippers care more about the shipment and associated losses due to delay in shipment, while carriers are more concerned with incurring transport service related cost such as vehicle, staff, and fuel cost.

\subsubsection{Model Specification}

The most commonly used factors in the model include cost, travel time, reliability, loss and/or damage, frequency, and flexibility.

\subsubsection{Model Structure}

Different forms of logit, such as binary, multinomial, or mixed, have been applied to estimate the VOR in freight studies. In terms of model assumption, SP design violates the Independent and Identically Distribution (IID) across individuals, alternatives, and choice situations as responses are collected multiple times from the same individual. Previous studies considered each response as independent and estimated the MNL in a traditional way.

However, recent studies took this into consideration and proposed different approaches to estimate the model. One solution to estimate the models after applying bootstrapping involved taking mean values of estimated coefficients for the random samples. 
A mixed logit model is another way to consider the random preferences of individuals and to overcome the aforementioned limitations. However, an estimation of this model requires knowledge of statistics and large sample sizes. The latter can be problematic as few freight studies have indicated poor estimates of ML models stemmed from insufficient data.

\subsubsection{Survey design}

Insufficient sample data has been a concern for conducting freight studies. Most studies reported the difficulty of getting an adequate sample size. Possible reasons may include the fear of giving commercially sensitive data to competitors, lack of culture of sharing information, a limited numbers of firms, and a lack of financial incentives for participation in the surveys.

The task of designing a survey questionnaire is a trade-off between statistical efficiency and quality of responses. A higher number of choice questions results in a more efficient survey, but this comes with the risk of low participation rates and/or respondents becoming bored and failing to make trade-offs. Studies tend to adopt an orthogonal design whenever the number of attributes becomes large. There exists a trend of employing personal experience or expert insight in order to further reduce choices. The literature suggests investing a great deal of time and effort into designing and testing SP surveys.

Several studies have applied the Adaptive Stated Preference (ASP) method to overcome the limitations of a small sample size. Although this method does not have any significant advantage over the traditional SP methods (Small. et. al., 1997), this method can be used to cross check the values. 


\subsubsection{Comparison of VOR Data}

Table 2-7 shows a summary of VOR estimates from various freight studies. These values are not directly comparable due to differences in the measure of reliability, shipment weight, and market segments. This highlights the necessity for a uniform approach towards the estimation of VOR.

Table 2-7 Summary of VOR Estimates from Selected Freight Studies

\begin{tabular}{|c|c|c|c|c|}
\hline Author(s) & Country & Mode & $\begin{array}{l}\text { Measure of Reliability } \\
\text { (unit) }\end{array}$ & $\begin{array}{l}\text { Value of } \\
\text { Reliability } \\
(2010 \text { \$US) }\end{array}$ \\
\hline Winston, 1981 & USA & Road & Standard deviation (day) & $\$ 404$ \\
\hline Wigan, 2000 & Australia & Road & Scheduled delay (hour per & $\$ 1.3$ to $\$ 1.6$ \\
\hline Small , 1999 & USA & Road & $\begin{array}{l}\text { Scheduled delay } \\
\text { (hour per shipment) }\end{array}$ & $\$ 497$ \\
\hline Kurii et al., 2000 & Finland & Road, Rail & $\begin{array}{l}\text { Scheduled delay } \\
\text { (hour per shipment) }\end{array}$ & $\$ 460$ \\
\hline Fowkes, 2004 & UK & Road & $\begin{array}{l}\text { Scheduled delay } \\
\text { (hour per shipment) }\end{array}$ & $\$ 52.85$ \\
\hline $\begin{array}{l}\text { Bolis and Maggi, } \\
2003\end{array}$ & Switzerland & Road & $\begin{array}{l}\% \text { the number of shipments } \\
\text { on scheduled time ( } 1 \% \text { unit) } \\
\text { (hour per ton) }\end{array}$ & $\$ 28$ to $\$ 51.0$ \\
\hline \multirow[t]{3}{*}{ Beuthe et al., 2007} & \multirow{3}{*}{$\begin{array}{l}\text { Italy, } \\
\text { Switzerlan } \\
\text { d }\end{array}$} & Road & \multirow{3}{*}{$\begin{array}{l}\% \text { the number of shipments } \\
\text { on scheduled time ( } 1 \% \text { unit) } \\
\text { (hour per ton) }\end{array}$} & $\$ 5.50$ \\
\hline & & Rail & & $\$ 0.60$ \\
\hline & & $\begin{array}{l}\text { Inland } \\
\text { navigatio }\end{array}$ & & $\$ 0.02$ \\
\hline Halse et al., 2010 & Norway & Road. Rail & $\begin{array}{l}\text { Both Scheduled delay and } \\
\text { standard deviation (hour per }\end{array}$ & $\$ 11.83$ to $\$ 387$ \\
\hline $\begin{array}{l}\text { Zamparini et al., } \\
2011\end{array}$ & Tanzania & Road & $\begin{array}{l}\% \text { of shipment within } \\
\text { scheduled window }(1 \%)\end{array}$ & $\$ 0.12$ \\
\hline \multirow{5}{*}{$\begin{array}{l}\text { Significance et al., } \\
2012\end{array}$} & \multirow[t]{5}{*}{ Netherlands } & Road & \multirow{5}{*}{$\begin{array}{l}\text { Standard deviation } \& \\
\text { Scheduled delay (hour per } \\
\text { shipment) }\end{array}$} & $\$ 18$ \\
\hline & & Rail & & $\$ 290$ \\
\hline & & Air & & $\$ 2144$ \\
\hline & & $\begin{array}{l}\text { Inland } \\
\text { waterway }\end{array}$ & & $\$ 402$ \\
\hline & & Sea & & $\$ 80$ \\
\hline
\end{tabular}




\section{CHAPTER 3}

\section{METHODOLOGY}

The main purpose of this research was to investigate the role of reliability in freight users' transportation decisions and to quantify their willingness to pay for the improvement of the travel time reliability.

This chapter presents an overview of the methodology implemented throughout this study. The methodology is comprised of two major tasks:

1. Development of a SP survey framework for valuation of travel time reliability in freight transportation

2. Development of Econometric models to estimate VOR values for freight users

In general, the design of a SP survey involves the following major tasks: defining the context and identifying alternatives, selecting attributes and their value levels, developing choice experiment, identifying market segment, and developing recruitment instruments (Hensher et al., 2005; Louviere et al., 2000). Considering the differences in how the users perceive cost and transportation reliability, this framework covers shippers and carriers in four transportation modes, along with various other market segments. For the model development, the study explored several econometric models, including multinomial and mixed logit model. The remaining subsections of this chapter discuss the methodology in more detail. 


\subsection{Development of a Stated Preference Survey Framework}

The main purpose of this sub-section was to propose a common framework for SP survey design for the valuation of VOR in freight transportation. This study proposed a SP survey framework making use of web and paper platforms for the valuation of freight user's travel time unreliability, which can be implemented into three phases: Recruitment, Pilot, and Main stated preference survey. "Qualtrics," a web based commercial software, was used to build and administer the online survey.

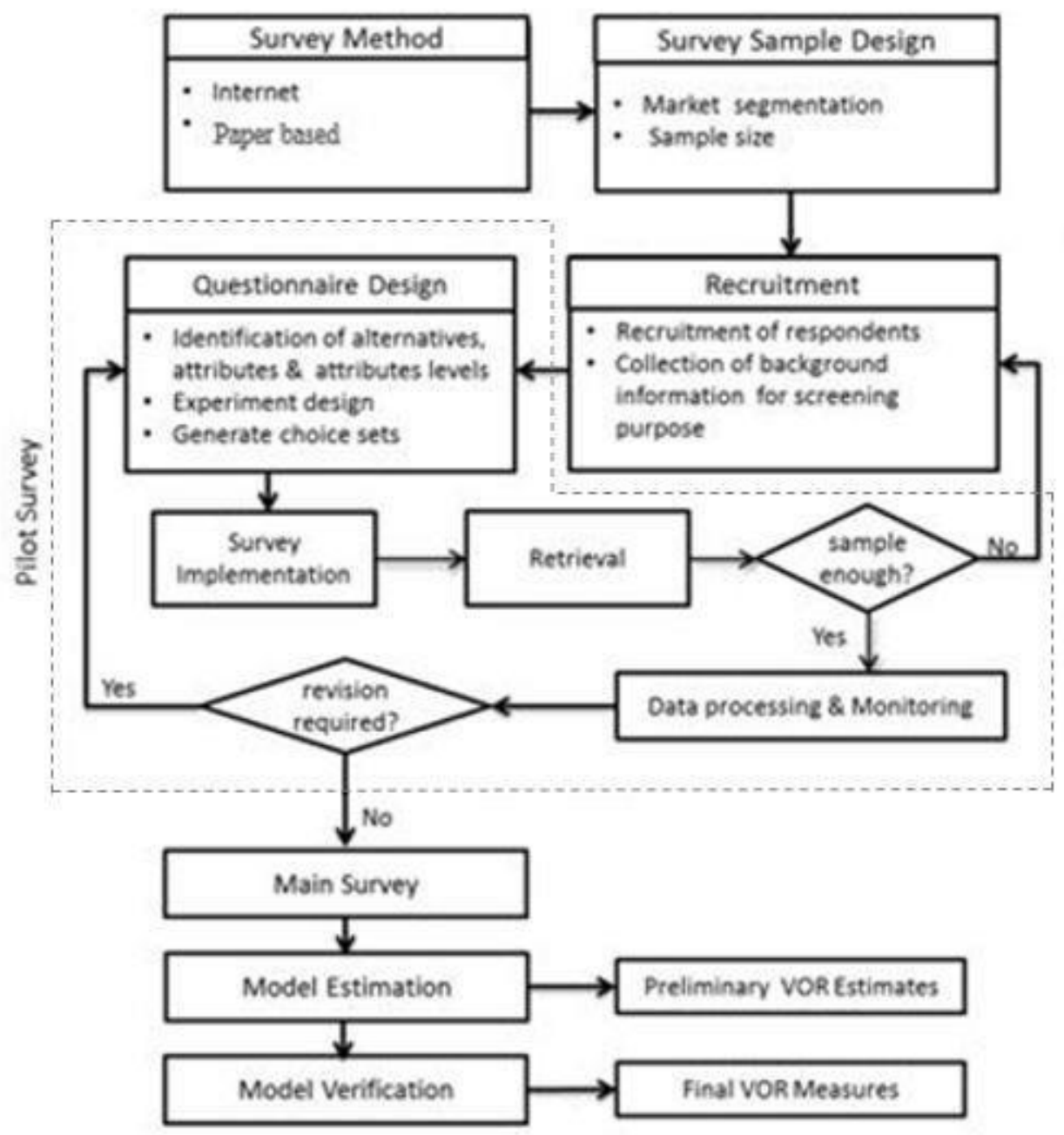

Figure 3-1 Proposed approach for the SP survey 
The Recruitment step mainly focused on recruiting participants and collecting background information from the firms, whereas Pilot SP survey involved the SP survey design and testing the adequacy of the design. Once the choice questions are finalized and enough respondents have been collected, it goes to the final step - main survey, as shown in Figure 3-1.

The next section starts with the description of the proposed market segmentation and sample design, followed by a detailed summary of stated preference choice experiment designs.

\subsubsection{Market Segmentation and Sample design}

\subsubsection{Market Segmentation}

Market segmentation is a marketing strategy that divides the users into subgroups who have common needs, priorities, and demand characteristics. It implies that individuals within a subgroup will behave approximately in the same way in responding to changes in the market, while preferences among the groups differ. Market segmentation enables the differential design and implementation of strategies targeting different users. In travel behavior analysis, market segmentation have been widely used as an effective means to identify relative homogenous users so that better descriptions of the travel behavior can be obtained. This is critical for demand analysis and policy decision-making as it accommodates user heterogeneity; and the estimated parameters can represent the true sensitivity of the market. In addition, market segmentation plays an important role in sample design. 
This study proposed separate experiments for shippers and carriers, given their distinct nature of business. Shippers are in a better position to assess the value of time and reliability related to the value of the goods, whereas carriers are in a better position to relate the value of time and reliability to the cost of the transport services.

In the literature various other factors have been considered having influence on the willingness to pay to save travel time and improve travel time reliability, such as commodity type (perishable or not), whether there is delivery window pressure, shipping distance, commodity weight (in terms of pounds or tons), whether it is containerized (possibility of intermodal transfer), and the departure time of the shipment. These factors could serve as potential market segments to analyze VOT and VOR. A complete summary of market segmentation strategies in the literature had been provided in the previous report.

Although more market segments could lead to better understanding of the market, it also required a larger sample size to support the analysis. Considering the balance between market segments and the sampling cost, this study recommended the following factors for segmentation, also illustrated in Table 3-1:

- User Type : Shippers (with or without transport ) and Carriers

- Commodity Types for shippers: Perishable Commodity

- Shipping Distance for carriers: <50 miles, 50-300 miles, and 300+ miles.

- Shipment Type: Containerized or Non-Containerized (representative of intermodal transport)

- Mode: Truck (light, medium, and heavy), rail, sea and air 
Table 3-1 Proposed Market Segmentation

\begin{tabular}{|c|c|c|c|c|c|c|c|c|c|c|c|c|c|c|c|}
\hline \multicolumn{8}{|c|}{ Shippers } & \multicolumn{8}{|c|}{ Carriers } \\
\hline & \multirow{2}{*}{$\begin{array}{l}\text { Delivery } \\
\text { Window } \\
\text { Pressure }\end{array}$} & \multicolumn{3}{|c|}{ Truck } & \multirow{2}{*}{ Rail } & \multirow{2}{*}{$\begin{array}{l}\text { Water } \\
\text { ways }\end{array}$} & \multirow{2}{*}{ Air } & & \multirow{2}{*}{$\begin{array}{l}\text { Shipping } \\
\text { Distance }\end{array}$} & \multicolumn{3}{|c|}{ Truck } & \multirow{2}{*}{ Rail } & \multirow{2}{*}{$\begin{array}{l}\text { Water } \\
\text { ways }\end{array}$} & \multirow{2}{*}{ Air } \\
\hline & & Light & Medium & Heavy & & & & & & Light & Medium & Heavy & & & \\
\hline \multirow{3}{*}{ 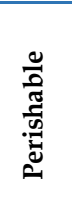 } & \multirow{2}{*}{ No } & \multirow{2}{*}{$x$} & \multirow{2}{*}{$x$} & \multirow{2}{*}{$x$} & \multirow{2}{*}{$X$} & \multirow{2}{*}{$x$} & \multirow{2}{*}{$X$} & \multirow{3}{*}{ 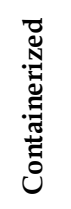 } & $<50$ Miles & $x$ & $x$ & $x$ & - & - & - \\
\hline & & & & & & & & & $\begin{array}{l}50-300 \\
\text { Miles }\end{array}$ & $X$ & $X$ & $X$ & -- & & -- \\
\hline & Yes & $x$ & $x$ & $x$ & $x$ & $x$ & $x$ & & $300+$ Miles & $X$ & $X$ & $X$ & - & - & - \\
\hline \multirow{3}{*}{ 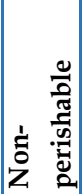 } & \multirow{2}{*}{ No } & \multirow[t]{2}{*}{$X$} & \multirow[t]{2}{*}{$X$} & \multirow[t]{2}{*}{$X$} & \multirow[t]{2}{*}{$x$} & \multirow[t]{2}{*}{$X$} & \multirow[t]{2}{*}{$x$} & \multirow{3}{*}{ 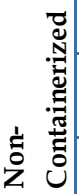 } & $<50$ Miles & $X$ & $x$ & $x$ & - & - & - \\
\hline & & & & & & & & & $\begin{array}{l}50-300 \\
\text { Miles }\end{array}$ & $X$ & $X$ & $X$ & & & \\
\hline & Yes & $X$ & $X$ & $X$ & $x$ & $X$ & $X$ & & 300+ Miles & $X$ & $x$ & $x$ & $x$ & $X$ & $x$ \\
\hline
\end{tabular}

The classifications for truck types were obtained from the Florida Intermodal

Statewide Highway Model (FISHFM), as shown in Table 3-2 below.

Table 3-2 Truck Type Definition from the FISHFM

\begin{tabular}{|c|c|}
\hline Classification & Description \\
\hline Light & Pick-ups and Vans \\
\hline Medium & Two-Axle, Six-Tire Single-Unit Trucks \\
\hline Heavy & Three or more single unit/trailer/multi-trailer trucks \\
\hline
\end{tabular}

\subsubsection{Sample Design}

In order to incorporate market segmentation into the VOT and VOR analysis for freight users, this study proposed a stratification-based random sampling strategy. In other words, survey participants randomly selected from the sample frame, while close monitoring was enforced to make sure there were enough observations for each cell in the segmentation table. The rule of thumb for minimal sample size was 10 observations for each stratum to support the behavior modeling purpose. 
The overall sample size needed to estimate the proportion of the population in preference to one choice (such as the willingness to pay tolls) is based on the acceptable confidence level, the margin of error, and the variance of the proportion, as shown in the formula below (Eq 23):

$$
\mathrm{N}=\frac{Z^{2} \times P \times(1-P)}{M E^{2}}
$$

where

$\mathrm{N}=$ the sample size needed; $\mathrm{z}=$ the $\mathrm{z}$ value corresponding to a certain confidence level, e.g.

1.96 for a $95 \%$ confidence level, 2.58 for a $99 \%$ confidence level; $\mathrm{p}=$ the proportion of the population picking a choice, use 0.5 for sample size purpose, which yields the largest sample size; $\mathrm{ME}=$ margin of error, e.g. 0.04 means $\pm 4 \%$ of the estimated value

Based on the above formula, with a $95 \%$ confidence level, and a margin of error at $\pm 5 \%, \mathrm{~N}$ equals to 384.17 . Considering earlier discussions on stratified sampling, 10 observations for each stratum times 45 strata identified in Table 3-1, the total sample needed was 450 for the purpose of segmentation. Combining the two purposes, the proposed target for total sample size was 450 for this study.

\subsubsection{Recruitment Instrument Design}

This is the initial step of the stated preference study, which collects background information from the firms. The subjects of the questions typically fall into the following two categories:

- Information describing the firm, such as commodity types, number of employees, whether uses own transportation, measures of late delivery, etc. 
- Characteristics of a typical shipment, such as shipping distance, transportation cost, monetary value of shipment, shipment size or weight, shipping duration, transport mode, use carrier or own fleet, legal terms on delivery time agreement, frequency and magnitude of late shipments.

This information is used to customize the attribute values in the choice sets for each respondent, so that the scenarios presented to the survey participants can be realistic and meaningful for them to assess the trade-offs among the alternatives.

Appendix presents the instrument for recruitment. The sequence of data collection is as follows: 1) collect background information concerning the firm's characteristics and services; 2) ask the respondents to provide detailed information on one or more typical shipments; and 3) focus on attitudes and preferences towards delay, mode shifting, and departure time shifting, which is used to assign the respondents to different choice experiments as described in the next section.

\subsubsection{Stated Preference Choice Experiment}

Choice experiment design refers to the construction of hypothetical scenarios to be presented to the respondents. Each scenario is comprised of the alternatives, as well as the attribute values describing the alternatives, such as shipping time, cost, and reliability. Each respondent faces multiple scenarios where attribute values varied for one or more of the attributes corresponding to one or more of the alternatives. Therefore, the choice sets in the scenarios needed to be carefully designed, in order to accommodate a variety of combinations of attribute values to reflect the subtle trade-offs among the alternatives. 
This study focused on four types of trade-offs, therefore four distinct choice experiments

- $\mathrm{C} 1$ - focused on the trade-off between travel time, cost, and reliability.

- $\mathrm{C} 2$ - focused on the willingness to shift to off-peak hours to save transport cost (may consist of time, monetary cost, and reliability) only for shipments currently happening during peak hours and when the respondents indicated the possibility of shifting departure time.

- C3 - focused on the willingness to shift mode, only for shipments currently carried via trucks or rail.

- $\quad$ C4 - involved shifting both mode and departure time.

The process of assigning respondents to one of the four experiments is illustrated in Figure 3-2 below. Air and Waterway shipments are always assigned to C1 experiment, as it is considered unrealistic to shift mode and departure time. As for shipping carried by road and rail, the respondents were assigned to: $\mathrm{C} 1$, if there was no possibility to shift neither mode nor departure time; $\mathrm{C} 2$ or $\mathrm{C} 3$, if it was possible to shift either departure time or mode; and $\mathrm{C} 4$, if it was possible to shift both mode and departure time for the shipment. 


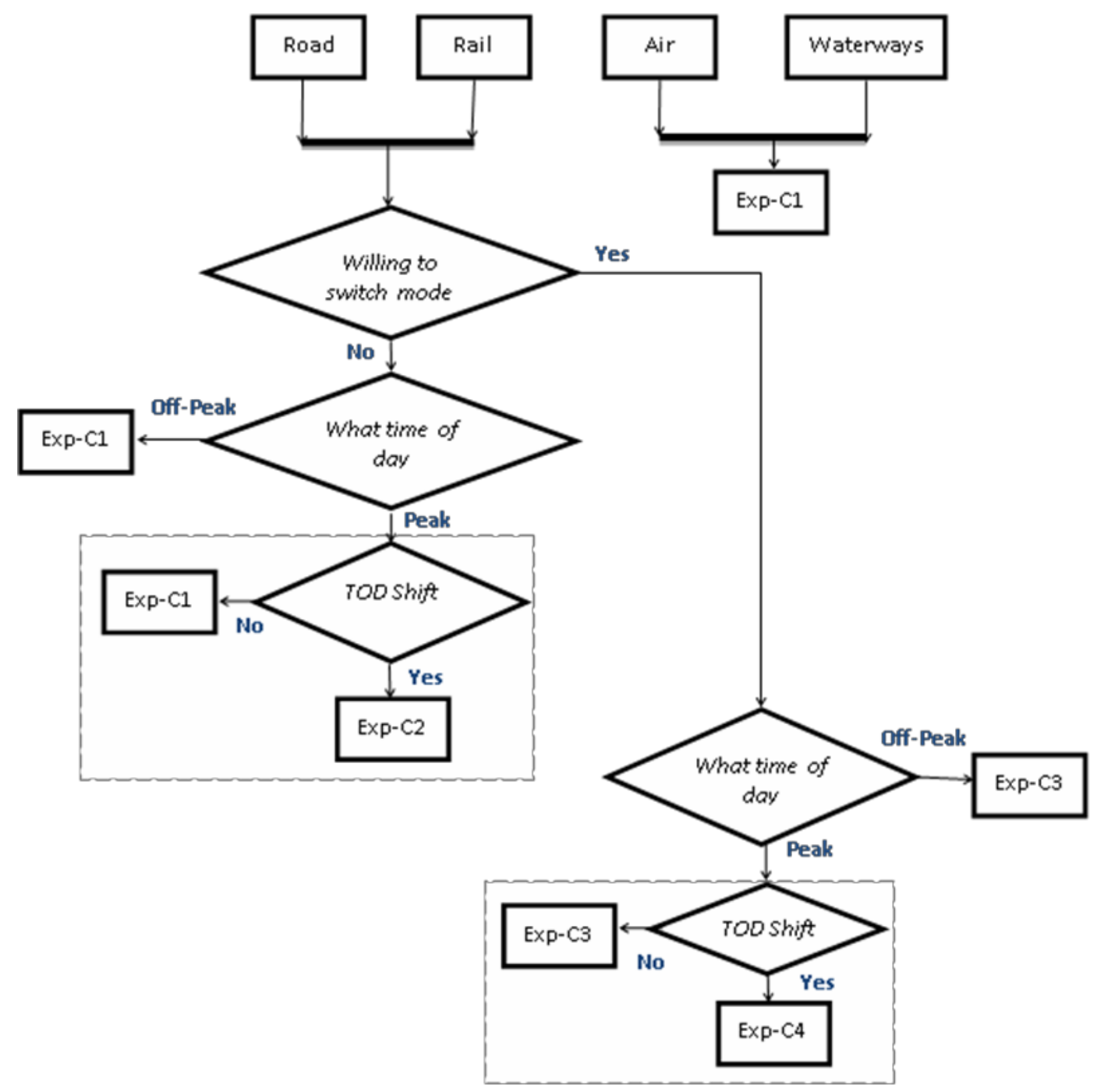

Figure 3-2 Classification of experiment design

As a result, the attributes involved in the four experiments differed. While $\mathrm{C} 1$ primarily concerned travel time, cost and reliability, experiment $\mathrm{C} 2$ considered an additional attribute - departure time; whereas experiment $\mathrm{C} 3$ and $\mathrm{C} 4$ considered other mode-related attributes (such as, property damage, and service flexibility, etc.), without and with the consideration of departure time shift, respectively. 


\subsubsection{Determining Attributes and Attribute Levels}

This section describes the six attributes and corresponding attribute levels employed in the survey, including travel time, travel cost, reliability, departure time, service flexibility and probability of property damage.

- Travel Time: This includes the time spent for door-to-door shipping, including transfer time and the average delay the respondent normally encounters.

- Travel Cost: This study adopted two different definitions of travel cost for shippers with own transport and carriers, and shippers who hire others for transport. For carriers and own account shippers, this refers to door-todoor transportation costs, including fuel, staff, depreciation and maintenance of equipment used, administration, insurance, social security payments and taxes charged, possible transshipment costs, but excluded the initial loading and final unloading. For shippers that contract out transport services, it was the price paid for the door-to-door transport services, including transshipments.

- Reliability: This study adopted the standard deviation of travel time as a reliability measure since the estimated values could be easily integrated into travel demand model for benefit-cost analysis.

- Departure Time: This was the time when shipment departs. This attribute was used to reflect the schedule constraints faced by the respondents. This study limited the shifts between peak hours and off-peak hours. 
- Service Flexibility: This attribute signified the ability to start shipping without any prior notice. It is often important to shippers and carriers when choosing the freight mode.

- Probability of Shipment Property Damage: This attribute denoted the probability of property damage during the shipment. It is a qualitative attribute, which often reflects the freight users' attitude towards modes.

Table 3-4 shows the summary of the attribute levels and the modifier (additive and deductive) employed by this study. After constructing the "base table" using typical shipment information collected from the recruitment survey, these modifiers were used to get the values from different attribute levels.

Considering that the base values from the respondents may have a wide range, the same level of variations around the base value may not be realistic for every respondent. Therefore, this survey employed two sets of variations for travel time and travel cost based on the shipping distance and duration. Set 1 was designed for shipments that were within 300 miles, which typically take less than 10 hours; whereas Set 2 includes shipments that were beyond 300 miles in shipping distance that usually takes more than a day.

Table 3-3 Attribute Level and the Values Considered in the Experiments

\begin{tabular}{|c|c|c|c|}
\hline Attribute & Set & Values & Unit \\
\hline Transit Time & Set $1-0-10$ & $-5,-2.5$, Current, $+2.5,+5$ & hours \\
\cline { 2 - 4 } & Set $2-$ multiple & $-1-,-1 / 2$, Current, $+1 / 2,+1$ & days \\
\hline Travel Cost & Set $1-0-300$ & $-200,-100$, Current, $+100,+200$ & US dollar \\
& Set $2-300+$ & $-600,-250$, Current, $+300,+600$ & h) \\
\hline Departure time & Set-1 \& Set-2 & Peak, Off-Peak \\
\hline $\begin{array}{c}\text { Service flexibility } \\
\text { Probability of Shipment } \\
\text { property damage }\end{array}$ & Set-1 \& Set-2 & Low, Medium, High & - \\
\hline \multirow{2}{\text{“_“=Notapplicable}}{} & Set-1 \& Set-2 & Low, Medium, High & - \\
\hline
\end{tabular}


Regarding reliability attribute, five levels of pre-determined values were employed for each set, as shown in Table 3.4 and Table 3.-5. This format is a modified version of Small (1999) where only on-time and late delays were considered. It is important to mention that these attribute values were carefully chosen from the pilot study and also in consultation with freight professionals based on experience.

Table 3-4 Attribute Values of Transit time reliability considered for Set 1

\begin{tabular}{|c|c|c|c|c|}
\hline Very High & High & Medium & Low & Very Low \\
\hline $\begin{array}{c}\text { 4 out of 5 times } \\
\text { on-time }\end{array}$ & $\begin{array}{c}\text { 3 out of 5 times } \\
\text { on-time }\end{array}$ & $\begin{array}{c}\text { 2 out of 5 times } \\
\text { on-time }\end{array}$ & $\begin{array}{c}\text { 2 out of 5 times } \\
\text { on-time }\end{array}$ & $\begin{array}{c}\text { 1 out of } 5 \text { times } \\
\text { on-time }\end{array}$ \\
\hline $\begin{array}{c}\text { 1 out of 5 times } 2 \\
\text { hours late }\end{array}$ & $\begin{array}{c}\text { 2 out of 5 times 2- } \\
\text { 4 hours late }\end{array}$ & $\begin{array}{c}\text { 3 out of 5 times 2- } \\
\text { 4 hours late }\end{array}$ & $\begin{array}{c}\text { 3 out of 5 times 4- } \\
\text { 8 hours late }\end{array}$ & $\begin{array}{c}\text { 4 out of } 5 \text { times 6- } \\
8 \text { hours late }\end{array}$ \\
\hline
\end{tabular}

Table 3-5 Attribute Values of Transit time reliability considered for Set 2

\begin{tabular}{|c|c|c|c|c|}
\hline $\begin{array}{c}\text { Very High } \\
\text { 4 out of } 5 \text { times } \\
\text { on-time }\end{array}$ & $\begin{array}{c}\text { Hout of } 5 \text { times } \\
\text { on-time }\end{array}$ & $\begin{array}{c}\text { Medium } \\
\text { out of } 5 \text { times } \\
\text { on-time }\end{array}$ & $\begin{array}{c}\text { 2 out of } 5 \text { times } \\
\text { on-time }\end{array}$ & $\begin{array}{c}\text { 1 out of } 5 \text { times } \\
\text { on-time }\end{array}$ \\
\hline $\begin{array}{c}\text { 1 out of } 5 \text { times } \\
1 / 2 \text { day late }\end{array}$ & $\begin{array}{c}\text { 1 out of } 5 \text { times } \\
\text { 1 day late }\end{array}$ & $\begin{array}{c}\text { 3 out of } 5 \text { times } \\
1-2 \text { days late }\end{array}$ & $\begin{array}{c}\text { 3 out of } 5 \text { times } \\
\text { 2 days late }\end{array}$ & $\begin{array}{c}\text { 4 out of } 5 \text { times 2- } \\
4 \text { days late }\end{array}$ \\
\hline
\end{tabular}

\subsubsection{Experiment Design for C1}

This experiment focused mainly on within-mode choices with alternatives characterized by three attributes: travel time, travel cost and reliability. Sequential orthogonal design was adopted for this experiment. Such an orthogonal design for five levels of three attributes consisted of 25 treatment combinations as shown in Table 3-6. Orthogonal design yielded no correlation among the attributes, while avoiding the large number of combinations that resulted from full factorial design (where each level of each attribute was combined with every other level of every other attribute). 
Table 3-6 Orthogonal Factorial Design for Experiment C1

\begin{tabular}{|c|c|c|c|}
\hline $\begin{array}{c}\text { Treatment } \\
\text { Combination }\end{array}$ & $\begin{array}{c}\text { Travel } \\
\text { Time }\end{array}$ & $\begin{array}{c}\text { Travel } \\
\text { Cost }\end{array}$ & $\begin{array}{c}\text { Reliabilit } \\
\text { y }\end{array}$ \\
\hline 1 & Very Low & Base \\
\hline 2 & Very Low & Low & Low \\
\hline 3 & Low & Base & Very Low \\
\hline 4 & Base & Very Low & Low \\
\hline 5 & High & Base & Very Low \\
\hline 6 & Base & Base & High \\
\hline 7 & Base & High & Base \\
\hline 8 & High & High & Very Low \\
\hline 9 & Very High & High & Low \\
\hline 10 & Low & High & Very \\
\hline 11 & Base & Very Low & High \\
\hline 12 & High & Low & Very \\
\hline 13 & Very & Base & Base \\
\hline 14 & Very & Very & Low \\
\hline 15 & Low & High & High \\
\hline 16 & Very & Very & Very \\
\hline 17 & Very Low & Very Low & Very Low \\
\hline 18 & Very Low & Very & High \\
\hline 19 & Very Low & Very Low & Base \\
\hline 20 & High & Low & Very \\
\hline 21 & Very & Low & Base \\
\hline 22 & Low & Low & Very Low \\
\hline 23 & Base & Very Low & High \\
\hline 24 & High & & \\
\hline 25 & Low & & \\
\hline & & & \\
\hline & & &
\end{tabular}

Each treatment represented one combination of attribute values describing one alternative, while each scenario needed to present multiple alternatives for the respondents to evaluate the trade-offs among the attribute values. Therefore, subsequent alternatives were not generated, which is shown in Table 3-7.

The same design (Table 3-6) was used to construct subsequent alternatives by systematically changing the attribute levels (Street et. al., 2005). This method was more efficient and better than those that came from random sampling, or simultaneous alternatives construction; as the former ran the risk of being either a zero difference or unbalanced (unequal number of the attribute levels). The latter required significantly larger number of choice-sets (Street et. al., 2005). 
Table 3-7 Choice Sets Using the Sequential Orthogonal Design for Experiment C1

\begin{tabular}{|c|c|c|c|c|c|c|c|c|c|}
\hline \multirow[b]{2}{*}{ Bloc } & \multicolumn{3}{|c|}{ Alternative } & \multicolumn{3}{|c|}{ Alterative 2} & \multicolumn{3}{|c|}{ Alternative 3} \\
\hline & TT & $\mathrm{TC}$ & Rel. & TT & $\mathrm{TC}$ & Rel. & TT & $\mathrm{TC}$ & Rel. \\
\hline 1 & Base & VH & VL & VH & VL & $\mathrm{L}$ & $\mathrm{H}$ & $\mathrm{L}$ & Base \\
\hline 1 & VL & VH & VL & Base & $\mathrm{H}$ & $\mathrm{L}$ & $\mathrm{H}$ & Base & Base \\
\hline 1 & VL & $\mathrm{H}$ & Bas & $\mathrm{L}$ & VH & VH & Base & Base & $\mathrm{H}$ \\
\hline 1 & VL & $\mathrm{H}$ & Bas & $\mathrm{L}$ & Base & $\mathrm{H}$ & Base & $\mathrm{L}$ & $\mathrm{L}$ \\
\hline 1 & Base & Base & $\mathrm{H}$ & $\mathrm{H}$ & $\mathrm{L}$ & Base & VH & VL & $\mathrm{L}$ \\
\hline 1 & $\mathrm{H}$ & Base & $\mathrm{L}$ & VH & $\mathrm{H}$ & Base & VL & $\mathrm{VH}$ & $\mathrm{H}$ \\
\hline 1 & Base & VH & $\mathrm{H}$ & $\mathrm{H}$ & $\mathrm{H}$ & VH & VH & Base & VL \\
\hline 1 & $\mathrm{H}$ & $\mathrm{H}$ & $\mathrm{H}$ & VH & VL & Base & VL & VH & VH \\
\hline 2 & VH & $\mathrm{VL}$ & VL & VL & VH & $\mathrm{L}$ & $\mathrm{L}$ & $\mathrm{H}$ & Base \\
\hline 2 & $\mathrm{~L}$ & VH & $\mathrm{L}$ & Base & $\mathrm{H}$ & Base & $\mathrm{H}$ & VL & $\mathrm{H}$ \\
\hline 2 & Base & $\mathrm{H}$ & VL & $\mathrm{H}$ & VH & VH & VH & VL & $\mathrm{L}$ \\
\hline 2 & $\mathrm{H}$ & VL & VL & VH & $\mathrm{L}$ & VH & VL & Base & $\mathrm{L}$ \\
\hline 2 & VH & $\mathrm{L}$ & $\mathrm{H}$ & VL & Base & VL & $\mathrm{L}$ & VH & VH \\
\hline 2 & VH & Base & $\mathrm{L}$ & VL & $\mathrm{H}$ & VL & $\mathrm{L}$ & VH & VH \\
\hline 2 & $\mathrm{~L}$ & VH & VH & Base & $\mathrm{L}$ & $\mathrm{H}$ & $\mathrm{H}$ & VL & Base \\
\hline 2 & VH & VL & Bas & VL & VH & $\mathrm{L}$ & L & $\mathrm{L}$ & $\mathrm{H}$ \\
\hline 3 & VL & $\mathrm{H}$ & VL & $\mathrm{L}$ & VH & VH & Base & VL & $\mathrm{H}$ \\
\hline 3 & VL & $\mathrm{VH}$ & $\mathrm{VH}$ & $\mathrm{L}$ & VL & VL & Base & $\mathrm{L}$ & $\mathrm{L}$ \\
\hline 3 & VL & Base & Bas & L & $\mathrm{L}$ & $\mathrm{L}$ & Base & VL & VL \\
\hline 3 & $\mathrm{H}$ & $\mathrm{L}$ & $\mathrm{VH}$ & VH & VL & $\mathrm{H}$ & VL & VH & VL \\
\hline 3 & VH & VL & VH & VL & Base & VH & $\mathrm{L}$ & $\mathrm{L}$ & Base \\
\hline 3 & $\mathrm{~L}$ & $\mathrm{H}$ & VH & Base & Base & VL & $\mathrm{H}$ & $\mathrm{L}$ & $\mathrm{L}$ \\
\hline 3 & Base & $\mathrm{H}$ & Bas & $\mathrm{H}$ & Base & $\mathrm{H}$ & VH & $\mathrm{L}$ & VH \\
\hline 3 & $\mathrm{H}$ & $\mathrm{L}$ & VL & VH & Base & Base & VL & $\mathrm{H}$ & $\mathrm{L}$ \\
\hline 3 & $\mathrm{~L}$ & $\mathrm{~L}$ & $\mathrm{H}$ & Base & Base & VH & $\mathrm{H}$ & VL & VL \\
\hline
\end{tabular}

This design was sometimes prone to generate unrealistic and dominant alternatives, which could be overcome by rotating the attribute levels within choice sets until there was no dominant alternative (Humber et al., 1996; Hensher, 2001). For example, if the travel time of alternative A was shorter than the travel time of other alternatives (B or C), then at least one of the attributes, such as travel cost and reliability would be worse than the other alternatives. 


\subsubsection{Experiment Design for C2}

$\mathrm{C} 2$ is the extension of the previous experiment $\mathrm{C} 1$ with an additional attribute: departure time. The alternatives of this experiment were characterized by five levels of three attributes (travel time, travel cost and reliability) and two levels of one attribute (departure time). Nearly orthogonal design was employed instead of fully orthogonal design. The justification of doing this was to lessen the burden of over sampling at the cost of very little statistical efficiency. The combinations are shown in Table 3-8.

Table 3-8 Orthogonal Factorial Design for Experiment C2

\begin{tabular}{|c|c|c|c|c|}
\hline $\begin{array}{c}\text { Treatment } \\
\text { Combination }\end{array}$ & Travel Time & Travel Cost & Reliability & Departure time \\
\hline 1 & Low & Low & High & Off-peak \\
\hline 2 & Very High & Very Low & Low & Off-peak \\
\hline 3 & High & Very Low & Base & Peak \\
\hline 4 & Very Low & Low & Very High & Peak \\
\hline 5 & Base & Very Low & High & Off-peak \\
\hline 6 & Low & Base & Base & Off-peak \\
\hline 7 & High & Low & Low & Peak \\
\hline 8 & Very High & Low & Very Low & Off-peak \\
\hline 9 & Very High & High & High & Peak \\
\hline 10 & High & High & Very High & Off-peak \\
\hline 11 & Base & High & Very Low & Peak \\
\hline 12 & Low & High & Low & Peak \\
\hline 13 & Low & Very Low & Very High & Peak \\
\hline 14 & High & Base & Very Low & Off-peak \\
\hline 15 & Very Low & Base & High & Peak \\
\hline 16 & Very Low & Very Low & Very Low & Peak \\
\hline 17 & Base & Low & Base & Peak \\
\hline 18 & Very High & Very High & Base & Peak \\
\hline 19 & Very Low & High & Base & Off-peak \\
\hline 20 & Base & Very High & Very High & Off-peak \\
\hline 21 & Low & Very High & Very Low & Peak \\
\hline 22 & High & Very High & High & Peak \\
\hline 23 & Very High & Base & Very High & Peak \\
\hline 24 & Very Low & Very High & Low & Off-peak \\
\hline 25 & Base & Base & Low & Peak \\
\hline
\end{tabular}

The choice sets of three alternatives were constructed following similar approach taken in C1, as shown in Table 3-9. Additionally, to make the scenarios more realistic, travel time during peak hours was always greater than the travel time during off-peak. 
Table 3-9 Choice Sets Using the Sequential Orthogonal Design for Experiment C2

\begin{tabular}{|c|c|c|c|c|c|c|c|c|c|c|c|c|}
\hline \multirow[b]{2}{*}{ Block } & \multicolumn{4}{|c|}{ Alternative 1} & \multicolumn{4}{|c|}{ Alternative 2} & \multicolumn{4}{|c|}{ Alternative 3} \\
\hline & TT & $\mathrm{TC}$ & Rel. & Dept time & TT & $\mathbf{T C}$ & Rel. & $\begin{array}{l}\text { Dep } \\
\mathbf{t}\end{array}$ & TT & $\mathbf{T C}$ & Rel. & $\begin{array}{l}\text { Dept } \\
\text { time }\end{array}$ \\
\hline 1 & $\mathrm{~L}$ & Base & $\mathrm{H}$ & Off-P & $\mathrm{H}$ & $\mathrm{L}$ & VL & $\mathrm{P}$ & Base & $\mathrm{H}$ & VH & Off-P \\
\hline 1 & VL & $\mathrm{L}$ & $\mathrm{L}$ & Off-P & $\mathrm{VH}$ & VL & Base & $\mathrm{P}$ & $\mathrm{L}$ & Base & $\mathrm{H}$ & Off-P \\
\hline 1 & $\mathrm{H}$ & Base & Base & $\mathrm{P}$ & VL & VL & $\mathrm{H}$ & Off-P & $\mathrm{VH}$ & $\mathrm{VL}$ & $\mathrm{VH}$ & $\mathrm{P}$ \\
\hline 1 & VL & Base & VL & $\mathrm{P}$ & VL & $\mathrm{H}$ & $\mathrm{H}$ & Off-P & Base & $\mathrm{L}$ & $\mathrm{L}$ & $\mathrm{P}$ \\
\hline 1 & Base & $\mathrm{L}$ & $\mathrm{H}$ & Off-P & $\mathrm{VH}$ & VL & VL & $\mathrm{P}$ & $\mathrm{H}$ & Base & $\mathrm{VH}$ & Off-P \\
\hline 1 & $\mathrm{~L}$ & $\mathrm{H}$ & Base & Off-P & $\mathrm{H}$ & Base & $\mathrm{H}$ & $\mathrm{P}$ & Base & VH & $\mathrm{VH}$ & Off-P \\
\hline 1 & $\mathrm{H}$ & Base & Base & $\mathrm{P}$ & VL & $\mathrm{H}$ & $\mathrm{L}$ & Off-P & $\mathrm{VH}$ & $\mathrm{L}$ & $\mathrm{L}$ & $\mathrm{P}$ \\
\hline 1 & VL & Base & VL & Off-P & $\mathrm{VH}$ & $\mathrm{L}$ & $\mathrm{L}$ & $\mathrm{P}$ & $\mathrm{L}$ & $\mathrm{H}$ & Base & Off-P \\
\hline 2 & VH & VL & VH & $\mathrm{P}$ & VL & $\mathrm{VH}$ & VL & Off-P & $\mathrm{L}$ & VH & VH & $\mathrm{P}$ \\
\hline 2 & $\mathrm{H}$ & $\mathrm{H}$ & VL & Off-P & $\mathrm{VH}$ & VL & $\mathrm{VH}$ & $\mathrm{P}$ & VL & VH & $\mathrm{L}$ & Off-P \\
\hline 2 & $\mathrm{H}$ & $\mathrm{H}$ & VL & $\mathrm{P}$ & Base & $\mathrm{VH}$ & Base & Off-P & $\mathrm{VH}$ & VL & $\mathrm{L}$ & $\mathrm{P}$ \\
\hline 2 & Base & $\mathrm{H}$ & $\mathrm{L}$ & $\mathrm{P}$ & $\mathrm{L}$ & $\mathrm{VH}$ & $\mathrm{H}$ & Off-P & $\mathrm{H}$ & VL & Base & $\mathrm{P}$ \\
\hline 2 & Base & Base & $\mathrm{VH}$ & $\mathrm{P}$ & $\mathrm{L}$ & $\mathrm{L}$ & $\mathrm{L}$ & Off-P & $\mathrm{H}$ & VL & VL & $\mathrm{P}$ \\
\hline 2 & $\mathrm{H}$ & $\mathrm{H}$ & $\mathrm{L}$ & Off-P & $\mathrm{VH}$ & Base & VL & $\mathrm{P}$ & VL & VH & Base & Off-P \\
\hline 2 & $\mathrm{~L}$ & $\mathrm{H}$ & $\mathrm{H}$ & $\mathrm{P}$ & VL & $\mathrm{VH}$ & $\mathrm{VH}$ & Off-P & Base & Base & VL & $\mathrm{P}$ \\
\hline 2 & $\mathrm{~L}$ & VL & VL & $\mathrm{P}$ & VL & Base & Base & Off-P & Base & $\mathrm{L}$ & $\mathrm{L}$ & $\mathrm{P}$ \\
\hline 3 & $\mathrm{H}$ & $\mathrm{L}$ & Base & $\mathrm{P}$ & Base & $\mathrm{H}$ & $\mathrm{H}$ & Off-P & $\mathrm{VH}$ & Base & $\mathrm{VH}$ & $\mathrm{P}$ \\
\hline 3 & VH & VL & Base & $\mathrm{P}$ & VL & $\mathrm{VH}$ & VH & Off-P & $\mathrm{L}$ & $\mathrm{L}$ & $\mathrm{H}$ & $\mathrm{P}$ \\
\hline 3 & VL & $\mathrm{H}$ & $\mathrm{H}$ & Off-P & Base & VL & Base & $\mathrm{P}$ & $\mathrm{L}$ & VH & $\mathrm{VH}$ & Off-P \\
\hline 3 & Base & $\mathrm{VH}$ & VH & Off-P & $\mathrm{VH}$ & VL & VL & $\mathrm{P}$ & $\mathrm{H}$ & $\mathrm{L}$ & $\mathrm{L}$ & Off-P \\
\hline 3 & Base & VL & VL & $\mathrm{P}$ & $\mathrm{L}$ & VH & $\mathrm{L}$ & Off-P & $\mathrm{VH}$ & $\mathrm{L}$ & Base & $\mathrm{P}$ \\
\hline 3 & $\mathrm{H}$ & VH & $\mathrm{H}$ & $\mathrm{P}$ & VL & $\mathrm{L}$ & $\mathrm{VH}$ & Off-P & $\mathrm{VH}$ & VL & VL & $\mathrm{P}$ \\
\hline 3 & $\mathrm{VH}$ & Base & $\mathrm{VH}$ & $\mathrm{P}$ & VL & VH & VL & Off-P & $\mathrm{L}$ & $\mathrm{H}$ & $\mathrm{L}$ & $\mathrm{P}$ \\
\hline 3 & VL & $\mathrm{VH}$ & $\mathrm{L}$ & Off-P & Base & VL & $\mathrm{H}$ & $\mathrm{P}$ & $\mathrm{L}$ & $\mathrm{L}$ & Base & Off-P \\
\hline 3 & $\mathrm{H}$ & $\mathrm{H}$ & $\mathrm{L}$ & $\mathrm{P}$ & Base & VH & $\mathrm{H}$ & Off-P & $\mathrm{VH}$ & Base & Base & $\mathrm{P}$ \\
\hline
\end{tabular}

\subsubsection{Experiment Design for C3}

This experiment was designed primarily for shippers and carriers who were willing to change modes, but not shift their current departure times. Hence, the alternatives of this experiment were mainly road and rail modes, characterized by three attributes: travel time, travel cost and reliability. Unlike $\mathrm{C} 1$ and $\mathrm{C} 2$, this experiment was developed based on the Bradley Design rather than the orthogonal design. It was because an orthogonal 
design generates too many unrealistic and dominant alternatives, whereas the Bradley Design does not allow any dominant alternatives by default. According to the Bradley Design, the base level for each attribute will always be present in the choice pair, in either alternative. The third level (out of five) of the travel cost, travel time and reliability was considered as the base level.

Table 3-11 shows the constructed choice pairs, wherein travel time always increases on the rail alternative. Additional choice pairs can be easily generated by mirroring the left and right alternatives and by replacing all increases with decreases and vice versa.

In summary, the basic characteristics of this design were:

- Each choice pair had the base level of all the attributes in either of the alternatives.

- For all attributes, there were two levels with higher value than the base level, and there were two levels with lower value than the base level.

- These base values and increased or decreased values were combined in the choice pairs in such a way that none of the pairs had a dominant alternative. 
Table 3-10 Choice Sets Using the Bradley Design for Experiment C3

\begin{tabular}{|c|c|c|c|c|c|c|c|c|c|c|c|c|c|c|c|}
\hline \multicolumn{2}{|c|}{ Road } & \multicolumn{2}{|c|}{ Rail } & \multicolumn{2}{|c|}{ Road } & \multicolumn{2}{|c|}{ Rail } & \multicolumn{2}{|c|}{ Road } & \multicolumn{2}{|c|}{ Rail } & \multicolumn{2}{|c|}{ Road } & \multicolumn{2}{|c|}{ Rail } \\
\hline TT & 0 & TT & $\uparrow$ & TT & 0 & TT & $\uparrow$ & TT & 0 & TT & $\uparrow$ & TT & 0 & TT & $\uparrow$ \\
\hline TC & 0 & $\mathrm{TC}$ & $\bar{\uparrow}$ & $\mathrm{TC}$ & 0 & $\mathrm{TC}$ & $\uparrow$ & $\mathrm{TC}$ & $\uparrow$ & $\mathrm{TC}$ & 0 & $\mathrm{TC}$ & $\uparrow$ & $\mathrm{TC}$ & 0 \\
\hline Rel & 0 & Rel & $\uparrow$ & Rel & $\uparrow$ & Rel & 0 & Rel & $\uparrow$ & Rel & 0 & Rel & $\uparrow$ & Rel & 0 \\
\hline SF & 0 & SF & $\downarrow$ & SF & 0 & SF & $\downarrow$ & SF & 0 & SF & $\downarrow$ & SF & 0 & SF & $\downarrow$ \\
\hline PD & 0 & PD & $\downarrow$ & PD & 0 & PD & $\downarrow$ & PD & 0 & PD & $\downarrow$ & PD & $\downarrow$ & PD & 0 \\
\hline \multicolumn{2}{|c|}{ Road } & \multicolumn{2}{|c|}{ Rail } & \multicolumn{2}{|c|}{ Road } & \multicolumn{2}{|c|}{ Rail } & \multicolumn{2}{|c|}{ Road } & \multicolumn{2}{|c|}{ Rail } & \multicolumn{2}{|c|}{ Road } & \multicolumn{2}{|c|}{ Rail } \\
\hline TT & 0 & TT & $\uparrow$ & TT & 0 & TT & $\uparrow$ & TT & 0 & TT & $\uparrow$ & TT & 0 & $\mathrm{TT}$ & $\uparrow$ \\
\hline TC & 0 & TC & $\downarrow$ & TC & 0 & $\mathrm{TC}$ & $\downarrow$ & $\mathrm{TC}$ & $\downarrow$ & TC & 0 & TC & $\downarrow$ & $\mathrm{TC}$ & 0 \\
\hline Rel & 0 & Rel & $\uparrow$ & Rel & $\uparrow$ & Rel & 0 & Rel & $\uparrow$ & Rel & 0 & Rel & $\uparrow$ & Rel & 0 \\
\hline SF & 0 & SF & $\uparrow$ & SF & 0 & SF & $\uparrow$ & SF & 0 & SF & $\uparrow$ & SF & 0 & SF & $\uparrow$ \\
\hline PD & 0 & PD & $\downarrow$ & PD & 0 & PD & $\downarrow$ & PD & 0 & PD & $\downarrow$ & PD & $\downarrow$ & PD & 0 \\
\hline \multicolumn{2}{|c|}{ Road } & \multicolumn{2}{|c|}{ Rail } & \multicolumn{2}{|c|}{ Road } & \multicolumn{2}{|c|}{ Rail } & & & & & & & $\mathrm{R}$ & \\
\hline $\mathrm{TT}$ & 0 & TT & $\uparrow$ & $\mathrm{TT}$ & 0 & $\mathrm{TT}$ & $\uparrow$ & $\mathrm{TT}$ & 0 & TT & $\uparrow$ & TT & 0 & $\mathrm{TT}$ & $\uparrow$ \\
\hline $\mathrm{TC}$ & 0 & TC & $\downarrow$ & TC & 0 & TC & $\downarrow$ & $\mathrm{TC}$ & $\downarrow$ & TC & 0 & TC & $\downarrow$ & $\mathrm{TC}$ & 0 \\
\hline Rel & 0 & Rel & $\uparrow$ & Rel & $\uparrow$ & Rel & 0 & Rel & $\uparrow$ & Rel & 0 & Rel & $\uparrow$ & Rel & 0 \\
\hline SF & 0 & SF & $\downarrow$ & $\mathrm{SF}$ & 0 & $\mathrm{SF}$ & $\downarrow$ & $\mathrm{SF}$ & 0 & SF & $\downarrow$ & SF & 0 & SF & $\downarrow$ \\
\hline PD & 0 & PD & $\bar{\uparrow}$ & PD & 0 & PD & $\uparrow \uparrow$ & PD & 0 & PD & $\bar{\imath}$ & PD & $\uparrow$ & PD & 0 \\
\hline Rc & & & & & & & & & & & & & & $\mathrm{R}_{i}$ & \\
\hline TT & 0 & TT & $\uparrow$ & TT & 0 & TT & $\uparrow$ & TT & 0 & TT & $\uparrow$ & TT & 0 & $\mathrm{TT}$ & $\uparrow$ \\
\hline $\mathrm{TC}$ & 0 & $\mathrm{TC}$ & $\downarrow$ & $\mathrm{TC}$ & 0 & $\mathrm{TC}$ & $\downarrow$ & $\mathrm{TC}$ & $\downarrow$ & $\mathrm{TC}$ & 0 & $\mathrm{TC}$ & $\downarrow$ & $\mathrm{TC}$ & 0 \\
\hline Rel & 0 & Rel & $\downarrow$ & Rel & $\downarrow$ & Rel & 0 & Rel & $\downarrow$ & Rel & 0 & Rel & $\downarrow$ & Rel & 0 \\
\hline SF & 0 & SF & $\uparrow$ & $\mathrm{SF}$ & 0 & $\mathrm{SF}$ & $\uparrow$ & $\mathrm{SF}$ & 0 & SF & $\uparrow$ & SF & 0 & SF & $\uparrow$ \\
\hline PD & 0 & PD & $\uparrow$ & PD & 0 & PD & $\uparrow$ & PD & 0 & PD & $\uparrow$ & PD & $\uparrow$ & PD & 0 \\
\hline & & & & & & & & & & & & & & $\mathrm{R}_{i}$ & \\
\hline TT & 0 & TT & $\uparrow$ & TT & 0 & TT & $\uparrow$ & TT & 0 & TT & $\uparrow$ & TT & 0 & $\mathrm{TT}$ & $\uparrow$ \\
\hline TC & $\uparrow$ & $\mathrm{TC}$ & 0 & $\mathrm{TC}$ & $\uparrow$ & TC & 0 & $\mathrm{TC}$ & $\uparrow$ & $\mathrm{TC}$ & 0 & $\mathrm{TC}$ & $\downarrow$ & TC & 0 \\
\hline Rel & $\uparrow$ & Rel & 0 & Rel & $\uparrow$ & Rel & 0 & Rel & $\uparrow$ & Rel & 0 & Rel & $\uparrow$ & Rel & 0 \\
\hline SF & 0 & SF & $\downarrow$ & $\mathrm{SF}$ & $\downarrow$ & $\mathrm{SF}$ & 0 & $\mathrm{SF}$ & $\downarrow$ & SF & 0 & SF & 0 & SF & $\uparrow$ \\
\hline PD & 0 & PD & $\downarrow$ & PD & 0 & PD & $\downarrow$ & PD & $\downarrow$ & PD & 0 & PD & 0 & PD & $\downarrow$ \\
\hline & & & & & & & & & & & & & & $\mathrm{R}_{i}$ & \\
\hline TT & 0 & TT & $\uparrow$ & TT & 0 & TT & $\uparrow$ & TT & 0 & TT & $\uparrow$ & TT & 0 & TT & $\uparrow$ \\
\hline TC & $\downarrow$ & TC & 0 & TC & $\downarrow$ & $\mathrm{TC}$ & 0 & $\mathrm{TC}$ & $\downarrow$ & TC & 0 & $\mathrm{TC}$ & $\downarrow$ & TC & 0 \\
\hline Rel & $\uparrow$ & Rel & 0 & Rel & $\uparrow$ & Rel & 0 & Rel & $\uparrow$ & Rel & 0 & Rel & $\uparrow$ & Rel & 0 \\
\hline SF & 0 & SF & $\downarrow$ & SF & $\downarrow$ & SF & 0 & SF & $\downarrow$ & SF & 0 & SF & $\uparrow$ & SF & 0 \\
\hline PD & 0 & PD & $\uparrow$ & PD & 0 & PD & $\uparrow$ & PD & $\uparrow$ & PD & 0 & PD & 0 & PD & $\downarrow$ \\
\hline & & & & & & & & & & & & & & $\mathrm{R}_{i}$ & \\
\hline $\mathrm{TT}$ & 0 & TT & $\uparrow$ & TT & 0 & TT & $\uparrow$ & TT & 0 & TT & $\uparrow$ & TT & 0 & $\mathrm{TT}$ & $\uparrow$ \\
\hline $\mathrm{TC}$ & $\downarrow$ & $\mathrm{TC}$ & 0 & $\mathrm{TC}$ & $\downarrow$ & $\mathrm{TC}$ & 0 & $\mathrm{TC}$ & $\downarrow$ & $\mathrm{TC}$ & 0 & $\mathrm{TC}$ & $\downarrow$ & $\mathrm{TC}$ & 0 \\
\hline Rel & $\downarrow$ & Rel & 0 & Rel & $\uparrow$ & Rel & 0 & Rel & $\uparrow$ & Rel & 0 & Rel & $\uparrow$ & Rel & 0 \\
\hline SF & 0 & SF & $\uparrow$ & $\mathrm{SF}$ & $\uparrow$ & $\mathrm{SF}$ & 0 & SF & $\uparrow$ & SF & 0 & SF & $\uparrow$ & SF & 0 \\
\hline PD & 0 & PD & $\uparrow$ & PD & 0 & PD & $\uparrow$ & PD & $\uparrow$ & PD & 0 & PD & $\downarrow$ & PD & 0 \\
\hline
\end{tabular}




\subsubsection{Experiment Design for C4}

This experiment involved both mode and departure time shifts. Similar to experiment $\mathrm{C} 2$, nearly orthogonal design was applied. The treatment combinations concerning travel time, travel cost, reliability, departure time, service flexibility, and shipment property damage are presented in Table 3-11.

Table 3-11 Orthogonal Factorial Design for Experiment C4

\begin{tabular}{|c|c|c|c|c|c|c|}
\hline $\begin{array}{c}\text { Treatment } \\
\text { Combination }\end{array}$ & $\begin{array}{l}\text { Travel } \\
\text { Time }\end{array}$ & Travel Cost & Reliability & $\begin{array}{l}\text { Departure } \\
\text { time }\end{array}$ & $\begin{array}{c}\text { Service } \\
\text { Flexibility }\end{array}$ & $\begin{array}{l}\text { Shipment } \\
\text { Property } \\
\text { damage }\end{array}$ \\
\hline 1 & Very Low & Very Low & Very High & Off-Peak & Low & Low \\
\hline 2 & Very Low & Low & Base & Off-Peak & Base & Base \\
\hline 3 & Very Low & Base & Very Low & Peak & High & High \\
\hline 4 & Very Low & Base & High & Off-Peak & Base & Base \\
\hline 5 & Very Low & High & Low & Peak & High & High \\
\hline 6 & Very Low & Very High & Very Low & Peak & Low & Low \\
\hline 7 & Low & Very Low & Very Low & Off-Peak & Base & Base \\
\hline 8 & Low & Very Low & Low & Peak & High & Base \\
\hline 9 & Low & Low & Very High & Peak & Base & High \\
\hline 10 & Low & Base & Base & Peak & Low & Low \\
\hline 11 & Low & High & Very Low & Off-Peak & High & Low \\
\hline 12 & Low & Very High & High & Off-Peak & Low & High \\
\hline 13 & Base & Very Low & High & Peak & Low & High \\
\hline 14 & Base & Low & Low & Off-Peak & Low & High \\
\hline 15 & Base & Base & Very High & Peak & Base & Low \\
\hline 16 & Base & High & Very Low & Off-Peak & Base & Low \\
\hline 17 & Base & Very High & Base & Peak & High & Base \\
\hline 18 & Base & Very High & Very High & Off-Peak & High & Base \\
\hline 19 & High & Very Low & Base & Peak & Base & High \\
\hline 20 & High & Low & High & Off-Peak & High & Low \\
\hline 21 & High & Low & High & Peak & High & Low \\
\hline 22 & High & Base & Low & Off-Peak & Low & Base \\
\hline 23 & High & High & Very High & Peak & Low & Base \\
\hline 24 & High & Very High & Very Low & Off-Peak & Base & High \\
\hline 25 & Very High & Very Low & Base & Off-Peak & High & Low \\
\hline 26 & Very High & Low & Very Low & Peak & Low & Base \\
\hline 27 & Very High & Base & Very High & Off-Peak & High & High \\
\hline 28 & Very High & High & Base & Off-Peak & Low & High \\
\hline 29 & Very High & High & High & Peak & Base & Base \\
\hline 30 & Very High & Very High & Low & Peak & Base & Low \\
\hline
\end{tabular}


The same method for $\mathrm{C} 1$ and $\mathrm{C} 2$ was applied to develop choice sets for $\mathrm{C} 4$, through systematically changing the attribute levels. Each scenario consists of three alternatives, one by road, one by rail, and one by randomly selected road or rail. Table 3-12 shows all hypothetical choice sets, which have been divided into five blocks, so each respondent will have a set of six hypothetical scenarios.

Table 3-12 Choice sets using the sequential orthogonal design for Experiment $\mathrm{C} 4$

\begin{tabular}{|c|c|c|c|c|c|c|c|c|c|c|c|c|c|c|c|c|c|}
\hline Block & \multicolumn{4}{|c|}{ Alternative 1 (Road) } & \multicolumn{7}{|c|}{ Alternative 2 (Rail) } & \multicolumn{6}{|c|}{ Alternative 3 (Road or Rail) } \\
\hline 1 & TT TC & Rel & Dep. & Flex & PD & TT & TC & Rel & Dep. & Flex & PD & TT & $\mathrm{TC}$ & Rel & Dep. & Flex & PD \\
\hline 1 & VL VH & $\mathrm{VH}$ & Off-P & $\mathrm{L}$ & $\mathrm{L}$ & B & B & $\mathrm{L}$ & $P$ & B & B & $\mathrm{H}$ & $\mathrm{H}$ & $\mathrm{L}$ & $\mathrm{P}$ & $\mathrm{H}$ & $\mathrm{B}$ \\
\hline 1 & VL $\mathrm{H}$ & B & Off-P & & B & B & B & $\mathrm{L}$ & $\mathrm{VH}$ & $\mathrm{P}$ & $\mathrm{H}$ & $\mathrm{H}$ & B & $\mathrm{H}$ & $P$ & $\mathrm{~L}$ & $\mathrm{H}$ \\
\hline 1 & B VH & $\mathrm{VL}$ & $\mathrm{P}$ & $\mathrm{H}$ & $\mathrm{H}$ & $\mathrm{L}$ & B & $\mathrm{B}$ & Off-P & $\mathrm{L}$ & $\mathrm{L}$ & $\mathrm{VL}$ & $\mathrm{H}$ & B & Off-P & $\mathrm{H}$ & $\mathrm{L}$ \\
\hline 1 & VL VH & $\mathrm{H}$ & Off-P & B & B & B & B & $\mathrm{L}$ & $P$ & $\mathrm{H}$ & $\mathrm{H}$ & $\mathrm{H}$ & $\mathrm{H}$ & VL & $\mathrm{P}$ & $\mathrm{L}$ & $\mathrm{H}$ \\
\hline 1 & B $\mathrm{H}$ & $\mathrm{L}$ & $\mathrm{P}$ & $\mathrm{H}$ & $\mathrm{H}$ & $\mathrm{L}$ & VL & $\mathrm{H}$ & Off-P & $\mathrm{L}$ & $\mathrm{L}$ & VL & B & $\mathrm{L}$ & Off-P & $\mathrm{H}$ & $\mathrm{L}$ \\
\hline 1 & $\mathrm{~L} H$ & VL & Off-P & B & B & $\mathrm{VH}$ & VL & B & $\mathrm{P}$ & $\mathrm{H}$ & $\mathrm{H}$ & $\mathrm{H}$ & B & $\mathrm{H}$ & $\mathrm{P}$ & $\mathrm{L}$ & $\mathrm{L}$ \\
\hline 1 & $\begin{array}{ll}\mathrm{H} & \mathrm{B} \\
\end{array}$ & $\mathrm{L}$ & $\mathrm{P}$ & $\mathrm{H}$ & B & $\mathrm{L}$ & $\mathrm{VL}$ & $\mathrm{H}$ & Off-P & $\mathrm{L}$ & $\mathrm{H}$ & B & $\mathrm{L}$ & VH & Off-P & $\mathrm{L}$ & $\mathrm{H}$ \\
\hline 1 & $\mathrm{H} \quad \mathrm{L}$ & $\mathrm{L}$ & $\mathrm{P}$ & B & $\mathrm{H}$ & $\mathrm{L}$ & & $\mathrm{VH}$ & Off-P & $\mathrm{H}$ & $\mathrm{L}$ & B & B & B & Off-P & $\mathrm{VH}$ & $\mathrm{L}$ \\
\hline 1 & \begin{tabular}{l|l}
$\mathrm{H}$ & $\mathrm{B}$
\end{tabular} & B & $\mathrm{P}$ & $\mathrm{L}$ & $\mathrm{L}$ & B & $\mathrm{VH}$ & $\mathrm{VH}$ & Off-P & B & B & L & $\mathrm{H}$ & $\mathrm{H}$ & Off-P & $\mathrm{L}$ & B \\
\hline 2 & \begin{tabular}{l|l}
$\mathrm{L}$ & $\mathrm{H}$
\end{tabular} & VL & Off-P & $\mathrm{H}$ & $\mathrm{L}$ & $\mathrm{H}$ & $\mathrm{VL}$ & B & $P$ & $\mathrm{~L}$ & B & $\mathrm{VH}$ & B & $\mathrm{H}$ & $P$ & VL & B \\
\hline 2 & $\mathrm{~L} \mid \mathrm{VH}$ & $\mathrm{H}$ & Off-P & $\mathrm{L}$ & $\mathrm{H}$ & $\mathrm{H}$ & & VL & $\mathrm{P}$ & B & $\mathrm{L}$ & B & $\mathrm{L}$ & B & $\mathrm{P}$ & $\mathrm{H}$ & $\mathrm{L}$ \\
\hline 2 & VH B & $\mathrm{L}$ & $\mathrm{P}$ & $\mathrm{L}$ & $\mathrm{H}$ & B & $\mathrm{VL}$ & VL & Off-P & B & $\mathrm{L}$ & L & VH & B & Off-P & $\mathrm{L}$ & $\mathrm{L}$ \\
\hline 2 & \begin{tabular}{l|l}
$\mathrm{B}$ & $\mathrm{L}$
\end{tabular} & $\mathrm{L}$ & Off-P & $\mathrm{L}$ & & $\mathrm{VH}$ & $\mathrm{H}$ & $\mathrm{H}$ & $\mathrm{P}$ & B & $\mathrm{L}$ & $\mathrm{H}$ & VH & B & $\mathrm{P}$ & $\mathrm{L}$ & $\mathrm{L}$ \\
\hline 2 & VH B & VH & $\mathrm{P}$ & B & $\mathrm{L}$ & B & $\mathrm{H}$ & $\mathrm{L}$ & Off-P & $\mathrm{H}$ & B & L & VH & B & Off-P & $\mathrm{L}$ & B \\
\hline 2 & \begin{tabular}{l|l}
$B$ & $\mathrm{~L}$
\end{tabular} & VL & Off-P & B & $\mathrm{L}$ & $\mathrm{VH}$ & $\mathrm{H}$ & $\mathrm{B}$ & $\mathrm{P}$ & $\mathrm{H}$ & B & $\mathrm{H}$ & $\mathrm{L}$ & $\mathrm{H}$ & $\mathrm{P}$ & $\mathrm{VH}$ & B \\
\hline 2 & $\mathrm{H} \quad \mathrm{B}$ & $\mathrm{H}$ & $\mathrm{P}$ & $\mathrm{L}$ & B & $\mathrm{VH}$ & $\mathrm{L}$ & B & $\mathrm{P}$ & $\mathrm{H}$ & B & B & VH & VH & Off-P & $\mathrm{L}$ & $\mathrm{H}$ \\
\hline 2 & \begin{tabular}{l|l}
$\mathrm{H}$ & $\mathrm{B}$
\end{tabular} & B & Off-P & B & B & B & $\mathrm{VH}$ & $\mathrm{VH}$ & Off-P & $\mathrm{H}$ & B & $\mathrm{VH}$ & $\mathrm{L}$ & $\mathrm{L}$ & $\mathrm{P}$ & $\mathrm{L}$ & $\mathrm{H}$ \\
\hline 2 & $\mathrm{H} \quad \mathrm{L}$ & VL & $\mathrm{P}$ & $\mathrm{H}$ & $\mathrm{H}$ & $\mathrm{L}$ & $\mathrm{H}$ & B & $\mathrm{P}$ & B & $\mathrm{H}$ & $\mathrm{VL}$ & B & $\mathrm{VH}$ & Off-P & $\mathrm{H}$ & $\mathrm{L}$ \\
\hline 2 & VL $B$ & B & Off-P & B & $\mathrm{L}$ & $\mathrm{L}$ & $\mathrm{H}$ & $\mathrm{H}$ & Off-P & $\mathrm{H}$ & $\mathrm{L}$ & $\mathrm{H}$ & $\mathrm{L}$ & VL & $\mathrm{P}$ & $\mathrm{L}$ & B \\
\hline 3 & B B & B & Off-P & B & $\mathrm{L}$ & B & & VL & $\mathrm{P}$ & $\mathrm{H}$ & $\mathrm{L}$ & VL & $\mathrm{H}$ & $\mathrm{H}$ & Off-P & $\mathrm{L}$ & B \\
\hline 3 & $\begin{array}{ll}\text { VL } & \text { L }\end{array}$ & $\mathrm{L}$ & Off-P & $\mathrm{H}$ & B & $\mathrm{L}$ & B & $\mathrm{H}$ & Off-P & $\mathrm{L}$ & B & $\mathrm{H}$ & VH & VL & $\mathrm{P}$ & B & $\mathrm{H}$ \\
\hline 3 & L VL & VL & Off-P & $\mathrm{H}$ & B & $\mathrm{H}$ & $\mathrm{H}$ & $\mathrm{H}$ & $\mathrm{P}$ & $\mathrm{L}$ & B & VL & B & L & Off-P & B & $\mathrm{H}$ \\
\hline 3 & VL $B$ & $\mathrm{H}$ & Off-P & $\mathrm{VH}$ & $\mathrm{H}$ & $\mathrm{L}$ & $\mathrm{VH}$ & VL & Off-P & B & $\mathrm{H}$ & $\mathrm{H}$ & $\mathrm{L}$ & B & $\mathrm{P}$ & $\mathrm{H}$ & $\mathrm{L}$ \\
\hline 3 & B VL & VL & Off-P & B & $\mathrm{H}$ & $\mathrm{L}$ & B & B & Off-P & $\mathrm{H}$ & $\mathrm{L}$ & $\mathrm{VH}$ & B & $\mathrm{VH}$ & $\mathrm{P}$ & $\mathrm{L}$ & B \\
\hline 3 & $\begin{array}{ll}\text { VH L } \\
\end{array}$ & $\mathrm{H}$ & Off-P & B & B & B & & VL & $\mathrm{P}$ & $\mathrm{H}$ & B & L & VH & B & Off-P & $\mathrm{L}$ & $\mathrm{H}$ \\
\hline 3 & B L & B & $\mathrm{P}$ & $\mathrm{H}$ & $\mathrm{H}$ & $\mathrm{L}$ & $\mathrm{H}$ & $\mathrm{L}$ & Off-P & $\mathrm{L}$ & $\mathrm{H}$ & VH & VL & $\mathrm{VH}$ & $\mathrm{P}$ & B & $\mathrm{L}$ \\
\hline 3 & VH VL & $\mathrm{L}$ & $\mathrm{P}$ & B & B & B & & VL & $\mathrm{P}$ & $\mathrm{H}$ & B & L & $\mathrm{H}$ & $\mathrm{H}$ & Off-P & $\mathrm{VH}$ & $\mathrm{H}$ \\
\hline 3 & $\mathrm{VH} \quad \mathrm{B}$ & $\mathrm{VH}$ & $\mathrm{P}$ & $\mathrm{VH}$ & $\mathrm{L}$ & B & $\mathrm{VH}$ & $\mathrm{L}$ & $\mathrm{P}$ & B & $\mathrm{L}$ & L & B & L & Off-P & $\mathrm{H}$ & B \\
\hline
\end{tabular}




\subsubsection{Summary}

Four different stated preference experiments were tested among the survey respondents, each focused on the trade-offs among distinct combination of alternatives. C1 was within-mode experiment, which primarily considered the trade-off among travel time, cost and reliability, experiment $\mathrm{C} 2$ was an extension of $\mathrm{C} 1$, which considered an additional attribute, departure time. C3 and C4 were cross-mode experiments, which considered other mode-related attributes such as, property damage, and service flexibility, without and with the consideration of departure time shift, respectively. Table 3-13 summarizes the applicability of the experiments by mode. In terms of survey approach, this study employed stratification-based random sampling strategy, in order to incorporate market segmentation into the VOT and VOR analysis.

Table 3-13 Proposed Experiments by Mode

\begin{tabular}{|c|c|c|c|c|}
\hline Experiment Type & Road & Rail & Air & Waterways \\
\hline C1 & $\sqrt{ }$ & $\sqrt{ }$ & $\sqrt{ }$ \\
\hline C2 & $\sqrt{ }$ & & \\
\hline C3 & $\sqrt{ }$ & $\sqrt{ }$ & \\
\hline C4 & $\sqrt{ }$ & $\sqrt{ }$ & \\
\hline
\end{tabular}

The survey consisted of three stages: recruitment, pilot and main survey. The recruitment stage collected critical background information about the firm and detailed typical shipment information that inform the sample monitoring and the stated preference questionnaire design. The pilot survey provided an opportunity to evaluate the structure and design of the survey instrument. Based on the feedback from the pilot survey, the stated preference questions may be revised.

A complete description of the survey questionnaires is provided in the next chapter and appendix. 


\subsection{Development of Econometric Models for VOR Estimation}

This section intended to highlight various features of the modeling techniques proposed for the valuation of freight users' travel time reliability.

Application of discrete choice models have been well documented in travel behavior studies (Vaziri et al., 2014; Jin et al., 2014; Asgari et al., 2014; Asgari, 2015; Asgari and Jin, 2015; Jin et al., 2015; Shams et al., 2015; Shams et al., 2016).Various forms of logit structures including multinomial logit (MNL), mixed logit (ML), heteroscedastic extreme value (HEV) model have been found in the literature to estimate VOT and VOR values. The main motive for exploring different model structures was to determine the best specification that can fit and explain the sample. Among them, MNL and ML were the two most widely used model structures that was proposed for this study. Additionally, in order to investigate the user heterogeneity, the study proposed to develop separate models for different market segments, or to interact variables representing potential sources of heterogeneity with the main transport-related variables.

More details are provided in next sections.

\subsubsection{Model Structure}

\subsubsection{Multinomial Logit}

The study proposes the multinomial logit model technique was to estimate the value of reliability from the data collected from the SP survey. Two main assumptions of this model were a) the error component needed to be identical and independently distributed (IID), and b) the choice alternative needed to follow the independence from the irrelevant alternatives (IIA) property (Ben Akiva et al., 1985). 
Specifically, two types of MNL specifications were proposed for this study, additive and multiplicative, as shown in equation (24) and equation (25), respectively Additive specification:

$$
U=\beta_{c} * C+\beta_{T} * T+\beta_{R} * R+\varepsilon
$$

where

$\beta_{\mathrm{T}}, \beta_{\mathrm{c}}$, and $\beta_{\mathrm{R}}$ are the coefficients for travel time, cost, and travel time reliability variable, respectively. T, C, and $\sigma$ is the travel time, cost, and measure of time reliability (standard deviation of travel time) respectively; $\varepsilon$ is the random error term.

Multiplicative specification with WTP Space:

$$
U=\lambda * \log (C+V O T * T+V O R * R)+\epsilon
$$

where

$\lambda$ is the scale parameter associated with the error term, $\epsilon$; VOT and VOR are coefficients for the value of travel time and travel time reliability respectively.

Using these assumptions, the probability of each alternative is estimated using the following equation:

$$
P_{j}=\frac{\exp \left(U_{j}\right)}{\sum_{k=1}^{k} \exp \left(U_{k}\right)}
$$

where

$P(j)=$ probability that any particular alternative $(j)$ will be chosen; $U_{j}=$ utility of that alternative $(j)$.

To overcome the violation of model assumption of independence of irrelevant alternatives (IIA), the models were estimated following the individual-specific (panel specification) data approach. 
According to microeconomic theory, VOT is defined as the marginal rate of disutility between travel time and travel cost and VOR is defined as the marginal rate of disutility between travel time reliability and travel cost. Therefore,

$$
\begin{gathered}
\mathrm{VOT}=\frac{\partial \mathrm{U}_{\mathrm{i}} / \partial \mathrm{T}_{\mathrm{i}}}{\partial \mathrm{U}_{\mathrm{i}} / \partial \mathrm{C}_{\mathrm{i}}}=\frac{\beta_{T}}{\beta_{C}} \\
\mathrm{VOR}=\frac{\partial \mathrm{U}_{\mathrm{i}} / \partial R_{\mathrm{i}}}{\partial \mathrm{U}_{\mathrm{i}} / \partial \mathrm{C}_{\mathrm{i}}}=\frac{\beta_{R}}{\beta_{C}}
\end{gathered}
$$

\subsubsection{Mixed Logit}

Mixed logit (ML), an extension of the MNL model, was another commonly used modeling techniques in the valuation studies (Halse et al., 2011; De Jong et al., 2014, Hossan et al., 2016).

Instead of assuming a fixed (mean value) for coefficients, ML model considers an underlying distribution. The relaxation of this assumption generalized the standard multinomial logit model (MNL) and allowed the coefficients to vary across decisionmakers and scenarios, accommodating user heterogeneity. Accordingly, an individual, $\mathrm{n}$ $(\mathrm{n}=1,2 \ldots \mathrm{N})$ when faced with alternative, $\mathrm{i}$ in $\mathrm{t}$ choice scenario, the utility was expressed as:

$$
U_{i t n}=\beta_{n} X_{i t n}+\left[\eta_{i n}+\varepsilon_{i t n}\right]
$$

where

$\mathrm{X}_{\mathrm{itn}}$ represents the vector of explanatory variables, which includes travel time, cost, and reliability; $;_{n}$ represents the vector of coefficients that needs to be estimated; $\eta_{\mathrm{in}}$ is the error term that is normally distributed over individuals and alternatives; $\varepsilon_{i t n}$ is the extreme value-distributed error term that is independently and identically distributed over individuals or alternatives. 
Since there are no closed analytical forms for the likelihood functions of ML models, the coefficients were estimated integrating the traditional logit model over all values of $\eta_{\text {in, }}$ where $\phi$ are the fixed variables) as shown in equation (3-7)

$$
: P_{i n}=\int_{\eta_{i n}} L_{i n}\left(\beta_{n} \mid \phi\right) f\left(\beta_{n} \mid \phi\right) \eta_{i n}
$$

where

$P_{\text {in }}=$ Probability that individual $\mathrm{n}$ chooses alternative $\mathrm{i}$.

Following the literatures, this study considered travel time and travel time reliability as random parameters with a normal distribution. One thousand halton draws were proposed in light with the literatures for model estimation.

The VOT and VOR estimation technique for mixed logit is similar to multinomial logit by taking the total derivative of utility with respect to changes in travel time and travel time reliability respectively.

\subsubsection{Treatment of User Heterogeneity}

User heterogeneity refers to the taste variations among the users. In order to examine the taste variation across users, one may use either interaction effects or estimate separate coefficients for different market segmentation. Both of these approaches were employed for this study.

In the first approach, the interaction terms between main transport-related attributes (such as travel time, cost and reliability) and exogenous attributes were added to the utility function:

$$
U_{\text {in }}=\beta X_{\text {in }}+\gamma_{s}+\left(S_{\text {in }} * X_{\text {in }}\right)+\varepsilon_{\text {in }}
$$


where

$\beta=$ coefficient vector of main transport variables; $X_{\text {in }}=$ vector of main

transport variables (i.e. travel time, cost and reliability); $\gamma_{s}=$ coefficient of

interaction variables; $S_{i n}=$ exogenous variables, which represent potential

sources of heterogeneity.

For the exogenous variables, shipping and firms' characteristics related attributes were considered to investigate the interaction effect with main transport-related attributes. Based on the equation (3-8), if the becomes significant, then the interacted variables (exogenous variables) is considered as source of heterogeneity.

For the second approach, coefficients for main transport-related attributes (such as travel time, cost and travel time reliability) are estimated through the development of separate models for different groups. In line with the literature, this study develops model for two user groups: commodity and user types (i.e. shippers, carriers, forwarding companies). Although the survey allows to collect shipment information from ten types of commodity, few commodity groups are merged together to get statistically significant results. The commodity types include agriculture, food, minerals, construction, lumber, paper and chemicals, petroleum products, warehousing, non-durable manufacturing products and miscellaneous. 


\subsubsection{Summary}

The core task of this dissertation was to design and administer a stated preference survey for the valuation of VOR in freight transportation. VOR was modeled as the standard deviation of travel time, and presented as a frequency of on-time and late delivery choice scenarios. Before implementing the final survey, a pilot survey was conducted to assess the adequacy and efficiency of the survey design. Market segmentation and sampling plan were devised for the survey. In terms of model structure, this dissertation explored multinomial and mixed logit model. To overcome the IIA violation, the study proposed a panel data (individual specific) approach for the model estimation. 


\section{CHAPTER 4}

\section{PILOT SURVEY, SURVEY QUESTIONNAIRE AND IMPLEMENTATION}

This chapter presents the details of the pilot survey, the survey questionnaires presented to the participants, and the implementation strategies to collect the necessary data. Additionally, the descriptive analyses of survey data are included in this chapter.

\subsection{Pilot Survey}

In order to recruit potential participants and also to get feedback, different strategies were employed to reach out to the freight community and recruit potential participants. For those whose contact information could be obtained through the internet, individual companies were contacted via phone calls and emails, to introduce the purpose of the survey and invite them to participate. Freight user conferences, professional associations, and social events were also targeted as opportunities to recruit participants and obtain feedback regarding the survey instrument.

Two major feedbacks obtained from the pilot survey were:

- The choice questions/scenarios may be too complicated for some potential participants, which eventually may discourage survey participation.

- The technical terms used to describe the choices/scenarios, such as transit time and cost, need to be clearly defined, since every contract varies depending on the merit of client and situations. 
To address these concerns properly, the research team was able to establish connections with the FCBF and other freight professional associations. Further discussion will address these issues, help enhance and promote the survey as detailed in the next section.

\subsubsection{Florida Customs Brokers \& Forwarders Association, Inc. (FCBF)}

Several in-person meetings and discussions were held between the FCBF and the research team to find the best solution to address the above issues. The research team presented a simplified and modified version of the choice questions. Figure 4-1 below shows the original (a) and the revised format (b) of the hypothetical choice question. The revised version employed a different way to present reliability measure that would be easily understood by the freight users.

\begin{tabular}{|c|c|}
\hline Alternative 1 & Alternative 2 \\
\hline Transit time : $10 \mathrm{hrs}$ & Transit time : $12.5 \mathrm{hrs}$ \\
\hline $\begin{array}{l}\text { You have an equal probability of } \\
\text { each of these } 5 \text { transit times (hrs) }\end{array}$ & $\begin{array}{l}\text { You have an equal probability of } \\
\text { each of these } 5 \text { transit times (hrs) }\end{array}$ \\
\hline On time & 1 hour early \\
\hline On time & On time \\
\hline On time & On time \\
\hline On time & 1 hour late \\
\hline $\begin{array}{l}30 \text { minutes late } \\
\text { (Hints : Very High Reliability) }\end{array}$ & $\begin{array}{c}2 \text { hours late } \\
\text { (Hints : Medium Reliability) }\end{array}$ \\
\hline $\begin{array}{l}\text { Shipping cost : } \$ 600 \\
(20 \% \text { more than standard) }\end{array}$ & $\begin{array}{l}\text { Shipping cost : } \$ 400 \\
(20 \% \text { less than standard) }\end{array}$ \\
\hline I prefer this option & $\begin{array}{c}\text { I prefer this option } \\
\mathrm{O}\end{array}$ \\
\hline
\end{tabular}

(a) Original hypothetical choice question 


\begin{tabular}{|c|c|}
\hline Alternative 1 & Alternative 2 \\
\hline $\begin{array}{c}\text { Actual } \\
\text { transit time }\end{array}$ & $\begin{array}{l}2.5 \text { hours more than } \\
\text { Actual transit time }\end{array}$ \\
\hline $\begin{array}{l}\text { Your shipment has the following } \\
\text { risk of delay }\end{array}$ & $\begin{array}{l}\text { Your shipment has the following } \\
\text { risk of delay }\end{array}$ \\
\hline \begin{tabular}{l|l} 
On & 4 out of 5 times \\
time: &
\end{tabular} & \begin{tabular}{l|l} 
On & 2 out of 5 times \\
time: &
\end{tabular} \\
\hline $\begin{array}{l}1 \text { out of } 5 \text { times, with } \\
\text { a possible delay of } \\
2 \mathrm{hrs}\end{array}$ & \begin{tabular}{l|l} 
Late: & $\begin{array}{l}3 \text { out of } 5 \text { times, with } \\
\text { a possible delay of } \\
2-4 \mathrm{hrs}\end{array}$
\end{tabular} \\
\hline (Hints : Very High Reliability) & (Hints : Medium Reliability) \\
\hline$\$ 100$ more than & $\$ 100$ less than \\
\hline Actual shipping cost & Actual shipping cost \\
\hline $\begin{array}{c}\text { I prefer this option } \\
\text { O }\end{array}$ & $\begin{array}{c}\text { I prefer this option } \\
\bigcirc\end{array}$ \\
\hline
\end{tabular}

(b) Revised hypothetical choice question

Figure 4-1 A set of hypothetical example of choice sets

In addition, more explanatory notes were added in the survey to aid respondents in understanding the given choices. The next section summarizes the survey revisions incorporating all the feedbacks and input from the freight industry.

\subsubsection{Survey Revisions}

Combining all the feedback obtained through the pilot survey and discussions with the freight industry, the major revisions to the survey are summarized here.

\subsubsection{Survey Approach}

Initially the survey was designed with a two-stage approach, where participants were recruited in the first stage by completing a short questionnaire about the firm and one typical or recent shipment, then a stated preference survey questionnaire was developed based on the information collected from the first stage and sent to the participants. This approach yielded choice scenarios that are customized for each 
participant, but feedback from the pilot survey and the industry indicated that the retention rate would be very low. Therefore, it was determined to combine the two stages into one to minimize the dropout rate. As a result, instead of using typical shipment information collected from the first stage to customize the choice scenarios in the second stage, three sets of pre-defined attribute values (based on shipment distance) were developed to describe the choice alternatives. This may have affected the effectiveness of the survey design. Under the circumstances, this was the most suitable approach to attract as many participants and reduce dropouts.

\subsubsection{Survey Questionnaire}

The recruitment questionnaire was shortened, as the original survey was long. As a result, only essential questions concerning one typical shipment were kept and attitudinal questions were moved to the end of the survey for optional participation.

Secondly, certain definitions (shipment, cost, etc.) needed further clarification, as different parties may have had various interpretations for one shipment,' which will affect their responses to the choice questions. The same applies for "shipping distance" and "cost." To provide better clarification, additional illustration and explanation were added at the beginning.

Furthermore, presentation of the choice scenarios may be confusing, especially the representation for travel time reliability. The presented transit time and shipping cost may be out of range for some respondents, therefore making it challenging for them to relate to the proposed scenarios. After discussion with the industry expert, a format was finalized, which is discussed more in the following sections. 
Additionally, a short tutorial was added before the choice question to aid the respondents in understanding the question setting, as shown in the screenshot below.

Finally, the survey process has been made as dynamic as possible, so that participants only were given questions that were applicable to them based on their previous answers. In the final format, the survey was designed to take about 15-20 minutes for each participant: 5-10 minutes to fill the recruitment questions and 7-10 minutes to take part in the hypothetical choice questions, with few optional questions at the end. In the next section, more details about the final survey platform and questionnaire are discussed.

\subsubsection{Summary}

The findings from the pilot survey finalize the survey framework. Addressing these minor but critical details has made the survey more dynamic and less superfluous.

\subsection{Survey Components}

This survey was primarily designed to quantify the users' willingness to pay for the improvement of travel related attributes, such as travel time, reliability, and travel time saving in their transportation choices. Considering heterogeneity among the users, this study intended to cover a variety of user groups, including shippers, carriers, third party logistics providers (3PL) and freight brokers. The survey consisted of four major sections:

- Part 1: Introduction and qualification questions

- Part 2: Information on a recent/typical shipment

- $\quad$ Part 3: Stated preference questions and validation question 
- Part 4: Background and attitude questions (optional)

In addition, based on the users' willingness to switch mode or switch to off-peak hours, the respondents were automatically assigned to one of the four experimental designs, which were discussed further in the previous sections. The complete summary of survey questionnaire are presented in Appendix.

\subsubsection{Part 1: Introduction and Qualification Questions}

At the beginning of the survey, the respondents were presented a qualification question asking about their nature of business and requested them to choose one of the following categories:

- Shippers

- Carriers

- Third party logistics providers or freight forwarders

- None of the Above

Respondents who chose None of the Above were disqualified from the survey.

Figure 4-2 shows the screen capture of the shipment qualification question.

Respondents who qualified for the survey asked to answer a series of questions about their most recent/typical shipment. Additionally, the respondents who identified themselves as Shipper were further asked whether they used their own vehicle, hired transport, or a third party for shipping the goods. 


\section{FLORIDA FREIGHT SURVEY}

Shippers: If your business is involved in manufacturing, or warehousing, or any kinds of product development related activity and typically ship goods to customers using your own transportation or hiring carriers or through a third party.

Carriers: If your business is only limited to carrying goods from Customer A to B and is not involved in any kinds of manufacturing, or warehousing.

Forwarding or Third-Party Logistics Provider: If your business is involved in providing a one-stop shop service (including transportation, warehousing, cross-docking, inventory management, packaging and freight forwarding) to the customers of outsourced logistic services for part or all of their supply chain management functions.
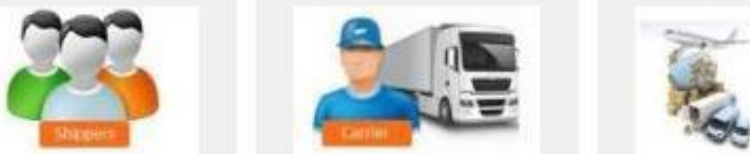

NONE OF THE ABOVE

Figure 4-2 Sample screen capture: qualification question

\subsubsection{Part 2: Base Shipment Characteristics}

The main purpose of "Base Shipment Characteristics" was to collect information regarding their recent/typical shipment, which was used as a reference shipment. The information collected from this stage provided a frame of reference for respondents when completing the stated preference scenarios in the next section of the survey. Below is the list of shipment characteristics collected in the survey:

- Primary mode used to transport

- Types of commodity transported 
- Shipping distance, duration and cost

- Shipment size

- Trucking type and truck type used to transport

- Delivery time defined by clients or contract

- Provision of monetary penalty for the late delivery

\subsubsection{Pre-survey Instruction}

An introductory instruction was presented before the respondents were asked to answer the questions. The instructions were intended to educate participants beforehand about the survey and also clear potential ambiguity on the terms used in the survey.

The instruction mainly provided the definition of shipment and provided guidelines to the respondents when there were multiple modes, commodities, or drops involved in a single shipment. As an example, users who used two or more modes were asked to select the mode which carried most of the shipment duration. This was defined as the "primary mode" for the shipment. Similarly, participants were asked to choose the commodity type which consisted of the major share in the shipment. This detailed explanation was particularly helpful for carriers and 3PLs, since they often used more than one mode, or handled multiple commodities in one shipment.

Finally, the survey asked the respondents to think of a regular shipment, not a special or emergency arrangement, when answering the questions in the survey. Figure 43 shows the screen capture of the instruction. 


\section{FLORIDA FREIGHT SURVEY}

This section asks about one of your recent shipments, which will only be used to generate possible scenarios for your shipment in later part. You are advised to give approximate values, in case you find this information sensitive. To avoid any kind of ambiguity, please read the following instructions before you fill up the questions:

1. Your typical shipment may consists of many types of commodity, such as agricultural, minerals, food products, heavy construction materials, etc, but please select any one of these commodities.

2. If you use more than one mode for that shipment, please select the primary mode, which carries the majority of the shipment duration. For example, trucks are often used to transport goods to and from rail stations, but "Rail" is considered as the primary mode.

3. Your shipment consists of a one-way distance (or duration), traveled (or spent) from your departure location (typically includes your distribution center or your client's pick up location) to the designated arrival location (client's specified, customer's location). It includes all the intermediary times or distance spent between these points.

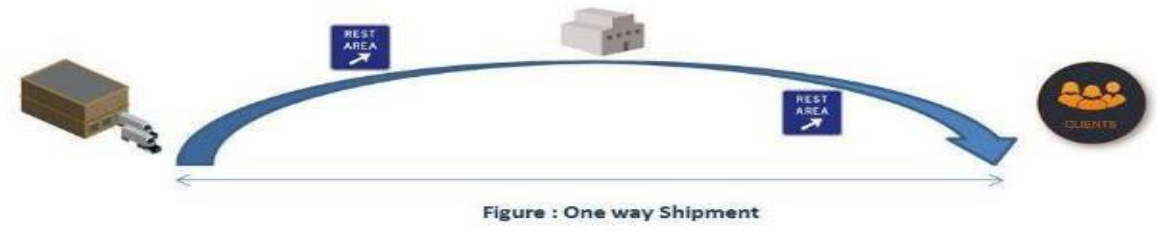

4. You may have multiple drops for a single shipment. In that case, please select first drop as your typical shipment (in case you are not sure about the first drop, please take your best guess!).

\section{Figure 4-3 Sample screen capture: pre-survey instructions}

\subsubsection{Shipment Related Questions}

A series of questions regarding their recent or typical shipments were presented to the respondents. Information on the primary mode and commodity type of the shipment was collected, as shown in Figure 4-4.

Later, the participants were asked to provide information about their shipping distance. This study used a range of pre-determined values to collect this information from the respondents. This approach avoided the risk of asking commercially sensitive information and made the survey more appealing to a loss of little statistical accuracy. Different sets of selections for shipping distance were shown to the respondents based on the primary mode they chose, as shown in Figure 4-5 and Figure 4-6 below: 


\section{FLORIDA FREIGHT SURVEY}

This section will ask you about one recent or typical shipment. You are advised to give approximate values, in case you find this information sensitive.

If you use more than one mode for your typical shipments, please select the primary mode, which carries/occupies the most of the shipment duration. For example, trucks are often used to transport goods to and from rail station, but "Rail" is considered as the primary mode.

Please select the primary mode for your recent or typical shipment

Truck

Rail

Air

Waterways

What was the commodity type for the shipment? ( please choose all that apply)

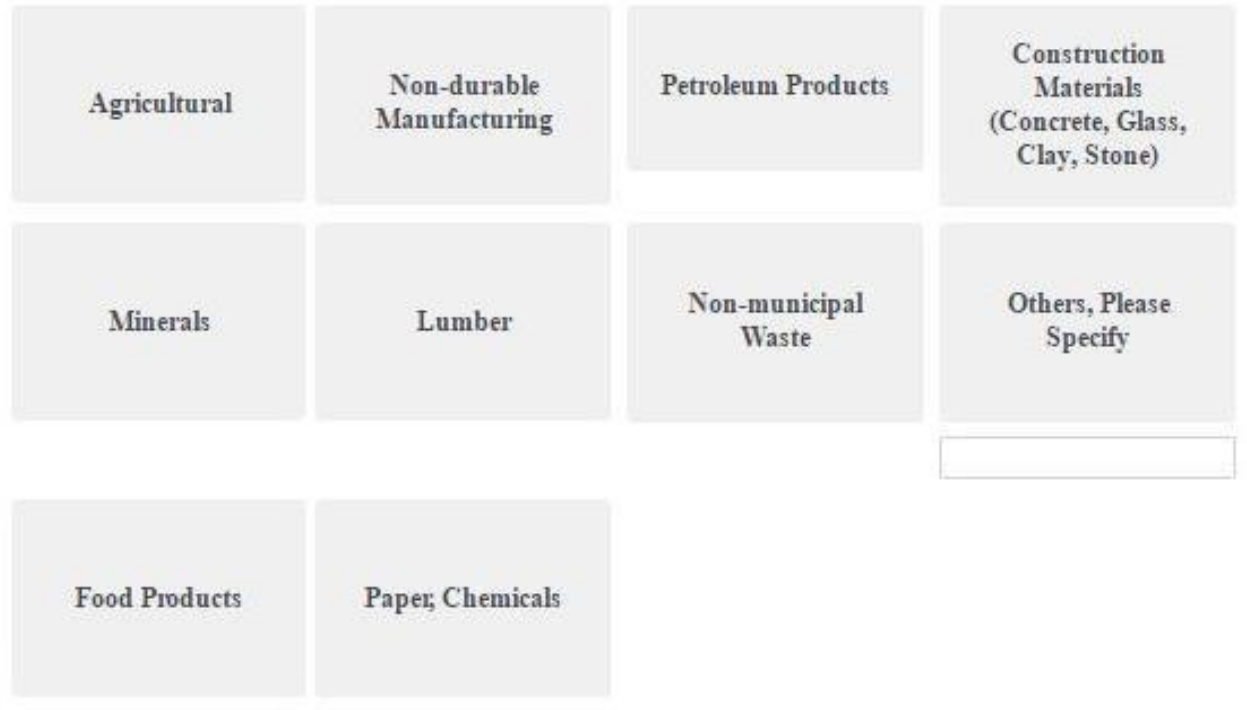

Figure 4-4 Sample screen capture: mode and commodity type 


\section{FLORIDA FREIGHT SURVEY}

What was the shipping distance?

Less than $\mathbf{5 0}$ miles

50-300 miles

Greater than 300 miles

Figure 4-5 Sample screen capture: shipping distance for road mode

\section{FLORIDA FREIGHT SURVEY}

What was the shipping distance?

Less than 300 miles

300-1000 miles

Greater than 1000 miles

Figure 4-6 Sample screen capture: shipping distance for rail mode

For air and waterway modes, the participants were asked whether their shipment ended within or outside of Florida, as shown in Figure 4-7. If outside of Florida was selected, they were then asked to provide the origin and destination cities for the shipment. 


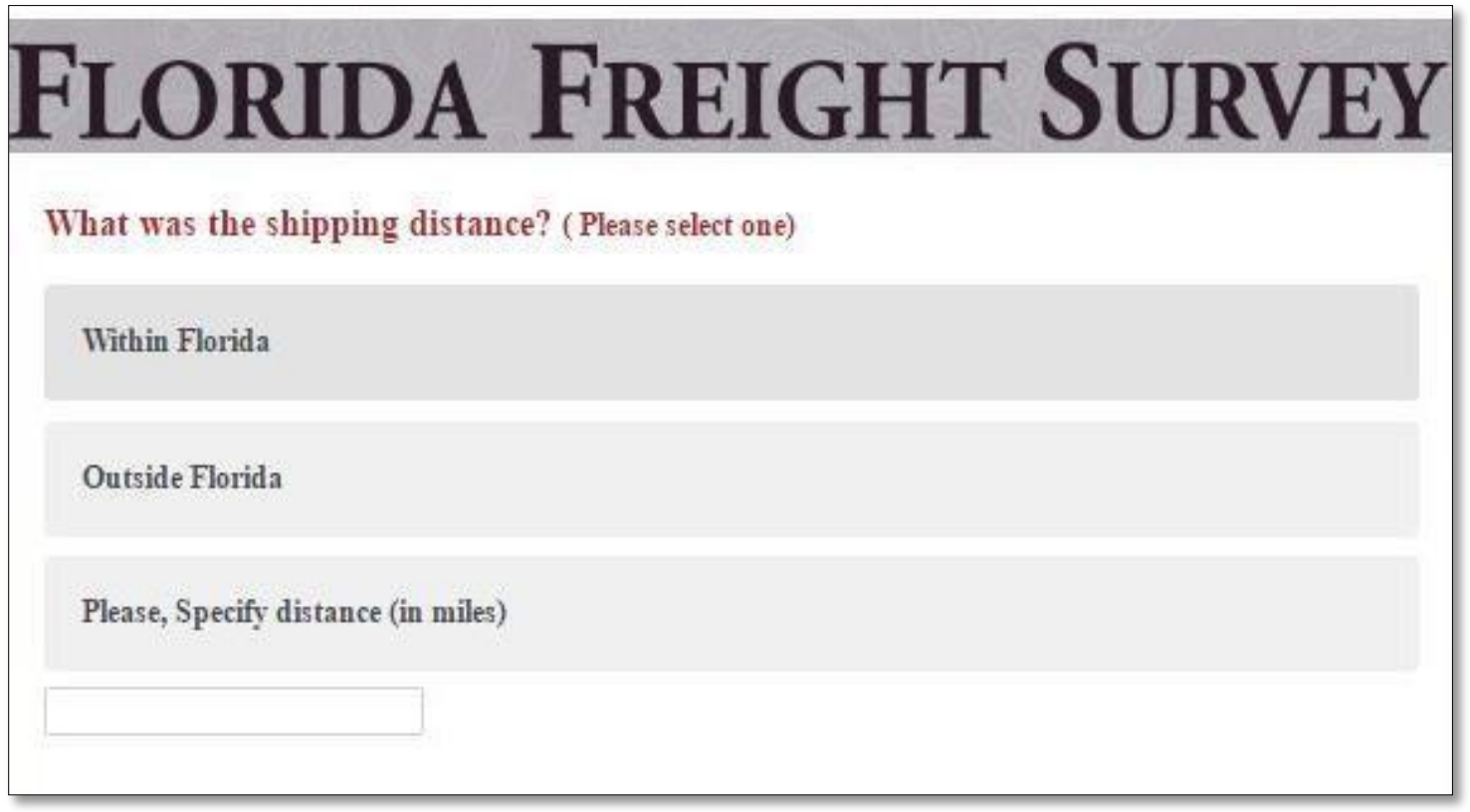

Figure 4-7 Shipping distance for air and waterway modes

Then the respondents were asked to provide the cost for their recent or typical shipment. Similarly, a range of values was provided to the respondents instead of asking for a direct value which could have been deemed sensitive information. The survey also used different cost definitions for different users. For carriers and shippers with own transport, shipping cost included the operating cost (i.e. fuel, driver, administration, insurance) and possible transshipment cost, if applicable. The cost for 3PLs and shippers without own transport contributed to the price paid for the transport service. Figure 4-8 and 4-9 show the screen capture of the shipping cost for different users. 


\section{FLORIDA FREIGHT SURVEY}

What was the approximate cost of shipping?

It includes transportation operating costs (which may include fuel, driver, administration, insurance, etc.) and possible transshipment costs (excluding initial loading and final unloading)

(Please provide either a value or an appropriate range)

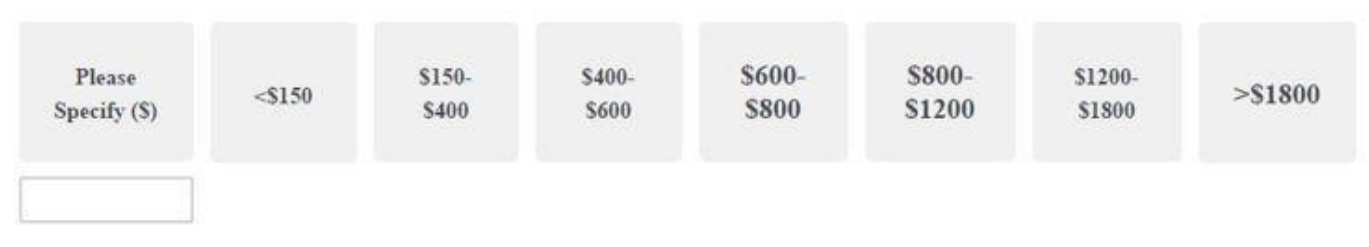

Figure 4-8 Sample screen capture: shipping cost (carriers \& shippers with own transport)

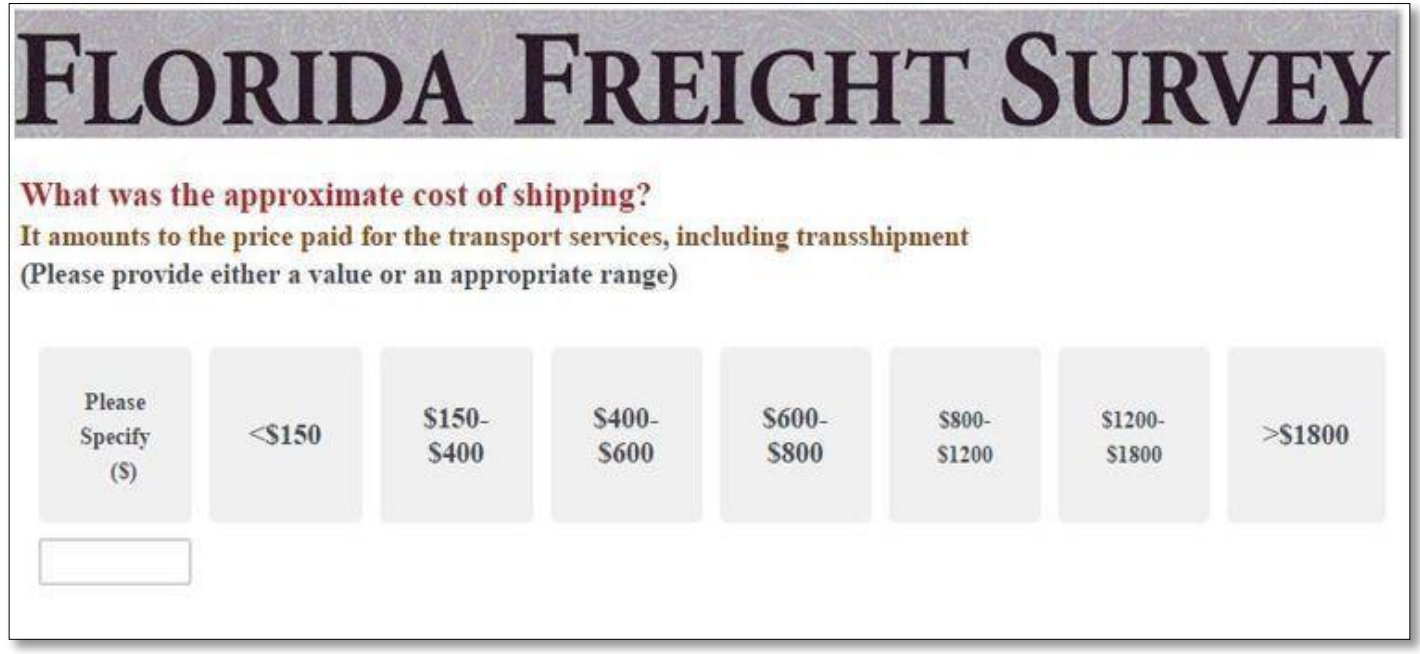

Figure 4-9 Sample screen capture: shipping cost (3PL \& shippers without own transport)

Information about other features of the shipment was collected next, including shipping duration and shipment size, as shown in Figure 4-10. 


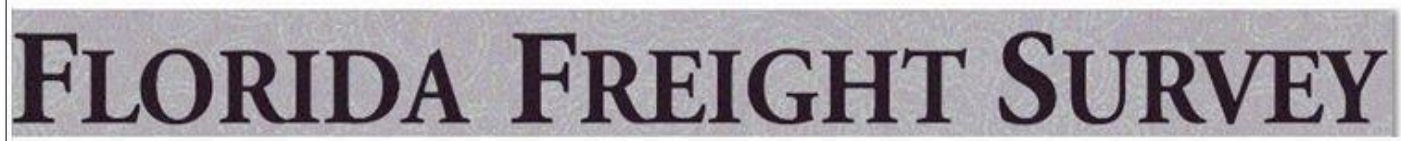

What was the shipping duration?

(Please provide either a value or an appropriate range)

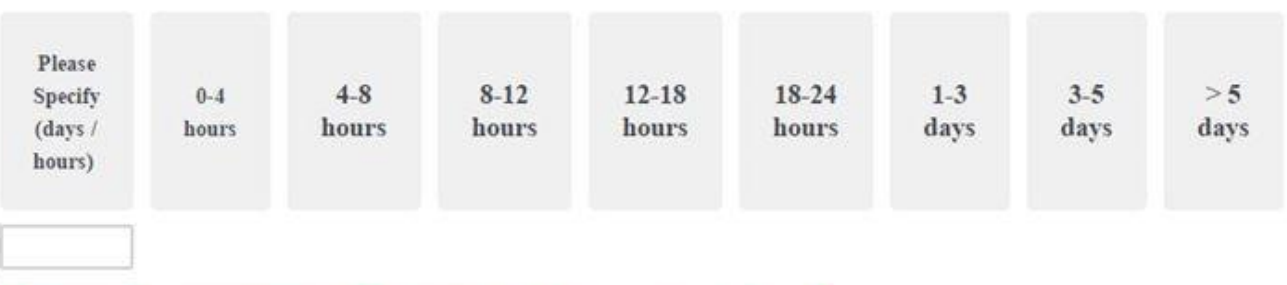

What was the approximate shipment size? (in tons/items/liters/ $\mathrm{ft}^{3}$ )

Figure 4-10 Sample screen capture: shipping duration and shipment size

Finally, the details of delivery time or any provision for monetary penalty for late delivery specified in the contract were asked. Figure 4-11 shows the screen capture of these questions.

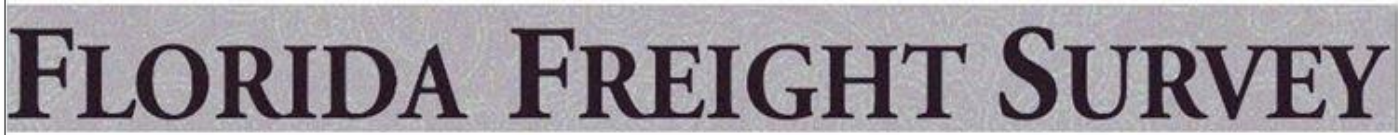

How is the delivery time defined by the clients or the contract?

Within certain hour(s) of day $\quad$ Within certain day (s) Within certain week (s)

Not applicable

Was there any provision for monetary penalty in case of late delivery?

Yes

No

Figure 4-11 Sample screen capture: delivery time and delay penalty 


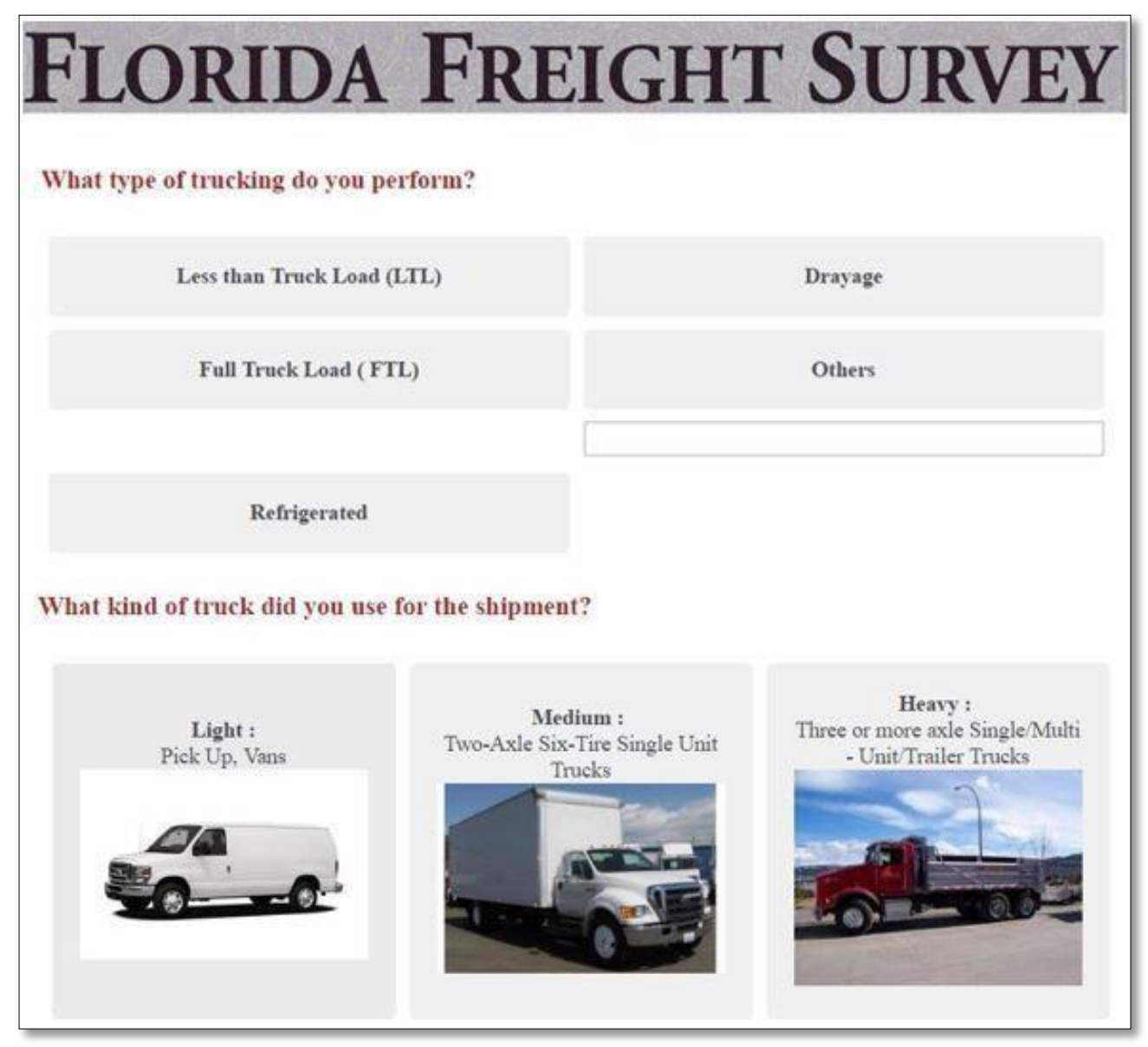

Figure 4-12 Sample screen capture: trucking type and truck size

As indicated earlier, this survey also included user specific questions. As an example, "Carriers" or "Shippers with own transport" who selected road as the primary mode were asked about the types of trucks and trucing type they used. Figure 4-12 shows the screen capture of the question.

\subsubsection{Part 3: Stated Preference Questions}

The SP questionnaires were primarily developed to gather information on how respondents would react to choices defined in the hypothetical scenarios. Each respondent was presented 6 or 7 SP choice questions based on the information provided by them in the "Base Shipment Information" section. Based on their preferences, this 
study assigned the respondent to the most appropriate set of questions (experiments), which differ by the number of attributes shown in the choice questions. Each respondent was asked whether they were willing to shift departure time or mode, then the survey took them to one of the four choice experiments accordingly:

- $\mathrm{C} 1$ - focused on within-mode trade-offs among transit time, cost, and reliability;

- $\mathrm{C} 2$ - focused on within-mode trade-offs among transit time, cost, reliability, and departure time;

- C3 - focused on cross-mode trade-offs between roadway and railway shipment based on transit time, cost, travel time reliability, service flexibility and probability of shipment damage.

- $\quad$ C4 - focused on cross-mode trade-offs between roadway and railway based on transit time, cost, travel time reliability

\subsubsection{Introductory Note and Qualification questions for SP experiment types}

Similar to the previous part, this section started with an introductory note describing the probable reasons of enhanced or deteriorated shipment related attributes, such as time, cost and reliability, and the likely benefits/impacts for them from the changes of these attributes. This was followed by a set of qualification questions based on which the respondents were assigned to the most appropriate choice experiments. 
At this stage, the survey mainly collected information on whether the respondents shipped goods during peak hours and if they had any alternative mode available to them for the shipment, and if so, whether they were willing to consider shifting to off-peak hours or the other mode.

Figure 4-13 shows the screen capture of the introductory note and qualification questions.

In the following sections, you will be presented with various hypothetical scenarios, each has two or three shipping alternatives, with varying levels of transit time, shipment cost, reliability or departure time period. In the hypothetical scenarios, you will find some alternatives may have higher or lower transit time, cost or travel time reliability compared to other alternatives. You can think of the following reasons behind these:

1. The increase in transit time, or decrease in transit time reliability may be the result of increased traffic congestion, incidents, or construction etc, whereas the increase in shipment cost could be due to the use of longer route or a toll road.

2. The decrease in transit time or the increase in transit time reliability conld be due to improvement in the infrastructure, or other strategies to improve level of service.

3. Any gain in transit time saving means that you could pay less for operating cost, including fuel cost, driver and staff wage.

4. In case of improved reliability in transportation network, you may plan for more services or consolidating multiple deliveries, increasing your productivity: On contrary, decrease in reliability or unexpected delay in transit time may result in product deterioration, financial penalty or insurance claim, reputation, running out of stock, etc.

Do you typically transport goods during peak hours (7:00 AM to 9:59 AM and 4:00 PM to 6:59 PM)?

Yes

No

Figure 4-13 Sample screen capture: introduction and qualification for experiments

Figure 4-14 shows the screen capture of the questions regarding the willingness to shift departure time and mode. 


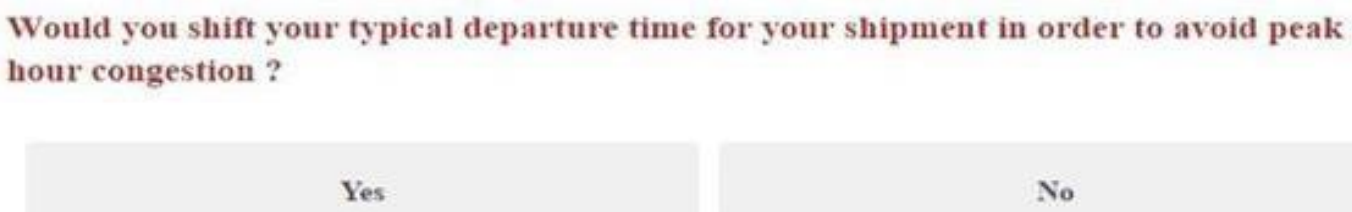

Did you have any alternative mode for the recent/typical shipment mentioned above?

Yes

Yes

Would you consider changing your mode for this typical /recent shipment in the future, if better service is provided?

No

\section{Figure 4-14 Sample screen capture: willingness to shift departure time and mode}

\subsubsection{Tutorial}

This survey employed a short tutorial for the purpose of educating the respondents about different attributes used to define alternatives in the choice questions. In the tutorial, respondents were asked to select one of the two alternatives shown to them, followed by an explanation of the alternatives they had chosen. Figure 4-15 shows the screen capture of the tutorial choice questions. 


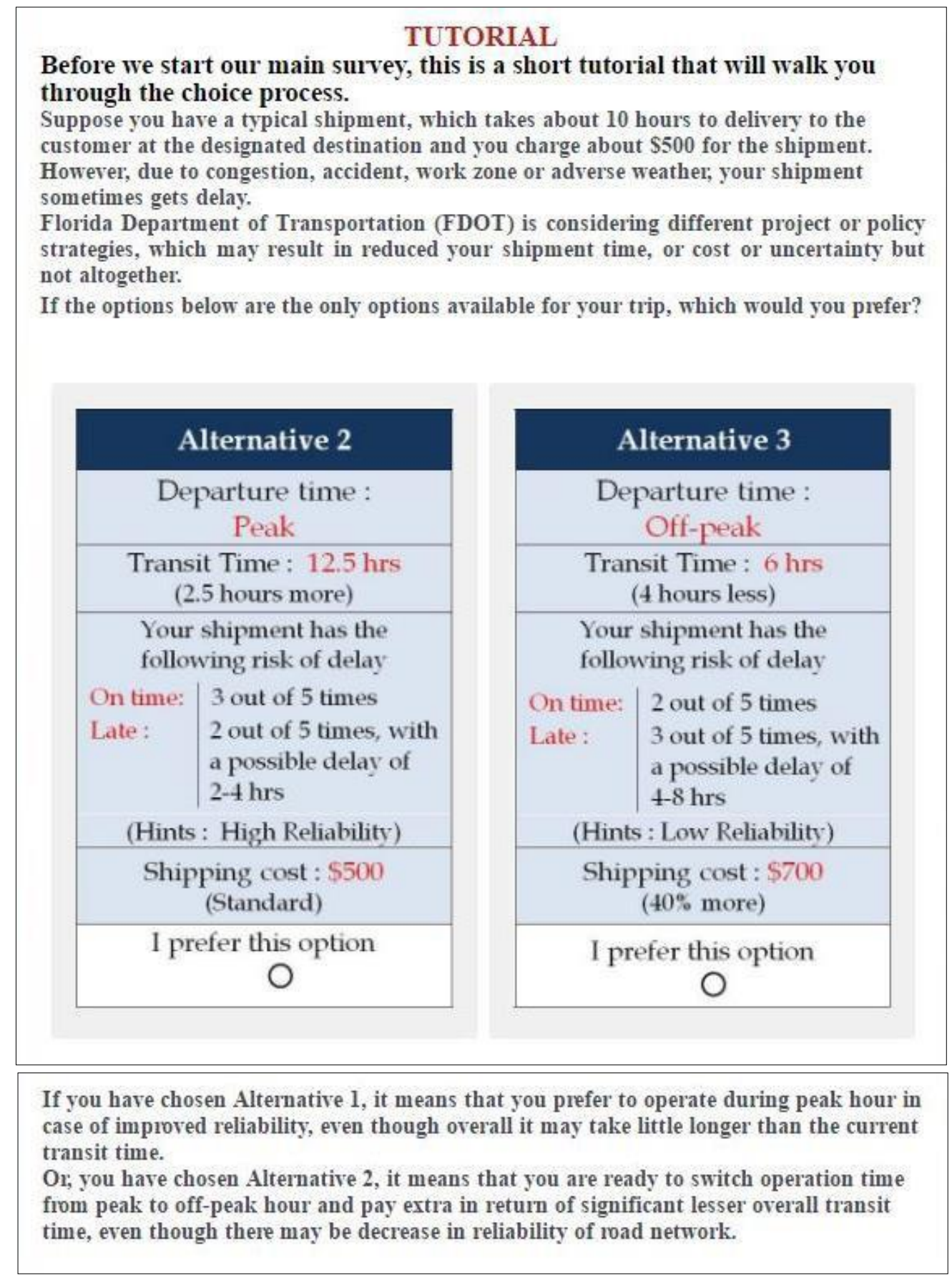

\section{Figure 4-15 Sample screen capture: tutorial question}

\subsubsection{Attitudinal Questions}

Before starting the main SP survey, this study collected information regarding the degree of importance users put on different transport related attributes. This task helped 
understand the respondent's attitudinal view towards transport related attributes and also made the respondents aware of the trading attributes in the main SP survey. Figure 4- 16 shows the screen capture of the attitudinal questions presented to the respondents.

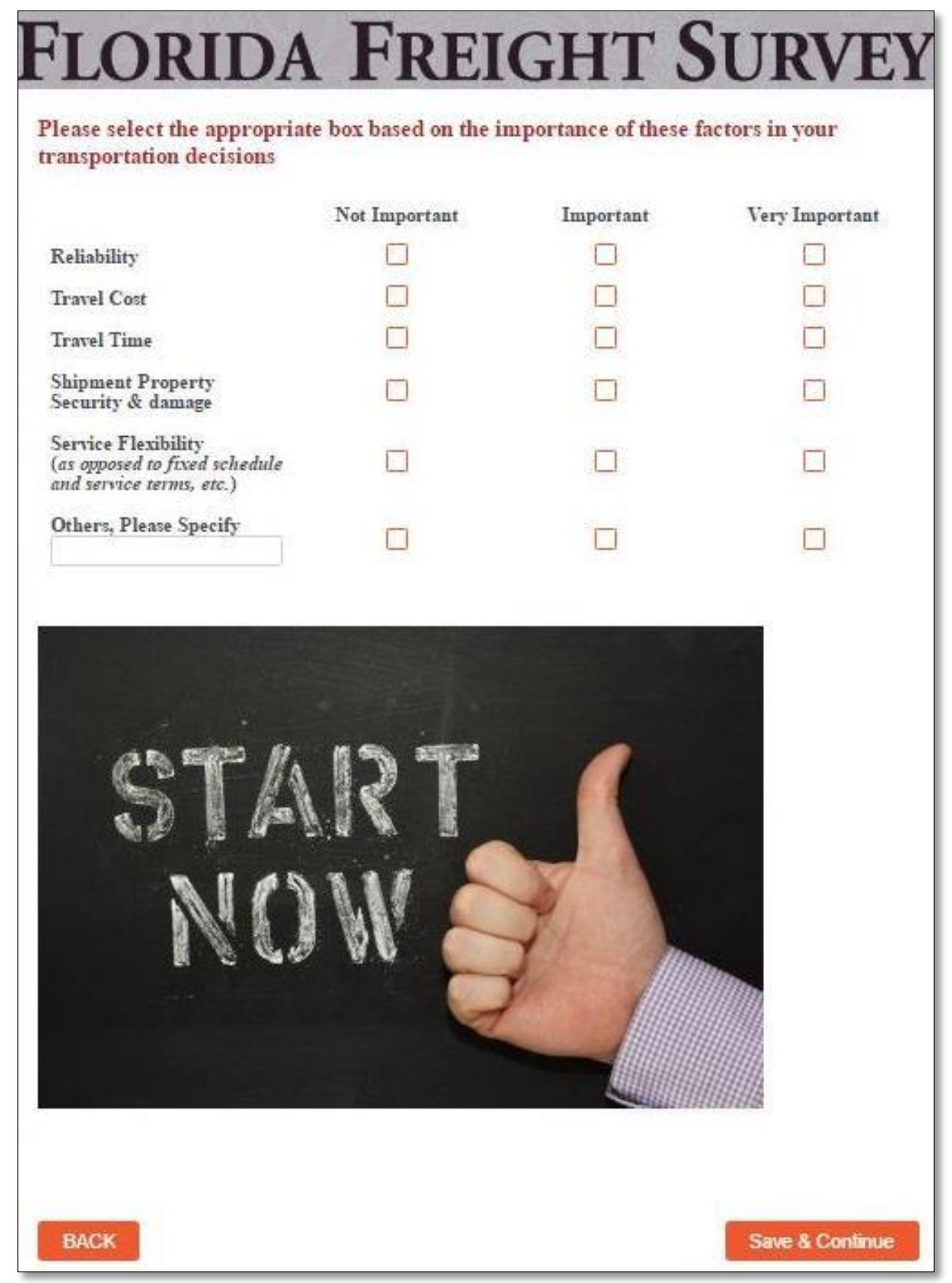

Figure 4-16 Sample screen capture: attitudinal questions 


\subsubsection{Main SP Choice Questions}

Based on the information provided by the respondents in Part 2: Base Shipment information, the respondents were assigned to different experiment types. SP choice questionnaires of these experiments included up to three alternatives, which are characterized by different combinations of attribute values, such as transit time, cost, reliability, service flexibility, and damage and security of the shipment.

Figure 4-17 to 4-20 show the screen captures of examples for the four experiment types. For those who did not show interest in changing neither departure time nor mode was assigned to C1 (Figure 4-17). Figure 4-18 and 4-19 present the sample choice questions for those who showed interest in changing either time (C2) or mode (C3), respectively. Figure 4-20 presents the sample SP choice for those for showed interest in changing both (C4).

For experiments $\mathrm{C} 1$ and $\mathrm{C} 2$, the choice alternatives were defined by transit time, cost, reliability and departure time (for C2 only). Experiments C3 and C4 mainly focused on the trade-off between road and rail modes, and additional attributes were introduced in the choice questions, including service flexibility and damage risk. 
If the options below are the only options available for your trip, which would you prefer?
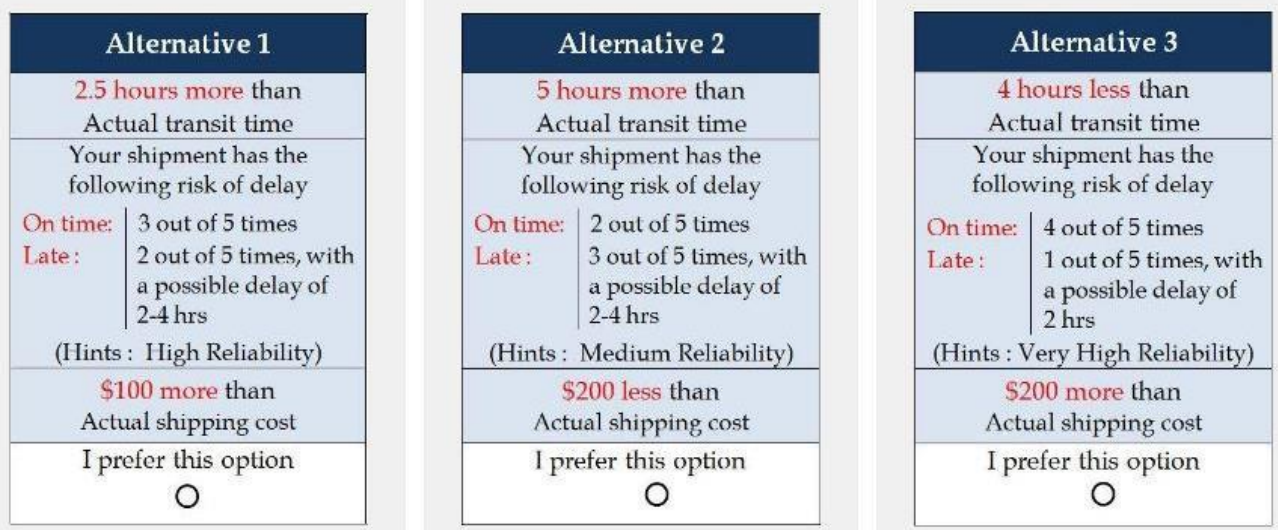

Figure 4-17 Sample screen capture: an example of SP choice question for $\mathrm{C} 1$ experiment

If the options below are the only options available for your trip, which would you prefer?
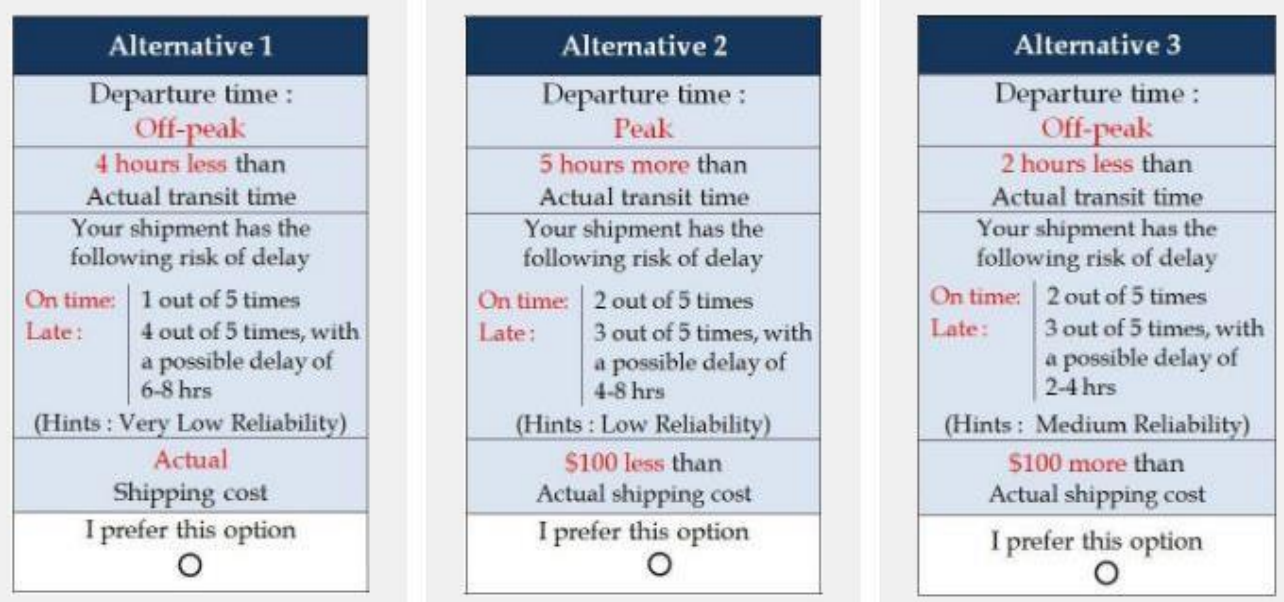

Figure 4-18 Sample screen capture: an example of SP choice question for C2 experiment 
If the options below are the only options available for your trip, which would you prefer?

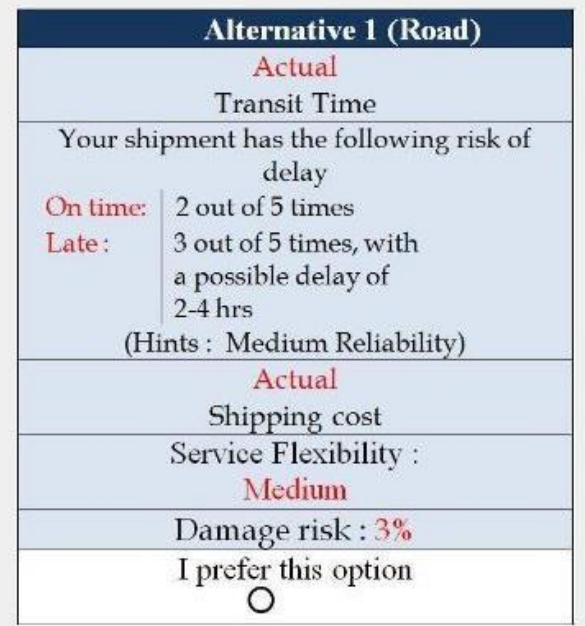

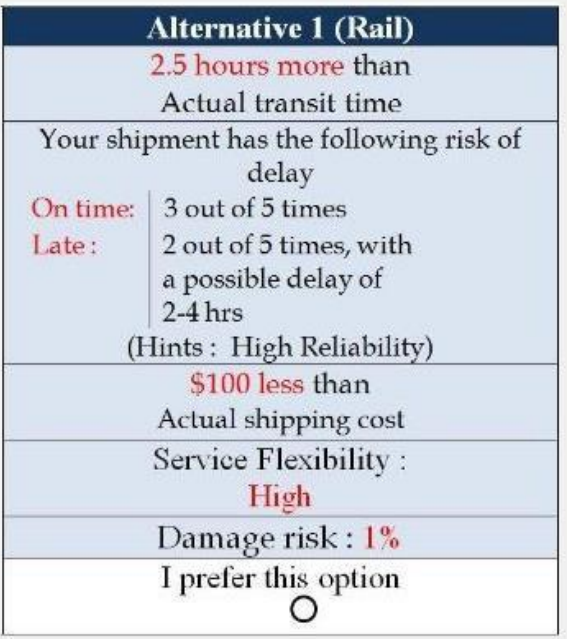

Figure 4-19 Sample screen capture: an example of SP choice question for C3 experiment

If the options below are the only options available for your trip, which would you prefer?

\begin{tabular}{|c|c|}
\hline & $\begin{array}{l}\text { Alternative } 1 \\
\text { (Road) }\end{array}$ \\
\hline \multicolumn{2}{|c|}{$\begin{array}{l}\text { Departure time: } \\
\text { Off-peak }\end{array}$} \\
\hline \multicolumn{2}{|c|}{$\begin{array}{l}4 \text { hours less than } \\
\text { Actual transit time }\end{array}$} \\
\hline \multicolumn{2}{|c|}{$\begin{array}{l}\text { Your shipment has the } \\
\text { following risk of delay }\end{array}$} \\
\hline $\begin{array}{l}\text { On time: } \\
\text { late: } \\
\text { (Hints: V }\end{array}$ & $\begin{array}{l}4 \text { out of } 5 \text { times } \\
1 \text { out of } 5 \text { times, with } \\
\text { a possible delay of } \\
2 \text { hrs } \\
\text { ery High Reliability) }\end{array}$ \\
\hline \multicolumn{2}{|c|}{$\begin{array}{l}\$ 200 \text { more than } \\
\text { Actual shipping cost }\end{array}$} \\
\hline \multicolumn{2}{|c|}{$\begin{array}{c}\text { Service Flexibility: } \\
\text { Low }\end{array}$} \\
\hline \multicolumn{2}{|c|}{ Damage risk: $1 \%$} \\
\hline I pre & $\begin{array}{l}\text { efer this option } \\
0\end{array}$ \\
\hline
\end{tabular}

\begin{tabular}{|c|c|}
\hline \multicolumn{2}{|c|}{$\begin{array}{c}\text { Alternative } 2 \\
\text { (Rail) }\end{array}$} \\
\hline \multicolumn{2}{|c|}{$\begin{array}{c}\text { Departure time: } \\
\text { Peak }\end{array}$} \\
\hline & $\begin{array}{c}\text { Actual } \\
\text { Transit Time }\end{array}$ \\
\hline $\begin{array}{l}\text { Your } \\
\text { follo }\end{array}$ & $\begin{array}{l}\text { shipment has the } \\
\text { wing risk of delay }\end{array}$ \\
\hline $\begin{array}{l}\text { On time: } \\
\text { Late: } \\
\text { (Hint }\end{array}$ & $\begin{array}{l}2 \text { out of } 5 \text { times } \\
3 \text { out of } 5 \text { times, with } \\
\text { a possible delay of } \\
2-4 \text { hrs } \\
\text { s: Low Reliability) }\end{array}$ \\
\hline & $\begin{array}{l}\text { Actual } \\
\text { Shipping cost }\end{array}$ \\
\hline Serv & $\begin{array}{l}\text { ice Flexibility : } \\
\text { Medium }\end{array}$ \\
\hline $\mathrm{Da}$ & mage risk : $3 \%$ \\
\hline $\mathrm{I}_{\mathrm{pl}}$ & efer this option \\
\hline
\end{tabular}

\begin{tabular}{|c|}
\hline $\begin{array}{c}\text { Alternative } 3 \\
\text { (Road) }\end{array}$ \\
\hline $\begin{array}{c}\text { Departure time : } \\
\text { Peak }\end{array}$ \\
\hline 2.5 hours more than \\
Actual transit time
\end{tabular}

Figure 4-20 Sample screen capture: an example of SP choice question of $\mathrm{C} 4$ experiment 
As can be seen on the screen capture for the choice questions, the SP design considered the reference shipment information (travel time and travel cost) provided by each participant as the base (actual/current) alternative and adjusted the attribute values around it for the construction of other alternatives.

\subsubsection{Validation Question}

After the SP choice questions, the respondents were asked whether they had considered all the attributes or not. These questions were useful for validating the responses. Figure 4-21 shows the screen capture of the validation question.

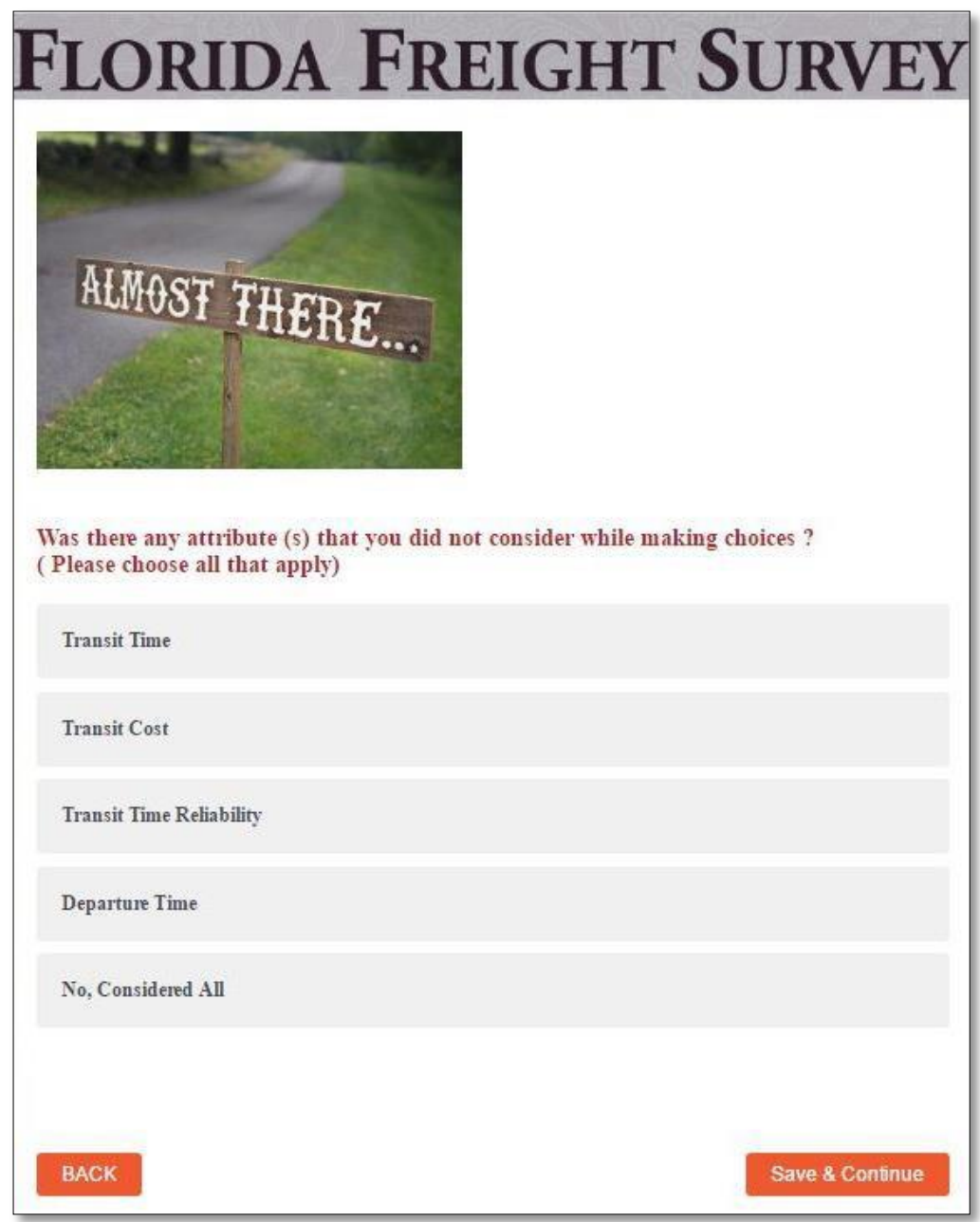

Figure 4-21 Sample screen capture: validation question 


\subsubsection{General Questions (Optional)}

The final section of the survey was optional for the respondents. This part focused on collecting background information of the firms and the business. The questions include the frequency of late out-bound shipment, followed by number of employees in the firm, and the percentage of shipment under delivery pressure. Figure 4-22 shows the screen capture of the questions in this part of the survey.

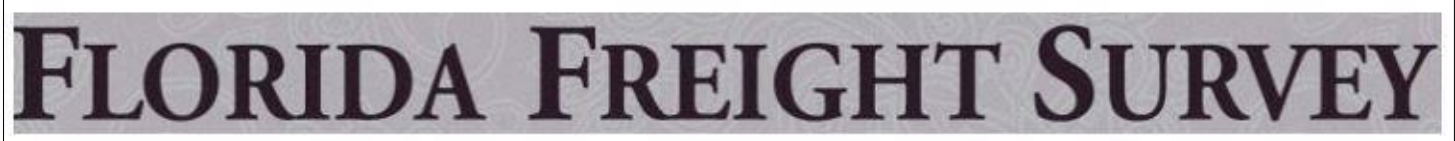

How often are your out-bound shipment late (out of 10 times)?

Never

1-3

4-7

$7-10$

How many employees does your firm have?

Less than 20

Greater than 20

What percentages of your shipments are on delivery pressure?

Less than $20 \%$

20 to $50 \%$

50 to $80 \%$

$80-100 \%$

Figure 4-22 Sample screen capture: firm background information 
Additionally, carriers and 3PLs were asked to indicate who was in charge of route decisions (i.e. whether to take toll road) and whether they would receive toll reimbursement from the client. These questions helped clarify the forces behind the choice.

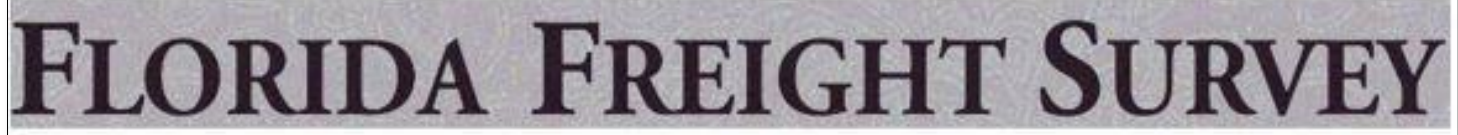

Within your company, who has the routing choice decisions (such as which route to take, or whether to take the toll road)?

Owner / Operator

The Driver

Depends on the situation ( please explain)

Do you get reimbursed for tolls from your client?

Yes

No

Figure 4-23 Routing and Toll related questions (Carriers \& 3PLs) 


\subsection{Survey Implementation}

The survey went live in January through May 2016. Various approaches were taken to promote the survey and recruit participants. Through collaboration with a number of freight associations, including the Florida Chamber of Brokers \& Forwarders (FCBF), the Florida Trucking Association (FTA) and the Miami-Dade Metropolitan Planning Organization (MPO), the survey link was sent to their members in monthly newsletters. A local marketing consultancy firm was also employed to recruit participants.

Although the survey was initially designed for a web-based approach, paperbased responses were also collected. Table 4-1 shows the completed responses by the survey method.

Table 4-1 Completed responses by survey method

\begin{tabular}{|c|c|}
\hline Survey Format & Completed Surveys \\
\hline Online & 74 \\
\hline Paper format & 85 \\
\hline Total & 159 \\
\hline
\end{tabular}

Table 4-2 displays the summary statistics of road users by the originally proposed market segment. Some cells have zero or very low responses. These groups need to be merged for model estimation to get statistically significant outcomes. More details are provided in the Model Estimation Chapter 5.

Table 4-2 Number of Survey Participants by Segment (Road Only)

\begin{tabular}{|c|c|c|c|c|c|c|c|c|}
\hline \multicolumn{4}{|c|}{ Shippers } & \multicolumn{4}{|c|}{ Carriers } & \multirow{3}{*}{ 3PL } \\
\hline \multirow{2}{*}{$\begin{array}{l}\text { Commodity } \\
\text { type }\end{array}$} & \multirow{2}{*}{$\begin{array}{l}\text { Delivery } \\
\text { Window } \\
\text { Pressure }\end{array}$} & \multicolumn{2}{|c|}{$\begin{array}{l}\text { Ownership of } \\
\text { Transport }\end{array}$} & \multirow{2}{*}{$\begin{array}{l}\text { Shipping } \\
\text { Distance } \\
\text { (Miles) }\end{array}$} & \multicolumn{3}{|c|}{ Truck Type } & \\
\hline & & No & Yes & & Light & Medium & Heavy & \\
\hline \multirow{2}{*}{ Perishable } & No & 10 & 6 & $<50$ & 1 & 2 & 2 & \multirow{3}{*}{7} \\
\hline & Yes & 2 & 1 & \multirow{2}{*}{$50-300$} & \multirow{2}{*}{1} & \multirow{2}{*}{6} & \multirow{2}{*}{12} & \\
\hline \multirow[t]{2}{*}{ Non-perishable } & No & 13 & 2 & & & & & \\
\hline & Yes & 1 & 0 & $300+$ & 0 & 9 & 75 & \\
\hline
\end{tabular}


Figure 4-24 shows the geographic distribution of the survey respondents. As shown in the figure, the survey sample covered major freight activity centers in Florida.

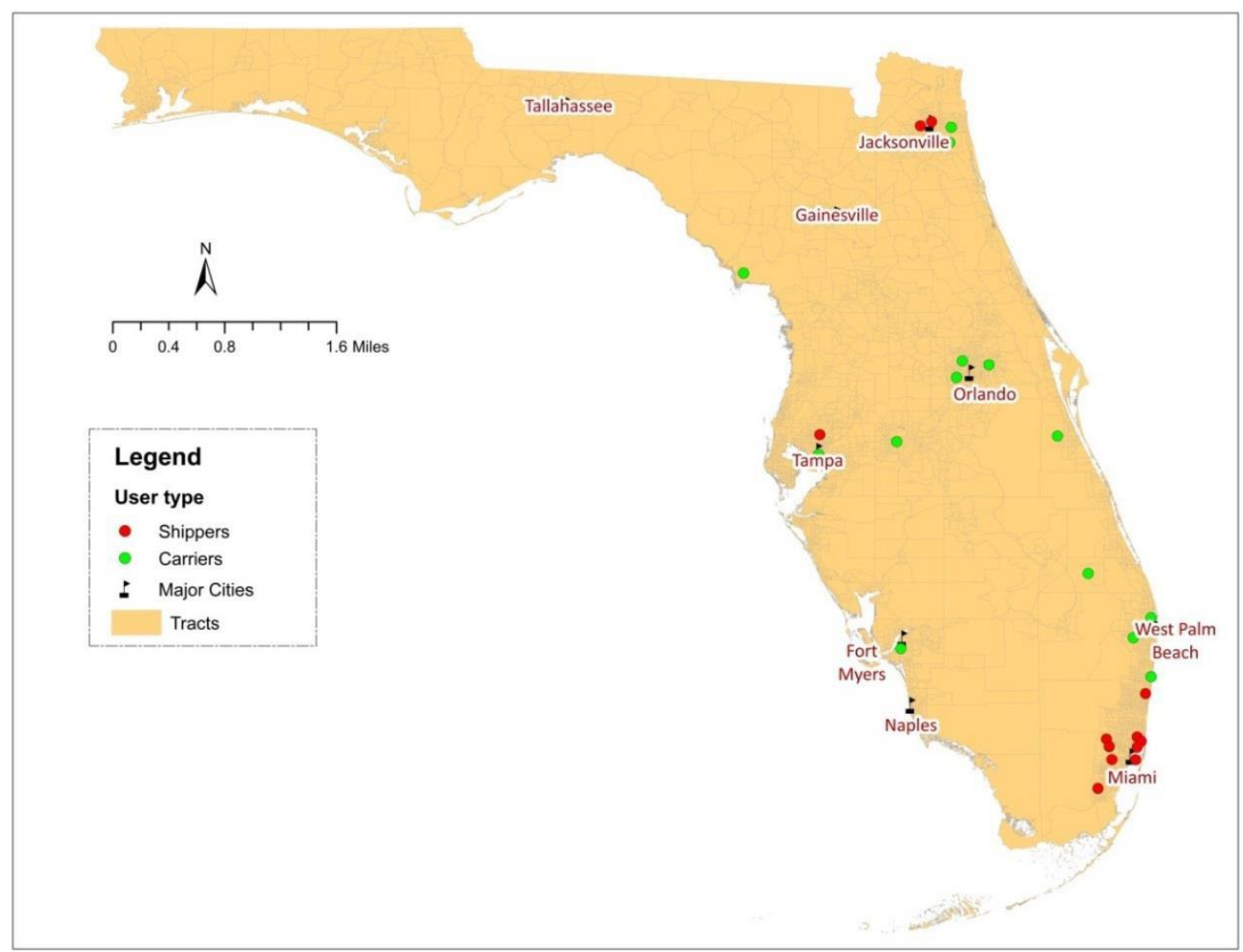

Figure 4-24 Spatial distribution of completed responses by user type

\subsection{Survey Results}

A total of 159 firms completed the survey. This chapter summarizes the survey results in three sections: base shipment characteristics, stated preference questions and general information. 


\subsubsection{Base Shipment Characteristics}

In this section, the respondents were asked to describe a recent/typical shipment. This included information related to mode, commodity type, shipping distance and duration, shipping cost, and other characteristics of the shipment.

\subsubsection{Mode}

Most of the respondents in this sample used road as the primary mode. Only 7 out of 159 respondents used other modes (two for Air and five for waterways). Table 4-3 shows the summary statistics of responses by user group and mode used. The survey did not capture any rail users.

Table 4-3 Number of Survey Participants by User Group and Mode

\begin{tabular}{|c|c|c|c|c|c|}
\hline User Type & Road & Rail & Air & Waterways & Total \\
\hline Carrier & 108 & 0 & 0 & 5 & 113 \\
\hline Shippers with own transport & 9 & 0 & 0 & 0 & 9 \\
\hline Shippers w/o own transport & 26 & 0 & 0 & 0 & 26 \\
\hline 3PL/ Forwarders & 7 & 0 & 2 & 2 & 11 \\
\hline Total & 150 & 0 & 2 & 7 & 159 \\
\hline
\end{tabular}

In the subsequent sections, analyses of responses from road users are first presented, and then outcomes of users from other modes are provided. Additionally, all tabulations and graphs used to summarize the analyses are segmented by user group, which include carriers, shippers with own transport, shippers without own transport and 3PLs.

\subsubsection{Commodity Type}

Nearly all road users (149 out of 150) responded to the questions when they were asked about the types of commodity shipped. As shown in Figure 4-25, carriers and 
shippers without own transport represented almost all industries. For both groups, food products had the highest share. On the other hand, most of the surveyed shippers and 3PL groups came from the agriculture industry, which were $66.7 \%$ and $42.9 \%$ respectively; followed by food products and miscellaneous products (indicated as "others" in the survey). The data showed that miscellaneous types mainly included auto parts, electronics, and heavy machinery equipment.

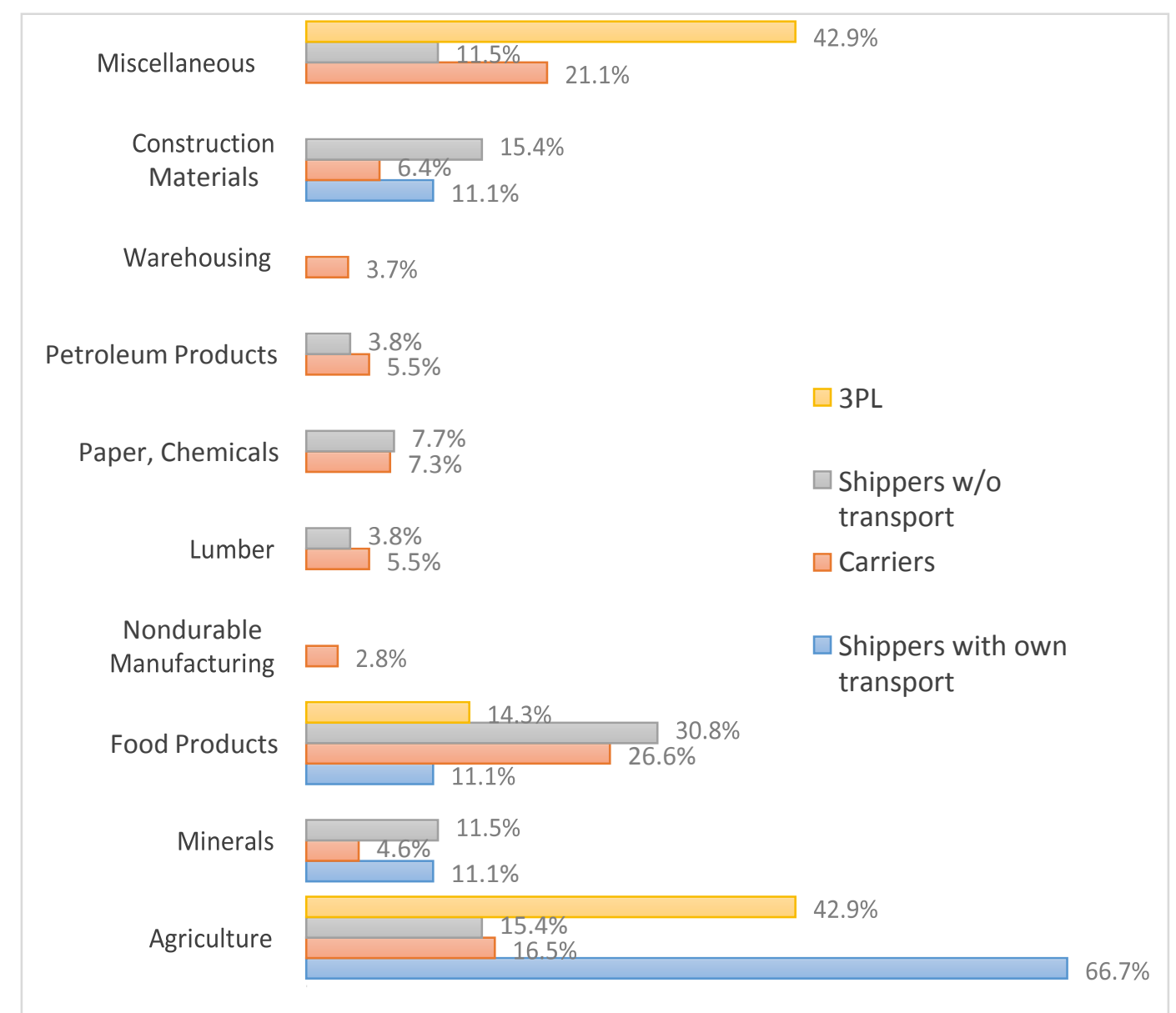

\section{Figure 4-25 Shipment by commodity type (road only)}

Users from waterways and air mode in the sample mainly transported food products, construction materials and miscellaneous types, except two in waterways where all types of commodities were transported. Table 4-4 provides the summary of commodity types transported by other mode users. 
Table 4-4 Commodity types transported by users from Waterways and Air

\begin{tabular}{|c|c|}
\hline Mode & Commodity Types ( number of responses) \\
\hline Waterways & Food products (3), Construction Materials (2), All types (2) \\
\hline Air & Miscellaneous : Auto parts , Medical equipment (2) \\
\hline
\end{tabular}

\subsubsection{Shipping Distance and Duration}

For all groups except shippers with own transport, the distances of typical (or recent) shipments were more than 300 miles. As shown in Figure 4-26, the share of long distance (>300 miles) shipment were $77 \%$ for carriers, $88 \%$ for shippers without transport and $71 \%$ for $3 \mathrm{PL}$ respectively. On the contrary, more than half $(55 \%)$ of the shippers with own transport reported a typical/recent shipment between 50 and 300 miles, while $33 \%$ of them reported a shipment greater than 300 miles and $11 \%$ reported a shipment within 50 miles.

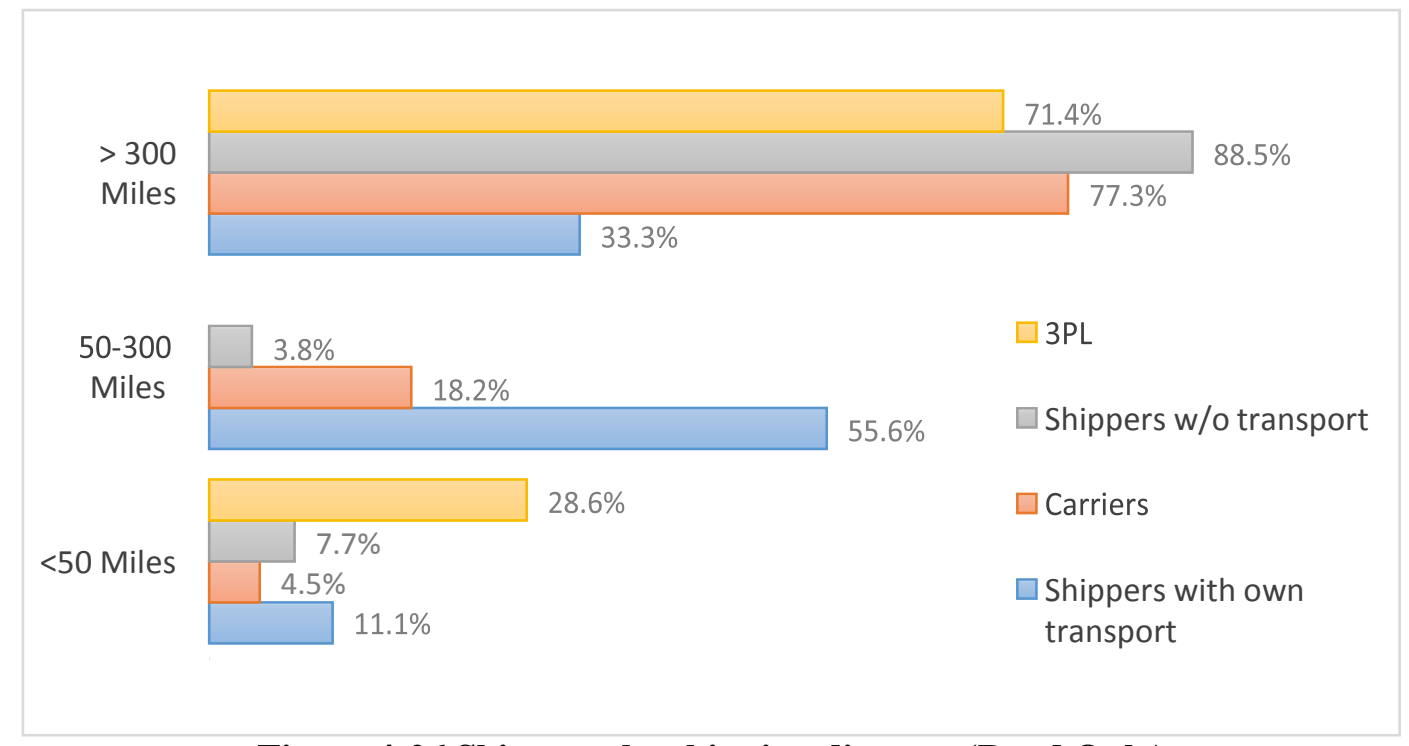

Figure 4-26 Shipment by shipping distance (Road Only) 
Figure 4-27 shows the sample distribution of road users by shipping duration. For carriers, most of the shipments were between 12 to 18 hours (42\%), followed by 8 to 12 hours (24\%), and 1 to 3 days (16\%). Similarly, a major share (58\%) of the shipment for shippers without own transport fell between 12 to 24 hours, with only $4 \%$ between 3 to 5 days and $15 \%$ between 1 to 8 hours. It was also seen that the shipments from shippers with own transport were either less than 12 hours or across multiple days, whereas the 3PLs mostly handled shipment of long durations (multi-day shipments).

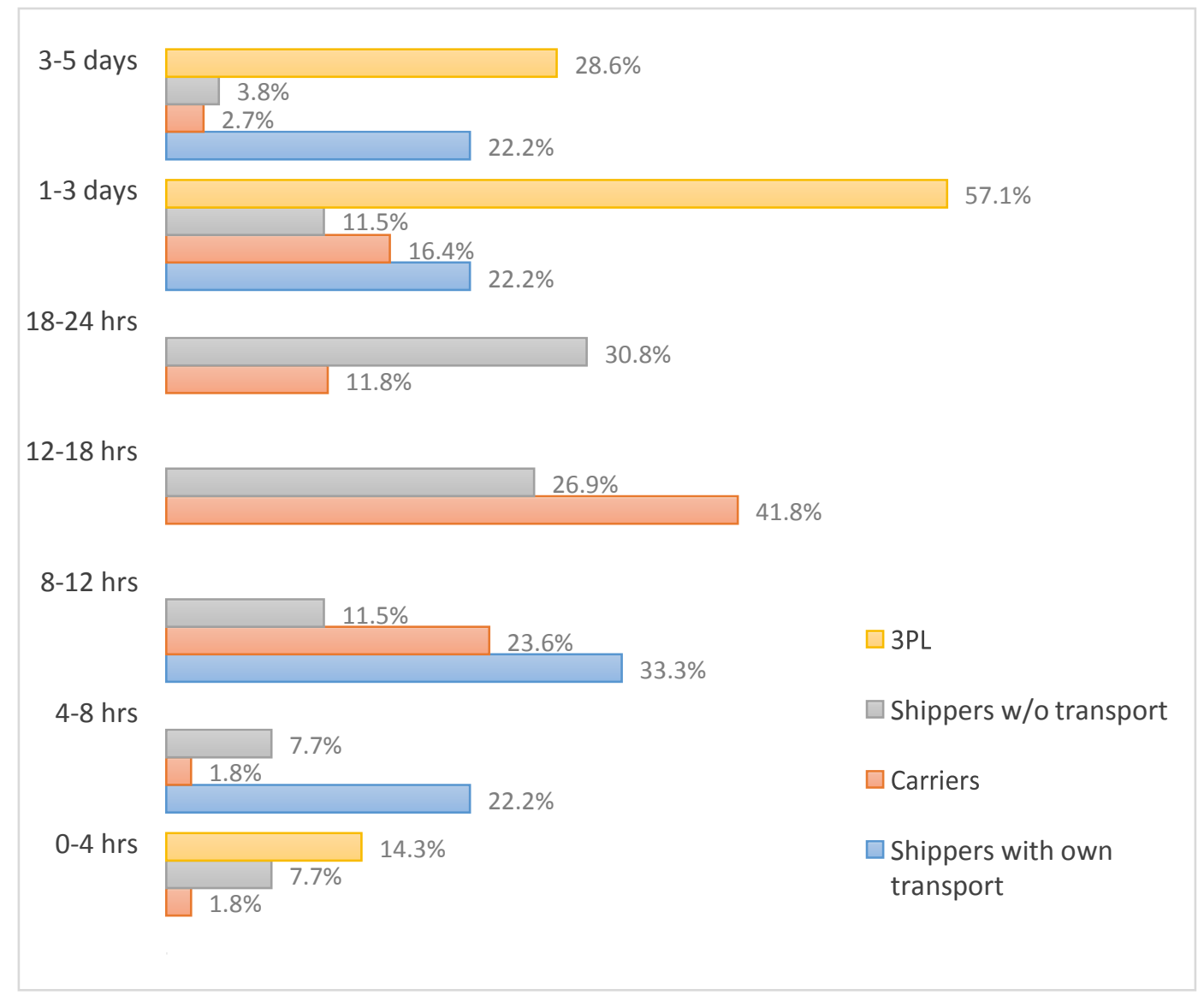

Figure 4-27 Shipment by shipping duration (Road Only) 


\subsubsection{Shipping Cost}

In the surveyed sample, the shipping costs for carriers and shippers with own transport covered a wide range as shown in Figure 4-28. The shipping costs of all shipments for shippers without own transport were below $\$ 400$, although more than half of their shipments took 12 to 24 hours. On the contrary, $50 \%$ of shipping cost for 3PL were more than $\$ 1800$, and probably related to the long-distance multi-day shipments.

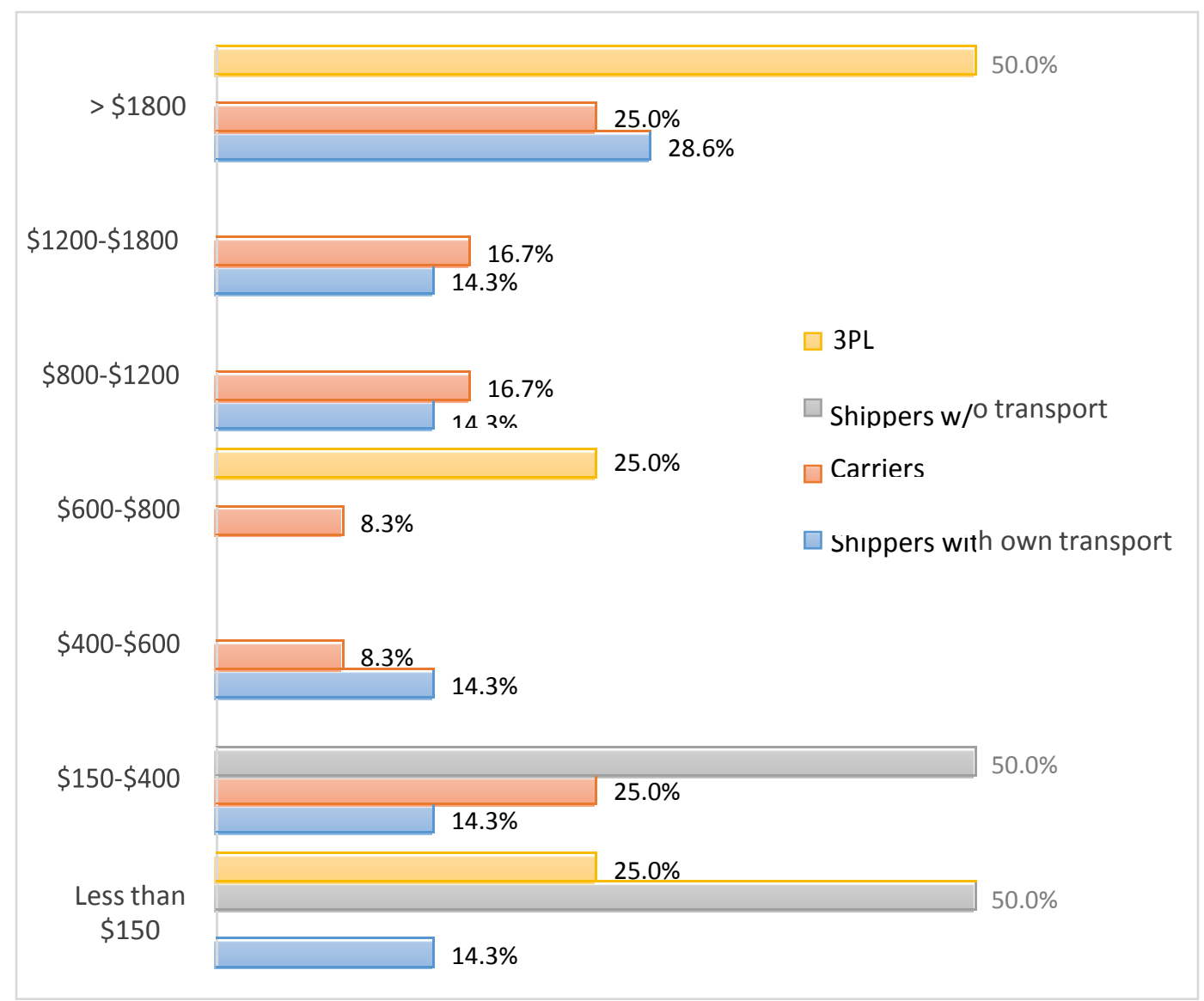

Figure 4-28 Shipment by Shipping Cost (Road Only) 


\subsubsection{Shipment Size}

The sample contains a wide range of shipment sizes and types. Most respondents (76\%) used pounds to describe their shipment size, which are summarized in Table 4-5. The mean weight of shipment for all groups except shippers with own transport weighed more than 40,000 lbs. (20 ton) in the sample.

Table 4-5 Shipping size by groups (lbs. only)

\begin{tabular}{|c|c|c|c|c|}
\hline & Transport & & Transport & \\
\hline Min & 6000 & 1000 & 500 & 1000 \\
\hline Max & 40000 & 80000 & 80000 & 80000 \\
\hline Mean & 23000 & 49291 & 61395 & 42500 \\
\hline Total Respondents & 2 & 92 & 21 & 4 \\
\hline
\end{tabular}

The sample also contains few shipments of other units, which includes gallon, items, pallets, and skids.

\subsubsection{Trucking and Truck Type}

In terms of truck type used, heavy trucks were used for a majority of the shipments among all groups. Figure 4-29 shows that about $80 \%$ of the shipments from carriers and 3PLs used heavy trucks. The shippers in this sample showed higher rates of using medium and light trucks than other groups, especially shippers without transport, where $25 \%$ of the shipments were carried by medium and light trucks, respectively. 


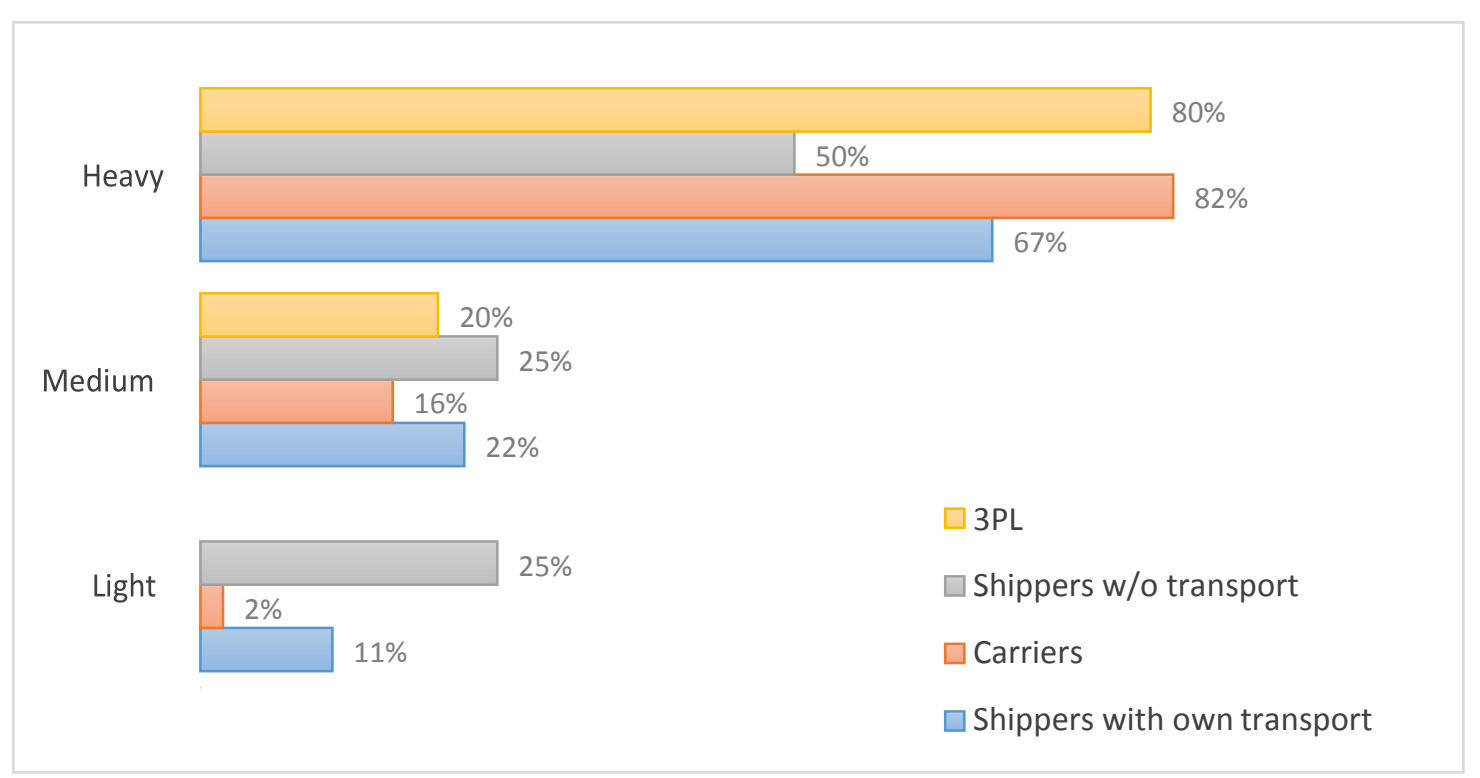

Figure 4-29 Shipment by Truck type (Road Only)

The results showed that trucking type for carriers and both groups of shippers were mostly of full truck load (FTL). $20 \%$ of shippers with own transport used less than truck load (LTL) and 25\% of carriers employed refrigerated method. On the other hand, LTL and refrigerated trucking type comprised the major share of shipments for the 3PL. The sample also contained very few shipments of drayage and other special types, as shown in Figure 4-30. 


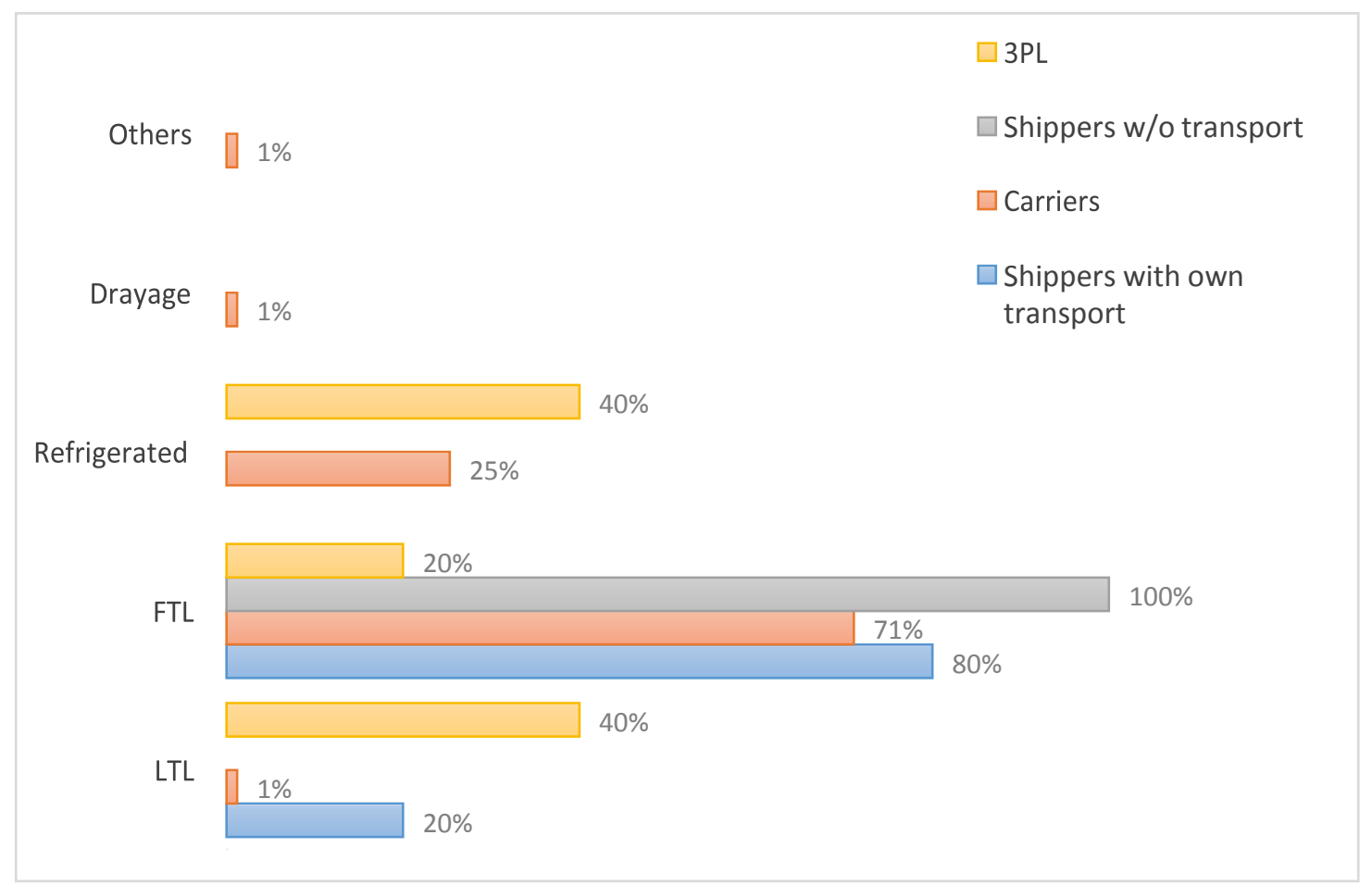

Figure 4-30 Shipment by trucking type (road only)

\subsubsection{Delivery Time Specification and Monetary Penalty for Delay}

Figure 4-31 presents how delivery time was specified for the shipments, which may have also impact the user's choices in view of travel time reliability. Except for 3PL, most of the shipments were required to be delivered within certain hours. For 3PL, the time window for $57 \%$ of the shipments was "within certain days," followed by "within certain hours," (28\%) and "within certain weeks." 


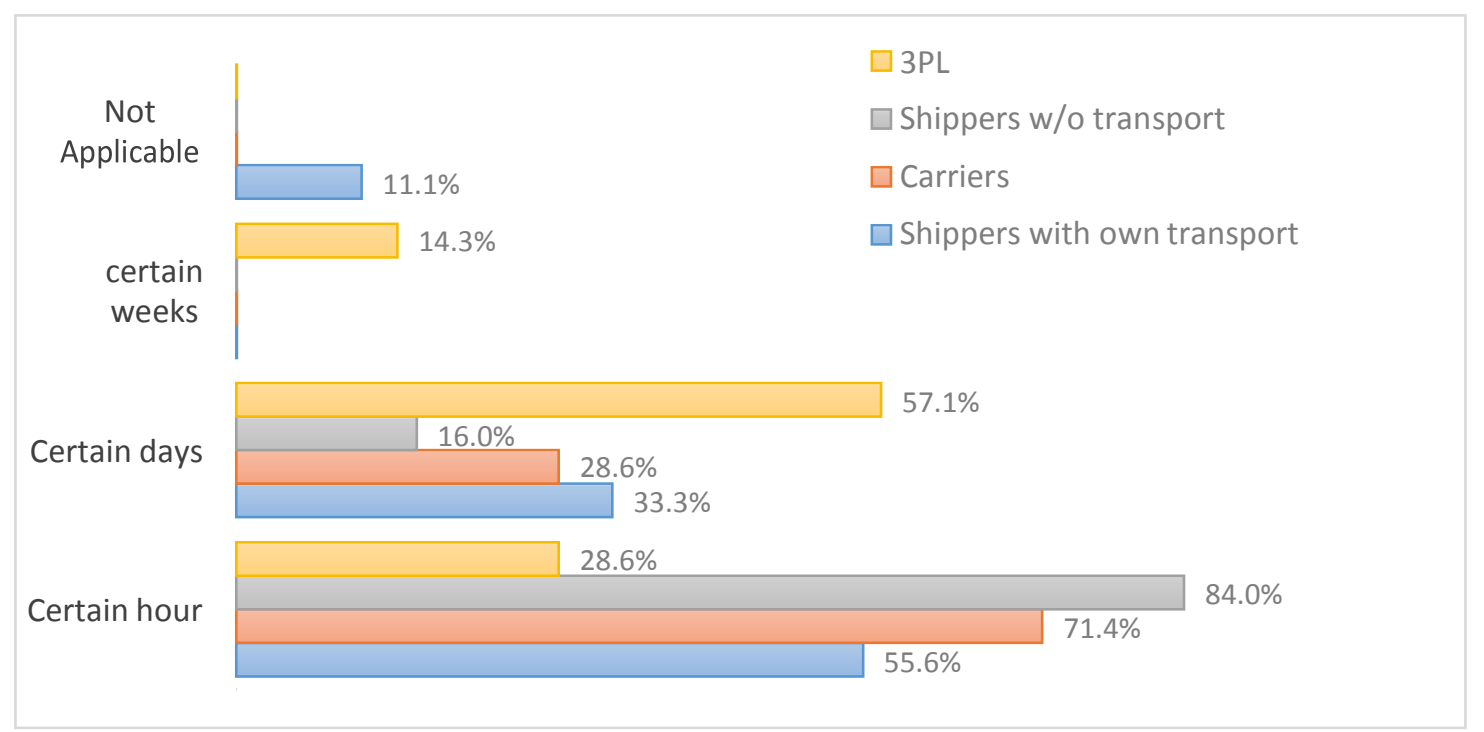

Figure 4-31 Shipment by delivery time specified in contract

In terms of whether a monetary penalty was imposed for the shipments, Figure 432 shows that a majority of the carriers and shippers (both groups) reported no provisions for late delivery, while only $11 \%$ of the shipments were bounded by late penalty. On the other hand, half of the shipments $(57 \%)$ for 3PL were subject to monetary penalty.

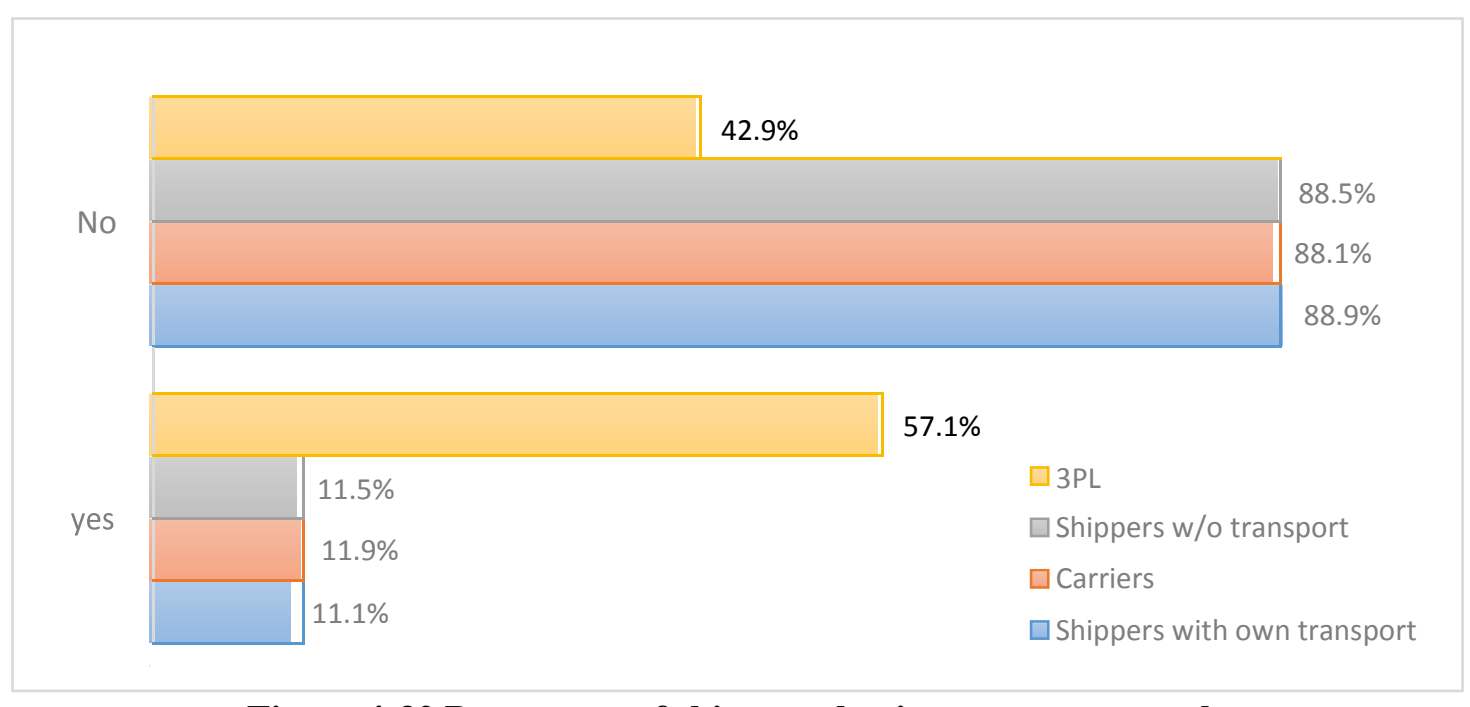

Figure 4-32 Percentage of shipment having monetary penalty 


\subsubsection{Stated Preference Choice Question}

\subsubsection{Attitudinal Questions}

Figures 4-33 to 4-37 summarize the general attitudes toward various transport related attributes, including shipping time, cost, reliability, security and damage, and flexibility. Forty-two percent of the respondents expressed their preferences toward shipping time, which are summarized in Figure 4-33. Among the respondents, only $7 \%$ of carriers and $20 \%$ of shippers with own transport stated that shipping time was not important to them.

Thirty percent of the respondents expressed their opinion on shipping cost, which are shown in Figure 4-34. The figure shows that about $80 \%$ of shippers with own transport viewed shipping cost as the most important, followed by carriers (69\%), 3PLs (50\%), and shippers without transport (26\%). About $6 \%$ of carriers and $11 \%$ of shippers without transport stated that shipping cost was important to them.

Thirty-one percent of the respondents expressed their opinions on travel time reliability, among them most of them (more than $80 \%$ ) viewed reliability as the most important, especially for carriers as shown in Figure 4-35.

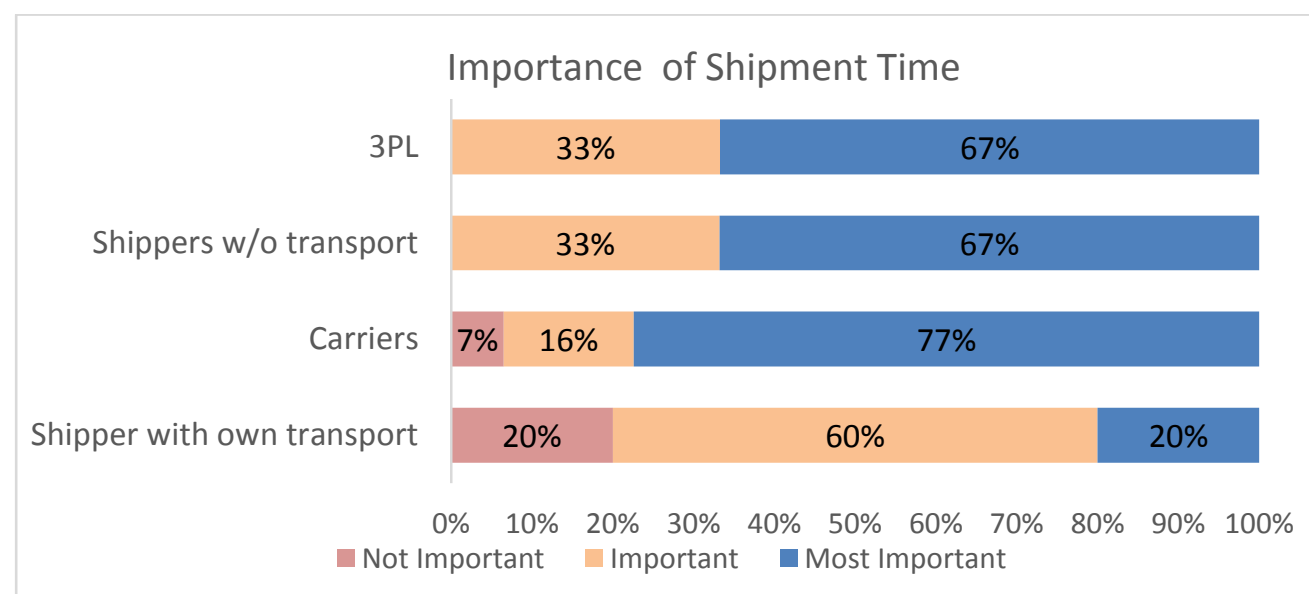

Figure 4-33 Importance of shipping time 


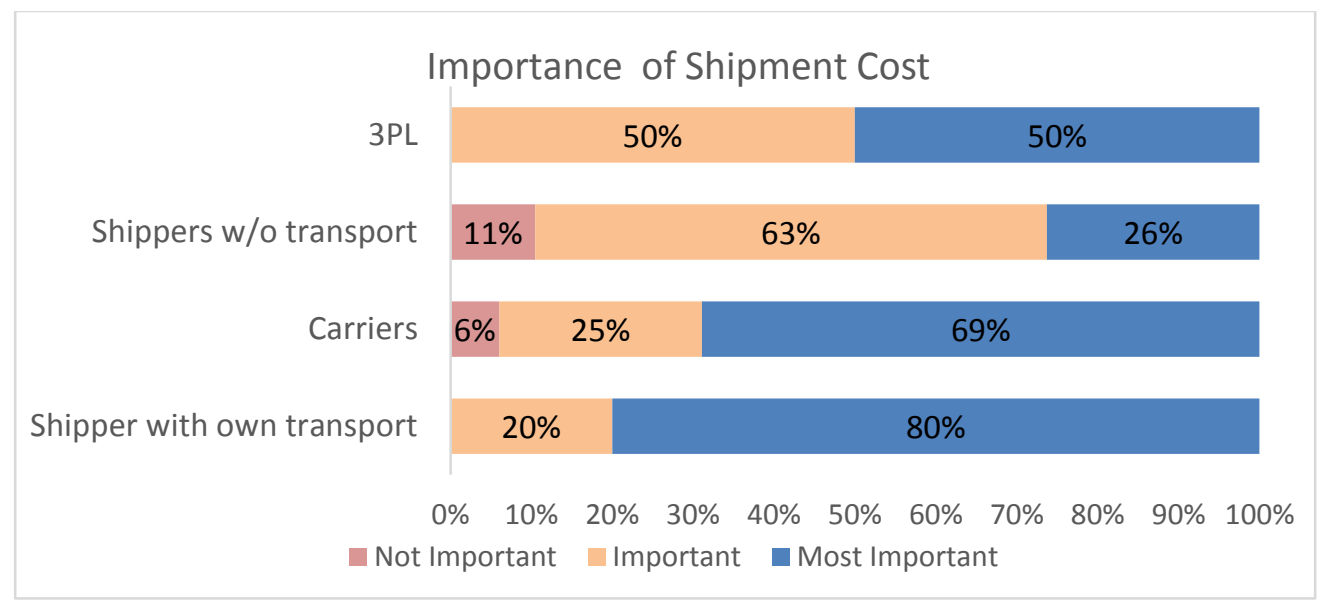

Figure 4-34 Importance of Shipping cost

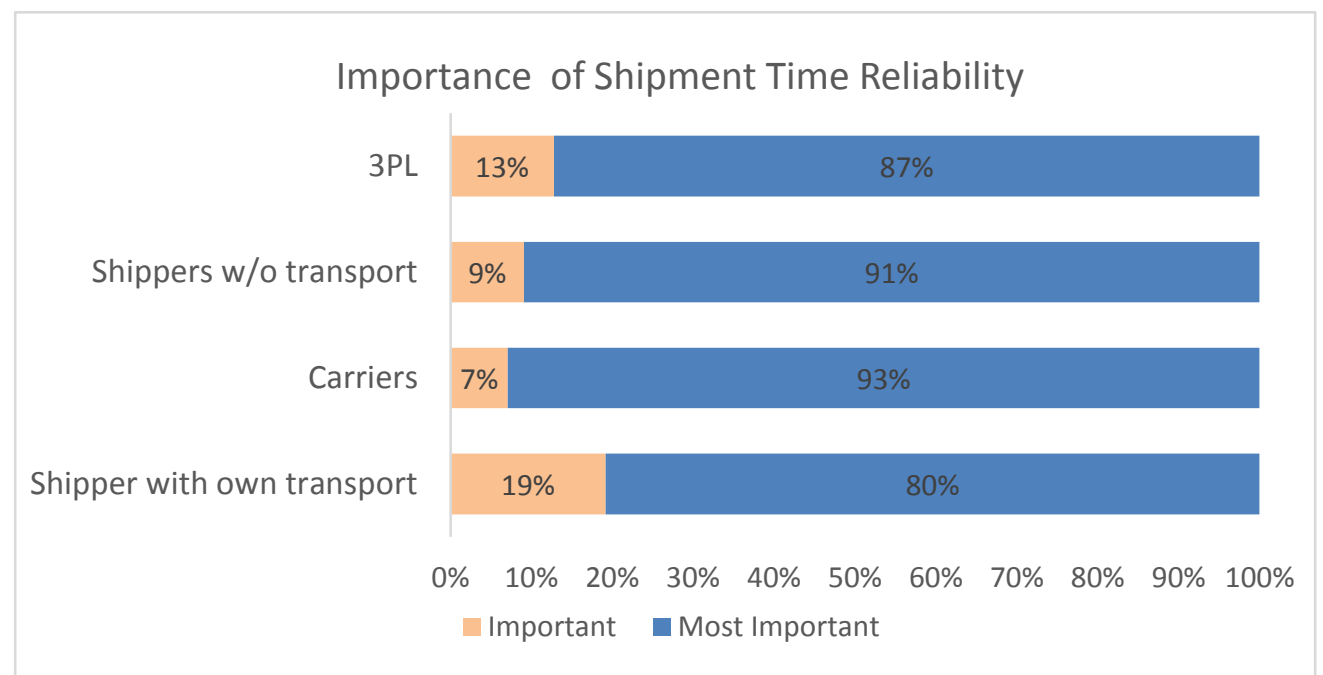

Figure 4-35 Importance of shipping time reliability

The survey also showed that shipment security was important for most of the respondents. As shown in Figure 4-36, shippers without transport and carriers placed a relatively higher importance on security compared to other groups. 
Importance of Shipment Security \& Damage

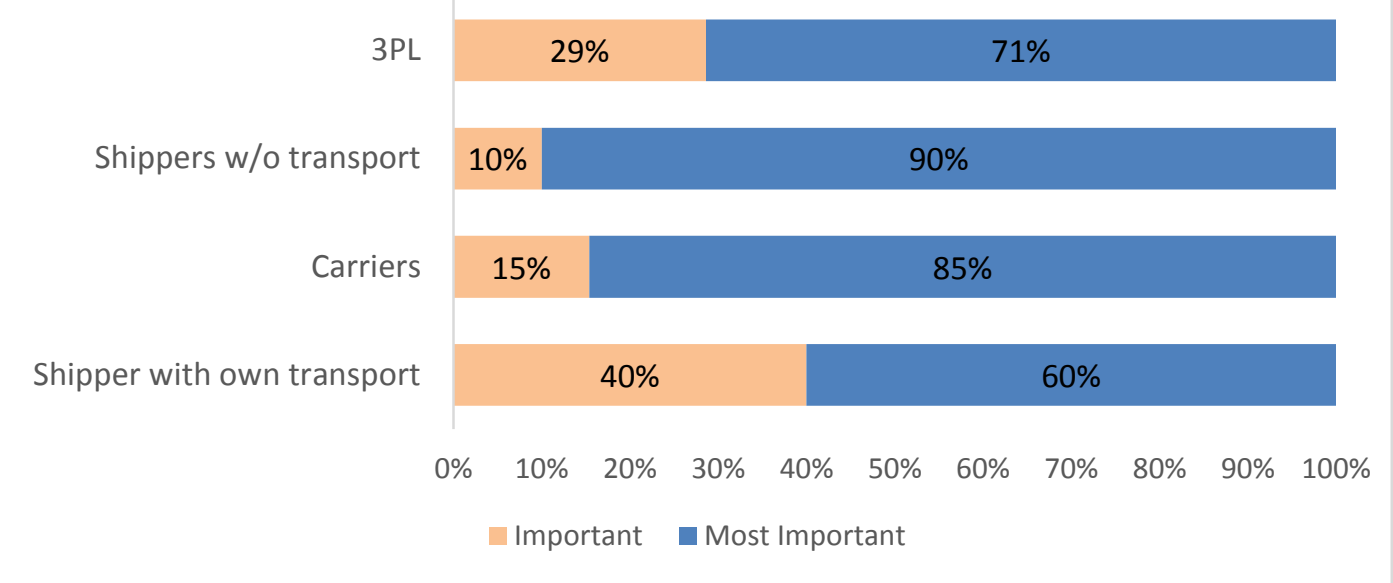

Figure 4-36 Importance of security and damage

Figure 4-37 presents the level of importance on service flexibility for the $23 \%$ of the respondents who stated their opinion towards service flexibility. The result showed that $80 \%$ of shippers with own transport viewed service flexibility as the most important, a much higher shared compared to other groups.

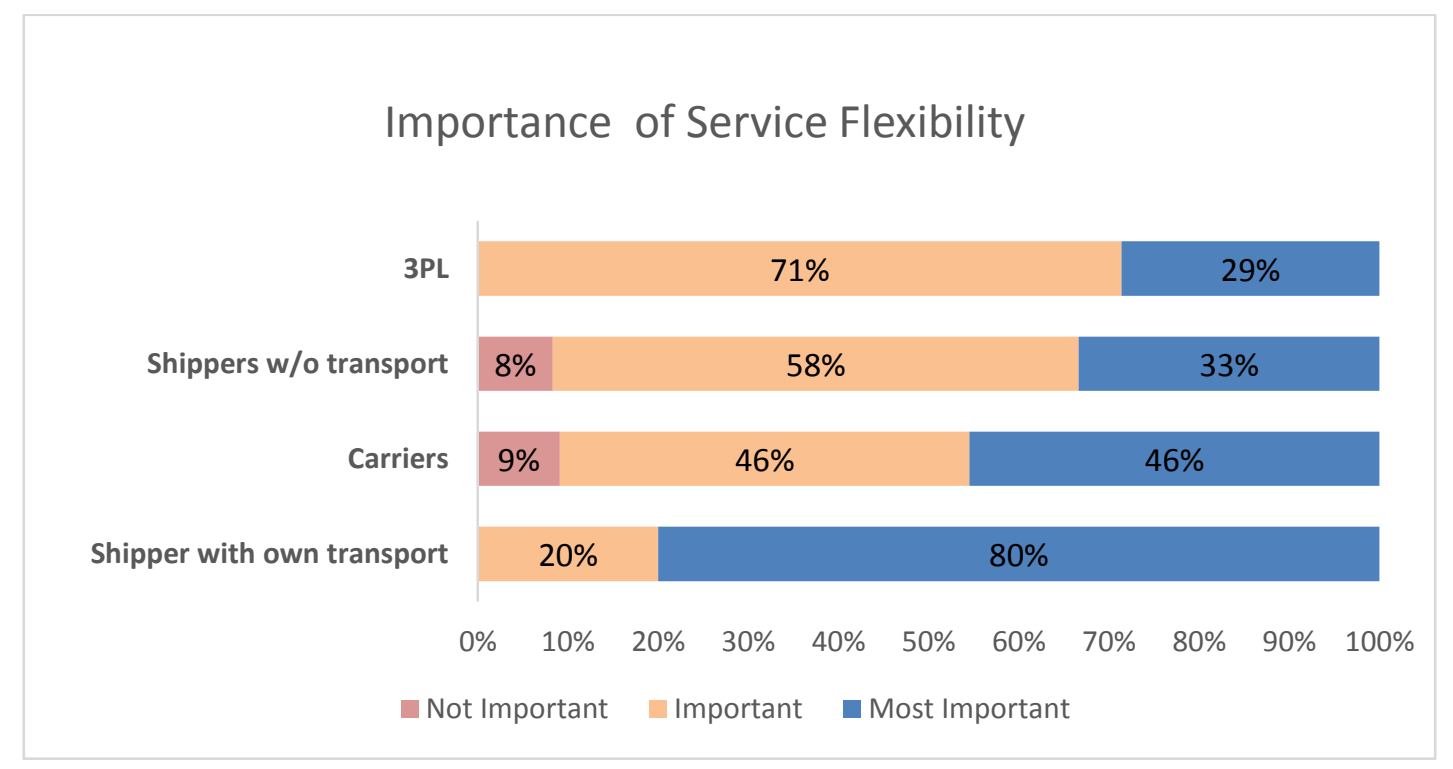

Figure 4-37 Importance of service flexibility 


\subsubsection{Trade-Off}

In SP surveys, it is important that respondents trade-off the attributes in their decision-making. In this regard, result shows that only 14 respondents (out of 150 road users) always chose the fastest option. Additionally, the survey responses were checked for respondents who always chose the left option, and found only two such instances. Table 4-6 shows the summary of the analyses on trading behavior. However, due to the limitation of the small sample size, these responses are kept for model estimation.

Table 4-6 Trading Behavior

\begin{tabular}{|c|c|}
\hline Scenarios & Number ( Percentage ) \\
\hline Always choose the cheapest option & $0(0 \%)$ \\
\hline Always choose the fastest option & $14(9 \%)$ \\
\hline
\end{tabular}

\subsubsection{Validation Questions}

When asked about the attributes they considered in SP choice making, 140 (88\%) of respondents answered to this question. One hundred and thirty-three (84\%) reported that they considered all the attributes, which includes shipping time, cost, reliability and (or) departure time. Only few respondents (4\%) considered cost, time or reliability while making a choice. 


\subsubsection{General Information (Optional part)}

This part of the survey was made optional to reduce respondent burden and make the survey more appealing to the respondents. Most of the questions of this part are related to the background information of the firms and their business.

\subsubsection{Frequency of outbound shipment delay}

Sixteen percent of the respondents reported frequency of shipment delay. Figure 4-38 shows that delays are regularly experienced by all groups, more than $80 \%$ of all respondents indicated delay at least one to seven out of 10 times. Twenty percent of carriers and $14 \%$ of shippers with own transport reported frequent delays (7 out of 10 times).

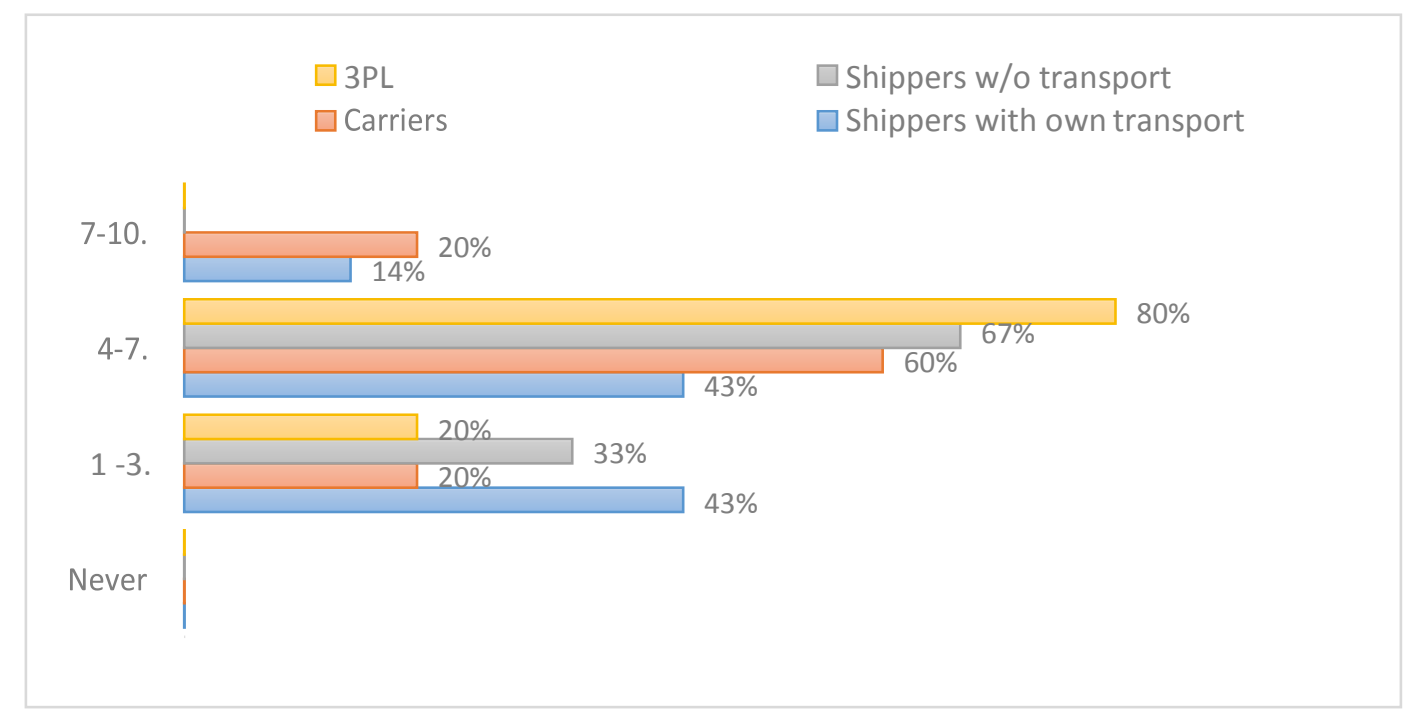

Figure 4-38 Frequency of out-bound shipment delay (out of 10 times)

\subsubsection{Number of Employees}

Thirty percent of the respondents described their firm size. Figure 4-39 shows that most of them had more than 20 employees. 


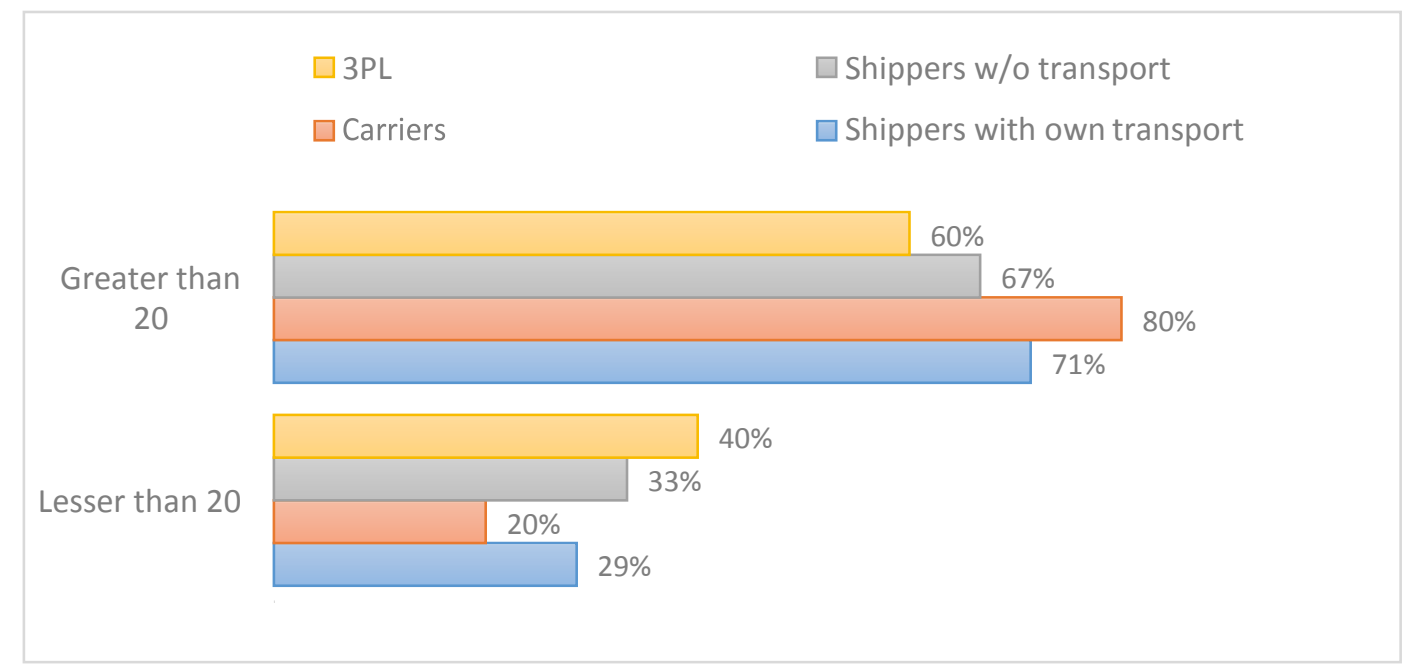

\subsubsection{Number of Employees}

Figure 4-39 Firm size

Twenty-eight percent of respondents provided information regarding the percentage of shipment under delivery pressure. Figure 4-40 shows that 3PLs and shippers were likely to be under delivery pressure than carriers, as $80 \%$ of $3 \mathrm{PL}$ and $67 \%$ of shippers (both groups) reported that more than $50 \%$ of their shipments were under delivery pressure. That share was $36 \%$ for carriers.

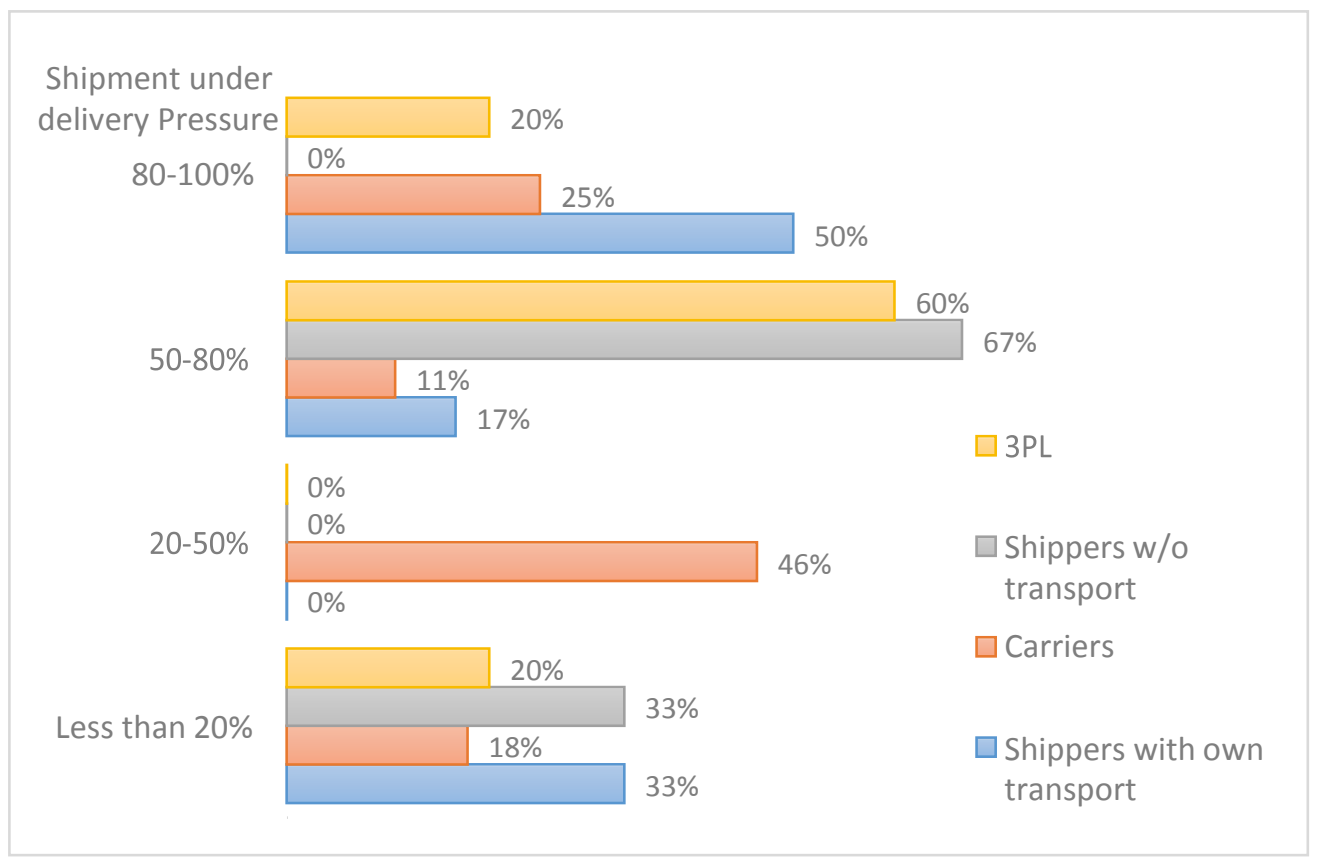

Figure 4-40 Shipment under delivery pressure 


\subsubsection{Routing Decisions and Reimbursement of Tolls}

The questions regarding routing decisions and reimbursement of tolls were only asked to carriers and shippers with own transport. Around 28 responses in routing decision and 30 responses in reimbursement for tolls were collected, where $82 \%$ of them reported that they did not get any reimbursement for tolls from the clients (Figure 4-41). Seventy percent of the drivers made the routing decisions (Figure 4-42). Similarly, among six shippers with own transport, $83 \%$ of them reported no reimbursement from the client and owner, operator and drivers were found to take routing decisions equally.

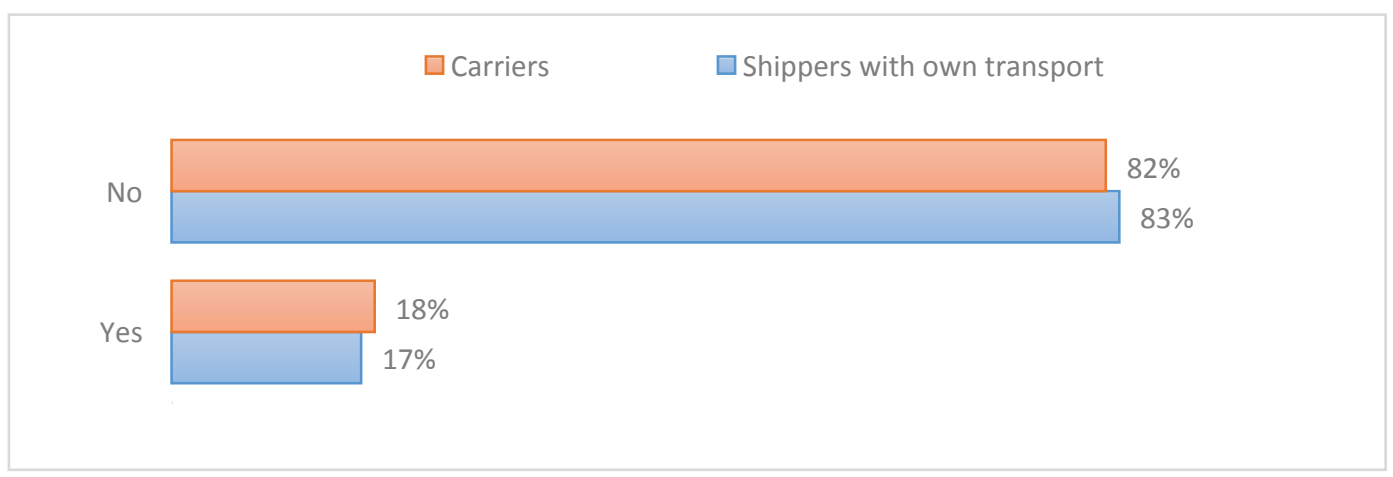

Figure 4-41 Reimbursement for tolls

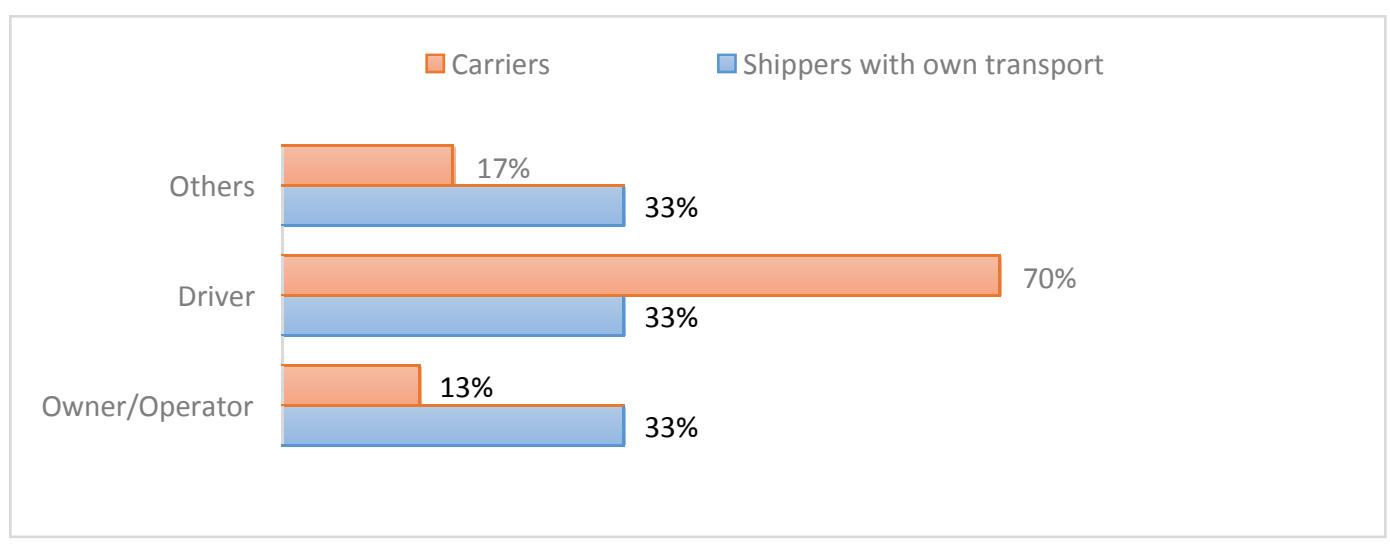

Figure 4-42 Routing decisions 


\section{CHAPTER 5}

\section{MODEL ESTIMATION}

This chapter represents the results for the estimated models based on data collected from the freight study. First, the chapter presents the outcomes of the base model which considers only main transport related attributes, such as travel cost, travel time and travel time reliability for the model development. Following this, a summary of commodity type model, user specific models, and interaction models investigating the effect of different shipment and firm characteristics on transport attributes are provided. The chapter concludes with the summary of WTP values for all models.

\subsection{Base Models}

Table 5-1 shows the results for the MNL and ML models developed for the whole dataset without consideration of user heterogeneity. All the coefficients showed the expected signs and were statistically significant. While the MNL specification for both additive and log WTP multiplicative space models showed similar goodness-of-fit measures, the ML model showed better performance with a higher R-square value.

Similarly, the two MNL models showed close values for VOT and VOR, while the ML model suggested lower values, especially for VOT. From the statistical point of view, it is evident that the sample gained little benefit from the use of multiplicative WTP space structure. The standard deviation estimates for both random variables (travel time and travel time reliability) in the ML model showed significant coefficients, indicating the presence of user heterogeneity. 
Table 5-1 MNL and ML Models Based on the Whole Dataset

\begin{tabular}{|l|c|c|c|}
\hline \multicolumn{1}{|c|}{ Coefficients } & $\begin{array}{c}\text { MNL Model } \\
\text { (additive) }\end{array}$ & $\begin{array}{c}\text { MNL Model } \\
\text { (Log WTP } \\
\text { multiplicative } \\
\text { space) }\end{array}$ & ML Model \\
\hline Constant Specific - Alt 2 & $-0.20(-1.43)$ & $52.0(0.86)$ & $-0.026(-0.57)$ \\
\hline Constant Specific - Alt 3 & $0.187(1.40)$ & $-54.3(-0.88)$ & $0.023(0.48)$ \\
\hline Travel Time & $-0.061(-4.33)$ & - & $-0.026(-3.19)$ \\
\hline Travel time Reliability & $-0.0773(-3.76)$ & - & $-0.039(-2.80)$ \\
\hline Travel Cost & $-0.0013(-2.84)$ & - & $-0.0007(-4.55)$ \\
\hline Coeff_VOT & - & $46.5(4.64)$ & - \\
\hline Coeff_VOR & - & $73.0(4.07)$ & - \\
\hline scale & - & $3.96(5.58)$ & $0.0481(4.67)$ \\
\hline STD. of Travel Time & - & - & $-0.0467(-2.60)$ \\
\hline STD. of Travel Time & - & - & -425.16 \\
\hline Reliability & -425.16 & -425.16 & -331.10 \\
\hline Initial Log likelihood & -397.60 & -386.49 & 0.25 \\
\hline Final Log likelihood & 0.05 & 0.08 & \\
\hline Adjusted R-Square & & 387 & 37.0 \\
\hline Number of Observations & & 97 & 55.0 \\
\hline Number of Individuals & 46.9 & 46.5 & \\
\hline Value of Time (per shipment) & 59.46 & 73.0 & \\
\hline $\begin{array}{l}\text { Value of Reliability (per } \\
\text { shipment) }\end{array}$ & & & \\
\hline
\end{tabular}

Note: t-stat are shown in the parentheses; “-” represents not applicable.

\subsection{User Specific Models}

Table 5-2 shows the model results for the user specific models. MNL models were developed for carriers, shippers with transportation, shippers without transportation, and 3PLs separately. The table shows that 3PLs had an insignificant coefficient for travel time, and, as a result, a VOT value could not be derived for 3PLs.

As shown in the table, some variables were insignificant based on a t-test but significant for a robust t-test at a $95 \%$ confidence interval. Probably because a t-test performs well when the sample is normally distributed with equal variance, which probably is not true for this sample as freight shipments tend to vary largely in terms of size, shipping cost, and duration. Relying on the t-test would be too stringent in this case. 
Therefore, those coefficients were kept in the model.

Among all models, the shippers sample showed better model performance, especially shippers without transportation, while the 3PL sample showed the poorest model performance. In terms of willingness to pay, shippers without transportation showed the highest VOT, whereas shippers with transportation showed the highest VOR values.

Table 5-2 User Specific MNL Model Results

\begin{tabular}{|c|c|c|c|c|}
\hline Coefficients & Carriers & $\begin{array}{l}\text { Shippers with } \\
\text { Transportation }\end{array}$ & \begin{tabular}{|c|} 
Shippers \\
without \\
Transportation
\end{tabular} & 3PL \\
\hline \multirow{2}{*}{ Constant Specific } & $-0.214(-1.02)$ & $0.117(0.23)$ & $-0.025(-0.03)$ & $-0.294(-0.53)$ \\
\hline & $0.078(0.203)$ & $-0.418(-0.67)$ & $1.27(1.50)$ & $-1.17(-1.98)$ \\
\hline Travel Time & $-0.044(-2.91)$ & $-0.178(-1.3)^{*}$ & $-0.416(-2.85)$ & $-0.033(-0.24)$ \\
\hline Travel Reliability & $-0.106(-3.94)$ & $-1.43(-3.86)$ & $-0.113(-1.72)^{*}$ & $-0.460(-2.32)$ \\
\hline Travel Cost & $-0.0037(-5.19)$ & $-0.0081(-2.15)$ & $-0.0015(-1.39)^{*}$ & $-0.009(2.43)$ \\
\hline Initial Log likelihood & -213.13 & -47.24 & -131.83 & -32.95 \\
\hline Final Log likelihood & -177.67 & -24.20 & -15.96 & -20.40 \\
\hline Adjusted R-Square & 0.10 & 0.31 & 0.83 & 0.08 \\
\hline No. of Observations & 194 & 43 & 120 & 30 \\
\hline No. of Individuals & 71 & 7 & 15 & 4 \\
\hline Value of Time (per shipment) & 12 & 22 & 277 & - \\
\hline $\begin{array}{l}\text { Value of Reliability (per } \\
\text { shipment) }\end{array}$ & 29 & 177 & 75.0 & 51.0 \\
\hline
\end{tabular}

*Statistically significant for robust - t test at $95 \%$ confidence interval

\subsection{User Specific Models with Interaction Effects}

Table 8-3 presents the results for the user specific models with interaction effects. It shows that the models performed better when interaction effects were taken into consideration, as indicated by higher R-square values compared to the models shown in Table. The model for the 3PLs did not show any improvement, thus was not presented in Table 5-3. 
The results on the interaction effects suggest that shipping weight was a possible source of heterogeneity for all user groups. Specifically, shipping weight contributed to the heterogeneity towards travel time reliability for carriers and shippers with transportation; while shippers without transportation showed heterogeneity towards travel time by shipping weight.

For shippers with transportation, a positive sign for the interaction effect between shipment weight of less than 10 tons and reliability suggest that they had less concern on reliability for light shipments compared to heavy shipments. This finding is consistent with Masiero and Hensher (2012) who focused on shippers and found higher VOR values as shipping weights increased. Interestingly, the opposite effect was observed for carriers. A positive sign for the interaction variable between shipment weight of more than 20 tons and reliability suggests that carriers valued reliability less for heavy shipments.

The sample for shippers without transportation did not show significant interaction effects for travel time reliability, but showed positive interaction effects between travel time and shipping weight of less than 10 tons. This indicates that shippers without transportation were less concerned about travel time savings for shipments of light volumes than heavy shipments.

In addition to shipping weight and shipping distance, trucking type and truck size also showed significant contributions towards sensitivity to travel time reliability for carriers. A positive value for the interaction effect between shipment distance of 300 
miles or more and reliability indicates that, all else being equal, carriers showed less VOR for long distance (greater than 300 miles) shipments. It is logical as the window of delivery for longer distance shipment is relatively wider, and tolerance for variability or delay would be higher. This finding is consistent with the literature (Wigan et al., 2000; Beuthe and Bouffioux, 2008; Masiero and Hensher, 2012), where higher VOR values were found for shorter distances compared to longer distances.

Table 5-3 User Specific MNL Model Results (With Interaction Effects)

\begin{tabular}{|c|c|c|c|c|}
\hline \multicolumn{2}{|c|}{ Coefficients } & Carriers & $\begin{array}{l}\text { Shippers with } \\
\text { Transportation }\end{array}$ & $\begin{array}{l}\text { Shippers without } \\
\text { Transportation }\end{array}$ \\
\hline \multirow{2}{*}{ Constant Specific } & Alt2 & $-0.268(-1.08)$ & $-0.58(-0.10)$ & $-0.078(-0.10)$ \\
\hline & Alt3 & $0.04(0.17)$ & $-1.65(-1.04)$ & $1.21(1.46)$ \\
\hline \multicolumn{5}{|c|}{ Transport Related Attributes } \\
\hline \multicolumn{2}{|c|}{ Transit Time } & $-0.068(-3.53)$ & $-0.15(-1.08)^{*}$ & $-1.26(-0.04)^{*}$ \\
\hline \multicolumn{2}{|c|}{ Transit Time Reliability } & $-0.476(-2.89)$ & $-2.974(-2.44)$ & $-0.106(-1.64)$ \\
\hline \multicolumn{2}{|c|}{ Shipment Cost } & -0.006 & $-0.0089(-2.14)$ & $-0.0014(-1.33)^{*}$ \\
\hline \multicolumn{5}{|c|}{ Interaction effect with Transit Time Reliability } \\
\hline Distance (miles) & $300+$ & $0.407(2.59)$ & & \\
\hline \multirow{3}{*}{$\begin{array}{c}\text { Shipping } \\
\text { weight (ton) }\end{array}$} & $<10$ & & $2.25(1.93)$ & \\
\hline & $20-30$ & $0.144(2.12)$ & & \\
\hline & $30+$ & $0.154(1.32)^{*}$ & & \\
\hline Trucking Type & FTL & $-0.133(-1.39)^{*}$ & & \\
\hline Truck Size & $\begin{array}{l}\text { Light \& } \\
\text { Medium }\end{array}$ & $-0.102(-1.32)^{*}$ & & \\
\hline \multicolumn{5}{|c|}{ Interaction effect with Transit Time } \\
\hline $\begin{array}{c}\text { Shipping } \\
\text { weight (ton) }\end{array}$ & $<10$ & & & $0.87(0.03)^{*}$ \\
\hline \multicolumn{5}{|c|}{ Statistics of Model Fitness } \\
\hline \multicolumn{2}{|c|}{ Initial Log likelihood } & -169.17 & -47.24 & -123.04 \\
\hline \multicolumn{2}{|c|}{ Final Log likelihood } & -130.06 & -23.45 & -14.46 \\
\hline \multicolumn{2}{|c|}{ Adjusted R-Square } & 0.17 & 0.35 & 0.83 \\
\hline \multicolumn{2}{|c|}{ No. of Observations } & 154 & 43 & 112 \\
\hline \multicolumn{2}{|c|}{ No. of Individuals } & 61 & 7 & 14 \\
\hline
\end{tabular}

*Statistically significant for robust - $\mathrm{t}$ test at $95 \%$ confidence interval 
On the other hand, a negative sign for the interaction variable between full truck load (FTL) and reliability indicates that carriers showed a higher value towards reliability for this kind of service. Similarly, carriers showed a higher VOR for shipments transported by small and medium trucks compared to heavy trucks. This is reasonable given that small and medium trucks most likely serve urban multi-drop or short distance shipments (within a day) that demand greater certainty.

\subsection{Commodity Models}

Table 5-4 shows the ML model results for different commodities. As shown in the table, agriculture and food products were merged to get statistically significant results. Models developed for other commodity types such as mining and construction materials did not show statistically significant results, therefore are not presented. In addition, two models were estimated for perishable and non-perusable commodities separately. Given the significance of shipment weight as indicated in the previous section, the mean shipment weight for each group is also shown in the table.

It shows that the models had reasonable and comparable model goodness-of-fit, except for the heavy manufacturing group. In terms of willingness to pay, perishable shipments showed much higher VOR value than non-perishable shipments. Among the groups, agriculture and food products showed the highest VOR values and paper, chemical and non-durable manufacturing for the highest VOT values. 
Table 5-4 ML Model Results by Commodity Group and Product Type

\begin{tabular}{|c|c|c|c|c|c|c|c|}
\hline \multicolumn{2}{|c|}{ Coefficients } & $\begin{array}{l}\text { Agriculture } \\
\text { \& Food } \\
\text { Products }\end{array}$ & $\begin{array}{c}\text { Heavy } \\
\text { Manufacturi } \\
\text { ng, Auto } \\
\text { Parts, } \\
\text { Electronics } \\
\end{array}$ & $\begin{array}{c}\text { Paper, } \\
\text { Chemicals \& } \\
\text { Non-durable } \\
\text { Manufacturin } \\
\text { g }\end{array}$ & $\begin{array}{l}\text { Petroleum } \\
\text { Products \& } \\
\text { Minerals }\end{array}$ & Perishable & $\begin{array}{c}\text { Non- } \\
\text { Perishable }\end{array}$ \\
\hline \multirow{2}{*}{$\begin{array}{l}\text { Constant } \\
\text { Specific }\end{array}$} & Alt2 & $-0.301(-1.13)$ & $0.064(0.18)$ & $-0.915(-1.87)$ & $-0.73(-1.12)$ & $-0.315(-1.20)$ & $-0.16(-0.59)$ \\
\hline & Alt3 & $-0.531(-1.61)$ & $0.333(0.96)$ & $-0.462(-1.01)$ & $-1.21(-1.52)$ & $-0.493(-1.52)$ & $0.116(0.42)$ \\
\hline \multicolumn{2}{|c|}{$\begin{array}{c}\text { Travel } \\
\text { Time Mean }\end{array}$} & $\begin{array}{l}-0.110(- \\
1.39)^{*}\end{array}$ & $-0.149(-1.74)$ & $-0.242(-1.45)$ & $-0.14(-2.03)$ & $-0.142(-2.04)$ & $-0.115(-2.23)$ \\
\hline \multicolumn{2}{|c|}{$\begin{array}{c}\text { Travel } \\
\text { Reliability Mean }\end{array}$} & $-0.368(-3.77)$ & $-0.126(-2.31)$ & $-0.099(-1.36)^{*}$ & $\begin{array}{l}-0.167(- \\
1.27)^{*}\end{array}$ & $-0.396(-3.09)$ & $-0.279(-3.12)$ \\
\hline \multicolumn{2}{|c|}{ Transit Cost } & $-0.005(-3.52)$ & $-0.005(-3.41)$ & $-0.006(-2.69)$ & $-0.007(-2.05)$ & $-0.005(-3.70)$ & $-0.005(-4.17)$ \\
\hline \multicolumn{2}{|c|}{$\begin{array}{l}\text { STD. of Travel } \\
\text { Time }\end{array}$} & $-0.487(-3.77)$ & $0.262(2.44)$ & $0.426(1.97)$ & $0.80(1.46)$ & $-0.48(-4.10)$ & $-0.47(-3.86)$ \\
\hline \multicolumn{2}{|c|}{$\begin{array}{l}\text { STD. of Travel } \\
\text { Time Reliability }\end{array}$} & $0.442(3.19)$ & $-0.038(-0.28)$ & $0.003(0.04)$ & $1.27(1.60)$ & $-0.42(-3.15)$ & $0.37(3.61)$ \\
\hline \multicolumn{2}{|c|}{$\begin{array}{l}\text { Initial Log } \\
\text { likelihood }\end{array}$} & -199.95 & -92.28 & -61.52 & -46.14 & -209.83 & -214.22 \\
\hline \multicolumn{2}{|c|}{$\begin{array}{l}\text { Final Log } \\
\text { likelihood }\end{array}$} & -155.22 & -77.87 & -45.58 & -33.54 & -161.48 & -161.79 \\
\hline \multicolumn{2}{|c|}{$\begin{array}{l}\text { Adjusted R- } \\
\text { Square }\end{array}$} & 0.19 & 0.05 & 0.15 & 0.12 & 0.20 & 0.21 \\
\hline \multicolumn{2}{|c|}{$\begin{array}{c}\text { No. of } \\
\text { Observations }\end{array}$} & 182 & 84 & 56 & 42 & 191 & 195 \\
\hline \multicolumn{2}{|c|}{ No. of Individuals } & 45 & 19 & 15 & 9 & 47 & 49 \\
\hline \multicolumn{2}{|c|}{$\begin{array}{l}\text { Mean Shipment } \\
\text { Weight (in tons) }\end{array}$} & 26.16 & 27.24 & 25.46 & 24.23 & 26.10 & 24.49 \\
\hline \multicolumn{2}{|c|}{$\begin{array}{l}\text { Value of Time } \\
\text { (per shipment) }\end{array}$} & 22.0 & 29.80 & 40.3 & 20.57 & 28.40 & 23.0 \\
\hline \multicolumn{2}{|c|}{$\begin{array}{l}\text { Value of } \\
\text { Reliability (per } \\
\text { shipment) }\end{array}$} & 74.0 & 25.20 & 16.5 & 23.86 & 79.20 & 55.80 \\
\hline
\end{tabular}

*Statistically significant for robust - t test at $95 \%$ confidence interval

\subsection{WTP Estimation}

This section discusses the WTP values derived from this study for comparison purposes. The models and values derived presented in the previous sections are shipment based, as are most studies in the literature. This study also estimated ton-hour based values as shown in Table 8-5; the estimation models showed the same general pattern as the models presented in the previous sections and are not presented in the paper to 
save space. The reliability ration (RR) was also derived based on both shipment-hour and ton- hour values.

Table 5-5 presents a summary of all the VOT and VOR values derived for various groups in this study. In general, across all groups in the sample, a value of $\$ 37.0$ per shipment-hour ( $\$ 1.53$ per ton-hour) for travel time savings and $\$ 55.0$ per shipment-hour (\$3.81 per ton-hour) for improvements of reliability were found. In general, the freight users valued reliability approximately twice as much as the travel time. These observations are within the range indicated in the literature.

Among the user groups, the VOT values ranged from $\$ 12$ to $\$ 277$ per shipmenthour, and $\$ 0.5$ to $\$ 23.0$ per ton-hour, while the VOR values ranged from $\$ 28.0$ to $\$ 177.0$ per shipment-hour, and $\$ 3.0$ to $\$ 22.0$ per ton-hour. Carriers showed the lowest WTP, because they directly bear these additional costs. On contrary, WTP values were much higher for shippers, with the highest VOT values shown by shippers without transportation and the highest VOR values shown by shippers with transport. Still, these higher values for shippers in the range indicated in the literature, but deserve further investigation. As expected, shippers with transportation showed the greater RR values, but were followed by carriers, indicating that shippers without transportation value reliability much less than time savings compared to other groups.

As expected, perishable products showed higher VOT and VOR values than nonperishable products, as both time savings and reliability are important in shipping perishable items. Also, higher RR values for perishable products indicated that reliability was relatively more important than time savings compared with no-perishable products. 
Similarly, agriculture and food products reflected the highest VOT and VOR values, and RR values among the commodity groups.

Table 5-5 Summary of WTP Estimation by User Group and Commodity Type

\begin{tabular}{|c|c|c|c|c|c|c|c|}
\hline \multirow[b]{2}{*}{ Type } & \multirow[b]{2}{*}{ Sub-groups } & \multicolumn{2}{|c|}{ Value of Time } & \multicolumn{2}{|c|}{ Value of Reliability } & \multirow{2}{*}{$\begin{array}{c}\text { RR } \\
\text { (based on } \\
\text { shipment) }\end{array}$} & \multirow{2}{*}{$\begin{array}{l}\mathbf{R R} \\
\text { (based on } \\
\text { tonnage) }\end{array}$} \\
\hline & & $\begin{array}{l}\text { Per } \\
\text { Shipment- } \\
\text { Hour }\end{array}$ & $\begin{array}{c}\text { Per } \\
\text { Ton-Hour }\end{array}$ & $\begin{array}{l}\text { Per } \\
\text { Shipment- } \\
\text { Hour }\end{array}$ & $\begin{array}{l}\text { Per Ton- } \\
\text { Hour }\end{array}$ & & \\
\hline & All & 37.0 & 1.53 & 55.0 & 3.81 & 1.5 & 2.5 \\
\hline \multirow{4}{*}{ User Group } & Carriers & 12.0 & 0.50 & 29.0 & 3.0 & 2.41 & 6.0 \\
\hline & $\begin{array}{l}\text { Shippers with } \\
\text { Transportation }\end{array}$ & 22.0 & 1.0 & 177.0 & 22.0 & 8.0 & 22.0 \\
\hline & $\begin{array}{l}\text { Shippers without } \\
\text { Transportation }\end{array}$ & 277.0 & 23.0 & 75.0 & 5.13 & 0.3 & 0.22 \\
\hline & $3 \mathrm{PL}$ & - & & 51.0 & & - & - \\
\hline \multirow{4}{*}{$\begin{array}{l}\text { Commodity } \\
\text { Group }\end{array}$} & Agriculture and Food & 22.0 & 1.50 & 74.0 & 4.38 & 3.4 & 2.9 \\
\hline & Heavy Manufacturing & 30.0 & 1.75 & 25.0 & 2.25 & 0.8 & 1.3 \\
\hline & $\begin{array}{l}\text { Paper, Chemicals \& } \\
\text { Non-durable } \\
\text { manufacturing }\end{array}$ & 40 & 2.75 & 17.0 & 1.38 & 0.4 & 0.50 \\
\hline & Petroleum \& Minerals & 21 & 4.3 & 24.0 & 10.2 & 1.1 & 2.4 \\
\hline \multirow{2}{*}{ Product Type } & Perishable & 28 & 0.63 & 79 & 4.38 & 2.8 & 7.0 \\
\hline & Non-Perishable & 23.0 & 1.43 & 56 & 3.14 & 2.4 & 2.20 \\
\hline
\end{tabular}

Besides user group, commodity group and product type, the impacts of other shipment characteristics on WTP are presented in Table 5-6 and Figure 5-1. Table 5-6 presents the changes in VOT and VOR estimates when the interaction effects were taken into account. Both absolute and relative differences are provided. Figure 5-1 presents the absolute impacts on VOR values. As shown in Table 5-6 and Figure 5-1, when these shipment characteristics were considered, it revealed significant differences in the estimated WTP values.

Particularly, when shippers were hiring transportation for light shipments (less than 10 tons), they were less interested in paying for travel time savings, about $\$ 279$ per shipment-hour (or 69\%) less than average. Similarly, shippers with own transportation 
were also less concerned on reliability for light shipments, with a VOR value $76 \%$ lower than the average. These findings suggest that WTP for shippers increases with the shipment volume.

Table 5-6 Summary of WTP Estimation by Shipping Characteristics

\begin{tabular}{|c|c|c|c|c|c|}
\hline \multirow[t]{2}{*}{ Groups } & \multirow[t]{2}{*}{ Sources of Heterogeneity } & \multicolumn{2}{|c|}{$\begin{array}{c}\text { Absolute Differences } \\
\text { (in \$ per shipment-hour) }\end{array}$} & \multicolumn{2}{|c|}{$\begin{array}{c}\text { Relative Differences } \\
\text { (in \% per shipment-hour) }\end{array}$} \\
\hline & & $\Delta$ VOT & $\triangle \mathrm{VOR}$ & $\% \Delta \mathrm{VOT}$ & $\% \Delta \mathrm{VOR}$ \\
\hline \multirow{5}{*}{ Carriers } & Long distance (300+ miles) & & -68 & & $86 \% \downarrow$ \\
\hline & Shipping weight: $20-30 \mathrm{t}$ & & -24 & & $30 \% \downarrow$ \\
\hline & Shipping weight : $30+\mathrm{t}$ & & -26 & & $32 \% \downarrow$ \\
\hline & Trucking Type: FTL & & +22 & & $28 \% \uparrow$ \\
\hline & Truck Size: Light \& Medium & & +17 & & $21 \% \uparrow$ \\
\hline $\begin{array}{l}\text { Shippers with } \\
\text { Transportation }\end{array}$ & Shipping weight $:<10 \mathrm{t}$ & -279 & & & $69 \% \downarrow$ \\
\hline $\begin{array}{l}\text { Shippers without } \\
\text { Transportation }\end{array}$ & Shipping weight : $<10 \mathrm{t}$ & -250 & & $-76 \% \downarrow$ & \\
\hline
\end{tabular}

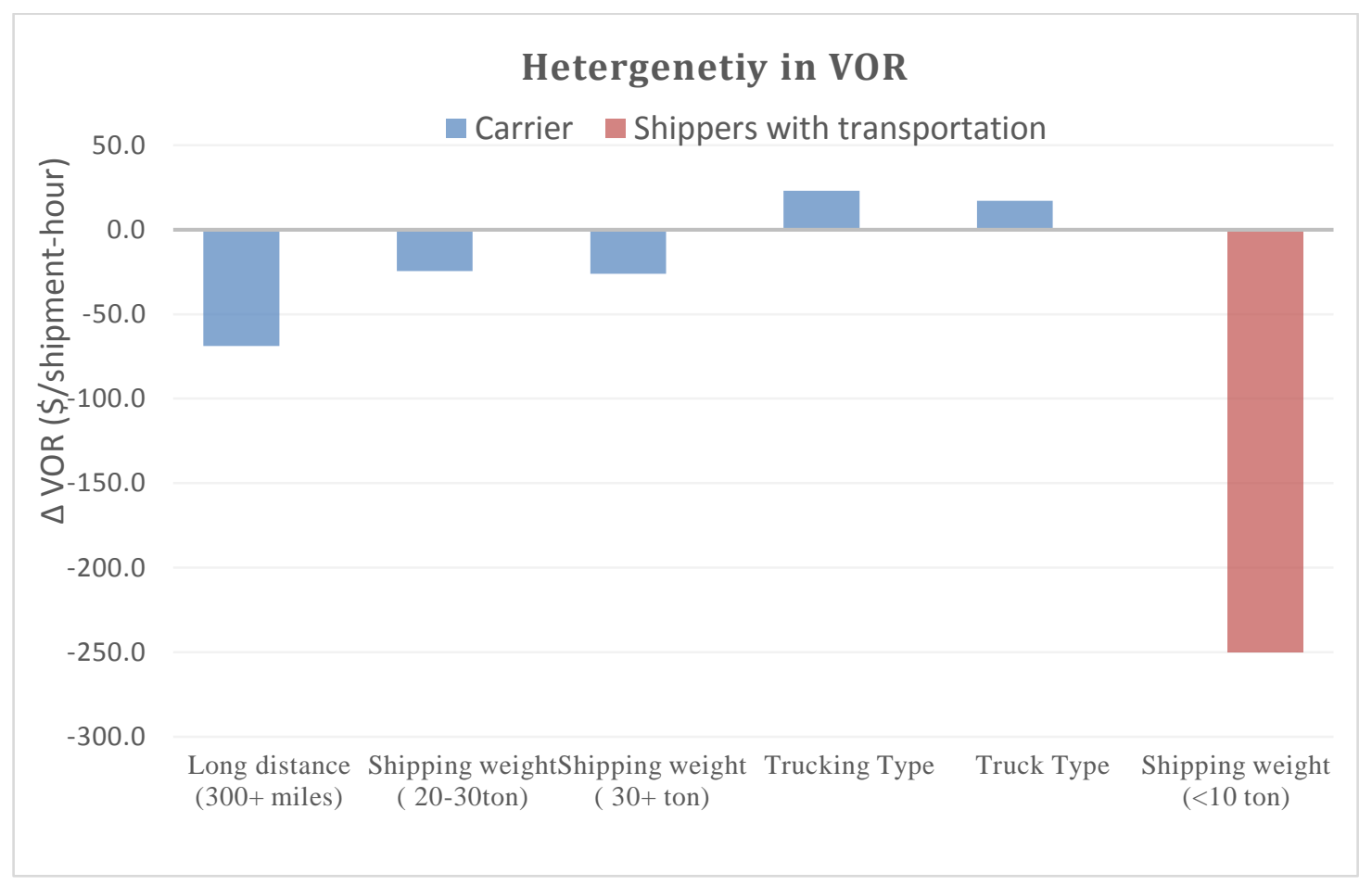

Figure 5-1 Summary of VOR value changes by shipping characteristics 
For carriers, depending on the shipping distance and shipping weight, their WTP to improve reliability may change from $\$ 68$ per shipment-hour less to $\$ 26$ per shipmenthour more than the average WTP. In this regard, long-distance (300 miles or longer) shipments had the largest negative impacts, while FTL showed the highest positive impacts on VOR.

In comparison with past studies, the literature suggested that VOT values varied from $\$ 13$ to $\$ 276$ per shipment-hour or $\$ 0.63$ to $\$ 10.72$ ton-hour (Halse et al., 2010; De Jong et al., 2014; Wigan et al., 2010; Bolis and Maggi, 2003; Small et al.; 1999), whereas values from this study ranged from $\$ 12$ to $\$ 277$ per shipment-hour or $\$ 0.5$ to $\$ 23.0$ per ton-hour. Similarly, as shown in Table 8.5 and discussed in the literature review section, past studies suggested VOR values from $\$ 28$ to $\$ 497$ per shipment-hour or $\$ 0.02$ to $\$ 5.5$ per ton-hour, whereas this study showed relatively comparable VOR values from $\$ 17$ to $\$ 177$ per shipment-hour, and $\$ 1.38$ to $\$ 10.2$ per ton-hour.

The RR values derived from this study as shown in Table 5-6, suggested a range of 0.3 to 9 , which confirmed the findings in the literature, 2 to 8 suggested by McMullen et al. (2015) and 1.2 recommended by De Jong et al. (2009). 


\section{CHAPTER 6}

\section{RECOMMENDATIONS FOR FREIGHT PLANNING AND EVALUATION}

The main purpose of this chapter is to discuss probable ways to incorporate the findings of this study into freight planning and project evaluation. In this regard, two major areas are identified, including:

1. Incorporating value of reliability (VOR) in the benefit-cost analysis (BCA) for project evaluation

2. Accommodating the effect of unreliability into demand models.

These two aspects are related as travel demand models often serve as the primary source to generate transportation performance data that are needed for the BCA. In a later section, the existing research and practices are first summarized, followed by discussions on how the study findings can be better integrated into freight planning and project appraisal.

\subsection{Benefit-Cost Analysis}

Benefit-cost analysis (BCA) is a tool widely used by planners, engineers, and practitioners to evaluate the economic advantages (benefits) and disadvantages (costs) of

a set of investment alternatives. The main objective of a BCA is to translate all flow of benefits and costs of an investment over time into monetary terms and provide a common basis (i.e. net present value) to determine whether it is a sound investment or to compare with alternative investments for prioritization. 
This section briefly describes the BCA procedure recommended by the American Association of State Highway and Transportation Officials (AASHTO) (AASHTO, 2010), followed by a discussion of the value of time (VOT) and VOR values to be used in the analysis.

AASHTO's report: User and Non-User Benefit Analysis for Highways (AASHTO, 2010) provided a framework of project evaluation for state and local transportation planning authorities. The manual included theories and methods on the estimation of the benefits and costs of highway projects. The manual identified three types of project benefits, which are 1) savings in travel time, 2) savings in out-of-pocket and other operating expenses, and 3) reduction in accidents. The "total cost" of the project comprised of a variety of incurring costs, which include capital, operation and maintenance, financial, and project delay costs.

The process involves the identification of user groups (e.g. income class, vehicle types, and trip purposes, etc.) and link(s)/corridor(s) that would likely be affected by the project. The changes in operation performance (e.g. volume, speed, and travel time) of the link(s)/corridor(s) due to alternative projects are then quantified in required units for further use using the formulas provided in the manual. Figure 6-1 provides a sketch of cost linkages, showing how the cost components are related to network and user characteristics.

The manual also provided detailed unit costs by user class, to convert project benefits into monetary values. In this regard, the report recommended a VOT value of 
$\$ 20.23$ for freight transportation, which was $20 \%$ greater than average driver wage (AASHTO, 2010).

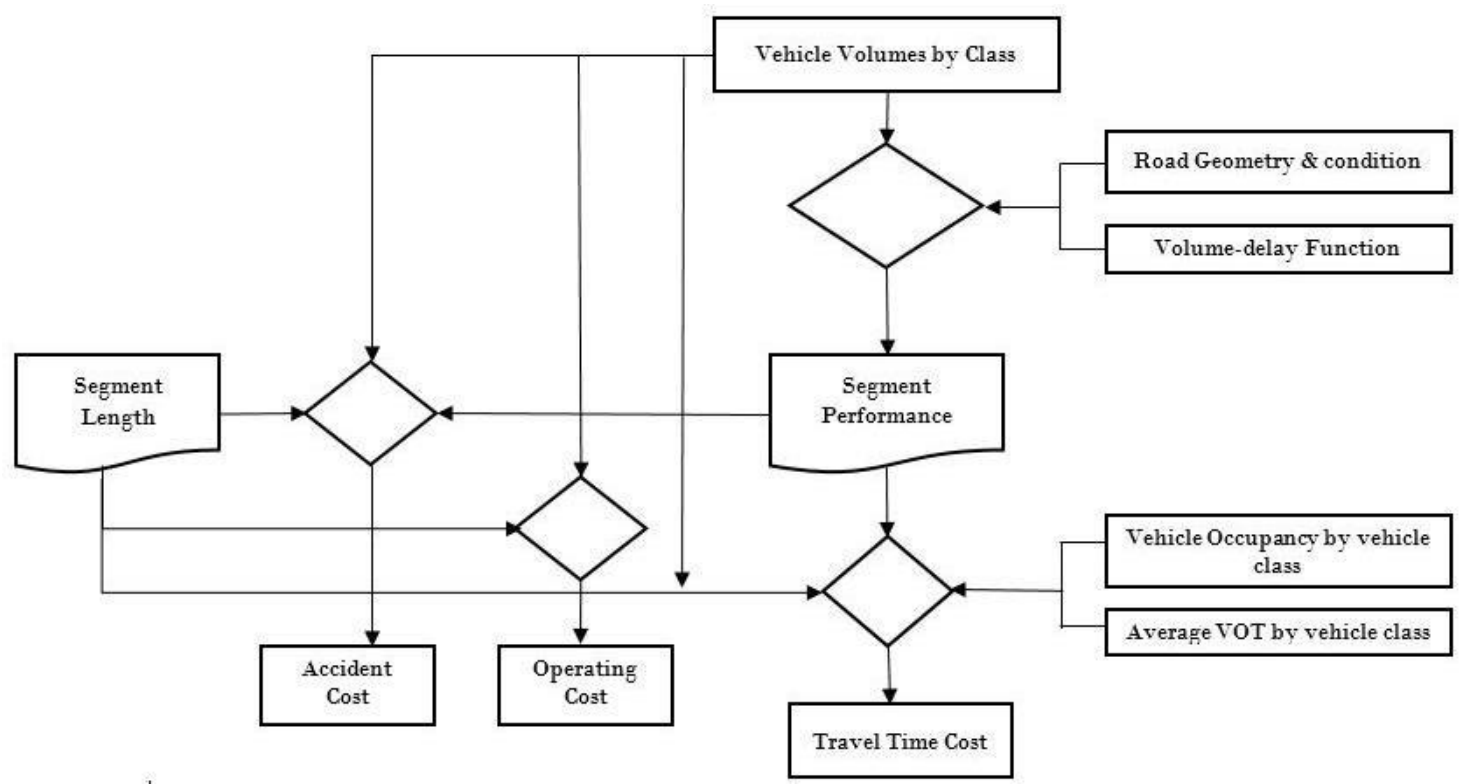

Figure 6-1 Stylized representation of the user cost linkages (Source: AASHTO, 2010)

While the manual provides a comprehensive framework to estimate the user benefits and costs of highway projects, it has several limitations to address project impacts on freight transportation. Compared to passenger travel, the determination of appropriate values of transportation network improvements for freight is much more complicated. A typical freight movement involves both shippers and carriers. The study results described in previous deliverables indicate that the valuation of travel time savings and reliability improvement vary substantially among user groups, commodity types, and different shipment characteristics (weight, shipping distance, etc.). From this perspective, the limitations of the manual include (Sage, et al., 2013):

- The value of travel time savings based on drivers' wage may underestimate the true value placed by carriers, which may include 
handling costs at shipment origin and destination and other supporting costs.

- Other components in the supply-chain costs that influence shipper decisions are not considered, which include inventory management costs, reliability buffer costs, freight loss and damage claim processing costs, and depreciation of commodity value, etc.

- The benefits of travel time reliability improvement are not explicitly considered in the process.

The findings from this study can be incorporated into the existing BCA process through: 1) adding a component to address the benefits of reliability improvement on freight and 2) updating the VOT values by various groups. Table 6-1 presents the recommended VOT and VOR values based on the study results of the Florida Freight Survey.

Table 6-1 Estimated VOT and VOR Values by Groups based on Florida Survey

\begin{tabular}{|c|c|c|}
\hline Components & VOT $\mathbf{( \$ \mathbf { h r } )}$ & VOR $\mathbf{( \$ \mathbf { h r } )}$ \\
\hline & User Specific & \\
\hline All & $\$ 37$ & $\$ 55$ \\
\hline Transportation service Related & $\$ 12$ & $\$ 29$ \\
\hline Cargo/Goods Related & $\$ 22-\$ 277$ & $\$ 75-\$ 177$ \\
\hline Agriculture and Food & Industry Specific & $\$ 74$ \\
\hline Heavy Manufacturing & $\$ 22$ & $\$ 25$ \\
\hline Paper, Chemicals \& Non- & $\$ 30$ & $\$ 17$ \\
\hline durable manufacturing & $\$ 40$ & $\$ 24$ \\
\hline Petroleum \& Minerals & $\$ 21$ & $\$ 79$ \\
\hline & Goods Specific & $\$ 56$ \\
\hline
\end{tabular}




\subsection{Travel Demand Modeling}

Travel demand models are the primary sources to provide the necessary input for BCA in terms of network performance data (volume, speed, travel time, and reliability). To be able to incorporate travel time reliability into demand modeling process or BCA, there is a need to establish a process to derive reliability measures and predict future values in light of transportation improvement projects.

Two approaches have been discussed in practice to incorporate reliability:

- The SHRP 2 project L04 recommended a method to predict the standard deviation of travel time (as a measure of reliability) based on travel time and travel distance.

- The Puget Sound Regional Council (PSRC) derived speed variances in relation to average speeds as a representation of unreliability, and employed a modified version of Volume Delay Function (VDF) to incorporate reliability in network assignment (PSRC, 2009).

The SHRP2 Project L04 developed a model that relates travel time and standard deviation (as a measure of unreliability) at route level, as shown below (Mahmassani et al., 2013):

$$
\sigma=a+b(T / D)
$$

where

$\mathrm{a}$ and $\mathrm{b}$ are coefficients that need to be estimated using local network data;

$\mathrm{T}$ is the route travel time and $\mathrm{D}$ is the travel distance.

This approach can be applied without the need to modify the existing travel demand models. The OD matrix produced by demand models can be used to derive 
reliability measures based on the above equation; the improvement in reliability will then be converted into monetary value using the recommended VOR values. Figure 6-2 shows the flowchart of this process. Feedback loops can also be added to the modeling process, to account for the choice behavior in response to reliability changes as shown in the figure. The outcome of the unreliability model will be incorporated in network assignment as an additional cost to the generalized cost function for the users. Further feedback iterations can be employed to accommodate the impacts of unreliability on mode choice and other choices.

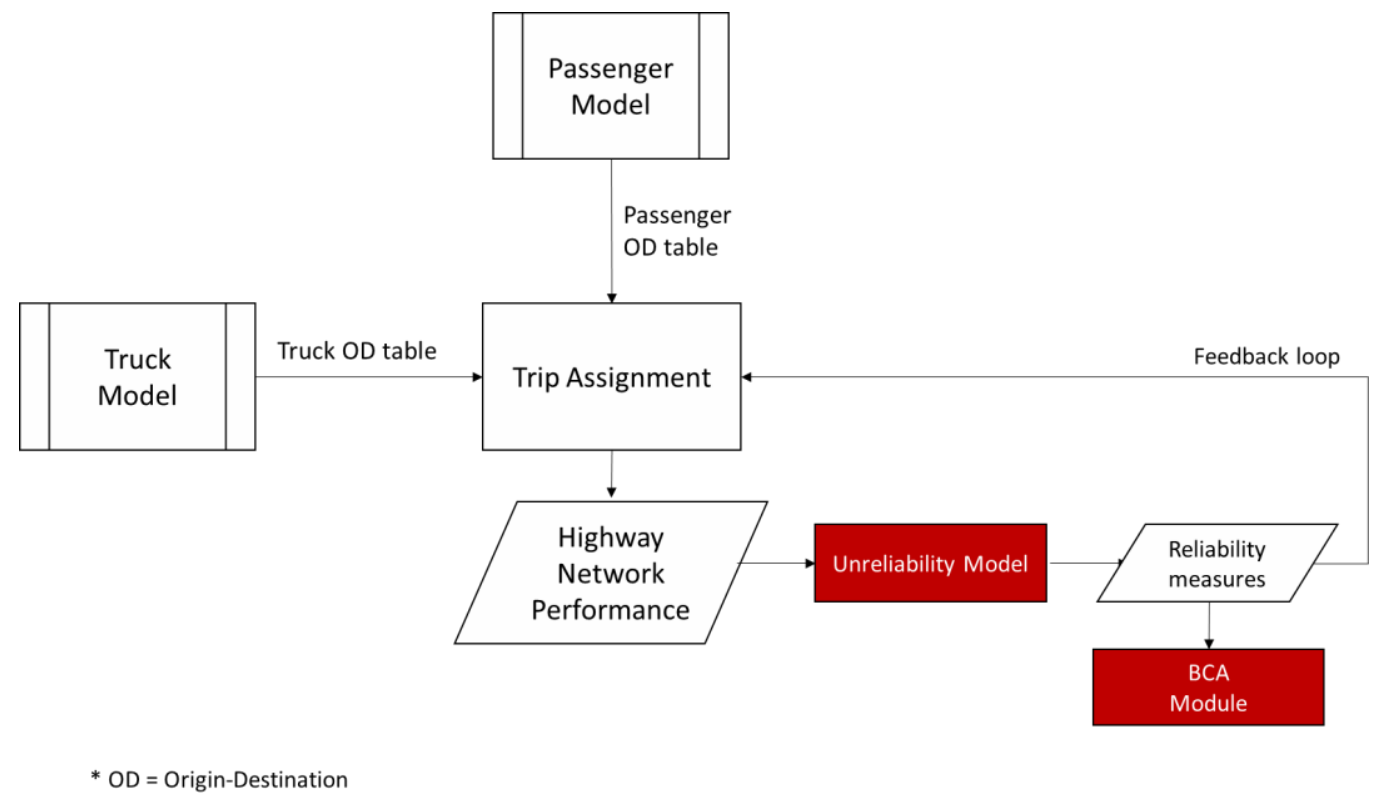

Figure 6-2 Incorporation of reliability into the travel demand modeling process

The PSRC employed the concept of "certainty equivalent" to simulate the value of unreliability (represented as the variation in speeds from the mean or typical condition). The concept was drawn from stock trading, where a buyer is willing to pay extra for an expected (guaranteed) price at a future time. This extra amount would represent the value of certainty. In the context of travel decisions, a traveler is willing to accept a lower average speed with absolute certainty in equivalency to traveling at a 
higher speed with a risk of experiencing much lower speed. This certainty equivalent, representing the willingness to pay to reduce variation in speed, was measured in time increments, which were then converted into dollar values based on VOTs by user class.

This "equivalent certainty" was incorporated into the PSRC travel demand model in the form of time penalty through the VDF. A modified VDF was developed which contains an additional delay component in consideration of unreliability. Equations Two and Three show the VDF formulas, with and without the consideration of reliability used in the PSRC model

$$
V D F \text { delay, } t_{i}=t_{o}+t_{o} a(V / C)^{\mathrm{b}}
$$

where

$t_{i}$ and $t_{0}$ are coefficients of delay and free flow time (in minutes per mile); $V$ is coefficient of total link volume in passenger car equivalent (PCE); $\mathrm{C}$ is total link capacity in PCE; $a$ and $b$ are coefficient of the BPR VDF function

$$
\text { VDF delay, } t_{i}=t_{o}+t_{o} a(V / C)^{b}+U\left(t_{i}\right)
$$

where

$\mathrm{U}\left(\mathrm{t}_{\mathrm{i}}\right)$ is certainty- equivalent delay penalty form unreliability at $\mathrm{t}_{\mathrm{i}}$, which can be expressed as : c $+\mathrm{et}_{\mathrm{i}}+\mathrm{ft}_{\mathrm{i}}{ }^{2}+\mathrm{gt}_{\mathrm{i}}{ }^{3}+\mathrm{ht}_{\mathrm{i}}{ }^{4}$ nd $\mathrm{c}, \mathrm{e}, \mathrm{f}, \mathrm{g}$ and $\mathrm{h}$ are coefficients that are estimated using real world traffic data for the segments.

This approach differs from the SHRP2 L04 approach, as the value placed on reliability is realized through time increments, and only VOT values are needed. The reliability measures used are also different between the two approaches. However, further investigations of these approaches are needed regarding data needs, model calibration, and validation for implementation in the Florida statewide model. 


\section{CHAPTER 7}

\section{CONCLUSIONS AND RECOMMENDATIONS}

\subsection{Conclusions}

This research aimed at investigating the users' preferences towards transportation related attributes, particularly the role of travel time reliability in their transportation choice and also providing advanced methods in quantifying the user's willingness to pay. Currently, there is a lack of knowledge on how freight users would respond to changes in travel reliability, as no such study was undertaken before in Florida. Therefore, the findings of this study would facilitate local, state, and national agencies in including reliability in their freight planning and project appraisal.

A stated preference survey, in consultation with various freight associations and groups, was designed and administered between January and May, 2016. The survey employed both online and paper format to administer the survey, although it was initially designed for online only. For reliability modeling, the study used the standard deviation of travel time as a measure so that the estimated values can be easily incorporated into project evaluation techniques. Each respondent faced six or seven hypothetical scenarios where they were asked to choose the best alternative among all others. To make the choice questions more realistic and applicable for the respondents, four types of experiments were developed and two sets of attributes values were used to construct choice questionnaires for these experiments. It is important to mention that, although the survey was designed to collect responses from users of all modes, including road, rail, air and waterways, the research team failed to collect enough samples other than the road mode. 
Therefore, all the model analyses are only limited to road freight users in this report.

The data collected from the surveys were analyzed using different discrete choice models, including multinomial logit (MNL) to estimate the user's willingness to pay for the improvement in travel time reliability. The panel data approach has been adopted to address the limitation of violations of independence of irrelevant alternatives (IIA).

In general, across all groups in the sample, a value of $\$ 37.00$ per shipment-hour ( $\$ 1.53$ per ton-hour) for travel time savings and $\$ 55.00$ per shipment-hour $(\$ 3.81$ per tonhour) for improvements of reliability were found. In comparison with past studies, the literature suggested that VOT values varied from $\$ 13.00$ to $\$ 276.00$ per shipment-hour or $\$ 0.63$ to $\$ 10.72$ ton-hour (Halse et al., 2010; De Jong et al., 2014; Wigan et al.,2010; Bolis and Maggi, 2003; Small et al., 1999), whereas values from this study ranged from $\$ 12.00$ to $\$ 277.00$ per shipment-hour or $\$ 0.50$ to $\$ 23.00$ per ton-hour. Past studies suggested VOR values from $\$ 28.00$ to $\$ 497.00$ per shipment-hour or $\$ 0.02$ to $\$ 5.50$ per ton-hour, whereas this study showed relatively comparable VOR values from $\$ 17.00$ to $\$ 177.00$ per shipment-hour, and $\$ 1.38$ to $\$ 10.2$ per ton-hour. Besides, the RR values derived from this study suggested a range of 0.30 to 9.00 , which confirmed the findings in the literature -2.00 to 8.00 suggested by McMullen et al. (2015) and 1.20 recommended by De Jong et al. (2008).

Furthermore, when investigating the effect of various shipping characteristic-related variables on the user's preference in WTP, the results found shipping distance and weight were two most significant variables. A summary of differences in the estimated WTP values by shipping characteristics were provided in the model result section. 
The dissertation provided some empirical evidences of users' greater importance on travel reliability and sources of heterogeneity of user's in WTP that may have greater significance to understand the users' behavior. Additionally, the research also provided WTP values by different components (such as goods-related and transportation-related) to further include these into the B-C analysis. However, one key concern is that higher values, particularly for shippers, suggests that it may have captured user's willingness to pay for other sources of unreliability as well. Therefore, the study team would recommend these estimated values be considered. Finally, the report concluded with a discussion on a conceptual framework to including the VOR and VOT values into the freight planning and project appraisals.

In summary, this research provides a robust approach, starting from designing a SP survey to analyzing the sample data and estimating VOR and VOR values for freight users. The findings of the study contribute to the research by providing empirical evidence of freight road users' WTP for the improvement in transportation related attributes in Florida and the impacts of user heterogeneity, although it has the limitation of low sample size.

In conclusion, this dissertation discussed the benefit-cost analysis process recommended by AASHTO, and highlighted the limitations of existing practices in addressing the impacts of reliability on freight transportation. In this regard, the study recommended VOT and VOR values by cost components that could be considered for future BCA. However, this study is subject to the sample size and geographic (within Florida) limitations. Therefore, these values should be used with caution. The study also discussed practical approaches to incorporate travel time reliability into the travel demand 
modeling process. Through the incorporation of reliability into benefit-cost analysis and the demand modeling process, it is expected to provide more accurate assessment of project benefits to freight transportation, therefore lead to better policy and investment decisions with freight considerations.

\subsection{Study Limitations and Recommendations of Future Research}

Like any other research effort, the results of this study are subject to a few shortcomings, including the following:

1. Low Sample Size: This study is subject to the sample size limitation. Although a well-sampling plan was devised beforehand, the study could not collect enough responses for all proposed groups accordingly. It is probably because of privacy concerns or fear of providing commercially sensitive data. Particularly, the number of forwarding companies and shippers with own transport participating in the survey are very low. However, from the freight transportation research perspective, this is common, as the sample size in most of the freight studies are between 20 and 200 firms.

2. Limitations of Online and Paper-based Surveys: Online and paper-based surveys provide great opportunities to reach vast numbers of potential participants, but less flexibility and controls over data quality. In this regard, Computerized Assisted Personal Interview (CAPI) can be a better option for future freight valuation study. 
Having discussed several major limitations of this study, some directions for further research are presented below:

1. The efficient experiment can be used to design the SP survey in freight transportation. Using prior information (the expected magnitude and sign of coefficients) of attributes, the efficient design produces the matrix of attributes in such a way that it can provide the same level of statistical efficiency as other designs, but requires a small sample size.

2. In terms of modeling, future research can investigate the impact of user's attitudinal and perceptional aspects on their willingness to pay for the improvement of transportation related attributes. This freight survey collected all this information. An investigation of robustness of VOR estimation technique can also be studied.

3. Future study can extend to be user specific, identifying major sources of unreliability and the user's preferences and willingness to pay for different types of mitigation measures. In particular, a detailed study of investigating the efficiency of the urban movement of goods and also the adequacy of existing facilities and last mile connectivity can be taken for future. 


\section{REFERENCES}

Al-Deek, H., and Emam, E. B. (2006). New Methodology for Estimating Reliability in Transportation Networks with Degraded Link Capacities. Journal of Intelligent Transportation Systems, 10(3), 117-129.

American Association of State Highway and Transportation Officials (AASHTO). (2010). User ad Non-User Benefit Analysis for Highways. American Association of State and Transportation Officials, Washingotn, D.C.

ALOGIT Software \& Analysis Ltd. (2008). ALOGIT Version 4.3 [Online]. Available at: http://www.alogit.com. Accessed : 28 September 2015.

Asgari, H., Jin, X. \& A. Mohseni (2014). Choice, Frequency, and Engagement - A Framework for Telecommuting Behavior Analysis and Modeling. Transportation Research Record: Journal of the Transportation Research Board, No. 2413, pp. 101-109.

Asgari, Hamidreza (2015). On the Impacts of Telecommuting over Daily Activity/Travel Behavior: A Comprehensive Investigation through Different Telecommuting Patterns. FIU Electronic Theses and Dissertations. Paper 2182. http://digitalcommons.fiu.edu/etd/2182

Asgari, H. and X. Jin (2015). Analysis of Telecommuting Behavior: Substitution or Supplementary? Combining Lifestyle Choice with Daily Engagement. TRB 94th Annual Meeting Compendium of Papers, Paper\#15-0283

Ben-Akiva, M., and Lerman, S.R. (1985). Discrete Choice Analysis: Theory and Application to Travel Demand. Cambridge: The MIT Press.

Ben-Akiva, M., Morikawa, T., and Shiroishi, F. (1992). Analysis of the Reliability of Preference Ranking Data. Journal of Business Research, 24(2), 149-164.

Bergkvist, E., and Westin, L. (2001). Regional Valuation of Infrastructure and Transport Attributes for Swedish Road Freight.The Annals of Regional Science 35 (4), 547-560.

Beuthe, M., and Bouffioux, C. (2008). Analysing Qualitative Attributes of Freight Transport from Stated Orders of Preference Experiment. Journal of Transport Economics and Policy, 42(1), 105-128.

Becker, Gary S. (1965). A Theory of the Allocation of Time. The Economic Journal, 493-517.

Bierlaire, M. (2008). An Introduction to BIOGEME Version 1.7 [Online]. Available at : http://biogeme.epfl.ch. Accessed : 15 September 2015.

Bolis, S., and Maggi, R. (2003). Logistics Strategy and Transport Service Choices: An 
Adaptive Stated Preference Experiment. Growth and Change, 34(4), 490-504.

Bone, I., Wallis, I., Fallon, C., and Nicholson, A. (2013). Reliability and FreightLiterature and Practice Review October 2013. New Zealand Transport Agency. Available at : https://www.nzta.govt.nz/assets/resources/research/reports/538/docs/538.pdf. Accessed : 18 September, 2014.

Bradley, R. A., and Milton, E. T. (1952). Rank Analysis of Incomplete Block Designs: I. the Method of Paired Comparisons. Biometrika, 324-345.

Bureau of Transportation Statistics (BTS). (2014). Special Report. Available at : http://www.rita.dot.gov/bts/sites/rita.dot.gov.bts/files/CFS_Complete.pdf. Accessed : 8 October 82014.

Cambridge Systematics, Transmode Consultants, National Cooperative Highway Research Program, American Association of State Highway and Transportation Officials. (1998). Multimodal Corridor and Capacity Analysis Manual. Transportation Research Board of the National Academies, Washington, D.C.

Cambridge Systematics. (2005). An Initial Assessment of Freight Bottlenecks on Highways. Federal Highway Administration, U.S. Department of Transportation, Washington, D.C.

Cambridge Systematics, Prime Focus, LLC, and Heanue, K. (2007). NCHRP Report 594: Guidebook for Integrated Freight into Transportation Planning and Project Selection Processes. Transportation Research Board of the National Academies, Washington, D.C.

Cambridge Systematics, TransMangement, INC, and Heanue, K. (2007). NCHRP report 570: Guidebook for Freight Policy, Planning, and Programming in Small-and Mediumsized Metropolitan Areas.Transportation Research Board of the National Academies, Washington, D.C.

Carrion, C., and Levinson, D. (2012). Value of Travel Time Reliability: A Review of Current Evidence. Transportation Research Part A: Policy and Practice , 46(4), 720-741.

Chapman, R. G., and Staelin, R. (1982). Exploiting Rank Ordered Choice Set Data within the Stochastic Utility Model. Journal of Marketing Research, 288-301.

Danielis, R., Marcucci, E., and Rotaris, L.(2005). Logistics Managers' Stated Preferences for Freight Service Attributes. Transportation Research Part E: Logistics and Transportation Review, 41(3), 201-215.

Davidson, J. D. (1973). Forecasting Traffic on STOL. Operational Research, Quarterly, 561-569.

Davidson, R., and Farquhar, R. (1976). Bibliography on Method of Paired Comparisons. Biometrics 32(2), 241-252. 
De Jong, G. (2008). Value of Freight Travel-Time Savings. Handbook of Transport Modelling. Elsevier.

De Jong, G., Bakker, C., Pieters, M., and Wortelboer-van, D., P. (2004). New Values of Time and Reliability in Freight Transport in the Netherlands. European Transport Conference 2004, Strasbourg.

De Jong, G., and Bliemer, M.C. (2015). On Including Travel Time Reliability of Road Traffic in Appraisal. Transportation Research Part A: Policy and Practice, 73, 80-95.

De Jong, G., Kouwenhoven, M., Bates, J., Koster, P., Verhoef, E., Tavasszy, L. and P. Warffemius. (2014). New SP-Values of Time and Reliability for Freight Transport in the Netherlands. Transportation Research Part E: Logistics and Transportation Review 64, 71-87.

Dullaert, W., and Zamparini, L. (2013). The Impact of Lead Time Reliability in Freight Transport: A Logistics Assessment of Transport Economics Findings. Transportation Research Part E: Logistics and Transportation Review 49(1), 190-200.

Fosgerau, M., and Karlström, A. (2010). The Value of Reliability. Transportation Research Part B: Methodological, 44(1), 38-49.

Federal Highway Administration (FHWA). (2006). Travel Time Reliability: Making It There on Time, All the Time. Available at : http://ops.fhwa.dot.gov/publications/tt_reliability/brochure/ttr_brochure.pdf. Accessed : 8 October 2016.

Federal Highway Administration (FHWA), Bureau of Transportation Statistics (BTS). (2013). Freight Facts And Figures. Available at : http://www.ops.fhwa.dot.gov/freight/freight_analysis/nat_freight_stats/docs/13factsfigure s/pdfs/fff2013_highres.pdf. Accessed : 8 October 2016.

Fetter, R. B., and Dalleck, W. (1961). Decision Models for Inventory Management. Richard D. Irwin, INC.

Florida Department of Transportation (FDOT). (2000) . The Florida Reliability Method in Florida's Mobility Performance Measures Program. Available at : http://www.fdot.gov/planning/statistics/mobilitymeasures/reliability.pdf. Accessed : 6 March, 2015.

Fosgerau, M. (2007). Using Nonparametrics to Specify a Model to Measure the Value of Travel Time. Transportation Research Part A: Policy and Practice, 41(9), 842-856.

Fowkes, A. S. and Tweedle, G. (1996). Modelling and Forecasting Freight Transport Demand. Mimeo, ITS-University of Leeds.

Fowkes, A.S., Firmin, P.E., Tweddle, G. and Whiteing, A.E. (2004). How Highly does the Freight Transport Industry Value Journey Time Reliability-and for What 
Reasons? International Journal of Logistics: Research and Applications, 7(1), 33-43.

Fowkes, T., and Whiteing, T. (2006). The Value of Freight Travel Time Savings and Reliability Improvements-Recent Evidence From Great Britain. European Transport Conference of the Association for European Transport, Strasbourg, France.

Fries, N., De Jong, G., Patterson, Z., and Weidmann, U. (2010). Shipper Willingness to Pay to Increase Environmental Performance In Freight Transportation. Transportation Research Record: Journal of the Transportation Research Board, 2168, 33-42.

Fridstrom, L., and Madslien, A. (1995). A Stated Preference Analysis of Wholesalers' Freight Choice. Institute of Transport Economics, Oslo.

Garrow, L. A. (2010). Discrete Choice Modelling and Air Travel Demand: Theory and Applications. Ashgate Publishing.

Gatta V., and Marcucci, E. (2016). Behavioural Implications of Non-Linear Effects on Urban Freight Transport Policies: The Case of Retailers And Transport Providers in Rome. Case Study on Transport Policy, 4(1), 22-28.

Gaver Jr, P. (1968). Headstart Strategies for Combating Congestion. Transportation Science, 2(2), 172-181.

Gong, Q., Miao, Q., Wang, B., and Adams, T. (2012). Assessing Public Benefits and Costs of Freight Transportation Projects: Measuring Shippers'value of Delay on the Freight System. Texas Transportation Insitute and University Transportation Center for Mobility.

Green, E. and Srinivasan, V.(1990). Conjoint Analysis in Marketing: New Developments with Implications For Research and Practice. The Journal of Marketing, 3-19.

Greene, William H. (1992). LIMDEP Version 6.0: User's Manual and Reference Guide. Available at : http://pages.stern.nyu.edu/ wgreene/DiscreteChoice/Software/LIMDEPShort-Student-Manual.pdf. Accessed : 13 March 2015.

Guo, Jessica Y. and Gong, Q.(2012). Understanding and Modeling Freight Stakeholder Behavior. Final Report. National Center for Freight and Infrastructure Research and Education, Wisconsin Department of Transportation, and Research and Innovative Technology Administration.

Halse, A., Samstad, H., Killi, M., Flugel, S., and Ramjerdi, F. (2010). Value of Freight Transport Time and Reliability. Institute of Transport Economics.

Hensher, D., John, R., and Greene,W. (2005). Applied Choice Analysis: A Primer. Cambridge University Press.

Hossan, M., Asgari, H. and X. Jin (2016). Investigating Preference Heterogeneity in Value of Time (VOT) and Value of Reliability (VOR) Estimation for Managed Lanes. 
Transportation Research Part A: Policy and Practice (94): pp. 638-649.

Huber, J., and , K. Zwerina (1996). The Importance of Utility Balance in Efficient Choice Designs. Journal of Marketing Research, 307-317.

Jackson, W., and J. Jucker,. (1982). An Empirical Study of Travel Time Variability and Travel Choice Behavior. Transportation Science,16(4), 460-475.

Jin, X., M.S. Hossan, and H. Asgari (2015). Investigating the Value of Time and Value of Reliability for Managed Lanes. Research Report, Prepared for Systems Planning Office, Florida Department of Transportation, FDOT Project Number BDV29-977-12.

Jovicic, G. (1998). Application of Models Based on Stated and Revealed Preference Data for Forecasting Danish International Freight Transport. Tetraplan AS, Aalborg, Denmark.

Kardes, F. R., and Herr., P. (1990). Order Effects in Consumer Judgment, Choice, and Memory: the Role of Initial Processing Goals. Advances in Consumer Research 17.

Kawamura, K. (1999). Commercial Vehicle Value of Time and Perceived Benefit of Congestion Pricing. Phd dissertation. University of California Transportation Center.

Knight, T. E. (1974). An Approach to the Evaluation of Changes in Travel Unreliability: A 'Safety Margin’ Hypothesis. Transportation, 3, 393-408.

Krantz, D.H., Luce, R.D., Suppes, P. and Tversky, A. (1971). Foundations of Measurement, Vol. 1, Additive and Polynomial Representations. Academic Press, New York.

Kuipers, B., and Rozemeijer, S. (2006). Strategies by Shippers and Transport Companies in Response of Decreasing Reliability of Travel Times. Report. TNO, Delft.

Kurri, J., Sirkiä, A., and Mikola,J. (2000). Value of Time in Freight Transport in Finland. Transportation Research Record: Journal of the Transportation Research Board, 1725(1), 26-30.

Lam, T. C., and Small, K. (2001). The Value of Time and Reliability: Measurement From a Value Pricing Experiment. Transportation Research Part E: Logistics and Transportation Review, 37(2), 231-251.

Li, Z., and Hensher,D. (2012). Accommodating Risk Attitudes in Freight Transport Behaviour Research. Transport Reviews, 32(2), 221-239.

List, F., Williams, B., Rouphail, N., Hranac, R., Barkley, T., Mai, E., Ciccarelli, E. SHRP 2 Report S2-L02-RR-1 : Establishing Monitoring Programs for Travel Time Reliability. Transportation Research Board of the National Academies, Washitngton,D.C. 
Louviere, J., Meyer, R., Stetzer, F., and Beavers, LL. (1973). Theory, Methodology and Findings in Mode Choice Behavior. Report. Urban Mass Transportation Administration and the University of IOWA, IOWA City.

Louviere, J. J., and Hensher, D. (1982). Design and Analysis of Simulated Choice or Allocation Experiments in Travel Choice Modeling.Transportation Research Record: Journal of the Transportation Research Board, 890.

Louviere, J. J., and Woodworth, G. (1983). Design and Analysis of Simulated Consumer Choice or Allocation Experiments: An Approach Based on Aggregate Data. Journal Of Marketing Research, 350-367.

Louviere, J. J., and Kocur, G. (1983). The Magnitude of Individual-Level Variations in Demand Coefficients: A Xenia, Ohio Case Example. Transportation Research Part A: General 17(5), 363-373.

Louviere, J. J., Hensher, D., and Swait, J. (2000). Stated Choice Methods: Analysis and Applications. Cambridge University Press.

McFadden, D. (1974). The Measurement of Urban Travel Demand. Journal of Public Economics, 3(4), 303-328.

Mahmassani, H., Kim, S., Chen, J., Stogios, Y., Brijmohan, Y., and Vovsha, P. (2013). SHRP 2 Report 52-L04-RR-1: Incorporating Reliability Performance Measures in Operations and Planning Modeling Tools. Transportation Research Board of the National Academies, Washington, D.C.

McKinnon, Alan C. (1998). The Impact of Traffic Congestion on Logistical Efficiency. Report. Institute of Logistics Research.

McKinnon, A., Palmer, A., Edwards, J., and Piecyk, M. (2008). Reliability of Road Transport from the Perspective of Logistics Managers and Freight Operators. Joint Transport Research Centre of the OECD and the International Transport Forum, Edinburgh, U.K.

Marcucci, E., and Gatta, V. (2012). Dissecting Preference Heterogeneity in Consumer Stated Choices. Transportation Research Part E: Logistics and Transportation Review, 48(1), 331-339.

Marcucci, E., and Gatta, V. (2013). Intra-Agent Heterogeneity in Urban Freight Distribution: the Case of Own-account Operators. International Journal of Transport Economics, 40(2), 267-286.

Margreta, M., Ford, C., and Grube, R. (2014). U.S. Freight on the Move: Highlights from the 2012 Commodity Flow Survey Preliminary Data. US Census Bureau and U.S. Department of Transportation. Available at : http://www.rita.dot.gov/bts/sites/rita.dot.gov.bts/files/CFS_Complete.pdf. Accessed : 18 September 2015. 
Masiero, L., and Hensher, D. A. (2010). Analyzing Loss Aversion and Diminishing Sensitivity in a Freight Transport Stated Choice Experiment. Transportation Research Part A: Policy and Practice, 44(5), 349-358.

Masiero, L., and Hensher, D. A. (2012). Freight Transport Distance and Weight as Utility Conditioning Effects on a Stated Choice Experiment. Journal of Choice Modelling, 5(1), 64-76.

McMullen, B. S., Holder, D., Want, Z., McCormack, E., Goodchild, A., Casavant, K., Sage, J. (2015). Reliability Measurement, Value of Travel Time and the Value of Travel Time Reliability for Freigth [PowerPoint slides] Avaiable at : http://ses.wsu.edu/wpcontent/uploads/2015/03/Freight-Travel-Time-and-Reliability- TRB- presentation-3-1313.pdf . Accessed : 15 July 2016.

Nasri, F., Paknejad, J. and Affisco, J. (2008). Investing in Lead-Time Variability Reduction in a Quality-Adjusted Inventory Model with Finite-Range Stochastic LeadTime. Advances in Decision Sciences.

Ngene. (2014). Ngene User Manual \& Reference Guide Version : 1.1.2. Available at : www.choice-metrics.com. Accessed : 13 July 2015.

Paknejad, M. J., Nasri, F., and Affisco, J. (1992). Lead-Time Variability Reduction in Stochastic Inventory Models. European Journal of Operational Research, 62(3), 311-322.

Puckett, S.M., Hensher, D.A., Rose, J.M., and Collins, A. (2007). Design and Development of a Stated Choice Experiment in a Two-Agent Setting: Interactions Between Buyers and Sellers of Urban Freight Services. Transportation, 34 (4), 429-451.

Puckett, S.M., and Rasciute, S. (2010). Freight Stakeholders' Sensitivities Under Road User Charging: A Latent Class Approach. Australasian Transport Research Forum (ATRF), 33,.

Puget Sound Regional Council (PSRC). (2009). Benefit-Cost Analysis : General Methods and Approach. Available at

http://www.psrc.org/assets/2127/BCA_Methods_Report_Mar2010update.pdf. Accessed : 2 October, 2016.

Sage, J., Casavant, K., Goodchild, A., McCormack, E., Wang, Z., McMullen, B. S. and Holder, D. (2013). Development of a Freight Benefit/Cost Methodology for Project Planning. Final Report. Washington State Department of Transportation, WA.

Sanko, N. (2001). Guidelines for Stated Preference Experiment Design. Master in Bussiness dissertation. Ecole Nationale des Ponts et Chaussées.

SAS. (2008). SAS Version 9.2. Available at : http://www.sas.com/. Accessed : 15 March, 2015.

Sawtooth Software. (1999) Available at : http://www.sawtoothsoftware.com/. Accessed : 
15 March, 2015.

Schrank, D., and Lomax, T. (2003). The 2003 Annual Urban Mobility Report. Texas Transportation Institute.

Schrank, D., Eisele, B., and Lomax, T. (2012). TTI's 2012 Urban Mobility Report. Proceedings of The 2012 Annual Urban Mobility Report. Texas A\&M and Transportation Institute.

Shams, K., Jin, X., Asgari, H., and Md. Hossan (2015). An Investigation of Temporal Transferability Comparing Trip-Based and Tour-Based Choice Models. TRB 94th Annual Meeting Compendium of Papers, Paper\#15-0287.

Shams, K., Asgari, H. and X. Jin (2016). Valuation of travel time reliability in freight transportation: A review and meta-analysis of stated preference studies. Transportation Research Part A: Policy and Practice, in press, http://dx.doi.org/10.1016/j.tra.2016.08.001.

Significance, VU University Amsterdam, and John Bates services. (2012). Value of Time and Reliability in Passenger and Freight Transport in the Netherlands. Final version Report for the Ministry of Infrastructure and the Environment, Netherlands.

Small, K. (1982). The Scheduling of Consumer Activities: Work Trips. The American Economic Review , 467-479.

Small, K. (1999). Valuation of Travel-Time Savings and Predictability in Congested Conditions for Highway User-Cost Estimation. Vol. 431. Transportation Research Board of the National Academies, Washington, DC.

Small, K., Winston, C., and Yan, J. (2005). Uncovering the Distribution of Motorists' Preferences for Travel Time And Reliability. Econometrica, 73(4), 1367-1382.

SPSS Inc. (1994). SPSS Professional Statistics Version 6.1. Available at : http://www.ibm.com/analytics/us/en/technology/spss/ . Accessed : 15 July 2015.

Strocko, E., Sprung, M., Nguyen, L., Rick, C. and Sedor, J. (2014). Freight Facts and Figures 2013. Technical Report, Federal Highway Administration.

Thurstone, L. L. (1927). A Law of Comparative Judgment. Psychological Review, 34(4), 273.

Vaziri, M., Dashtestaninejad, H., Asgari, H., and F., Salimi (2014). Rural Travel Behavior in Developing Countries: A Study of Farm-Based Villages in Iran. The Journal of Sustainable Mobility, Vol.1, No.2, pp. 25-45 (21).

Vernimmen, B., Dullaert, W., Willemé, P., and Witlox., F. (2008). Using the Inventorytheoretic Framework to Determine Cost-Minimizing Supply Strategies in a Stochastic 
Setting. International Journal of Production Economics, 115( 1), 248-259.

Wardman, M. (1988). A Comparison of Revealed Preference and Stated Preference Models of Travel Behaviour. Journal of Transport Economics and Policy, 71-91.

Weisbrod, G., Vary, D., and Treyz., G. (2001). Economic Implications of Congestion. NCHRP Report: 463, Washington, D.C.

Wigan, M., Rockliffe, N., Thoresen, T, and Tsolakis, D. (2000). Valuing Long-Haul and Metropolitan Freight Travel Time and Reliability. Journal of Transportation and Statistics, 3, 83-90.

Winston C. (1981). A Disaggregate Model of the Demand for Intercity Freight Transportation. Econometrica, 49( 4), 1006.

Zamparini, L., and Reggiani., A. (2007) . Freight Transport and the Value of Travel Time Savings: A Meta-analysis of Empirical Studies. Transport Reviews,27(5), 621-636.

Zamparini, L., Layaa, J., and Dullaert, W. (2011). Monetary Values of Freight Transport Quality Attributes: A Sample of Tanzanian Firms. Journal of Transport Geography, 19(6), 1222-1234.

Zotti, J., and Danielis, R. (2004). Freight Transport Demand in the Mechanics' Sector of Friuli Venezia Giulia: the Choice between Intermodal and Road Transport. European Transport, 25-26, 9-12. 


\section{APPENDIX}

\section{INSTRUCTION AND QUALIFICATION QUESTIONS}

\subsection{Dear Freight Stakeholders:}

Welcome to Florida Freight Survey!

In an effort to support the investment and policy decisions that reflect the needs of freight stakeholders in Florida, the Lehman Center for Transportation Research (LCTR) at the Florida International University (FIU) is working with the Florida Department of Transportation (FDOT) in conducting a stated preference survey to better understand how the freight industry values transportation system performance in travel time reliability.

The purpose of this survey is to help us understand the underlying factors in freight transportation decisions in terms of system performance attributes, and the user's willingness to pay to improve travel time reliability. Your response to this survey is crucial in achieving the goal of this study to provide the insights to support freight transportation planning and decision-making.

Participation in the survey is simple:

1. Complete the questionnaire about your firm and typical shipment, which takes about 10 minutes.

2. You will be presented with 6-7 hypothetical choice questions to choose the best option among these. It takes about 15 minutes to complete.

Your participation in the survey is completely voluntary and we take your privacy seriously. All records of this study will be kept confidential and protected. Analysis will be performed to the aggregated data only. Under no circumstances, will your name or other identification information be revealed.

If you have any questions regarding the survey or the methodology, please feel free to contact the Principal Investigator Dr. Xia Jin at xjin1@fiu.edu or 305-348-2825.

Thank you in advance for participating in the survey!

By agreeing with the participation, you will give your consent and confirm your participation in the survey.

1.2. Please select the appropriate category.

O Shippers

O Carriers

O Forwarders or third party logistics

O None of the Above 


\section{3. [ If respondent has selected the "None of the above"]}

Thank you for taking time to provide this information. Unfortunately, this survey will not be benefited from your responses, as it is designed for only shippers, carriers and forwarding/3PL parties. We really appreciate your sincere efforts.

If you have any questions regarding the survey or the methodology, please feel free to contact the Principal Investigator Dr. Xia Jin at xjin1@fiu.edu, or Kollol Shams at ksham004@fiu.edu.

\section{4. [ If respondent has selected the "Shippers"]}

How do you transport your shipments?

○ Own fleet

- For hire

- Third-party logistics

- Others, please specify 


\section{BASE SHIPMENT CHARACTERISTICS QUESTIONS}

This section asks about one of your recent shipments, which will only be used to generate possible scenarios for your shipment in a later part. You are advised to give approximate values, in case you find this information sensitive

To avoid any kind of ambiguity, please read the following instructions before you fill in the answers to the questions:

1) Your typical shipment may consist of many types of commodity, such as agricultural, minerals, food products, heavy construction materials, etc., but please select any one of these commodities.

2) If you use more than one mode for that shipment, please select the primary mode, which carries the majority of the shipment duration. For example, trucks are often used to transport goods to and from rail stations, but "Rail" is considered as the primary mode.

3) Your shipment consists of a one-way distance (or duration), traveled (or spent) from your departure location (typically includes your distribution center or your client's pick up location) to the designated arrival location (client's specified, customer's location). It includes all the intermediary times or distance spent between these points.

4) You may have multiple drops for a single shipment. In that case, please select first drop as your typical shipment (in case you are not sure about the first drop, please take your best guess!).

5) Shipment cost amounts to the price paid for the transportation services, including transshipments ( for shippers, 3PL or forwarding companies) or transportation operating costs (which may include fuel, driver, administration, insurance, etc.) and possible transshipment costs (excluding initial loading and final unloading).

We understand that it is hard to give a single shipment information (in particular, freight rate, transit time, etc.) since every contract varies depending on the merit of client and situations. Please provide a typical one with no case of special arrangement or emergency situation, which will only be used to ask your further questions.

2.1. Please select the primary mode for your recent or typical shipment
○ Truck
- Rail
O Air
- Waterways

2.2. What was the commodity type for the shipment?
$\circ$ Agricultural
- Minerals
- Lumber
- Paper, Chemicals
- Petroleum Products 
○ Warehousing

○ Non-municipal Waste

- Construction Materials (Concrete, Glass, Clay, Stone)

$\circ$ Others, Please Specify

- Food Products

○ Nondurable Manufacturing

2.3. [ If Truck is selected ]

What was the shipping distance?

○ Less than 50 miles

○ 50-300 miles

○ Greater than 300 miles

2.4. [If Rail is selected]

What was the shipping distance?

- Less than 300 miles

o o 300-1000 miles

○ Greater than 1000 miles

2.5. [ If Air or Water mode is selected ]

What was the shipping distance?

○ Within Florida

- Outside Florida

- Please specify distances (in miles)

2.6. [If Air or Water mode \& Outside Florida is selected]

Please specify your

- Origin (State, City)

○ Destination (State, City)

2.7. What was the shipping duration?

day(s)__ hour(s), OR

$\begin{array}{ll}\circ & 0-4 \mathrm{hrs} \\ \circ & 4-8 \mathrm{hrs} \\ \circ & 8-12 \mathrm{hrs} \\ \circ & 12-18 \mathrm{hrs} \\ \circ & 18-24 \mathrm{hrs} / 1 \text { day } \\ \circ & 1-3 \text { day } \\ \circ & 3-5 \text { day } \\ \circ & \text { Others }\end{array}$


2.8. [ If Shippers without transport or 3PL is selected ]

What was the shipping cost? (the price paid for the transportation services, including transshipments )

$\begin{array}{ll}\$ & \\ \circ & \text { Less than } \$ 150 \\ \circ & \$ 150-\$ 400 \\ \circ & \$ 400-\$ 600 \\ \circ & \$ 600-\$ 800 \\ \circ & \$ 800-\$ 1200 \\ \circ & \$ 1200-\$ 1800 \\ \circ & \text { Others }\end{array}$

2.9. [ If Shippers with transport or carriers is selected ]

What was the shipping cost? (transportation operating costs (which may include fuel, driver, administration, insurance, etc. and possible transshipment costs - excluding initial loading and final unloading)

$\$$ , OR
○ Less than $\$ 150$
○ $\$ 150-\$ 400$
○ $\$ 400-\$ 600$
○ $\$ 600-\$ 800$
○ $\$ 800-\$ 1200$
○ $\$ 1200-\$ 1800$
O Others

2.10. What was the shipping size? tons/ items $/ \mathrm{ft}^{3} /$ other_( select any unit) 
2.11. How is the delivery time defined by clients, or contract?

\section{Within}
$\bigcirc$ certain hour (s) of day
○ certain day (s)
O certain week (s)
○ Not applicable

2.12. Was there monetary penalty for late delivery?
○ Yes
○ No

\subsection{3. [ If Truck mode is selected ]}

What kind of truck did you use for the shipment?

Light : Pick-ups and Vans

○ Medium: Two-Axle, Six-Tire Single-Unit Trucks

O Heavy: Three or more single unit/trailer/multi-trailer trucks

2.14. [ If Trucking type is selected ]

What kind of trucking did you use for the shipment?

$\bigcirc$ Less than Truckload (LTL)

Full Truck Load (FTL)

O Refrigerated

$\bigcirc$ Drayage

O Others 


\section{STATED PREFERENCE QUESTIONS}

In the following sections, you will be presented with various hypothetical scenarios; each has two or three shipping alternatives, with varying levels of transit time, shipment cost, reliability or departure time period. In the hypothetical scenarios, you will find some alternatives may have higher or lower transit time, cost or travel time reliability compared to other alternatives. You can think of the following reasons behind these:

- The increase in transit time, or decrease in transit time reliability may be the result of increased traffic congestion, incidents, or construction etc., whereas the increase in shipment cost could be due to the use of longer route or a toll road.

- The decrease in transit time or the increase in transit time reliability could be due to improvement in the infrastructure, or other strategies to improve level of service.

- Finally, any gain in transit time saving means that you could pay less for operating cost, including fuel cost, driver and staff wage.

- Similarly, in case of improved reliability in transportation network, you may plan for more services or consolidating multiple deliveries, increasing your productivity. On contrary, decrease in reliability or unexpected delay in transit time may result in product deterioration, financial penalty or insurance claim, reputation, running out of stock, etc.

Please click "Next" to continue

3.1. Do you typically transport goods during peak hours (7:00 Am to 9:59 AM and 4:00 PM to 6:59 PM?

O Yes

O No

3.2. [ If respondent has selected "Yes"]

Would you shift your typical departure time for your shipment in order to avoid peak hour congestion?
○ Yes
O No

3.3. Did you have any alternative mode for the recent/typical shipment mentioned above?

○ Yes

O No

3.4. [ If respondent has selected "Yes"]

Would you consider changing your mode for this typical / recent shipment in future, if better service is provided?

○ Yes

O No

3.5. Before we start our main survey, this is a short tutorial that will walk you through the choice process.

Suppose you have a typical shipment, which takes about $\mathbf{1 0}$ hours to delivery to the customer at the designated destination and you charge about $\mathbf{\$ 5 0 0}$ for the shipment. However, due to 
congestion, accident, work zone or adverse weather, your shipment sometimes gets delay. Florida Department of Transportation (FDOT) is considering different project or policy strategies, which may result in reduced your shipment time, or cost or uncertainty but not altogether. Now, if you have to choose from the following two options, which one would you prefer?

\begin{tabular}{|c|c|}
\hline Alternative 1 & Alternative 2 \\
\hline Transit time : $\mathrm{XX}$ & Transit time : XX \\
\hline $\begin{array}{l}\text { Your shipment has the following risk of } \\
\text { delay }\end{array}$ & $\begin{array}{l}\text { Your shipment has the following risk of } \\
\text { delay }\end{array}$ \\
\hline \begin{tabular}{l|l} 
On time: & 4 out of 5 times \\
Late : & $\begin{array}{l}1 \text { out of } 5 \text { times, with a } \\
\text { possible delay of } 30 \text { min }\end{array}$
\end{tabular} & \begin{tabular}{l|r} 
On time: & 2 out of 5 times \\
Late : & 3 out of 5 times, with a \\
& possible delay of $1-2 \mathrm{hrs}$
\end{tabular} \\
\hline Shipping cost & Shipping cost : \\
\hline I prefer this option & I prefer this option \\
\hline
\end{tabular}

\subsection{Tips for tutorial}

If you have chosen Alternative 1, it means that you prefer to pay more than the current cost for improved reliability. Or, if you have chosen Alternative 2, it means that you ready to accept longer transit time than the regular one in return of lower operation cost.

3.7. Please select the appropriate box based on the importance of these factors in your transportation decisions

\begin{tabular}{|l|ccc|}
\hline \multicolumn{1}{|c}{ Attribute } & Not important & Important & Most important \\
\hline Reliability & $\mathrm{O}$ & $\mathrm{O}$ & $\mathrm{O}$ \\
Travel Cost & $\mathrm{O}$ & $\mathrm{O}$ & $\mathrm{O}$ \\
Travel Time & $\mathrm{O}$ & $\mathrm{O}$ & $\mathrm{O}$ \\
Security \& Damage & $\mathrm{O}$ & $\mathrm{O}$ & $\mathrm{O}$ \\
Service Flexibility( can provide & $\mathrm{O}$ & $\mathrm{O}$ & $\mathrm{O}$ \\
service without prior & & & \\
notification) & $\mathrm{O}$ & $\mathrm{O}$ & $\mathrm{O}$ \\
Others, Please specify & & &
\end{tabular}

3.8. Image : Start Now 


\subsection{Experiment, $\mathrm{C} 1$}

[If respondent is not willing to ship goods during peak hour - "No" on Question 16, or (s)he has selected "Yes" on Question 16 and "No" on Question 17 - AND (s)he is not interested in shifting to other modes - "No" on Question 18, or (s)he has selected "Yes" on Question 18 and "No" on Question 19]

You are re-evaluating your options for your shipments this month. Below are $<3>$ different options for your shipment. These options vary by Transit time, Cost, Travel time reliability. If the options below are the only options available for your trip, which would you prefer?

[For all the questions] Highlighted information may have changed.

\begin{tabular}{|c|c|c|c|c|}
\hline Alternative 1 & \multicolumn{2}{|c|}{ Alternative 2} & \multicolumn{2}{|c|}{ Alternative 3} \\
\hline $\begin{array}{c}\text { Actual } \\
\text { Transit Time }\end{array}$ & \multicolumn{2}{|c|}{$\begin{array}{c}\mathrm{X} \text { hrs more than } \\
\text { Actual transit time }\end{array}$} & \multicolumn{2}{|c|}{$\begin{array}{l}\mathrm{X} \text { hrs more than } \\
\text { Actual transit time }\end{array}$} \\
\hline $\begin{array}{l}\text { Your shipment has the } \\
\text { following risk of delay }\end{array}$ & \multicolumn{2}{|c|}{$\begin{array}{l}\text { Your shipment has the } \\
\text { following risk of delay }\end{array}$} & \multicolumn{2}{|c|}{$\begin{array}{l}\text { Your shipment has the } \\
\text { following risk of delay }\end{array}$} \\
\hline $\begin{array}{l}\text { Y out of } 5 \\
\text { times } \\
Y \text { out of } 5 \\
\text { times, with a } \\
\text { possible delay } \\
\text { of } \mathrm{Z} \text { hrs }\end{array}$ & $\begin{array}{l}\text { On } \\
\text { time: } \\
\text { Late : }\end{array}$ & $\begin{array}{l}\text { Y out of } 5 \\
\text { times } \\
\text { Y out of } 5 \\
\text { times, with a } \\
\text { possible delay } \\
\text { of } Z \text { hrs }\end{array}$ & $\begin{array}{l}\text { On } \\
\text { time: } \\
\text { Late : }\end{array}$ & $\begin{array}{l}\text { Y out of } 5 \\
\text { times } \\
\text { Y out of } 5 \\
\text { times, with a } \\
\text { possible delay } \\
\text { of } \mathrm{Z} \mathrm{hrs}\end{array}$ \\
\hline (Hints : XX Reliability) & \multicolumn{2}{|c|}{ (Hints : XX Reliability) } & \multicolumn{2}{|c|}{ (Hints : XX Reliability) } \\
\hline $\begin{array}{c}\text { X more than } \\
\text { Actual shipping cost }\end{array}$ & \multicolumn{2}{|c|}{$\begin{array}{c}\text { X less than } \\
\text { Actual shipping cost }\end{array}$} & \multicolumn{2}{|c|}{$\begin{array}{c}\mathrm{X} \text { less than } \\
\text { Actual shipping cost }\end{array}$} \\
\hline I prefer this option & \multicolumn{2}{|c|}{ I prefer this option } & \multicolumn{2}{|c|}{ I prefer this option } \\
\hline
\end{tabular}




\subsection{Experiment $\mathrm{C} 2$}

[If respondent is willing to ship goods during peak hour - "Yes" on Question 16, or (s)he has selected "No" on Question 16 and "Yes" on Question 17 AND (s)he is not interested in shifting to other modes - "No" on Question 18, or (s)he has selected "Yes" on Question 18 and "No" on Question 19]

You are re-evaluating your options for your shipments this month. Below are $\langle 3\rangle$ different options for your shipment. These options vary by Transit time, Cost, Travel time reliability, $<$ Departure time >.

If the options below are the only options available for your trip, which would you prefer?

[For all the questions] Highlighted information may have changed.

[For all the questions] Highlighted information may have changed.

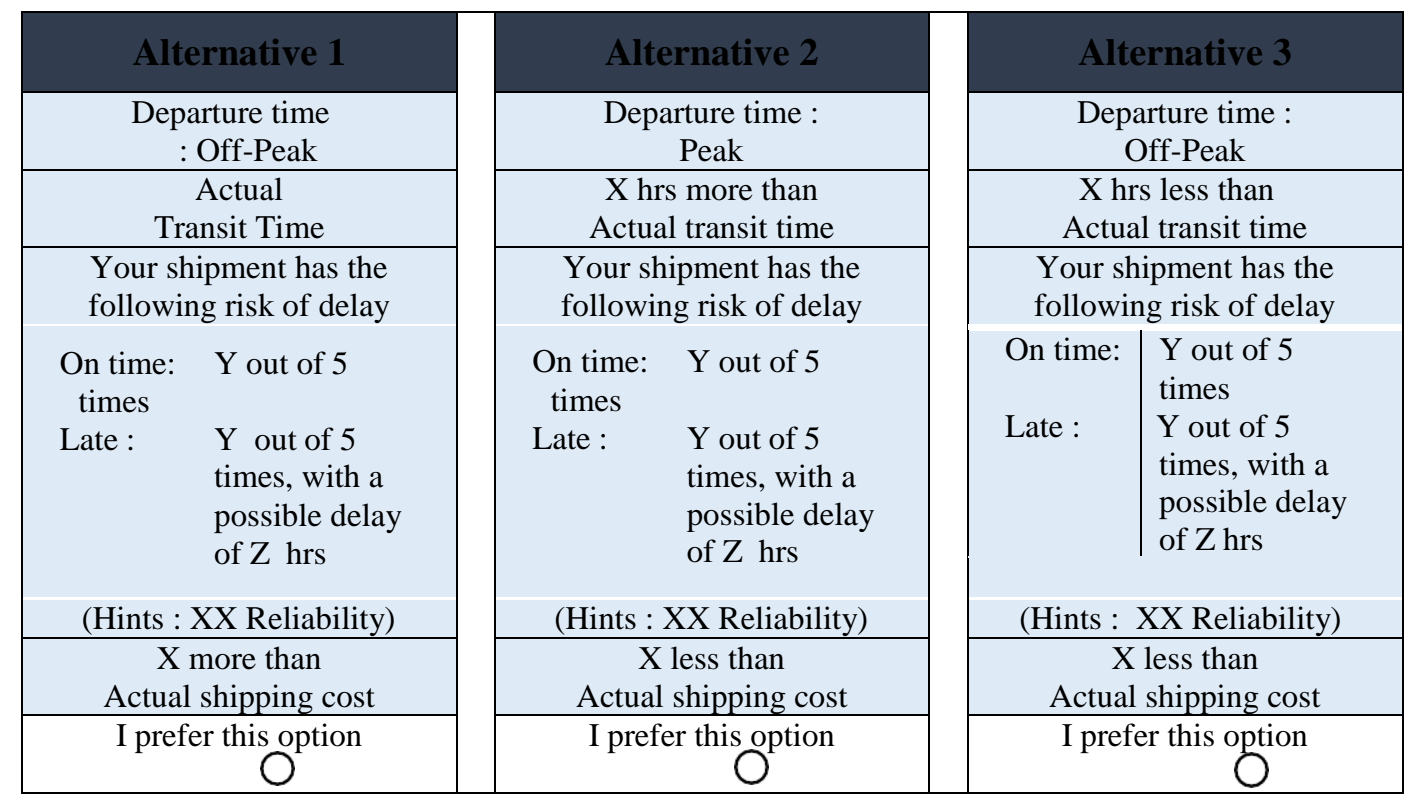

\subsection{Experiment $\mathrm{C} 3$}

[If respondent is not willing to ship goods during peak hour - "No" on Question 16, or (s)he has selected "Yes" on Question 16 and "No" on Question 17 AND (s)he is interested in shifting to other modes - "Yes" on Question 18 and "Yes" on Question 19]

You are re-evaluating your options for your shipments this month. Below are $\langle 2\rangle$ different options for your shipment. These options vary by Transit time, Cost, Travel time reliability, $<$ Service flexibility, Damage risk >.

If the options below are the only options available for your trip, which would you prefer? [For all the questions] Highlighted information may have changed. 
[For all the questions] Highlighted information may have changed.

\begin{tabular}{|c|c|}
\hline Alternative 1 (Road) & Alternative 1 (Rail) \\
\hline $\begin{array}{c}\text { Actual } \\
\text { Transit Time }\end{array}$ & $\begin{array}{l}\text { X hrs more than } \\
\text { Actual transit time }\end{array}$ \\
\hline Your shipment has the following risk of delay & Your shipment has the following risk of delay \\
\hline $\begin{array}{ll}\text { On time: } & \text { X out of } 5 \text { times } \\
\text { Late : } & \text { X out of } 5 \text { times, with a } \\
& \text { possible delay of } \mathrm{X} \text { hrs }\end{array}$ & \begin{tabular}{l|l} 
On time: & X out of 5 times \\
Late : & X out of 5 times, with \\
& a possible delay of $2-4 \mathrm{hrs}$
\end{tabular} \\
\hline (Hints : XX Reliability) & (Hints : XX Reliability) \\
\hline $\begin{array}{c}\mathrm{X} \text { more than } \\
\text { Actual shipping cost }\end{array}$ & $\begin{array}{c}\text { X less than } \\
\text { Actual shipping cost }\end{array}$ \\
\hline Service Flexibility : X & Service Flexibility : X \\
\hline Damage risk : $\mathrm{X} \%$ & Damage risk : $\mathrm{X} \%$ \\
\hline I prefer this option & I prefer this option \\
\hline
\end{tabular}

\subsection{Experiment $\mathrm{C} 4$}

[If respondent is willing to ship goods during peak hour - "Yes" on Question 16, or (s)he has selected "No" on Question 16 and "Yes" on Question 17 AND (s)he is interested in shifting to other modes - "Yes" on Question 18 and "Yes" on Question 19]

You are re-evaluating your options for your shipments this month. Below are $<3>$ different options for your shipment. These options vary by Transit time, Cost, Travel time reliability, $<$ Departure time, Service flexibility, Damage risk >.

If the options below are the only options available for your trip, which would you prefer? [For all the questions] Highlighted information may have changed.

[For all the questions] Highlighted information may have changed.
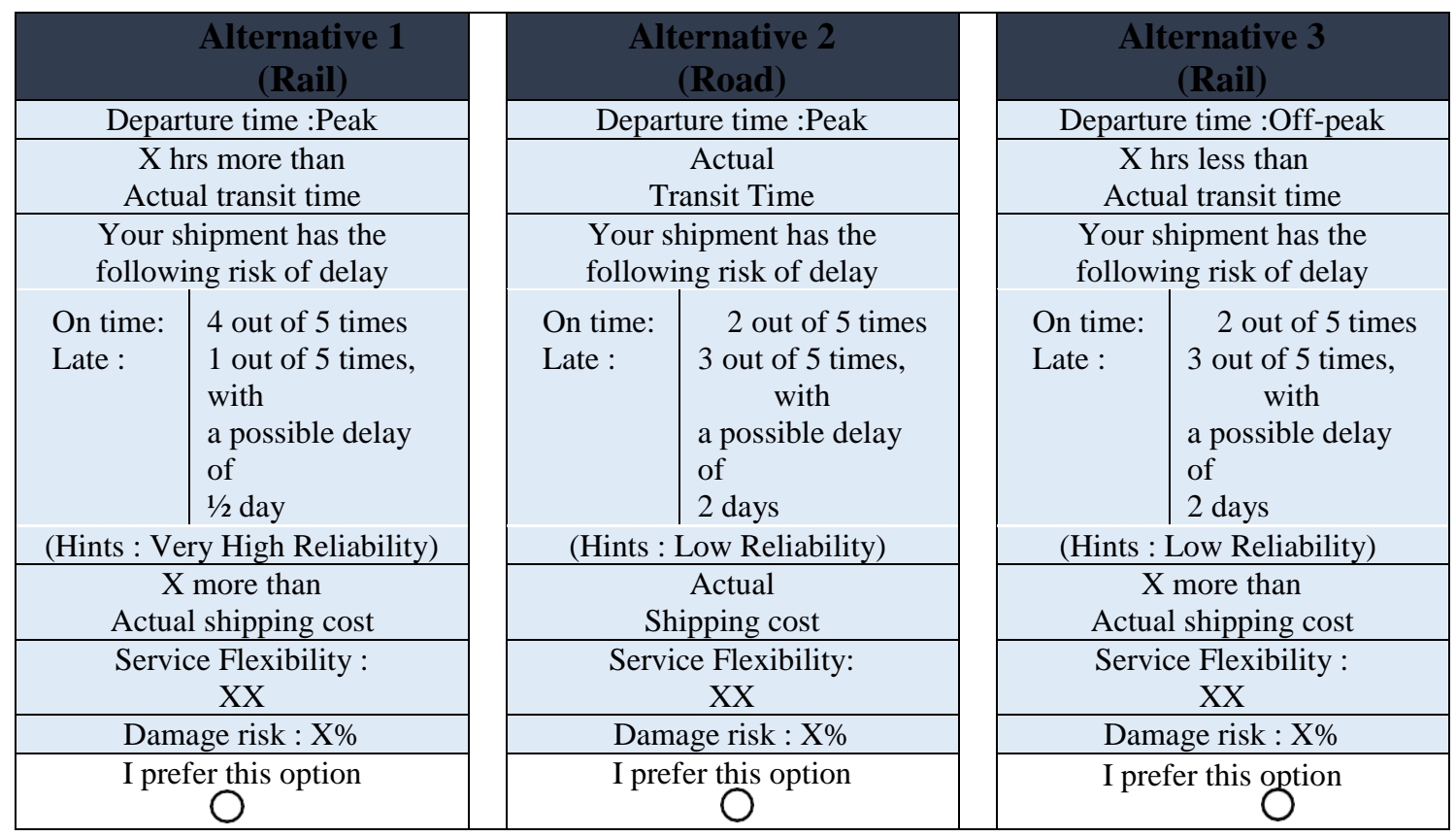

\section{VALIDATION QUESTIONS}


4.1. Image [ Almost There ]

4.2. Was there any attribute (s) that you did not consider while making choices (Please select all that apply)?

\begin{tabular}{|c|c|}
\hline Transit Time & $\square$ \\
\hline Transit Cost & $\square$ \\
\hline Transit Time Reliability & $\square$ \\
\hline No, considered all & $\square$ \\
\hline
\end{tabular}

4.3. This is an optional selection, which will ask you about a series of questions regarding your attitudes towards freight transportation. Do you want to continue?

○ Yes

O No

4.4. [If respondent selects "No"]

Contact Information (optional):

If you want to consider yourself for the $\$ 10$ gift card, please provide at least your name and e-mail address.

Your name:

Your e-mail address (mandatory):

Name of your company:

Position (mandatory):

Your contact information:

Thank you for taking the time to provide this information. We really appreciate your sincere efforts.

If you have any questions regarding the survey or the methodology, please feel free to contact the Principal Investigator Dr. Xia Jin at xjin1@ fiu.edu or 305-348-2825, or Kollol Shams at ksham004@ fiu.edu or 786-308-5942.

[If respondent selects "Yes", continue to 5.1] 


\section{GENERAL QUESTIONS (OPTIONAL)}

5.1. How often are your out-bound shipments late (out of 10 times)?
○ Never
○ $1-3$
○ $4-7$
○ $7-10$

5.2. How many employees does your firm have?

○ Less than 20

○ Greater than 20

5.3. What percentages of your shipments are on delivery pressure?
○ $<20 \%$
○ $20-50 \%$
○ $50-80 \%$
○ $80-100 \%$

5.4. [For Shippers, 3PL only ]

What percentages of your shipments are on delivery pressure?

$\begin{array}{lll}\circ & \text { Road transport } & \% \\ \circ & \text { Rail } & \% \\ \circ & \text { Air } & \% \\ \circ & \text { Waterways } & \% \\ \circ & \text { Others } & \end{array}$

5.5. [For Carriers \& Shippers with own transport]

Within your company, who makes the routing choice decisions (such as which route to take, or whether to take the toll road)?
O Owner/Operator
O Driver
D Depends on the situation (please explain)

5.6. [For Carriers \& Shippers with own transport]

Do you get reimbursed for tolls from your client?
○ Yes
○ No 


\subsection{Contact Information (optional):}

If you want to consider yourself for the $\$ 10$ gift card, please provide at least your name and e-mail address.

Your name:

Your e-mail address (mandatory):

Name of your company:

Position (mandatory):

Your contact information:

Thank you for taking the time to provide this information. We really appreciate your sincere efforts.

If you have any questions regarding the survey or the methodology, please feel free to contact the Principal Investigator Dr. Xia Jin at xjin1 @ fiu.edu or 305-348-2825, or

Kollol Shams at ksham004@fiu.edu or 786-308-5942. 
VITA

\section{KOLLOL SHAMS}

\section{EDUCATION}

2012 - Present Ph. D. Student

Department of Civil and Environmental Engineering

Florida International University,

Miami, Florida

Dhaka, Bangladesh

2004 - $2009 \quad$ B.Sc., Civil Engineering

Bangladesh University of Engineering and Technology,

Dhaka, Bangladesh

\section{PUBLICATIONS AND PRESENTATIONS}

Shams, K., H.Asgari and X. Jin. "Valuation of travel time reliability in freight transportation: a review and meta-analysis of stated preference studies". Transportation Research Part A: Policy and Practice, 2016 (In Press)

Inanloo, B., Tansel, B., K. Shams, X. Jin, and A. Gan. "A Decision Aid GIS-Based Risk Assessment and Vulnerability Analysis Approach for Transportation and Pipeline Networks". Safety Science 84, 2016, pp.57-66.

Hossan, Md., H. Asgari, K. Shams and X. Jin. "Incorporating Attitudinal Aspects in Roadway Pricing Analysis". Research in Transportation Economics (Accepted).

Shams, K. and X. Jin. "Value of reliability for road freight transportation: evidence from a stated preference survey in florida". The 2017 TRB 96th Annual Meeting. Proceedings of the 96th Annual Meeting of the Transportation Research Board, January 8-125, 2017 (Under Review).

Shams, K., and X. Jin. "Stated preference survey design to understand how freight users value travel time reliability", 14th World Conference on Transport Research, Shanghai, China 2016

Shams, K., X. Jin, H. Asgari, and M. S. Hossan. "An Investigation of Temporal Transferability Comparing Trip-Based and Tour-Based Choice Models," Proceedings of the 94th Annual Meeting of the Transportation Research Board, January 11-15, 2015 (Fully-refereed).

Shams, K., and X. Jin. "Examining Temporal Transferability of Trip Frequency Choice Models". Proceedings of the 93rd Annual Meeting of the Transportation Research Board, January 12-16, 2014 (Fully-refereed). 
Tansel, B., K. Shams, X. Jin, and A. Gan. "Interactive Vulnerability of Transportation and Pipeline Networks: GIS-based Quantitative Risk Assessment". Proceedings of the 93rd Annual Meeting of the Transportation Research Board, January 12-16, 2014 (Fullyrefereed).

Shams, K., X. Jin, and R. Fitzgerald, "Stated Preference Approach to Examine the Value of Travel Time and Reliability for Freight Transportation in Florida". Presented in The Florida Transportation Data Symposium, August 18-20, 2015, Orlando, FL.

Shams, K., X. Jin and M.S. Hossan, "Understanding the Value of Travel Time Reliability for Freight Transportation". Presented in Regional Conference for University Centers (UTCs) in the Southeastern Region, March 26-27, 2015. 